\title{
Strukturanalyse zum Katalysemechanismus und zur Stabilität der Arylsulfatase A
}

\author{
Dissertation \\ zur Erlangung des Doktorgrades \\ der Mathematisch-Naturwissenschaftlichen Fakultäten \\ der Georg-August-Universität zu Göttingen
}

vorgelegt von

Rixa von Bülow

aus Bochum

Göttingen 1999 
D7

Referent: Prof. G. M. Sheldrick, PhD

Korreferent: Prof. Dr. K. von Figura

Tag der mündlichen Prüfung: 26.01.2000 


\section{Inhaltsverzeichnis}

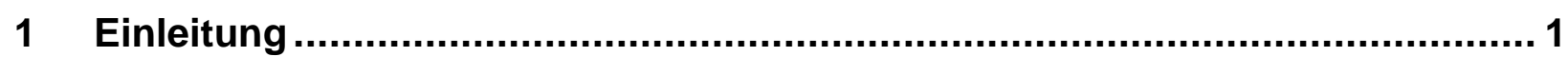

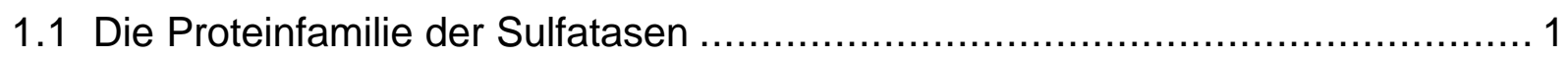

1.2 Biosynthese und Kristallstruktur der Arylsulfatase A …............................... 4

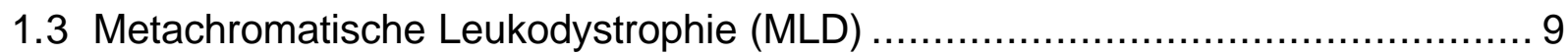



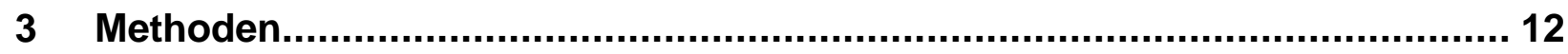

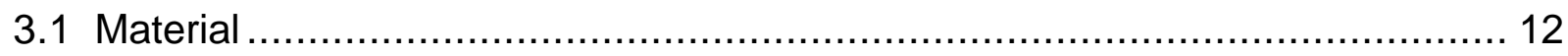

3.1.1 Häufig verwendete Puffer und Stammlösungen .................................. 12

3.1.2 Medien zur Anzucht von prokaryotischen Zellen ................................. 13

3.1.3 Zellkulturmedien und Lösungen zur Arbeit mit eukaryotischen Zellen........ 13



3.2.1 Mini-Präparation von Plasmid-DNA ................................................ 15

3.2.2 Midi-Präparation von Plasmid-DNA ............................................... 16

3.2.3 Präzipitation von DNA mit Ethanol .................................................... 17

3.2.4 Photometrische Konzentrationsbestimmung von DNA ......................... 17

3.2.5 Spaltung von Plasmid-DNA mit Restriktionsendonukleasen.................... 17

3.2.6 Agarose-Gelelektrophorese zur Auftrennung von DNA ......................... 18

3.2.7 Sequenzierung von Plasmid-DNA .................................................. 19

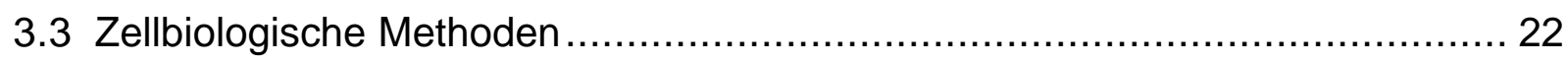

3.3.1 Allgemeine Arbeiten mit eukaryotischen Zellen.................................. 22

3.3.2 Trypsinieren von eukaryotischen Zellen .......................................... 23

3.3.3 Kryokonservierung von eukaryotischen Zellen.................................. 23

3.3.4 Auftauen und Revitalisieren von eukaryotischen Zellen......................... 23

3.3.5 Stabile Transfektion in eukaryotische Zellen....................................... 24

3.3.6 Selektion der stabil transfizierten Zellklone ....................................... 24

3.3.7 Expression von rekombinantem Protein im Großmaßstab ..................... 25

3.3.8 Dialyse von FKS für die Zellmarkierung ….................................... 25 
3.3.9 Metabolische Markierung wt-ASA und ASA-P426L mit

$\left[{ }^{35}\right.$ S]Methionin/Cystein 26

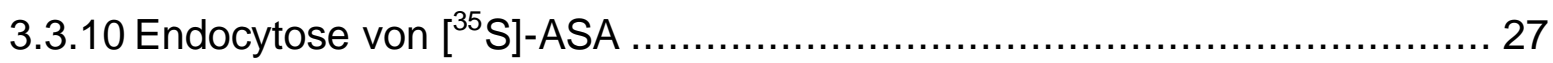

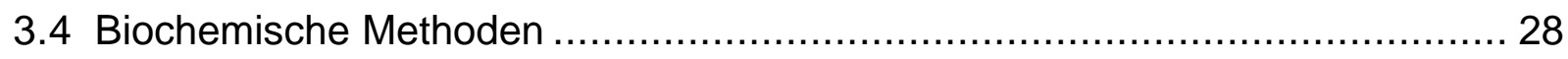

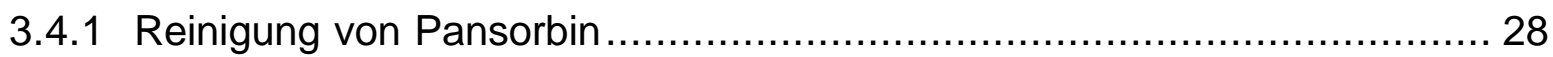

3.4.2 Immunpräzipitation metabolisch markierter Proteine ......................... 28

3.4.3 Reduktive Carboxymethylierung von Proteinen............................ 30

3.4.4 Tryptischer Abbau von ASA-C69A ....................................... 31

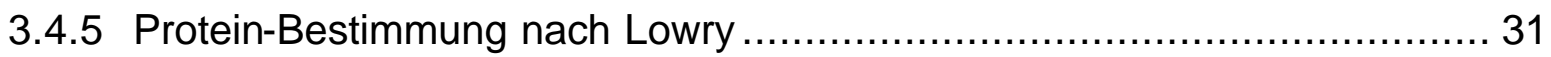

3.4.6 Konzentrationsbestimmung von ASA über $\mathrm{OD}_{280}$-Messung ................... 31

3.4.7 Bestimmung der Aktivität der Arylsulfatase A (ASA) ........................ 32

3.4.8 SDS-Polyacrylamid-Gelelektrophorese von Proteinen...................... 33

3.4.9 SDS-Polyacrylamid-Gelelektrophorese von Proteinen

(,Minigelelektrophorese“) .............................................. 35

3.4.10 Färbung von Polyacrylamid-Gelen mit kolloidaler Coomassie-Lösung ....... 37

3.4.11 Silberfärbung von Polyacrylamid-Gelen .................................. 38

3.4.12 Westernblot-Nachweis von Arylsulfatase A ................................. 39

3.4.13 Immunaffinitätschromatographische Aufreinigung von ASA aus

konditionierten Zellkulturmedien ........................................... 41

3.4.14 ASA-Reinigung über Gelfiltration an einer FPLC-Anlage ................... 42

3.4.15 ASA-Reinigung über Gelfiltration an einer HPLC-Anlage ................... 42

3.4.16 Abbau von ASA mit Cathepsinen....................................... 43

3.4.17 Reversed-Phase Hochauflösende Flüssigchromatographie (RP-HPLC) .... 46

3.4.18 Matrixunterstützte Laser-Ionisations/Desorptions-Flugzeit-

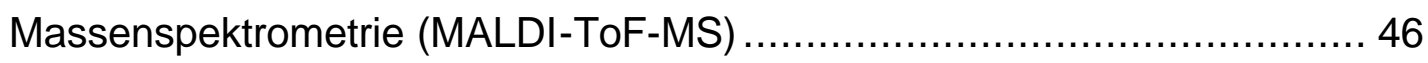

3.4.19 N-terminale Sequenzierung von Peptiden durch automatischen Edman-

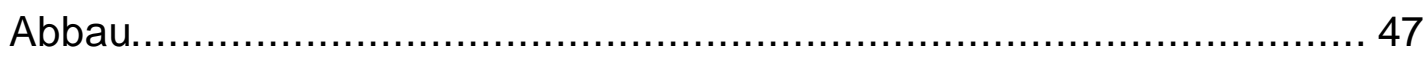

3.4.20 Untersuchung des Dimer-Oktamer-Gleichgewichts der ASA ................ 47

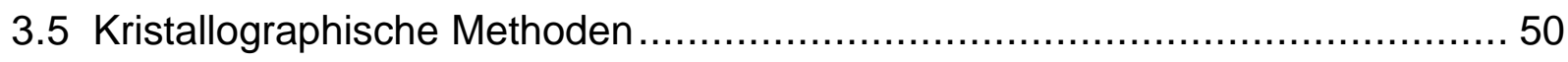

3.5.1 Kristallisation und Strukturanalyse von Dikalium- $p$-Nitrocatecholsulfat (pNCS) 




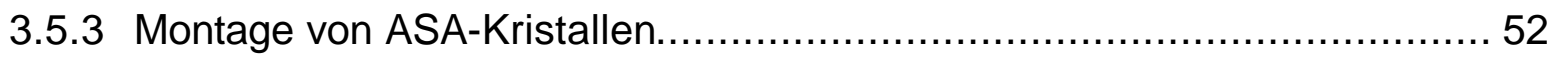

3.5.4 Datensammlung und -reduktion................................................. 55

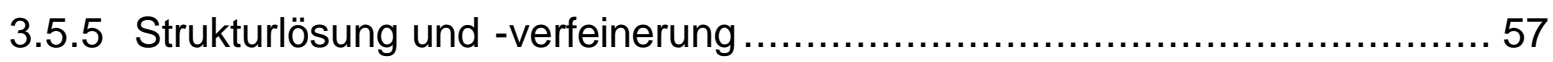



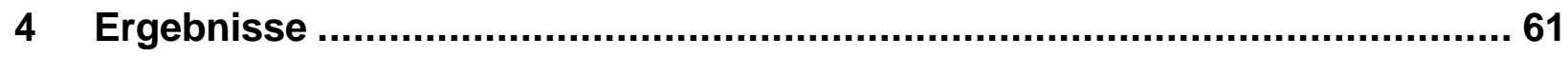

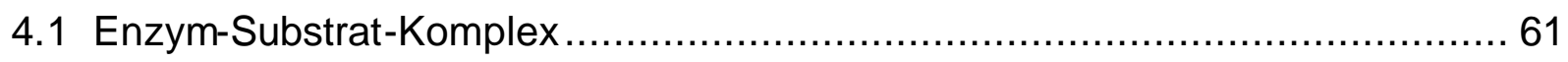

4.1.1 Expression und Reinigung der Mutante ASA-C69A .......................... 61

4.1.2 Kristallisation und Strukturanalyse von Dikalium- $p$-Nitrocatecholsulfat



4.1.3 Kristallisation von ASA-C69A und Komplexierung mit pNCS ................ 64

4.1.4 Datensammlung, Strukturlösung und -verfeinerung ASA-C69A+pNCS .... 65

4.1.5 Strukturbeschreibung der ASA-C69A+pNCS $\ldots \ldots \ldots \ldots \ldots \ldots \ldots \ldots \ldots \ldots \ldots$

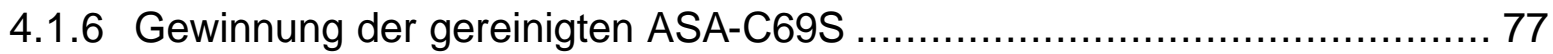

4.1.7 Kristallisation von ASA-C69S und Komplexierung mit pNCS .................78

4.1.8 Datensammlung, Strukturlösung und -verfeinerung von ASA-C69S und

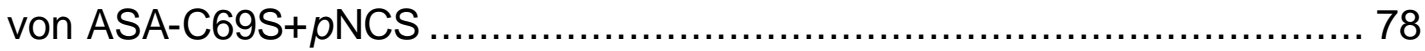

4.1.9 Strukturbeschreibungen der ASA-C69S und ASA-C69S $+p N C S \ldots \ldots \ldots \ldots . . . .82$



4.2.1 In vitro-Untersuchung zum Abbau der ASA-P426L durch Cathepsine ....... 85

4.2.2 Einfluß von Cathepsin L auf die Stabilität der ASA-P426L im Zellkultur-

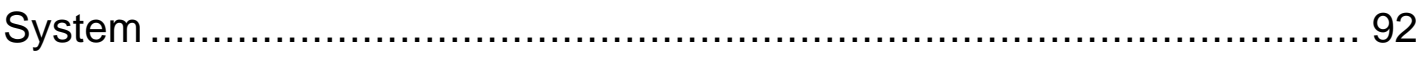

4.2.3 Identifizierung der Spaltprodukte nach Verdau von ASA-P426L mit

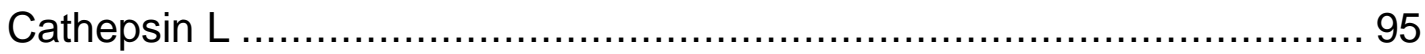

4.2.4 Kristallstrukturanalyse der Mutante ASA-P426L .......................... 97



4.2.6 Oligomerisierung der ASA-P426L in Lösung ...............................108

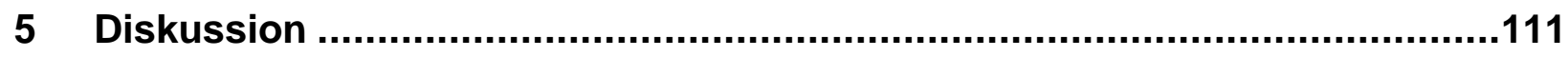

5.1 Substratbindung und Katalysemechanismus ....................................111

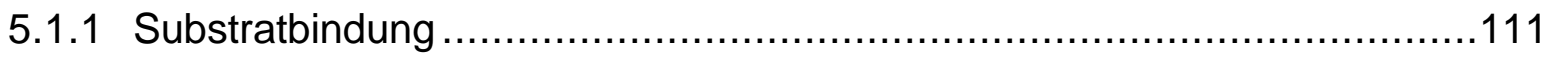

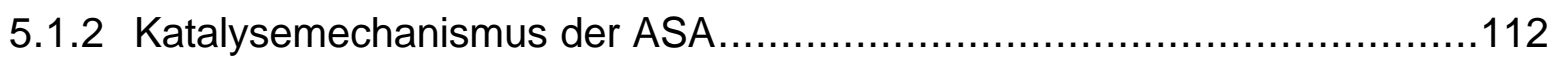


5.1.3 Vergleich der ASA mit der Arylsulfatase B und der alkalischen Phosphatase .............................................................. 115

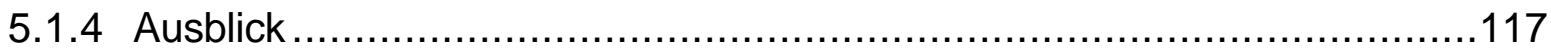

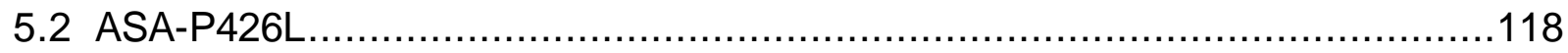

5.2.1 Oktamerisierungsverhalten und Stabilität der wt-ASA und der

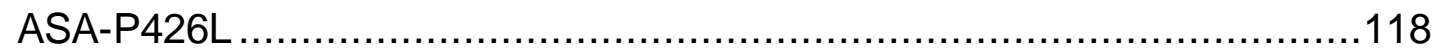

5.2.2 Vergleich zu anderen humanen Sulfatasen ...............................121

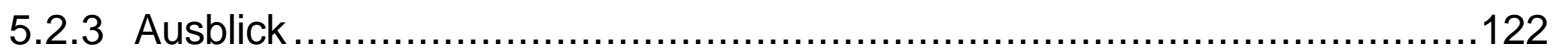

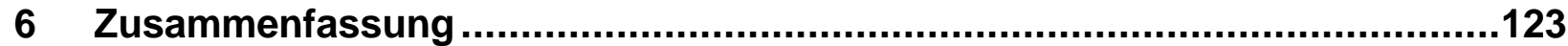








\section{Abkürzungsverzeichnis}

Ac

AP

APS

ASA

ASB

BSA

CBZ-

CCD

CDNA

cpm

DESY

DMEM

DMSO

DNA

DTT

$\varepsilon$

E. coli

EDTA

EMBL

ER

et al.

FKS

FPLC

$\mathrm{h}$

HPLC

$\mathrm{kb}$

$\mathrm{kDa}$

$M$

MALDI

MEF

MEM

$\min$

MPR

MWPC

NCBI

OD
Acetat

alkalische Phosphatase

Ammoniumperoxodiphosphat

Arylsulfatase A

Arylsulfatase $B$

Rinderserumalbumin

Carbobenzyloxy-

charges coupled device

komplementäre DNA

Zählimpuls pro Minute

Deutsches Elektronen Synchrotron

Dulbecco's Modified Eagle Medium

Dimethylsulfoxid

Desoxyribonukleinsäure

Dithiothreitol

molarer Extinktionseffekt

Escherichia coli

Dinatriumethylendiamintetraacetat

European Molecular Biology Laboratory

Endoplasmatisches Retikulum

et alii (lat.:und andere)

fötales Kälberserum

Fast Protein Liquid Chromatographie

Stunde

hochauflösende Flüssigkeitschromatographie

(high performance liquid chromatography)

Kilobasenpaare

Kilodalton

$\mathrm{mol} / \mathrm{l}$

matrix-assisted laser desorption ionisization

Fibroblasten von embryonalen Mäusen

minimal essential medium

Minute

Mannose-6-phosphat-Rezeptor

multiwire proportional counter

National Center for Biotechnology Information

Optische Dichte 
p.a. zur Analyse

PAA Polyacrylamid

PAGE Polyacrylamid-Gelelektrophorese

PBS Phosphat-gepufferte Kochsalzlösung

PCR Polymerase-Ketten-Reaktion

Pen/Strep Penicillin/Streptomycin

pNCS para-Nitrocatecholsulfat

RP Reversed-Phase

r.m.s. root mean square (mittlere quadratische Abweichung)

rpm Umdrehungen pro Minute

RT Raumtemperatur

SDS Natriumdodecylsulfat

TBS Tris-gepufferte Kochsalzlösung

TCA Trichloressigsäure

TEMED N,N,N',N'-Tetramethylendiamin

TFA Trifluoressigsäure

TGN trans-Golgi-Netzwerk

Tris Tris-(hydroxymethyl)-aminoethan

U Unit

UV ultraviolett

üN über Nacht

Verd. Verdünnung

Vol. Volumen

$\mathrm{v} / \mathrm{v} \quad$ Volumen zu Volumen

wt Wildtyp

w/v Masse zu Volumen

w/w Masse zu Masse

x g -fache Erdbeschleunigung 


\section{Einleitung}

Die vorliegende Arbeit befaßt sich mit einer lysosomalen Sulfatase, der Arylsulfatase A (ASA). Ergebnisse einiger kristallographischer und biochemischer Untersuchungen zur Substratbindung und zum Katalysemechanismus sowie zu den Eigenschaften einer Mutante, welche im Zusammenhang mit einer lysosomalen Speicherkrankheit steht, werden vorgestellt.

\subsection{Die Proteinfamilie der Sulfatasen}

Lysosomen sind membranumschlossene Zellkompartimente, in denen Makromoleküle abgebaut werden. Sie besitzen etwa 50 verschiedene Hydrolasen, wie Proteasen, Lipasen, Glycosidasen, Phosphatasen und Sulfatasen. Bei einem pH-Wert von 4,55,5 bauen diese Hydrolasen ihre makromolekularen Substrate zu Metaboliten ab, die wiederum in den Zellstoffwechsel eingeschleust werden.

Die in der vorliegenden Arbeit untersuchte Arylsulfatase A (ASA) ist eines dieser lysosomalen Enzyme. Sie gehört zur Familie der Sulfatasen, welche biochemisch dadurch charakterisiert sind, daß sie als hydrolytische Enzyme Schwefelsäureester spalten, z.B. Glykosaminglykane, sulfatierte Glykolipide, sulfatierte Tyrosinreste in Proteinen und sulfatierte Hydroxysteroide [Übersicht in Parenti et al., 1997; von Figura et al., 1998]. Alle Sulfatasen besitzen jeweils eine hohe Substratspezifität. Von den zehn verschiedenen menschlichen Sulfatasen, die bislang charakterisiert wurden, befinden sich sechs in den Lysosomen. Dort sind sie für die Degradation von Glycosaminglykanen und Sulfolipiden verantwortlich. Arylsulfatasen bilden eine Untergruppe innerhalb der Sulfatasefamilie, die dadurch charakterisiert ist, daß sie neben den physiologischen Substraten auch synthetische chromogene und fluorogene Arylsulfate spaltet, welche für Messungen der Enzymaktivität eingesetzt werden.

$\mathrm{Zu}$ den biochemisch charakterisierten Sulfatasen gehören Enzyme mit bakterieller, niederer eukaryotischer und humaner Herkunft [Parenti et al., 1997; von Figura et al., 1998]. Daneben wurden in Gendatenbanken (Genebank) eine große Zahl weiterer Gene gefunden, die aufgrund ihrer hohen Sequenzhomologie zur Sulfatasefamilie gezählt werden müssen. Auf Proteinebene zeigen die Sulfatasen über die gesamte Sequenz eine Identität von 20 bis $60 \%$, was auf einen gemeinsamen Ursprung schließen läßt. Speziell im N-terminalen Drittel ihrer Aminosäuresequenzen ist diese Übereinstimmung sehr hoch ( $\mathrm{NCBI}$, non redundant). Zudem sind die meisten Aminosäuren im Bereich des aktiven Zentrums innerhalb der eukaryotischen und prokaryotischen Mitglieder der Sulfatasefamilie konserviert (Abbildung 1.1), was auf einen gemeinsamen Katalysemechanismus hindeutet [Waldow et al., 1999]. 


\begin{tabular}{|c|c|c|c|c|c|c|c|}
\hline \multicolumn{8}{|c|}{ Sulfatase } \\
\hline & $\begin{array}{l}2930 \\
||\end{array}$ & $\begin{array}{ll}69 & 73 \\
\mid & \mid\end{array}$ & $\begin{array}{c}123 \\
\mid\end{array}$ & $\begin{array}{c}150 \\
\mid\end{array}$ & $\begin{array}{c}229 \\
\mid\end{array}$ & $\begin{array}{c}281282 \\
||\end{array}$ & $\begin{array}{c}302 \\
\mid\end{array}$ \\
\hline ASA & . LIFADDLG. . & . LCTPSR. . & . AGKWHLG. . & . LGIPYSH. . & . HTHYPQ . & . FTADNG. & . CGKGTT. \\
\hline ASB & . FLLADDLG. . & . LCTPSR. . & . . VGKWHLG. . & . FGYLLGS . & .. SVHEPL . & .FSTDNG. . & . . GRKWSL . . \\
\hline ASC & . . LVMADDLG . . & . LCTPSR. . & . IGKWHLG. . & . YGISLTN. . & ..HVHTAL. & ..FTSDQG. & . . GGKANN . \\
\hline ASD & . . LIMADDLG. . & . LCTPSR. . & . IGKWHQG. . & . .YGMPFTL. . & . HVHIPL. . & ..FTSDHG. . & . . GGKGMG. \\
\hline ASE & . . LLMADDLG . . & . LCTPSR. . & . IGKWHLG. . & . .YGMPFTL. . & ..HVHIPL. . & ..FTSDHG. . & . . GGKGMG . . \\
\hline ASF & . . LIMVDDLG. . & . LCSPSR. . & . IGKWHQG. . & . . YGMPFTL. . & ..HVHTPL. & ..FTSDHG. & . . GGKGMG . \\
\hline $\mathrm{Ga} 6 \mathrm{~S}$ & . . LLLMDDMG . . & . LCSPSR. . & . . VGKWHLG. . & . FGSPNCH. . & . ATHAPV. . & ..FTSDNG. . & . . CGKQTT. . \\
\hline G16S & . . LLLTDDQD . . & . L LCCPSR. & . AGKYLNE. . & . Y YALEKNS. . & . QAKTPM. . & ..YTSDNG. & . IDKRQL \\
\hline IDS & . LIIVDDLR. . & . VCAPSR. . & . VGKVFHP. . & . SSEKYEN . & . NISVPY.. & . FTSDHG. . & . WAKYSN . \\
\hline SP HM & . . LLLADDGG . . & ..SCSPSR. . & . IGKKHVG. . & . . NGSVLQV . . & . DVLVPY. . & ..FTSDNG. & ...SGRTNL. \\
\hline \multicolumn{8}{|c|}{ Niedere eukaryotische Sulfatasen: } \\
\hline Hemi & . LLVVADHMG. . & . VCTPSR. & . VGKWHLG. . & . VGHNLPF . . & .. HMHTSL. & . FISDHG. & . GGKSHS. \\
\hline Stro & . . LLLADDMG. . & . VCTPSR. . & . VGKWHLG. . & . VGHNLPF . . & . HMHTSL. . & ..FTSTHG. . & . GGKGQS. \\
\hline Heli & . . LMVADDMG. . & . VCTPSR. & . VGKWHLG. . & . VGYNLPF . . & . HMHTSL. & . FISDHG. & . GGKSHA. \\
\hline Volv & . VIFTDDQD . . & . VCCPSR. . & . .VGKFLVD . . & . LVTPYTF . . & ..SDKPAW. . & ..YSADNG. . & . AGKVTA \\
\hline Chla & . VIFTDDQD . & . VCCPSR. & . ASSLWTT. . & .PVTPYTF. . & . RERQAR. . & . YSADNG. . & . AGKTTG \\
\hline Neuro & .FILTDDQD. . & $\ldots$ ICCPAR. & . TGKLFNA. . & . YTYSYLN. . & . DVIVPR. & . YTADNG. & ..PGKECG \\
\hline \multicolumn{8}{|c|}{ Prokaryotische Sulfatasen: } \\
\hline Pseu & . VIVADDLG. . & . TCSPTR. & . AGKWHLG. . & . . SFSLLPG. & . APHWPL . . & . FMSDNA . & . LYKAFT \\
\hline Kleb & . VIIADDMG. . & . MSAPAR. . & . AGKWHLG. . & . AFAFMGG. . & . APHDPL . & . FLTDNG. & . YHKTTS \\
\hline Sin & . . I IMVDQLN . . & . LCAPAR. . & . . SGKMHFV. . & . RLTTDIY.. & . HР HDPY . & . FCSDHG. & . WF KMNF \\
\hline
\end{tabular}

Abbildung 1.1: Sequenzhomologie im Bereich der Aminosäuren des aktiven Zentrums der Sulfatasen. Die Nummerierung bezieht sich auf die Positionen der Aminosäuren in der ASA. Abkürzungen: ASA: Arylsulfatase A (Cerebrosid-3-sulfatase); ASB: Arylsulfatase B (N-Acetylgalactosamin-4-sulfatase); ASC: Arylsulfatase C (Steroidsulfatase); ASD: Arylsulfatase D; ASE: Arylsulfatase E; ASF: Arylsulfatase F; Ga6S: NAcetylgalactosamin-6-sulfatase; GI6S: NAcetylglucosamin-6sulfatase; IDS: Iduronatsulfatase; SPHM: Sulfoglucosamin-Sulfamidase (Heparan-N-Sulfatase); Hemi: Hemicentrotus pulcherrimus; Stro: Strongylocentrotus purpuratus; Heli: Heliocidaris erythrogramma; Volv: Volvox carteri; Chla: Chlamydomonas reinhardii; Neuro: Neurospora crassa; Pseu: Pseudomonas aeruginosa; Kleb: Klebsiella pneumoniae; Sin: Sinorhizobium meliloti.

In fünf Sulfatasen (Arylsulfatase A, Arylsulfatase B, Arylsulfatase von Volvox carteri, Klebsiella pneumoniae und Pseudomonas aeruginosa) konnte eine neuartige Proteinmodifikation nachgewiesen werden, welche für die katalytische Sulfataseaktivität essentiell ist [Selmer et al., 1996; Schmidt et al., 1995; Dierks et al., 1998; Miech et al., 1998]. Hierbei handelt es sich um eine posttranslationale Modifikation: ein Cystein- oder ein Serinrest wird zu einem $\mathrm{C} \alpha$-Formylglycinrest (2-Amino-3-oxopropionsäure) oxidiert [Schmidt et al., 1995; Dierks et al., 1997]. Sequenzierung und Massenbestimmung tryptischer Peptide der menschlichen ASA wiesen auf einen Aldehyd hin, welcher in Folgeexperimenten nachgewiesen werden konnte. Durch Reduktion mit ${ }^{3} \mathrm{H}$-markiertem Natriumborhydrid konnte der Aldehyd des $\mathrm{C} \alpha$-Formylglycins in ein $\left[{ }^{3} \mathrm{H}\right]$ Serin überführt werden, das sich durch Sequenzierung bzw. Radiosequenzierung nachweisen ließ. Die Umsetzung mit Dinitrophenylhydrazin zum entsprechenden Hydrazon war ein weiterer Hinweis für das Vorliegen eines Formylglycinrestes. Dieser Aldehyd befindet sich in der Aminosäuresequenz der ASA an der Position 69 und liegt wahrscheinlich in der in dieser Umgebung energetisch bevorzugten, hydratisierten Form, als Aldehydhydrat vor. 
Darauf weist neben theoretischen Überlegungen auch die Röntgenstruktur der ASA hin (s. Abschnitt 1.2).

Die biologische Bedeutung der menschlichen Sulfatasen zeigt sich auch darin, daß sie im Zusammenhang mit dem Auftreten von acht unterschiedlichen, genetisch bedingten Stoffwechselkrankheiten des Menschen stehen [Übersicht in Neufeld \& Muenzer, 1995]. Jede dieser Krankheiten geht einher mit dem Defekt der Desulfatierung spezifischer sulfatierter Metabolite. Fällt eines dieser Enzyme aus, akkumuliert unverdautes Material in den Lysosomen, weshalb die Defekte auch als lysosomale Speicherkrankheiten bezeichnet werden. Die Defizienz der fünf Sulfatasen, die spezifisch Sulfatgruppen von Glycosaminglykanen abspalten, führt zu lysosomalen Speicherkrankheiten des Mucopolysaccharidose-Typs. Die Defizienzen der unterschiedlichen Arylsulfatasen führen zu Krankheiten, die entweder zur weitreichenden Demyelinisierung im zentralen und peripheren Nervensystem führen (metachromatische Leukodystrophie), zu einer relativ milden Hautkrankheit (X-chromosomalen Ichthyose) oder zu einem Defekt in der Knochen- und Bindegewebsentwicklung (Chondrodysplasia punctata).

Neben diesen Einzel-Sulfatasedefizienzen gibt es eine weitere seltene, autosomalrezessiv vererbte Stoffwechselkrankheit, die multiple Sulfatasedefizienz (MSD), bei der die Aktivitäten aller Sulfatasen stark vermindert sind, so daß im Krankheitsbild die Charakteristika der Einzelsulfatase-Defizienzen kombiniert sind [Kolodny \& Fluharty, 1999]. Die Krankheit führt zum Tod des Patienten. Die genetische Ursache der MSD ist bis heute unbekannt, es steht aber fest, daß es sich nicht um einen zufälligen gemeinsamen Ausfall mehrere Enzyme handelt. Vielmehr handelt es sich um einen sekundären Defekt, der fehlerhaften posttranslationalen Modifikation eines Cysteins (oder Serins) zu dem oben erwähnten Co-Formylglycinrest [Übersicht in von Figura et al., 1998]. Die posttranslationale Modifikation ist für die katalytische Aktivität aller Sulfatasen erforderlich. Neben diesem im Mittelpunkt vieler Untersuchungen stehenden Formylglycin scheinen außerdem noch weitere Gruppen essentiell für das Funktionieren der enzymatischen Sulfatesterspaltung zu sein [Knaust et al., 1998; Waldow et al.,1999]. 


\subsection{Biosynthese und Kristallstruktur der Arylsulfatase A}

Die Biosynthese der lysosomalen ASA erfolgt an membranverankerten Ribosomen des rauhen endoplasmatischen Reticulums (ER). Eine N-terminale Signalsequenz von 18 überwiegend hydrophoben Aminosäuren initiiert die kotranslationale Translokation der ungefalteten Polypeptidkette der ASA ins ER-Lumen und wird dort anschließend abgespalten. Noch während oder kurz nach der Synthese des Peptidstranges und dessen Translokation in das Lumen des ERs wird der in allen eukaryotischen Sulfatasen konservierte Cysteinrest (in der ASA an Position 69) zum C $\alpha$ Formylglycinrest modifiziert. Das Protein ist zu diesem Zeitpunkt noch weitgehend ungefaltet. Eine Sequenz aus 12 Aminosäuren (Reste 69 bis 80) beginnend mit dem Cystein 69 dient als Erkennungssignal für die enzymatische Modifikation [Dierks et al., 1999]. Ferner werden im ER bei der ASA drei potentielle N-Glycosylierungsstellen mit Oligosacchariden des mannosereichen Typs glykosyliert [Sommerlade et al., 1994a; Dittmer \& von Figura, 1999]. Anschließend werden in frühen Golgi-Kompartimenten die Oligosaccharide der ersten und dritten Glykosylierungsstelle durch das Enzym Phosphotransferase modifiziert. Hierbei werden Mannosereste in zwei Schritten zu endständigen Mannose-6-Phosphat-Resten phosphoryliert. Dadurch wird die ASA als lysosomales Enzym markiert und kann nun selektiv durch die Mannose-6-phosphatRezeptoren gebunden und $\mathrm{zu}$ den Lysosomen transportiert werden [Übersicht in Pohlmann, 1996].

Im SDS-Gel zeigt die reife ASA eine apparente Masse von $62 \mathrm{kDa}$. Die rechnerisch ermittelte Masse der monomeren ASA beträgt 51,881 kDa (489 Aminosäuren, 6 Disulfidbrücken, C $\alpha$-Formylglycin), dazu werden noch etwa $4-5 \mathrm{kDa}$ der drei Oligosaccharidseitenketten addiert [Stein et al., 1989; Sommerlade et al., 1994]. Eine pH-Wert abhängige Oligomerisierung der ASA konnte schon früh gezeigt werden [Waheed \& van Etten, 1979; Waheed et al., 1985]. Demnach aggregiert die ASA bei saurem $\mathrm{pH}$-Wert $(4,5)$ im Vergleich zum neutralen $\mathrm{pH}$-Wert $(7,5)$. Es wurde vorhergesagt, daß bei dieser Oligomerisierung hydrophobe Wechselwirkungen eine bedeutende Rolle spielen [Nichol \& Roy, 1966]. Später wurde bestätigt, daß die ASA bei einem $\mathrm{pH}$-Wert von 7,5 als Dimer und bei einem $\mathrm{pH}$-Wert von 4,5 als Oktamer vorliegt und daß die Oligomerisierung hauptsächlich aufgrund hydrophober Wechselwirkungen stattfindet [Lukatela et al., 1998].

\begin{tabular}{c|c|c} 
pH-Wert: & 4,5 & 7,5 \\
\hline Oligomerisierung: & Oktamer & Dimer
\end{tabular}

In den Lysosomen liegt die ASA demnach als Oktamer vor, das sich aus vier Homodimeren zusammensetzt. 
Im Lysosom katalysiert die ASA den ersten Abbauschritt von Cerebrosidsulfaten und anderen sulfatierten Galaktolipiden [Mehl \& Jatzkewitz, 1964]. Das Hauptsubstrat ist das Sulfatid Cerebrosid-3-sulfat, ein Glykolipid, welches in den Membranen der Lysosomen und in den Myelinscheiden des Nervensystems vorkommt [Mehl \& Jatzkewitz, 1964]. In vitro-Aktivitätstests werden mit dem chromogenen Substrat p-Nitrocatecholsulfat durchgeführt (Abbildung 1.2).

p-Nitrocatecholsulfat, das in vitro-Substrat der ASA:



Cerebrosid-3-sulfat, das in vivo-Substrat der ASA:

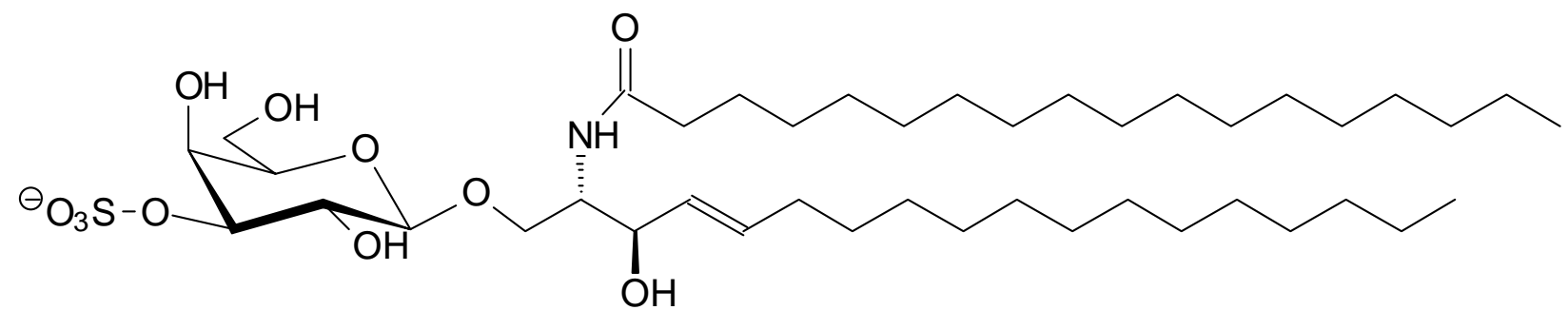

Abbildung 1.2: Substrate der Arylsulfatase A.

Die humane ASA weist ein $\mathrm{pH}-O p$ timum im sauren Milieu auf $(\mathrm{pH} 4,5-5,0)$, d.h. sie besitzt im Lysosom (pH-Wert $\approx 5$ ) ihre höchste Aktivität [Waldow et al., 1999]. Der isoelektrische Punkt der ASA liegt zwischen 4,6 und 4,8. Dies wird durch den hohen Anteil an Aspartat- und Glutamatresten erklärbar. Die Aminosäuresequenz zeigt einen hohen Anteil an Glycinen und Prolinen (jeweils ca. 10\%).

Durch Kristallisation und Röntgenstrukturanalyse konnte die dreidimensionale Struktur der humanen ASA ohne Substrat mit einer Auflösung von 2,1 $\AA$ bestimmt werden [Lukatela et al., 1998]. Die Proteinkristallographie ermöglicht es, sich direkt ein dreidimensionales Bild von biologischen Makromolekülen zu machen, welches der nativen Enzymstruktur sehr nahe kommt und als Grundlage zur Diskussion der Eigenschaften des Moleküls dient [Karle, 1992]. Zu diesen Eigenschaften gehören z.B. die Flexibilität des Proteins und Affinität zu anderen Molekülen. Besonders für die Untersuchung der Wechselwirkungen in Komplexen bietet sich die Methode der Röntgenstrukturanalyse an. Zwar sind Unterschiede der Proteinstrukturen im Festkörper und in Lösung anzunehmen, doch scheinen diese aufgrund des in der Regel hohen Wasseranteils im Kristall und der Einheit, die ein Protein bildet, gering zu sein. 
Bei der ASA handelt es sich um ein Enzym der Klasse der $\alpha / \beta$ Strukturen, das $26 \%$ $\alpha$ - und 310 -Helices sowie $16 \% \beta$-Faltblätter besitzt. Der größte Anteil mit $46 \%$ der Polypeptidkette besteht aus $\beta$ - und $3_{10}$-Turns. Bei den restlichen $12 \%$ handelt es sich um ungeordnete Schleifenbereiche. Die Tertiärstruktur beinhaltet ein zentrales zehnsträngiges $\beta$-Faltblatt, das vorwiegend aus parallelen Strängen aufgebaut ist und auf beiden Seiten von $\alpha$-Helices flankiert wird. In der C-terminalen Domäne befindet sich ein zweites viersträngiges aus antiparallelen Strängen aufgebautes Faltblatt. 6 Disulfidbrücken werden von 12 der 14 vorhandenen Cysteine ausgebildet. Es liegt eine recht hohe Anzahl an cis-Aminosäuren vor, dies sind 7 Proline und eine HistidinTyrosin-Folge.

Das Enzym zeigt als Monomer die Form eines Hutes mit ellipsoider Grundfläche. Die Grundfläche beträgt $45 \times 70 \AA^{2}$, die Höhe des „Hutes“ beträgt etwa $50 \AA$ (Abbildung 1.3).

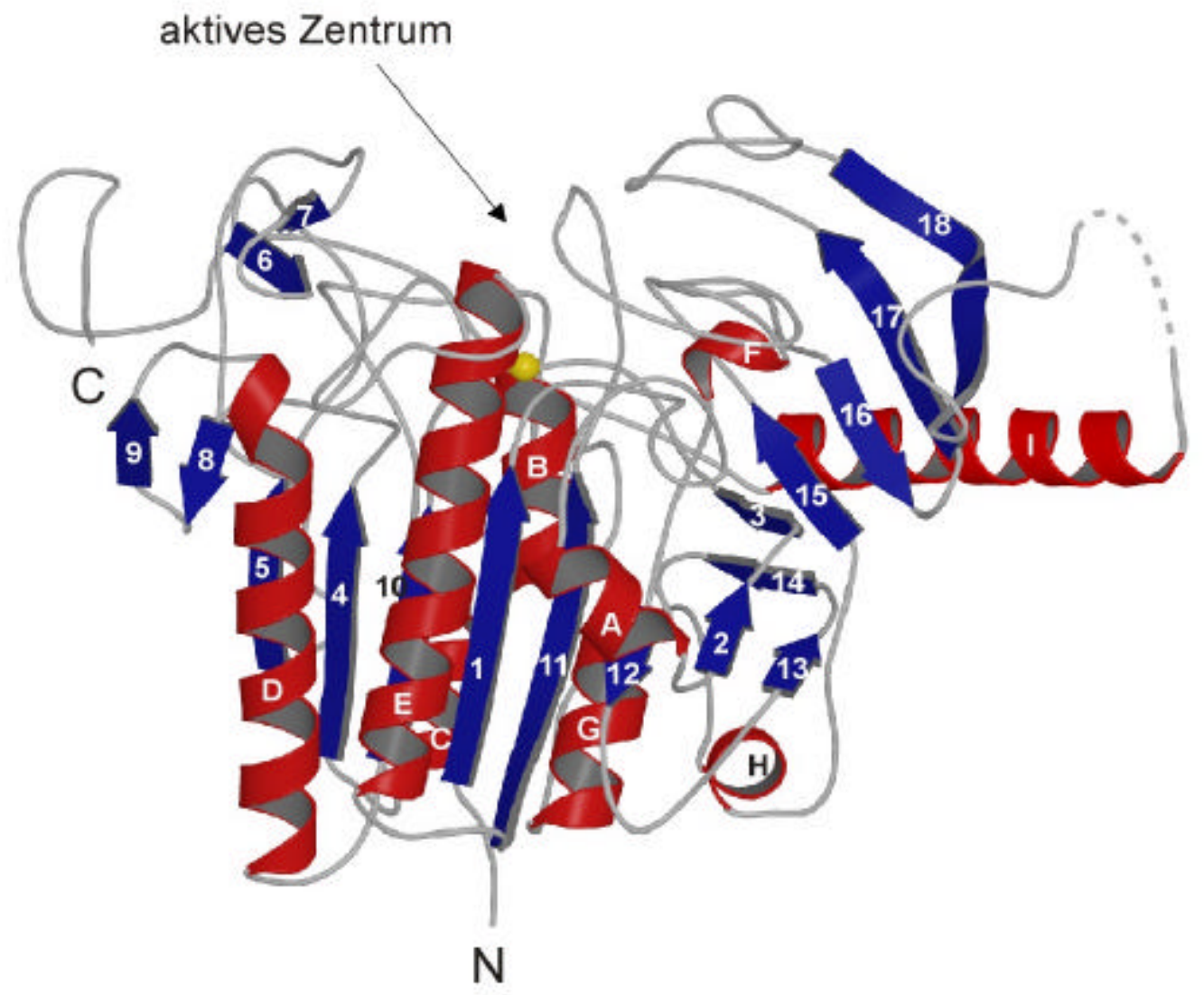

Abbildung 1.3: Tertiärstruktur des Arylsulfatase AMonomers. $\alpha$-Helices sind als Spiralen rot/grau, $\beta$-Faltblätter als Pfeile blau und Schleifenbereiche grau abgebildet. Das Magnesiumion ist als gelbe Kugel dargestellt. Der gestrichtelte Schleifenbereich deutet das in der Elektronendichte nicht gefundene Tetrapeptid Gly444 - Ala447 an. Helices und Faltblätter sind nach dem Schema durchnummeriert, wie es die Topologie der Sekundärstruktur vorgibt (s. Anhang). 
Der N-Terminus der ASA befindet sich an der „Hutspitze“. An der Grundfläche befindet sich in einer Einmuldung von $10 \times 10 \AA^{2}$ das aktive Zentrum. Die ASA wurde bei pH 5,3 - 5,4 als Oktamer in der Raumgruppe 1422 kristallisiert. Da die zweizählige kristallographische Achse des Dimers sich etwa parallel zur Achse des „Hutes“ befindet, sind in beiden Monomeren die aktiven Zentren auf der gleichen Seite im Dimer liegend angeordnet und sind somit beide frei zugänglich [Lukatela et al., 1998].

Es existieren zwei verschiedene Enzymkontakte in dem im Kristall vorliegenden Oktamer, welches aus vier Homodimeren zusammengesetzt ist. Zwei Monomere bilden über Wasserstoffbrückenbindungen auf der flachen Seite des „Hutes“ ein Homodimer. Bei diesem Kontaktbereich handelt es sich ausschließlich um eine Schleifenregion, die an der Außenseite des zentralen $\beta$-Faltblattes liegt. Die Wechselwirkung zweier Dimere besteht aus einer hydrophoben Kontaktregion, in der eine Wasserstoffbrückenbindung eingeschlossen ist. Die Polypeptidkette der ASA beginnt am N-Terminus mit Arginin 19 und endet mit Alanin 507. Drei Oligosaccharidseitenketten liegen auf der Oberfläche des Proteins [Lukatela et al., 1998].

Die ASA besitzt strukturelle Homologie zu zwei weiteren Proteinen, deren Kristallstruktur aufgeklärt wurde. Dies ist zum einen die Arylsulfatase $B$, welche ebenfalls ein Mitglied der Sulfatasefamilie ist [Bond et al., 1997], und zum anderen überraschenderweise die alkalische Phosphatase aus Escherichia coli [Kim \& Wyckoff, 1991], obwohl diese kaum Sequenzhomologie zur Sulfatasefamilie aufweist.

Beim physiologischen pH-Wert von 5 liegt im Bereich der Vertiefung der Grundfläche des Moleküls eine starke positive Ladungsdichte vor, die auf die Lokalisation der Bindungsstelle für das Substrat $\left(\mathrm{RSO}_{4}{ }^{2-}\right)$ hinweist [Lukatela et al., 1998]. Ein weiterer Hinweis darauf, daß dieser Bereich das aktive Zentrum bildet, ist die Anwesenheit des $\mathrm{C} \alpha$-Formylglycinrestes, der sich an dem Boden der Vertiefung befindet und der zu $100 \%$ essentiell für die katalytische Aktivität der ASA ist. Die Kristallisation der verwandten Arylsulfatase B (ASB) zeigte eine Sulfatgruppe kovalent an das äquivalente $\mathrm{C} \alpha$-Formylglycin gebunden, bei Kokristallisation mit dem substratanalogen Inhibitor Vanadat wurde an dieser Stelle das Vanadat gefunden [Bond et al., 1997]. Die alkalische Phosphatase (AP) wurde als Komplex mit einem substratanalogen Inhibitor kristallisiert [Kim \& Wykoff, 1991]. Der Inhibitor wurde in der Nähe der für die katalytische Aktivität essentiellen Aminosäure Serin 102 gefunden, welche nach Superposition der AP mit der ASA mit Formylglycin kolokalisiert.

In Nachbarschaft zum C $\alpha$-Formylglycin befindet sich in der ASA ein zweiwertiges Kation $\left(\mathrm{Mg}^{2+}\right)$ sowie eine Reihe polarer Reste, die durch ein Netz aus Wasserstoffbrücken verbunden sind (Abbildung 1.4). Zu diesen funktionellen Aminosäureresten, die die aktive Tasche bilden, zählen zwei Lysine, zwei Histidine, ein Asparagin, ein Serin sowie die das Magnesiumion koordinierenden drei Aspartate und ein Asparagin 
[Lukatela et al., 1998]. Die Substitution einzelner funktioneller Gruppen in Aminosäureaustauschmutanten führt jeweils zur deutlichen Erniedrigung der enzymatischen Aktivität [Waldow et al.,1999].

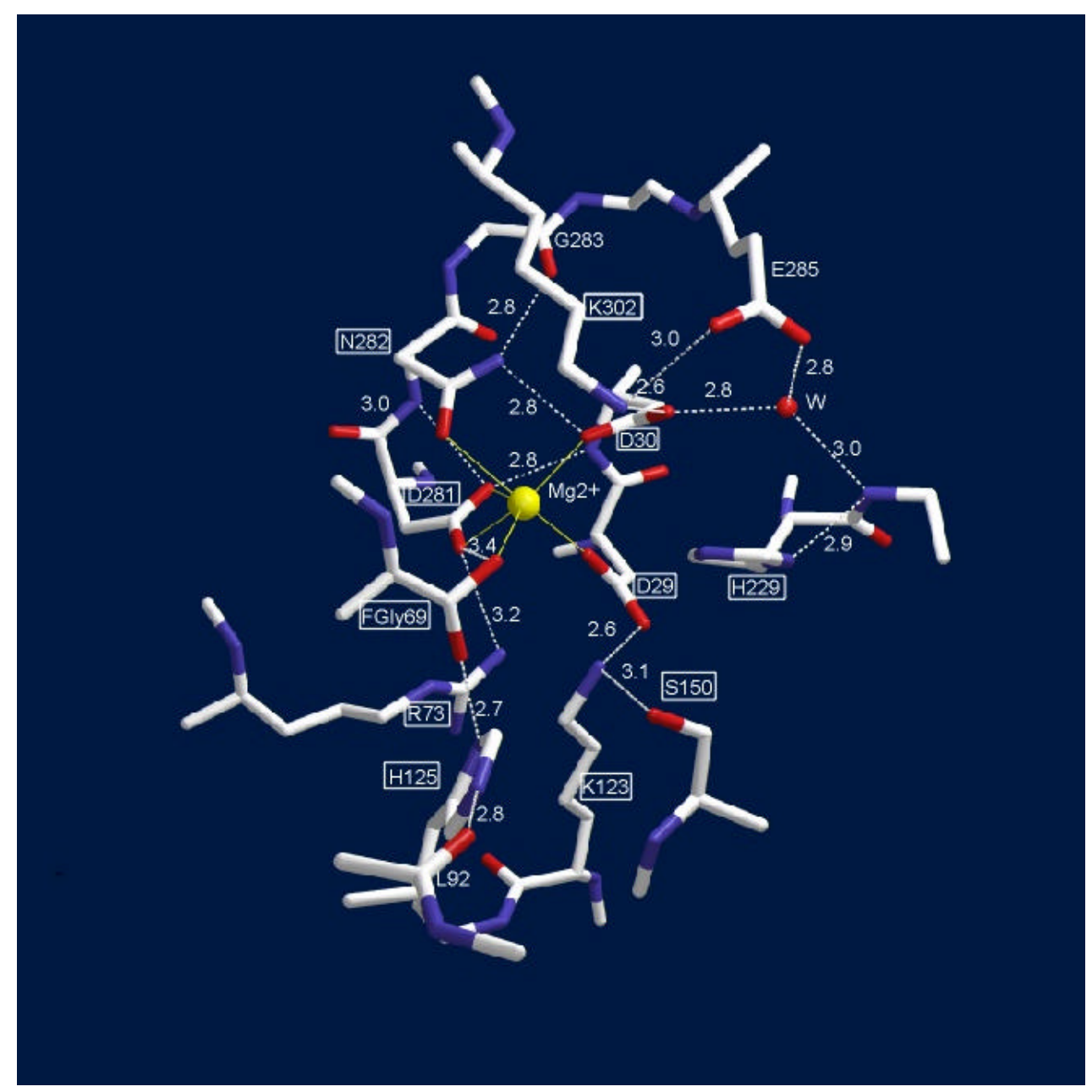

Abbildung 1.4: Aktives Zentrum der ASA. Dargestellt ist die dreidimensionale Struktur der putativen Aminosäurereste des aktiven Zentrums der ASA (hervorgehoben durch weiße Rahmen) und deren Wasserstoffbrücken (gestrichelte Linien) zu benachbarten Resten (Abstände in Å). Das $\mathrm{Mg}^{2+}$-Ion (gelbe Kugel) wird durch sechs benachbarte Atome koordiniert (gelbe durchgezogene Linien). Wassermoleküle sind als rote Kugeln dargestellt. Sauerstoffatome sind rot, Stickstoffatome blau wiedergegeben. Die Fragmente des Polypeptidrückgrates enden in der Abbildung immer mit einem Kohlenstoffatom (weiss).

Auf der Grundlage dieser Strukturdaten wurde folgender Katalysemechanismus für die Spaltung der Sulfatester vorgeschlagen (Abbildung 1.5) [Lukatela et al., 1998, Waldow et al. 1999]. Dieser Mechanismus geht von einem Aldehydhydrat als Grundzustand des Enzyms aus, also einem geminalen Diol anstelle eines Aldehydrestes. Demnach läuft die Spaltung des Sulfatesters in zwei Teilschritten ab, die einen Zyklus bilden. Den Ausgangspunkt bildet das Hydrat des C $\alpha$-Formylglycins, während der Sulfatschwefel durch positiv geladene Reste in der Nähe der zwei Hydroxylgruppen positioniert wird. Der Sulfatschwefel kann zudem durch die positiv geladenen Reste und das $\mathrm{Mg}^{2+}$ Kation, welche Elektronen von den Sauerstoffatomen abziehen, stärker positiv 
polarisiert werden. Eine der beiden Hydroxylgruppen könnte durch eine benachbarte Carboxylgruppe (Aspartat 281) zum starken Nukleophil aktiviert und in dieser Form durch das $\mathrm{Mg}^{2+}$-Ion stabilisiert werden. Ein nukleophiler Angriff auf das Schwefelatom des substratgebundenen Sulfatesters ist damit ermöglicht. Der Substratalkohol wird in dieser katalysierten $S_{N}$ 2-Substitutionsreaktion freigesetzt und ein Enzym-SulfatesterIntermediat entsteht.

Die Bindung zwischen dem C $\alpha$-Atom und dem Hydroxylsauerstoffatom des sulfatierten Enzyms wird gespalten, wobei die treibende Kraft dieses Schrittes die Rückbildung der Carbonylverbindung ist. Diese kann wiederum zum geminalen Diol hydratisiert werden. Histidin 125 wird aufgrund seiner sterischen Nähe als Kandidat angesehen, um die Deprotonierung der zweiten Hydroxylgruppe zu erleichtern.
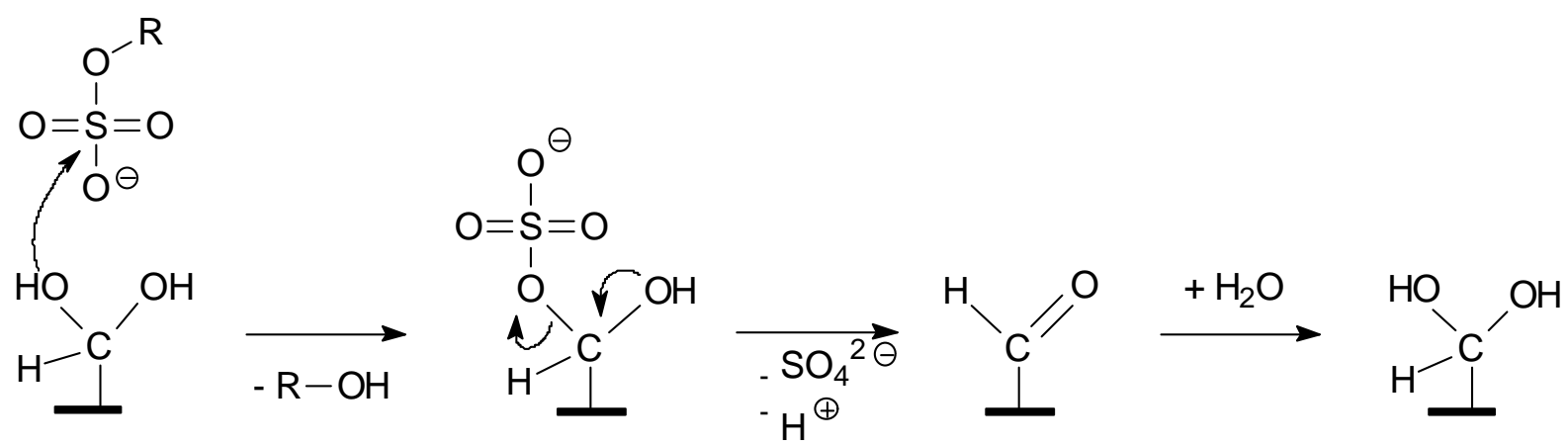

Abbildung 1.5: Hypothetischer Mechanismus der Sulfathydrolyse. Ein nukleophiler Angriff einer Hydroxylgruppe des Formylglycin-Hydrates auf das Sulfatschwefelatom führt zur Freisetzung des Substratalkohols R-OH unter Bildung eines Enzym-Sulfatester-Intermediats. Durch eine intramolekulare Umlagerung wird das Sulfat freigesetzt und die Aldehydgruppe wird wieder hergestellt. Der Reaktionszyklus endet mit der Hydratisierung des Formylglycinrestes zum Aldehydhydrat.

\subsection{Metachromatische Leukodystrophie (MLD)}

Die Arylsulfatase A katalysiert den ersten Abbauschritt von Cerebrosid-3-sulfat in Gegenwart des Kofaktors Sphingolipid-Aktivatorprotein B (SAP-B), einem Glykoprotein mit einem apparenten Molekulargewicht von 21,5 kDa. SAP-B bindet das lipophile in vivo-Substrat und macht es somit wasserlöslich [Mehl \& Jatzkewitz, 1964 \& 1968]. Das Sulfatid Cerebrosid-3-sulfat ist eines der Hauptmembranlipide der Myelinscheiden des Nervensystems. Die Defizienz der ASA oder des SAP-B führt zur Anreicherung von Sulfolipiden in den Lysosomen. In der Folge kommte es zu einer progressiven Demyelinisierung im zentralen und peripheren Nervensystem [Shapiro et al., 1979, Gieselmann et al., 1994]. Patienten mit diesen Defizienzen zeigen vielfältige neuronale Symptome, sensomotorische Störungen, Demenz, Krampfanfälle und mentale Retardierung. Im späteren Stadium führt dies zum Tod der Betroffenen [Gustavson \& Hagberg, 1971; Mehl \& Jatzkewitz, 1964; Überblick in Kolodny \& Fluharty, 1999]. 
Die MLD wird in den meisten Fällen durch die Defizienz der Arylsulfatase A verursacht [Gieselmann et al., 1991a, 1991b \&1994]. Der Name dieser Krankheit beruht auf der metachromatischen Anfärbung der akkumulierten Substanzen in histologischen Schnitten (metachromatisch = Farbabweichung bei der Gewebeanfärbung mit $\mathrm{pH}$ sensitiven Farbstoffen). Die MLD gehört damit zur Gruppe der lysosomalen Speicherkrankheiten. Sie tritt mit einer Häufigkeit von 1:40000 aller Neugeborenen auf, wobei es drei Verlaufsformen gibt, die je nach dem Zeitpunkt des Auftretens erster Symptome als spät infantile Verlaufsform (im Alter von ein bis zwei Jahren), als juvenile (zwischen dem dritten und 16. Lebensjahr) und als adulte Verlaufsform (im Erwachsenenalter) bezeichnet werden. Die Formen zeigen einen unterschiedlich schweren Verlauf der Erkrankung, d.h. die Symptome entwickeln sich bei späterem Auftrittsalter auch langsamer. Die Diagnose der MLD beruht üblicherweise auf ASAAktivitätsmessungen in Leukozyten oder Fibroblasten.

Bei einer Mutation, welche in MLD-Patienten mit einer Häufigkeit von $25 \%$ diese Krankheit verursacht, handelt es sich um einen C zu T Austausch im Nukleotid 2563 in Exon 8 des ASA-Gens. Diese führt zum Aminosäureaustausch von Prolin gegen Leucin an Stelle 426 (ASA-P426L) [Polten et al., 1991; Gieselmann et al., 1994]. Das mutierte Enzym ASA-P426L wird in normalen Mengen synthetisiert, besitzt enzymatische Aktivität und wird korrekt zum Lysosom transportiert. Dort jedoch findet eine drastische Erniedrigung der mittleren Lebensdauer auf weniger als 10\% statt [von Figura et al., 1986]. Diese Enzyminstabilität führt im homozygoten Fall zu einer Reduktion der effektiven enzymatischen Aktivität in Zellen auf 4\% [Porter et al., 1969]. Diese Patienten leiden unter der juvenilen oder adulten Form der MLD [Polten et al., 1991; von Figura et al., 1986].

Experimente mit Fibroblasten von Patienten, die homozygot dieses Allel besitzen, zeigten, daß Cysteinproteinasen für den raschen Abbau dieser ASA-Mutante verantwortlich sind, denn durch Zugabe von Cysteinproteinase-Inhibitoren konnte die mutierte ASA vor dem Abbau teilweise geschützt werden [von Figura et al., 1983 \& 1986]. Im Gegensatz dazu konnten Inhibitoren für Aspartylproteinasen den Abbau der ASA-Mutante nicht vermindern. Die wichtigsten Cysteinproteinasen der Lysosomen sind die Cathepsine. 


\section{Fragestellung}

Im ersten Teil der Arbeit soll die Struktur eines ASA-Substrat-Komplexes untersucht werden. Um die Spaltung des Substrats innerhalb des Komplexes zu vermeiden, sollen zwei katalytisch inaktive ASA-Mutanten, ASA-C69A und ASA-C69S kristallisiert werden. Nach Komplexierung mit dem Substrat pNCS und Röntgenstrukturanalyse soll ein Modell des ASA-pNCS-Komplexes erstellt werden. Die Strukturdaten sollen als Grundlage dafür dienen, die Rolle der einzelnen funktionellen Gruppen des aktiven Zentrums innerhalb des Mechanismus von Substratbindung und Katalyse der Sulfatesterspaltung zu diskutieren.

Im zweiten Teil der Arbeit soll die Struktur der Mutante ASA-P426L untersucht werden. Diese Mutante ist in Gegenwart von Cysteinproteinasen instabil und wird in den Lysosomen abgebaut. Die Untersuchungen der ASA-P426L, deren Aminosäureaustausch eine der häufigsten Ursachen für die lysosomale Speicherkrankheit metachromatische Leukodystrophie darstellt, sollen mit der Suche nach den Iysosomalen Proteinasen, die an der Spaltung der Mutante beteiligten sind, beginnen. Daraufhin soll die Identifizierung der Spaltstelle in der ASA-Mutanten erfolgen. Um den ursächlichen, strukturellen Zusammenhang zwischen der Mutation P426L und der erhöhten Sensitivität gegenüber Proteinasen herzustellen, soll die ASA-P426L kristallisiert und über Röntgenstrukturanalyse untersucht werden, wobei insbesondere der Bereich der Mutation und der Fragmentierung der Mutante im Vordergrund steht. 


\section{Methoden}

\subsection{Material}

Die Chemikalien wurden, sofern nicht anders angegeben, von den Firmen Aldrich Chemical Company (Milwaukee, USA), Baker (Deventer, Niederlande), BioRad (München), Boehringer (Mannheim), Calbiochem (Frankfurt), Fluka (Buchs, Schweiz), GIBCO/BRL (Eggenstein), Merck (Darmstadt), Pharmacia (Freiburg), Sigma (Deisenhofen), Serva (Heidelberg) und Roth (Karlsruhe) im Reinheitsgrad pro analysis bezogen. Die verwendeten Zellen, Antikörper, Enzyme oder spezielle Chemikalien sind in den jeweiligen Abschnitten der Methoden aufgeführt.

\subsubsection{Häufig verwendete Puffer und Stammlösungen}

\begin{tabular}{|c|c|c|}
\hline 50 x TAE: & $\begin{array}{l}2 \mathrm{M} \\
0,1 \mathrm{M}\end{array}$ & $\begin{array}{l}\text { Tris-Base } \\
\text { EDTA } \\
\text { mit Eisessig auf pH } 8,0 \text { einstellen }\end{array}$ \\
\hline TE: & $\begin{array}{l}10 \mathrm{mM} \\
1 \mathrm{mM}\end{array}$ & $\begin{array}{l}\text { Tris/HCl pH } 7,5 \\
\text { EDTA }\end{array}$ \\
\hline TBS: & $\begin{array}{l}150 \mathrm{mM} \\
10 \mathrm{mM}\end{array}$ & $\begin{array}{l}\mathrm{NaCl} \\
\text { Tris/HCl pH 7,4 }\end{array}$ \\
\hline $1 \mathrm{M}$ Tris/HCl: & \multicolumn{2}{|c|}{$\begin{array}{l}121,1 \mathrm{~g} \text { Tris } \\
\text { wurden in } 800 \mathrm{ml} \text { bidest. } \mathrm{H}_{2} \mathrm{O} \text { gelöst, der } \mathrm{pH} \text {-Wert mit } \\
\text { konzentrierter } \mathrm{HCl} \text { auf den gewünschten Wert }(7,07,5 ; 8,0 \text {; } \\
\text { 8,5) eingestellt, das Volumen auf } 1000 \mathrm{ml} \text { aufgefüllt und } \\
\text { autoklaviert. }\end{array}$} \\
\hline $20 \%$ SDS: & \multicolumn{2}{|c|}{$\begin{array}{l}20 \mathrm{~g} \text { Natriumdodecylsulfat } \\
\text { wurden in } 100 \mathrm{ml} \text { bidest. } \mathrm{H}_{2} \mathrm{O} \text { bei } 65^{\circ} \mathrm{C} \text { gelöst und sterilfiltriert. }\end{array}$} \\
\hline $1 \mathrm{M} \mathrm{NaAc}:$ & \multicolumn{2}{|c|}{$\begin{array}{l}136,0 \mathrm{~g} \text { Natriumacetat } \times 3 \mathrm{H}_{2} \mathrm{O} \\
\text { wurden in } 800 \mathrm{ml} \text { bidest. } \mathrm{H}_{2} \mathrm{O} \text { gelöst, der pH-Wert mit Eisessig } \\
\text { eingestellt, das Volumen auf } 1000 \mathrm{ml} \text { aufgefüllt und } \\
\text { autoklaviert. }\end{array}$} \\
\hline
\end{tabular}

10x PBS: $\quad 80 \mathrm{~g} \mathrm{NaCl}$ $1,6 \mathrm{~g} \mathrm{Na}_{2} \mathrm{HPO}_{4}$ wurden in $800 \mathrm{ml} \mathrm{H}_{2} \mathrm{O}$ bidest. gelöst, der pH-Wert auf 7,4 eingestellt und das Volumen auf $1000 \mathrm{ml}$ aufgefüllt. 


\subsubsection{Medien zur Anzucht von prokaryotischen Zellen}

LB-Medium: $\quad 10 \mathrm{~g}$ Bacto-Trypton (Difco)

$5 \mathrm{~g}$ Bacto-Hefe Extrakt (Difco)

$5 \mathrm{~g} \mathrm{NaCl}$

wurden in $800 \mathrm{ml}$ bidest. $\mathrm{H}_{2} \mathrm{O}$ gelöst, auf $\mathrm{pH}$ 7,5 eingestellt, anschließend mit bidest. $\mathrm{H}_{2} \mathrm{O}$ auf $1000 \mathrm{ml}$ aufgefüllt und autoklaviert.

LB-Ampicillin- Zur Bakterienanzucht wurde dem LB Medium vor dem Agarplatten: $\quad$ Autoklavieren Agar in einer Endkonzentration von 1,5\% zugesetzt. Nach dem Autoklavieren und dem Abkühlen auf $50^{\circ} \mathrm{C}$ wurde Ampicillin in einer Endkonzentration von 200 $\mu \mathrm{g} / \mathrm{ml}$ zugefügt. Der Agar wurde in $9 \mathrm{~cm}$ \#\#\# Petrischalen gegossen, bei Raumtemperatur abgekühlt und anschließend bei $4^{\circ} \mathrm{C}$ lichtgeschützt gelagert.

Abkürzung: LB: Luria Broth

\subsubsection{Zellkulturmedien und Lösungen zur Arbeit mit eukaryotischen Zellen} PBS (Zellkultur):

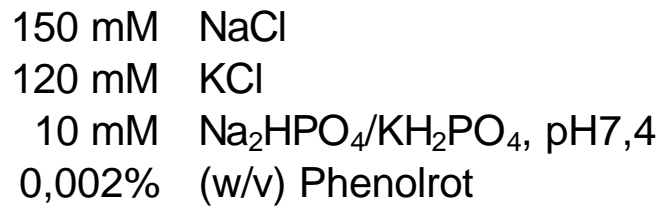

Dulbecco's Modified Eagle Medium

Seromed/Biochrom Berlin

(DMEM)

Fötales Kälberserum (FKS)

GIBCO/BRL, Eggenstein

Trypsin-EDTA-Lösung

GIBCO/BRL, Eggenstein

0,05\% (w/v) Trypsin GIBCO/BRL, Eggenstein

$0,02 \%(w / v)$ EDTA in modifizierter

Puck's Salzlösung

L-Glutamin (200 mM) 
Nicht essentielle Aminosäuren:

$1,782 \mathrm{~g} \alpha$-Alanin

$2,642 \mathrm{~g} \alpha$-Asparagin

$1,502 \mathrm{~g}$ Glycin

2,302 g $\alpha$-Prolin

$2,102 \mathrm{~g} \alpha$-Serin in $200 \mathrm{ml}$ bidest. $\mathrm{H}_{2} \mathrm{O}$ lösen.

Antibiotika:

Hygromycin B, p.A. Calbiochem, Frankfurt

Penicillin/Streptomycin Biochrom, Berlin

(10 000U bzw. $10000 \mathrm{mg} / \mathrm{ml}$ )

Medium für die Kultivierung von MEF (embryonalen Mausfibroblasten):

$\begin{array}{ll} & \text { DMEM } \\ 10 \% & \text { FKS } \\ 2 \mathrm{mM} & \text { L-Glutamin } \\ 100 \mathrm{U} / \mathrm{ml} & \text { Pen/Strep }\end{array}$




\subsection{Molekularbiologische Methoden}

Alle folgenden Methoden und Vorschriften wurden, soweit nicht anders angegeben, dem Laborbuch „Molecular Cloning“ [Sambrook et al., 1989] entnommen. Die molekularbiologischen Arbeiten mit cDNA beschränken sich in der Arbeit auf Arbeiten mit cDNA für humane Arylsulfatase A-C69A, einkloniert in den pMPSV-Vektor.

\subsubsection{Mini-Präparation von Plasmid-DNA}

Die Mini-Plasmidpräparation der cDNA für humane Arylsulfatase AC69A wurden nach Vorschrift des Herstellers Qiagen (Hilden) und unter Verwendung der folgenden mitgelieferten Puffer durchgeführt (Qiagen-Handbuch, April 1997):

P1:

$\begin{aligned} 50 \mathrm{mM} & \text { Tris/HCl pH 8,0 } \\ 10 \mathrm{mM} & \text { EDTA } \\ 100 \mu \mathrm{g} / \mathrm{ml} & \text { RNase A }\end{aligned}$

P2:

$$
\begin{array}{rl}
0,2 \mathrm{M} & \mathrm{NaOH} \\
1 \% & \mathrm{SDS}
\end{array}
$$

PB, PE, NE: keine Angaben des Herstellers

Bei der verwendeten Bakterienkultur handelt es sich um eine E. coli-Kolonie, transformiert mit cDNA für humane Arylsulfatase A-C69A im pMPSV-Vektor, die von Dr. A. Knaust zur Verfügung gestellt wurde [Knaust et al., 1998].

Vorkulturen mit einer $\mathrm{OD}_{600}$ von größer als 1 in LB-Medium wurden mit 0,25 Volumen $80 \%$ Glycerin versetzt und bei $-80^{\circ} \mathrm{C}$ aufbewahrt. Aus der Glycerinkultur kann direkt eine Vorkultur angeimpft werden.

$5 \mathrm{ml}$ LB-Medium mit $200 \mu \mathrm{g} / \mathrm{ml}$ Ampicillin wurden mit einer transformierten E. coliKolonie angeimpft und mindestens $5-8 \mathrm{~h}$ bei $37^{\circ} \mathrm{C}$ auf dem Drehrad inkubiert. $2 \mathrm{ml}$ der Bakteriensuspension wurden $5 \mathrm{~min}$ in der Eppendorfzentrifuge bei $1800 \mathrm{x} \mathrm{g} \mathrm{(6000} \mathrm{rpm)}$ zentrifugiert. Das Pellet wurde in $250 \mu$ le eiskaltem P1 aufgenommen, mit $250 \mu \mathrm{l}$ P2 versetzt, gemischt und 5 min bei RT inkubiert. Nach der Zugabe und dem Vermischen von $350 \mu \mathrm{l} \mathrm{N} 3$ erfolgte eine 15 minütige Inkubation auf Eis und eine anschließende Zentrifugation von $10 \mathrm{~min}$ bei $12000 \times \mathrm{g}$ und $4^{\circ} \mathrm{C}$. Der Überstand wurde auf eine Minisäule gegeben und $1 \mathrm{~min}$ bei $12000 \times \mathrm{g}$ zentrifugiert. Der Durchbruch wurde verworfen, $0,75 \mathrm{ml}$ PE-Puffer auf die Säule gegeben und diese wieder für $1 \mathrm{~min}$ zentrifugiert. Der Durchbruch wurde erneut verworfen und zum Entfernen der EthanolReste die Säule 1 min zentrifugiert. Die Elution der gebundenen DNA erfolgte mit $100 \mu \mathrm{l} \mathrm{H}_{2} \mathrm{O}$ bidest. $16 \mu \mathrm{l}$ wurden für den Verdau eingesetzt. 


\subsubsection{Midi-Präparation von Plasmid-DNA}

Die Midi-Plasmidpräparation von cDNA für humane Arylsulfatase A-C69A wurde nach Vorschrift des Herstellers Qiagen (Hilden) und unter Verwendung der folgenden mitgelieferten Puffer durchgeführt:

P1:

$\begin{aligned} 50 \mathrm{mM} & \text { Tris/HCl pH 8,0 } \\ 10 \mathrm{mM} & \text { EDTA } \\ 00 \mu \mathrm{g} / \mathrm{ml} & \text { RNase A }\end{aligned}$

P2:

$$
\begin{array}{rl}
0,2 \mathrm{M} & \mathrm{NaOH} \\
1 \% & \mathrm{SDS}
\end{array}
$$

P3:

$3 \mathrm{M}$ Kaliumacetat (KAc) pH 5,5

$\begin{array}{lrl}\text { QBT-Puffer: } & 750 \mathrm{mM} & \mathrm{NaCl} \\ & 50 \mathrm{mM} & \text { MOPS pH 7,0 } \\ & 15 \% & \text { Ethanol } \\ & 0,15 \% & \text { Triton X-100 } \\ & 1 \mathrm{M} & \mathrm{NaCl} \\ \text { QC-Puffer: } & 50 \mathrm{mM} & \text { MOPS pH 7,0 } \\ & 15 \% & \text { Ethanol } \\ & & \\ \text { QF-Puffer: } & 1,25 \mathrm{M} & \mathrm{NaCl} \\ & 50 \mathrm{mM} & \text { Tris/ } \mathrm{HCl} \mathrm{pH} \mathrm{8,5} \\ & 15 \% & \text { Ethanol }\end{array}$

Es wurden $100 \mathrm{ml}$ einer Bakterienkultur mit einer $\mathrm{OD}_{600}$ von größer als 1 bei $8500 \mathrm{x} \mathrm{g}$ (8000 rpm) im JA 10-Rotor (Beckmann, München) für $10 \mathrm{~min}$ abzentrifugiert. Das Bakterienpellet wurde in $4 \mathrm{ml} \mathrm{P1}$ resuspendiert, in JA-20 Röhrchen überführt, mit $4 \mathrm{ml}$ P2 versetzt, vorsichtig durch Invertieren gemischt und 5 min bei RT inkubiert. Durch Zugabe und sofortiges Invertieren von $4 \mathrm{ml}$ eiskaltem P3 wurde neutralisiert und anschließend 10-15 min auf Eis inkubiert. Der Ansatz wurde 30 min bei $30000 \times \mathrm{g}$ (18000 rpm) im JA 20-Rotor (Beckmann, München) zentrifugiert $\left(4^{\circ} \mathrm{C}\right)$, der Überstand sofort durch zwei Lagen Mull auf eine mit $4 \mathrm{ml}$ QBT-Puffer äquilibrierte Qiagen-Plasmid Prep Tip100-Säule gegeben. Die Plasmid-DNA bindet an das SilikagelAnionenaustauscher-Säulenmaterial. Die Säule wurde zweimal mit $10 \mathrm{ml}$ QC-Puffer gewaschen, die Plasmid-DNA anschließend mit $5 \mathrm{ml}$ QF-Puffer eluiert und in einem 50 ml-Röhrchen aufgefangen. Die DNA wurde mit 0,7 Volumen Isopropanol gefällt und bei $4{ }^{\circ} \mathrm{C}$ und $4400 \times \mathrm{g}$ für mindestens $45 \mathrm{~min}$ zentrifugiert. Das Pellet wurde mit $70 \%$ Ethanol gewaschen, bei RT oder im Vakuumkonzentrator getrocknet und in $0,5 \mathrm{ml} \mathrm{H}_{2} \mathrm{O}$ bidest. aufgenommen. Dazu wurden $166 \mu \mathrm{l}$ M Ammoniumacetatlösung und $1 \mathrm{ml}$ 
eisgekühltes Ethanol gegeben und gut gemischt. Die DNA wurde bei $4^{\circ} \mathrm{C}$ und $4400 \times \mathrm{g}$ für 10 min zentrifugiert. Das Pellet wurde mit 70\% Ethanol gewaschen, bei RT oder im Vakuumkonzentrator getrocknet und in einem geeigneten Volumen $\mathrm{H}_{2} \mathrm{O}$ bidest. aufgenommen. Die DNA-Konzentration wurde durch eine Messung der OD bei $260 \mathrm{~nm}$ bestimmt.

\subsubsection{Präzipitation von DNA mit Ethanol}

Das Volumen der DNA-Lösung wurde bestimmt, die Konzentration auf 0,3 M Na-Acetat eingestellt, mit 2 Volumen Ethanol versetzt und gemischt. Die Präzipitation erfolgte entweder für 20 min bei $-70^{\circ} \mathrm{C}, 10 \mathrm{~min}$ auf Trockeneis oder über Nacht bei $-20^{\circ} \mathrm{C}$. Die DNA wurde durch 10 min Zentrifugation bei $12000 \times$ g pelletiert, anschließend mit $70 \%$ Ethanol gewaschen und erneut 5 min zentrifugiert. Das DNA-Präzipitat wurde 3 bis 5 min im Vakuumkonzentrator getrocknet.

\subsubsection{Photometrische Konzentrationsbestimmung von DNA}

Die photometrische Messung von DNA erfolgte bei $260 \mathrm{~nm}$ in einer Quarzküvette gegen TE bzw. $\mathrm{H}_{2} \mathrm{O}$. Eine $\mathrm{OD}_{260}$ entspricht einer Konzentration von $50 \mu \mathrm{g} / \mathrm{ml}$ doppelsträngiger DNA und $31 \mu \mathrm{g} / \mathrm{ml}$ Oligonukleotiden.

\subsubsection{Spaltung von Plasmid-DNA mit Restriktionsendonukleasen}

Die Aktivität von Restriktionsendonukleasen wird in Units $(U)$ angegeben. Eine Unit entspricht der Menge an Enzym, die benötigt wird, um $1 \mu \mathrm{g}$ Lambda-Phagen-DNA in einer Stunde vollständig an den vorhandenen Schnittstellen zu schneiden.

Die durch Minipräparation gereinigte DNA wurde mit dem Restriktionsenzym EcoRI nach folgendem Ansatz verdaut: 


$\begin{array}{lll}\text { Reaktionsansatz : } & 0,5 \mu \mathrm{g} & \text { DNA } \\ 3 \mu \mathrm{l} & \begin{array}{l}\text { geeigneter 10x NEB-Puffer 3 } \\ \text { (New England Biolabs, Bad Schwalbach) }\end{array} \\ & 1 \mu \mathrm{l} & \begin{array}{l}\text { Restriktionsendonuklease EcoRI } \\ \text { (New England Biolabs, Bad Schwalbach) } \\ \end{array} \\ & \text { ad 30 } \mu \mathrm{l} & \mathrm{H}_{2} \mathrm{O} \text { bidest. }\end{array}$

NEB 3: $50 \mathrm{mM}$ Tris/HCl $(\mathrm{pH} \mathrm{8})+10 \mathrm{mM} \mathrm{MgCl} 2+1 \mathrm{mM} \mathrm{DTT}+100 \mathrm{mM} \mathrm{NaCl}$ Der Ansatz wurde zwei Stunden bei $37^{\circ} \mathrm{C}$ inkubiert und anschließend ein Aliquot davon im Agarosegel analysiert.

Als Reaktionspuffer wurde das New England Biolabs (NEB) Puffer-System verwendet. Diese Puffer werden vom Hersteller 10x konzentriert zusammen mit den Enzymen geliefert.

\subsubsection{Agarose-Gelelektrophorese zur Auftrennung von DNA}

Zur Auftrennung von DNA-Fragmenten unterschiedlicher Größe wurden Agarose-Gele verwendet. Die Agarose-Konzentration betrug $2 \%(\mathrm{w} / \mathrm{v})$, was einem Trennbereich von 0,1 bis $3,0 \mathrm{~kb}$ entspricht. Die erforderliche Agarose-Menge wurde in $300 \mathrm{ml} 1 \mathrm{x}$ TAE (40 mM Tris/ $\mathrm{HCl}, 2$ mM EDTA, pH 8,0) in der Mikrowelle aufgekocht und nach Abkühlen auf etwa $55^{\circ} \mathrm{C}$ mit Ethidiumbromid versetzt (Endkonzentration $0,5 \mu \mathrm{g} / \mathrm{ml}$ ). Die Agarose wurde in einen Gelträger gegossen und bei RT abgekühlt. Das erstarrte Gel wurde in die mit 1X TAE gefüllte Elektrophoresekammer überführt, die Proben wurden mit 10$20 \% \quad(\mathrm{v} / \mathrm{v}) \quad$ Proben-Puffer oder Ficoll-Marker (0,05\% Bromphenolblau, 0,05\% Xylencyanol, 15\% Ficoll) versetzt und in die vorgeformten Geltaschen pipettiert. Als Standard wurde DNA-Ladder (GIBCO/BRL, Eggenstein) verwendet. Die Elektophorese erfolgte bei einer Spannung von 3-4 V/cm. Durch das in die DNA interkalierende Ethidiumbromid wurden die DNA-Fragmente unter UV-Licht als Banden sichtbar. Zur Dokumentation wurde das Agarose-Gel auf dem UV-Transilluminator mit einem Videosystem (Intas, Göttingen) aufgenommen. 


\subsubsection{Sequenzierung von Plasmid-DNA}

\subsubsection{Sequenzierungsansatz}

Die Sequenzierung von Doppelstrang-DNA wurde mit einem DNA-Sequenzierer (Model 373A, Applied Biosystems, Weiterstadt) durchgeführt. Dabei wurde die Taq-CycleSequencing Methode des Herstellers Applied Biosystems angewandt, die auf der Methode nach Sanger [Sanger et al. 1977] aufbaut. Statt radioaktiv-markierter werden jedoch Fluorochrom-gekoppelte Didesoxynukleotide zum Kettenabbruch eingesetzt. Dazu wurde das ABI PRISM Dye Terminator Cycle Sequencing Ready ReactionProdukt der Firma Perkin Elmer (No. 402079) verwendet, das neben dem Puffer für die Sequenzierungsreaktion und der AmpliTaq ${ }^{\circledR}$ DNA Polymerase $(8 \mathrm{U} / \mu \mathrm{l})$ auch den dNTPMix und fluorochrom-gekoppelte Terminatoren im richtigen Verhältnis enthält (Taq: Thermophilus aquaticus). Der entscheidende Vorteil dieses Systems ist, daß aufgrund des Einsatzes von vier unterschiedlichen Fluorochromen nur eine Spur pro Probe auf dem Sequenzgel benötigt wird und daß die Auswertung Computer-unterstützt abläuft. Die Fluorochrome werden durch einen $40 \mathrm{~mW}$ Argon-Laser (488 nm und $514 \mathrm{~nm}$ ) angeregt, die Fluoreszenzsignale durch das Detektorsystem gelesen und mit den Programmen Collection und Analysis die DNA-Sequenz in Chromatogrammform dargestellt.

Die Sequenzierungsreaktion wurde wie folgt durchgeführt:

$\begin{array}{ll}\text { Premix } & 8 \mu \mathrm{l} \\ \text { DNA-Template } & 1,0 \mu \mathrm{g} \\ \text { (Plasmid-DNA-Doppelstrang) } & \\ \text { Primer } & 3-10 \mathrm{pmol} \\ \mathrm{H}_{2} \mathrm{O} \text { bidest. ad } & 20 \mu \mathrm{l}\end{array}$

Zur Sequenzierung wurden folgende Oligonukleotide als Primer eingesetzt:

\begin{tabular}{|l|l|l|}
\hline Bezeichnung & Leserichtung & Sequenz (in 5`^3) \\
\hline RP 23 & $(5 `$ ` $)$ & GTT AAC TGG TAA GTT TAG \\
\hline RP 24 & $\left(3^{\prime} \wedge 5\right)$ & GCA TTC TAG TTG TGG TT \\
\hline
\end{tabular}


Nach Pipettieren des Ansatzes wurden 25 PCR-Reaktionszyklen in einem Perkin Elmer Cetus Thermocycler Modell 9600 (Perkin Elmer Cetus, Norwalk, USA) durchgeführt:

$\begin{array}{lll}\text { Denaturierung } & 10 " & 96^{\circ} \mathrm{C} \\ \text { Annealing } & 5^{\prime \prime} & 50^{\circ} \mathrm{C} / 25 \text { Zyklen } \\ \text { Extension } & 4^{\prime} & 60^{\circ} \mathrm{C}\end{array}$

Nach Abschluß der Reaktion wurde die Probe auf $4^{\circ} \mathrm{C}$ gekühlt. Die DNA-Lösung wurde mit $2 \mu \mathrm{l} 3 \mathrm{M}$ Natriumacetat und $50 \mu \mathrm{l}$ Ethanol versetzt und gemischt. Die DNA wurde durch 20 minütige Zentrifugation bei $12.000 \times$ g pelletiert. Das Pellet wurde mit $250 \mu \mathrm{l}$ $70 \%$ Ethanol gewaschen und im Vakuumkonzentrator getrocknet. In getrockneter Form sind die Ansätze bei $-20^{\circ} \mathrm{C}$ lagerungsfähig. Das Pellet wurde in $4 \mu \mathrm{l}$ Formamid/EDTA, $\mathrm{pH} 8,0(5: 1)$ aufgenommen, $2 \mathrm{~min}$ bei $90^{\circ} \mathrm{C}$ denaturiert, 5 min auf Eis abgekühlt und zügig auf ein $6 \%$ Polyacrylamidgel aufgetragen.

\subsubsection{Polyacrylamidgele zur DNA-Sequenzierung}

Die DNA-Proben aus dem Sequenzansatz wurden in Polyacrylamidgelen aufgetrennt, für die spezielle, nicht fluoreszierende Chemikalien verwendet wurden:
$10 \times$ TBE:
$108 \mathrm{~g}$ Tris
$55 \mathrm{~g}$ Borsäure
$10 \mathrm{ml} 0,5 \mathrm{M}$ EDTA
wurden in $1 \mathrm{I} \mathrm{H}_{2} \mathrm{O}$ bidest. gelöst.

40\% Acrylamidlösung:

$90 \mathrm{~g}$ Acrylamid

$10 \mathrm{~g} \mathrm{~N}, \mathrm{~N}^{*}$-Methylenbisacrylamid wurden auf $500 \mathrm{ml}$ mit bidest. $\mathrm{H}_{2} \mathrm{O}$ aufgefüllt und eine Stunde mit 2-4 g lonenaustauscher (AG-501 Biorad) deionisiert, filtriert und in einer dunklen Flasche bei $4^{\circ} \mathrm{C}$ gelagert.

6\% Polyacrylamidgel:

$30 \mathrm{~g}$ Harnstoff

$9 \mathrm{ml} 40 \%$ Acrylamidlösung wurden in $20 \mathrm{ml} \mathrm{H}_{2} \mathrm{O}$ bidest. bei $37^{\circ} \mathrm{C}$ gelöst, mit $1,2 \mathrm{~g}$ lonenaustauscher versetzt und 5 Minuten gerührt, $6 \mathrm{ml} 10 \times$ TBE zugegeben, entgast und auf $60 \mathrm{ml}$ mit $\mathrm{H}_{2} \mathrm{O}$ bidest. aufgefüllt. 
Die Glasplatten wurden mit $\mathrm{H}_{2} \mathrm{O}$ bidest., Alconox und Ethanol gründlich gereinigt und an der Luft getrocknet. Die Reinheit der Platten wurde im Sequenzierungsgerät mit dem Laserstrahl überprüft. Anschließend wurden sie mit Abstandhaltern und Klammern zusammengesetzt.

Zu $50 \mathrm{ml}$ Lösung für ein 6\% Polyacrylamidgel wurden $27 \mu \mathrm{l}$ TEMED und $270 \mu \mathrm{l} 10 \%$ Ammoniumperoxo-di-sulfat pipettiert, gemischt, zügig zwischen die Glasplatten gegossen und der Kamm zur Formung der Geltaschen eingesetzt. Nach der Polymerisation (ca. $30 \mathrm{~min}$ ) wurden die Platten von außen erneut mit $\mathrm{H}_{2} \mathrm{O}$ bidest., Alconox und Ethanol gründlich gereinigt und auf Gelrückstände überprüft. Anschließend wurde der Probenkamm herausgezogen, die Klammern entfernt und das Gel in die Laufkammer des Sequenzierautomaten eingesetzt. Vor dem Probenauftrag wurde ein Vorlauf von mindestens 30 min durchgeführt. Die Elektrophorese fand in $1 \times$ TBE-Puffer bei $1300 \mathrm{~V}$ statt. 


\subsection{Zellbiologische Methoden}

\subsubsection{Allgemeine Arbeiten mit eukaryotischen Zellen}

Die Zellen wurden in wassergesättigter Atmosphäre unter $5 \% \mathrm{CO}_{2}$ bei $37^{\circ} \mathrm{C}$ kultiviert. Medien und Lösungen wurden auf $37^{\circ} \mathrm{C}$ vorgewärmt. Im Allgemeinen erfolgte die Kultivierung der Zellen mit folgendem Medium:

DMEM + 10\% FKS + $1 \times$ Penicillin/Streptomycin

Medien für stabil transfizierte Zellen enthielten zusätzlich $500 \mu \mathrm{g} / \mathrm{ml}$ Hygromycin B.

Die Zellen wurden alle 2 bis 4 Tage mit frischem Medium gefüttert.

Folgende Zellen wurden verwendet:

\begin{tabular}{|c|c|c|}
\hline Zellinie & Beschreibung & Referenz \\
\hline $\begin{array}{l}\mathrm{mpr}^{-} \mathrm{MEF} \\
(23-1 S \mathrm{~V})\end{array}$ & $\begin{array}{l}\text { immortalisierte embryonale } \\
\text { Mausfibroblasten (MEF), defizient für } \\
\text { endogenen MPR } 46 \text { und endogenen } \\
\text { MPR } 300\end{array}$ & Kasper et al., 1996 \\
\hline mpr ${ }^{-}$MEF / ASA-wt & $\begin{array}{l}\text { mpr }{ }^{-} \text {MEF transfiziert mit cDNA für } \\
\text { humane Arylsulfatase A }\end{array}$ & Dittmer, 1995 \\
\hline mpr MEF / ASA-C69A & $\begin{array}{l}\text { mpr }{ }^{-} \text {MEF transfiziert mit cDNA für } \\
\text { humane Arylsulfatase A-C69A }\end{array}$ & s. Abschnitt 3.3.5 \\
\hline mpr MEF / ASA-C69S & $\begin{array}{l}\text { mpr }{ }^{-} \text {MEF transfiziert mit cDNA für } \\
\text { humane Arylsulfatase A-C69S }\end{array}$ & $\begin{array}{l}\text { Recksieck et al. } \\
1998 \\
\end{array}$ \\
\hline mpr MEF / ASA-P426L & $\begin{array}{l}\text { mpr }{ }^{-} \text {MEF transfiziert mit cDNA für } \\
\text { humane Arylsulfatase A-P426L }\end{array}$ & $\begin{array}{l}\text { von Figura et al., } \\
\text { unveröffentlicht }\end{array}$ \\
\hline $\begin{array}{l}\text { Kontroll-MEF } \\
(\mathrm{C} 13+/+)\end{array}$ & $\begin{array}{l}\text { immortalisierte embryonale } \\
\text { Mausfibroblasten (MEF) }\end{array}$ & $\begin{array}{l}\text { Dr. W. Roth, } \\
\text { Institut f. molekulare } \\
\text { Medizin und }\end{array}$ \\
\hline $\begin{array}{l}\mathrm{CL}^{-} \mathrm{MEF} \\
(\mathrm{C} 12-/-)\end{array}$ & $\begin{array}{l}\text { immortalisierte Cathepsin } L \text { defiziente } \\
\text { MEF }\end{array}$ & $\begin{array}{l}\text { Zellforschung, } \\
\text { Universität Freiburg }\end{array}$ \\
\hline $\begin{array}{l}\text { humane } \\
\text { Hautfibroblasten }\end{array}$ & $\begin{array}{l}\text { primäre humane Hautfibroblasten, } \\
\text { Kontrolle I; G2017/98 }\end{array}$ & $\begin{array}{l}\text { Abt. Biochemie II, } \\
\text { Universität Göttingen }\end{array}$ \\
\hline
\end{tabular}




\subsubsection{Trypsinieren von eukaryotischen Zellen}

Trypsin-EDTA-Lösung: $\quad 0,05 \%(\mathrm{w} / \mathrm{v})$ Trypsin

$0,02 \%(w / v)$ EDTA in modifizierter Puck's Salzlösung

Die Passagierung der Zellen erfolgte routinemäßig nach Erreichen der Konfluenz des Zellrasens. Dazu wurde das Medium abgesaugt und die Zellen einmal mit PBS gespült, um inhibierende Einflüsse von Serumbestandteilen auf die Trypsinaktivität zu verhindern. Nach Absaugen des PBS wurden die Zellen ca. 5 min mit Trypsin/EDTA bei $37^{\circ} \mathrm{C}$ bis zur Abrundung der Zellen (mikroskopische Kontrolle) inkubiert. Die TrypsinReaktion wurde durch Zugabe von serumhaltigem Medium gestoppt, die Zellen durch mehrfaches Aufsaugen mit der Pipette vereinzelt und die Zellzahl pro Milliliter mit der Neubauer-Zählkammer bestimmt. Die Zellen wurden in der gewünschte Dichte ausgesät oder zur weiteren Verarbeitung durch Zentrifugation pelletiert (1000 rpm, 5 min, Labofuge), mit 1 \#\#\# PBS gewaschen und bei $-20^{\circ} \mathrm{C}$ gelagert.

\subsubsection{Kryokonservierung von eukaryotischen Zellen}

Die Zellen wurden trypsiniert, in Medium aufgenommen und in der Labofuge pelletiert (5 min, 1000 rpm, Labofuge). Nach Absaugen des Überstandes wurden die Zellen in $1 \mathrm{ml}$ kaltem Einfriermedium aufgenommen und in beschriftete, vorgekühlte Kryoröhrchen überführt. Die Zellen wurden zunächst bei $-80^{\circ} \mathrm{C}$ in einer Styropor-Schachtel eingefroren und anschließend in flüssigem Stickstoff gelagert.

Einfriermedium: $\quad 10 \%(\mathrm{v} / \mathrm{v})$ DMSO im jeweiligen Zellkulturmedium

\subsubsection{Auftauen und Revitalisieren von eukaryotischen Zellen}

Nach der Entnahme des Kryoröhrchens aus dem Stickstofftank wurde es etwa 1 min bei RT erwärmt und anschließend in $70 \%$ Ethanol bei $37^{\circ} \mathrm{C}$ aufgetaut, bis nur noch ein kleiner Eiskern zu sehen war. Die Zellsuspension wurde vorsichtig entnommen, in $5 \mathrm{ml}$ kaltes Medium $\left(4^{\circ} \mathrm{C}\right)$ überführt und in der Labofuge 5 min bei $1000 \mathrm{rpm}$ sedimentiert. Der Überstand wurde abgesaugt, das Zellpellet in $5 \mathrm{ml}$ kaltem Medium ohne Selektionsantibiotikum resuspendiert und in eine Zellkulturflasche überführt. Am nächsten Tag wurde standardmäßig das Medium gewechselt, um restliches DMSO, tote Zellen und Zelltrümmer zu entfernen sowie, falls erforderlich, Selektionsantibiotikum zuzuführen. 


\subsubsection{Stabile Transfektion in eukaryotische Zellen}

Die stabile Transfektion von mpr MEF(23-1SV)-Zellen [Kasper et al., 1996] mit cDNA für humane Arylsulfatase A-C69A wurde nach der Calcium-Phosphat-Methode durchgeführt [Chen \& Okayama, 1987].
Lösungen:
$2,0 \mathrm{M} \mathrm{CaCl} 2$
HBS $(2 x)$ :
$50 \mathrm{mM}$ HEPES
$1,5 \mathrm{mM} \quad \mathrm{Na}_{2} \mathrm{HPO}_{4}$
$0,28 \mathrm{M} \mathrm{NaCl} \mathrm{pH} \mathrm{7,01}$
Glycerin-Schock:
$15 \%(\mathrm{w} / \mathrm{v}) \quad$ Glycerin in $1 \times \mathrm{HBS}$

Die Zellen wurden am Vortag der Transfektion in einer Dichte von $6 \times 10^{5}$ Zellen auf einer $10 \mathrm{~cm}$ Gewebeschale ausgesät. Vier Stunden vor Zugabe der DNA wurde das Medium gewechselt. Zur Herstellung des Calciumphosphat/DNA-Präzipitats wurden $20 \mu \mathrm{g}$ des zu transfizierenden Plasmids (Qiagen-Präparation), jeweils $2 \mu \mathrm{g}$ des Selektionsplasmids pGKhygro [Mortensen et al., 1991] sowie $31,25 \mu l 2 \mathrm{M} \mathrm{CaCl}_{2}$ in einem Eppendorfgefäß vorgelegt und mit $\mathrm{H}_{2} \mathrm{O}$ bidest. auf $250 \mu \mathrm{l}$ aufgefüll und gemischt. Diese DNA-Mischung wurde unter Lufteinstrom in $250 \mu \mathrm{l} \mathrm{HBS}$ eingetropft. Das dabei entstandene Präzipitat wurde 45 Minuten erschütterungsfrei bei RT stehengelassen und anschließend auf die MEF-Zellen gegeben. Nach 4 Stunden wurde das Medium abgesaugt und die Zellen einem Glycerin-Schock unterworfen. Dafür wurde das Medium von den Zellen abgesaugt, und für 2,5 Minuten durch $3 \mathrm{ml} 15 \%$ Glycerin in $1 \times$ HBS ersetzt. Anschließend wurden die Zellen $2 \times$ mit PBS gewaschen und mit $5 \mathrm{ml}$ Medium weiter inkubiert.

\subsubsection{Selektion der stabil transfizierten Zellklone}

Einen Tag nach dem Glycerin-Schock wurden zur Selektion dem Medium $100 \mu \mathrm{g} / \mathrm{ml}$ Hygromycin B zugesetzt. An den folgenden Tagen wurde die Hygromycin-Konzentration um jeweils $100 \mu \mathrm{g} / \mathrm{ml}$ bis auf $500 \mu \mathrm{g} / \mathrm{ml}$ erhöht. Bei $300 \mu \mathrm{g} / \mathrm{ml}$ sterben ca. $90 \%$ der Zellen ab. Nach etwa 10 Tagen können Einzelklone auf eine 24-NapfGewebekulturplatte überführt werden. Der Expressionstest erfolgte 3 bis 4 Wochen nach Transfektionsbeginn. 


\subsubsection{Expression von rekombinantem Protein im Großmaßstab}

Zur Gewinnung der von den Zellen in das Kulturmedium abgegebenen löslichen rekombinanten Proteinen (wt-ASA, ASA-C69A, ASA-C69S und ASA-P426L) wurden die oben aufgelisteten Zellen verwendet (3.3.1).

Die MEF-Zellen des entsprechenden Klones wurden auf $14,5 \mathrm{~cm}$-Zellkulturplatten ausplattiert und bis zur Konfluenz in DMEM, 5\% FKS, 1x Pen/Strep inkubiert. Bei Erreichen der Konfluenz wurden die Zellen für $48 \mathrm{~h}$ mit je $20 \mathrm{ml}$ Hungermedium (DMEM, 2,5\% FKS, 1x Pen/Strep) inkubiert. Das Medium wurde abgenommen, die Zelltrümmer in einem JA-10-Rotor bei 8000 rpm für 20 min in der Beckman-Zentrifuge abzentrifugiert. Das Volumen des geklärten Mediums wurde gravimetrisch bestimmt und ein Aliquot zur Bestimmung der Menge an rekombinantem Protein durch ASAAssay (wt-ASA und ASA-P426L) bzw. Dot-Blot (inaktive Mutanten: ASA-C69A und ASA-C69S) entnommen. Das Medium wurde nach Zusatz von Ammoniumsulfat zu einer Endkonzentration von $50 \%(\mathrm{w} / \mathrm{v})$ bei $4^{\circ} \mathrm{C}$ bis zur weiteren Aufarbeitung gelagert.

Die Zellen wurden erneut mit $20 \mathrm{ml}$ Hungermedium inkubiert, das nach $48 \mathrm{~h}$ erneut geerntet wurde. Dieser Zyklus erfolgte 3-5 mal pro Platte bis die Zellen anfingen abzusterben.

\subsubsection{Dialyse von FKS für die Zellmarkierung}

\begin{tabular}{|c|c|c|}
\hline Lösung 1: & $\begin{array}{l}10 \mathrm{mM} \\
1 \mathrm{mM}\end{array}$ & $\begin{array}{l}\mathrm{NaHCO}_{3} \\
\text { EDTA }\end{array}$ \\
\hline Lösung 2: & $\begin{array}{l}10 \mathrm{mM} \\
150 \mathrm{mM}\end{array}$ & $\begin{array}{l}\mathrm{HEPES} / \mathrm{NaOH} \mathrm{pH} 7,4 \\
\mathrm{NaCl}\end{array}$ \\
\hline
\end{tabular}

Der Dialyseschlauch wurde für $1 \mathrm{~h}$ in kochender Lösung 1 eingeweicht. Dann wurde diese abgegossen und der Dialyseschlauch in frischer $\mathrm{NaHCO}_{3} /$ EDTA-Lösung bei $4^{\circ} \mathrm{C}$ aufbewahrt.

$100 \mathrm{ml}$ FKS wurden zunächst für $1 \mathrm{~h}$ bei $56^{\circ} \mathrm{C}$ im Wasserbad Hitze-inaktiviert. Dann erfolgte die Dialyse für $3 \times 5-10 \mathrm{~h}$ gegen jeweils 1,5 Liter HEPES-Puffer. Abschließend wurde das dialysierte FKS steril filtriert, aliquotiert und bei $-20^{\circ} \mathrm{C}$ gelagert. 


\subsubsection{Metabolische Markierung wt-ASA und ASA-P426L mit $\left[{ }^{35}\right.$ S]Methionin/Cystein}

Für die metabolische Markierung von wt-ASA und ASA-P426L mit $\left[{ }^{35} S\right]-M e t h i o n i n$ wurden die Zellen mpr MEF/ASA-P426L und mpr MEF/ASA-wt verwendet.

$\left[{ }^{35} \mathrm{~S}\right]-$ Methionin/Cystein: Revidue PRO-MIX $\left[{ }^{35} \mathrm{~S}\right]$ (Amersham Pharmacia Biotech, Braunschweig); spezifische Aktivität: 14,3 $\mu \mathrm{Ci} / \mu \mathrm{l}$.

Pro $14,5 \mathrm{~cm}$ Platte:

Hungermedium: $\quad 15 \mathrm{ml} \quad$ Methionin-Cystein-freies MEM

Markierungsmedium: $\quad 15 \mathrm{ml} \quad$ Methionin-Cystein-freies MEM

$0,375 \mathrm{ml}$ dialysiertes FKS (hitze-inaktiviert)

$500 \mu \mathrm{Ci} \quad\left[{ }^{35} \mathrm{~S}\right]$ Methionin/Cystein

Für die Markierung wurden die MPR-defiziente MEF-Zellen verwendet, die über $90 \%$ der überproduzierten humanen ASA ins Medium sezernieren und eine Selektion mit dem Antibiotikum Hygromycin $(500 \mathrm{mg} / \mathrm{ml})$ erlaubten. Die Zellen wurden am Vortag in der benötigten Dichte auf eine $14,5 \mathrm{~cm}$ Schale ausgesät. Eine Stunde vor Markierungsbeginn wurden die Zellen mit $1 \times 20$ ml PBS gewaschen, um nichtradioaktives Methionin von den Zellen und den Wänden der Petrischale zu entfernen. Danach wurden die Zellen für eine Stunde mit Hungermedium im Inkubator belassen, bevor das Medium gegen $15 \mathrm{ml}$ Markierungsmedium $\left(500 \mu \mathrm{Ci} \quad \# \# \#^{35} \mathrm{S \# \#}\right.$ Methionin/Cystein) ausgetauscht wurde. Die Zellen wurden bei $37^{\circ} \mathrm{C}$ und $5 \% \quad \mathrm{CO}_{2}$ inkubiert. Nach Markierung wurde das Medium abgesaugt und bei $9000 \mathrm{rpm}$ und $4^{\circ} \mathrm{C}$ für 20 min zentrifugiert. Die Proteine wurden durch Zugabe von $50 \%(\mathrm{w} / \mathrm{v})$ Ammoniumsulfat aus dem Medium gefällt und anschließend das Ammoniumsulfatpräzipitat durch Zentrifugation in einem JA-20-Rotor bei $9000 \mathrm{rpm}$ und $4^{\circ} \mathrm{C}$ für $20 \mathrm{~min}$ abzentrifugiert. Das Präzipitat wurde in $1-2 \mathrm{ml} \mathrm{H}_{2} \mathrm{O}$ bidest. suspendiert und in Ultahülsen (Ausschlußgrenze: $25 \mathrm{kDa}$ ) zweimal gegen je $200 \mathrm{ml}$ TBS, und zweimal gegen DMEM dialysiert und eventuell eingeengt. Die ASA-Aktivität sowie die Radioaktivität wurden bestimmt. 


\subsubsection{Endocytose von $\left[{ }^{35} \mathrm{~S}\right]-\mathrm{ASA}$}

Für die Endocytose von $\left[{ }^{35}\right.$ S]wt-ASA und $\left[{ }^{35}\right.$ S]ASA-P426L wurden Kontroll-MEF $(\mathrm{C} 13+/+), \mathrm{CL}^{-} \mathrm{MEF}(\mathrm{C} 12-/-)$ und humane Hautfibroblasten verwendet.

Endocytose-Medium:

DMEM mit $10 \%$ FKS

$20.000 \mathrm{cpm}\left[{ }^{35} \mathrm{~S}\right] w t-A S A$ bzw. $30.000 \mathrm{cpm}\left[{ }^{35} \mathrm{~S}\right] \mathrm{ASA}-\mathrm{P} 426 \mathrm{~L}$ (aus 3.3.9)

Konfluent bewachsene $10 \mathrm{~cm}$ Kulturschalen wurden mit je $5 \mathrm{ml}$ Endocytose-Medium für $16 \mathrm{~h}$ bei $37^{\circ} \mathrm{C}$ und $5 \% \mathrm{CO}_{2}$ im Inkubator inkubiert. Zur Kontrolle der Beteiligung von Cysteinproteinasen beim Abbau von ASA-P426L in humanen Hautfibroblasten wurde dem Medium CBZ-Phe-Ala- $\mathrm{CHN}_{2}$ in einer Endkonzentration von 0,8 $\mu \mathrm{M}$ zugegeben. Nach der Inkubation wurden die Platte aus dem Inkubator genommen und im Kühlraum auf Eis auf ca. $4^{\circ} \mathrm{C}$ abgekühlt. Anschließend wurde das Endocytose-Medium abgenommen und in ein Eppendorfgefäß überführt. Die Zellen wurden $4 \mathrm{x}$ mit eiskaltem Hanks-Puffer gewaschen und die Waschfraktionen in einem Zählröhrchen gesammelt, um die Radioaktivität im Gamma-Counter zu bestimmen. Die Zellen wurden mit einem Gummispatel abgeschabt. Sowohl Pellet als auch Überstand wurden im Gamma-Counter (Flüssigkeitsszintillationszähler Modell 1900TR, Packard, Frankfurt/M) gezählt. Die Zellen wurden solubilisiert und zur Immunpräzipitation mit anschließender SDS-Gelelektrophorese eingesetzt. 


\subsection{Biochemische Methoden}

\subsubsection{Reinigung von Pansorbin}

$\begin{array}{lrl}\text { NET-Puffer: } & 50 \mathrm{mM} & \text { Tris/ } \mathrm{HCl} \mathrm{pH} \mathrm{7,4} \\ & 150 \mathrm{mM} & \mathrm{NaCl} \\ 5 \mathrm{mM} & \text { EDTA }\end{array}$

10 leere Eppendorfgefäße wurden gewogen und anschließend mit je $1 \mathrm{ml}$ Pansorbin (Calbiochem) gefüllt. Die E-Cups wurden für 2 min bei 12000 rpm zentrifugiert und das Sediment in je $1 \mathrm{ml}$ NET-Puffer resuspendiert. Diese Suspension wurde daraufhin $30 \mathrm{~min}$ bei $85^{\circ} \mathrm{C}$ inkubiert, erneut pelletiert und in $1 \mathrm{ml}$ NET-Puffer mit $1 \%(\mathrm{w} / \mathrm{v})$ SDS gewaschen. Die Ansätze wurden 5 min auf $95^{\circ} \mathrm{C}$ erhitzt, zentrifugiert und die Pellets dreimal in je $1 \mathrm{ml}$ NET-Puffer mit $5 \mathrm{mg} / \mathrm{ml}$ BSA und 0,5\% (w/v) Triton X-100 gewaschen. Anschließend wurden die Pellets zweimal in 10 mM PBS gewaschen, gewogen, mit 10 $\mathrm{mM}$ PBS, $10 \mathrm{mg} / \mathrm{ml}$ BSA, 0,04\% (w/v) $\mathrm{NaN}_{3}$ auf eine Pansorbinkonzentration von 100 $\mathrm{mg} / \mathrm{ml}$ eingestellt und bei $4^{\circ} \mathrm{C}$ gelagert.

\subsubsection{Immunpräzipitation metabolisch markierter Proteine}

Sämtliche Arbeitsschritte zur Immunisolierung radioaktiv markierter ASA erfolgten auf Eis unter Verwendung gekühlter Lösungen.

Protease-Inhibitoren (Endkonzentration):

Homogenisations-Puffer:

Wasch-Immunomix (IMM):

2M-KCl-Immunomix:
$1 \mathrm{mM}$ EDTA (Stammlösung: 0,2 $\mathrm{M}$ in $\mathrm{H}_{2} \mathrm{O}$ )

$1 \mathrm{mM}$ PMSF (Stammlösung: 0,2 $\mathrm{M}$ in DMSO)

$5 \mathrm{mM}$ JAA (Stammlösung: 0,5 $\mathrm{M}$ in $\mathrm{H}_{2} \mathrm{O}$ )

$$
\begin{aligned}
1 \mathrm{mM} & \text { PMSF } \\
1 \mathrm{mM} & \text { EDTA } \\
5 \mathrm{mM} & \text { JAA } \\
50 \mathrm{mM} & \text { Tris/HCl pH 7,4 }
\end{aligned}
$$

$$
\begin{aligned}
& 1 \%(w / v) \text { Triton-X-100 } \\
& 0,5 \%(w / v) \text { Na-Desoxycholat } \\
& \text { in PBS }
\end{aligned}
$$

$2 \mathrm{M} \mathrm{KCl}$

in Wasch-Immunomix 


$\begin{array}{lrl}\text { Präzipitations-Immunomix: } & 0,2 \%(\mathrm{w} / \mathrm{v}) & \text { SDS } \\ 10 \%(\mathrm{w} / \mathrm{v}) & \mathrm{BSA} \\ 1 \mathrm{mM} & \text { EDTA } \\ 1 \mathrm{mM} \text { PMSF } \\ 5 \mathrm{mM} \text { JAA } \\ \text { in Wasch-Immunomix }\end{array}$

Neufeldpuffer:

0,05\% (w/v) Nonidet P-40

$0,1 \%(w / v)$ SDS

$0,6 \mathrm{M} \mathrm{NaCl}$

$10 \mathrm{mM}$ Tris/ $\mathrm{HCl} \mathrm{pH} \mathrm{8,5}$

Protaminsulfat:

$3 \%(\mathrm{w} / \mathrm{v})$ Protaminsulfat

in $\mathrm{H}_{2} \mathrm{O}$

Pansorbin:

gewaschen

Antikörper:

Ziege $\alpha$ humane Arylsulfatase A (aus humaner Placenta)

Präimmunserum:

Ziege

Zur Immunpräzipitation wurden die Zellen in $500 \mu \mathrm{l}$ Homogenisationspuffer aufgenommen. Die Homogenisierung der Ansätze erfolgte durch UltraschallBehandlung ( $3 \times 10 \mathrm{sec}$, bei maximaler Leistung) gefolgt von einer Zentrifugation bei $14000 \mathrm{rpm}$ für $1 \mathrm{~min}$ (Eppendorf-Tischzentrifuge). Die Überstände wurden mit 0,8 Vol. Präzipitations-Immunomix versetzt, zur Entfernung genomischer DNA auf 0,03\% (w/v) Protaminsulfat eingestellt und $10 \mathrm{~min}$ auf Eis inkubiert. Nach erneuter Zentrifugation (5 min, $4^{\circ} \mathrm{C}, 14000 \mathrm{rpm}$, Eppendorf-Zentrifuge) wurden die Überstände in neue Reaktionsgefäße überführt und wie die konditionierten Medien (ebenfalls versetzt mit 0,8 Vol. Präzipitations-Immunomix) mit je $3 \mu \mathrm{l}$ Präimmunserum aus Ziege und $60 \mu \mathrm{l}$ ungewaschenem Pansorbin versetzt. Die Ansätze wurden für mindestens $2,5 \mathrm{~h}$ bei $4^{\circ} \mathrm{C}$ auf dem Drehrad einer Präadsorption unterzogen und anschließend bei $45000 \mathrm{rpm}$ in einer Eppendorf-Tischzentrifuge und $4^{\circ} \mathrm{C}$ für 30 min zentrifugiert. Nach Zugabe von $2 \mu \mathrm{l}$ des Antikörpers Ziege $\alpha$ humane Arylsulfatase A zu den Überständen erfolgte ÜN bei $4^{\circ} \mathrm{C}$ auf dem Drehrad die Antigen-Antikörper-Reaktion. Die gebildeten Komplexe wurden anschließend durch Zusetzen von $60 \mu \mathrm{l}$ gewaschenem Pansorbin gebunden (1 h, Drehrad) und durch Zentrifugation (5 min, 14000 rpm, Eppendorf-Zentrifuge) pelletiert. 
Die Pansorbin-Pellets wurden einer ausgiebigen Waschprozedur mit je $0,8 \mathrm{ml}$ eiskaltem Puffer in folgender Reihenfolge unterworfen:
1. Neufeldpuffer
2. Wasch-Immunomix
3. 2 M KCl-Immunomix
4. $0,1 \times$ PBS
5. $0,1 \times$ PBS

Dabei wurde jedes Pellet sorgfältig durch Mixen im Vortex resuspendiert und anschließend durch Zentrifugation wiedergewonnen. Nach Waschen mit $2 \mathrm{M} \mathrm{KCl}$ Immunomix und nach dem ersten Waschschritt mit 0,1 x PBS wurden die Proben in neue Gefäße transferiert. Zur Ablösung der Antigen-Antikörper-Komplexe vom Pansorbin wurden die Pellets schließlich in $60 \mu \mathrm{l} 1 \mathrm{x}$ Probenpuffer $(2 \%$ SDS, reduzierend) resuspendiert, $5 \mathrm{~min}$ bei $95^{\circ} \mathrm{C}$ erhitzt und $2 \mathrm{~min}$ bei $14000 \mathrm{rpm}$ (Eppendorf-Zentrifuge) zentrifugiert. Die Überstände wurden zur SDS-PAGE auf ein 10\%iges SDS-Polyacrylamid-Gel aufgetragen.

\subsubsection{Reduktive Carboxymethylierung von Proteinen}

Die reduktive Carboxymethylierung von gereinigter ASA wurde durchgeführt, um die proteolytische Spaltbarbeit durch Trypsin zu verbessern und die Interpretation der erhaltenen Daten der darauffolgenden Edman-Sequenzierung oder Massenanalyse zu erleichtern. BSA (Rinderserumalbumin, Biomol, Hamburg) wurde nach dem gleichen Protokoll reduktiv carboxymethyliert, um die proteolytische Aktivität von Cathepsin S und $\mathrm{H}$ nachzuweisen.

$30-100 \mu \mathrm{g}$ Protein wurden gefriergetrocknet und in $6 \mathrm{M}$ Guanidiniumhydrochlorid, 400 mM Tris-HCl, 10 mM EDTA, pH 8,6 zu einer Endkonzentration von $2 \mu \mathrm{g} / \mu \mathrm{l}$ gelöst. Zur Entfernung von Sauerstoff wurden die Proben einige Sekunden mit Argon begast, 0,2 M DTT zu einer Endkonzentration von $10 \mathrm{mM}$ zugegeben und erneut mit Argon begast. Die Reduktion der Disulfidbrücken erfolgte für $1 \mathrm{~h}$ bei $55^{\circ} \mathrm{C}$. Nach Abkühlen der Probe auf Raumtemperatur wurde eine 0,4 M Ammoniumiodacetat-Lösung zu einer Endkonzentration von $30 \mathrm{mM}$ zugegeben und für $30 \mathrm{~min}$ bei Raumtemperatur im Dunkeln zur Alkylierung der freien Thiole inkubiert. Die Reaktion wurde durch Zugabe von DDT (Endkonzentration: $15 \mathrm{mM}$ ) abgestoppt.

Nach der reduktiven Carboxymethylierung wurden die Proteine über eine Fast Desalting PC 3.2/100 Säule (Säulenbettvolumen $800 \mu$, Pharmacia) in einem SMART-HPLCSystem (Pharmacia, Uppsala, Schweden) in 0,1\% Ammoniumacetat, pH 8,8, $10 \%$ Acetonitril in $\mathrm{H}_{2} \mathrm{O}$ umgepuffert. Die eluierten Fraktionen wurden für den Verdau mit Trypsin (ASA) bzw. mit Cathepsin S und H (BSA) eingesetzt. 


\subsubsection{Tryptischer Abbau von ASA-C69A}

Zur Vorbereitung der N-terminalen Peptidsequenzierung oder Massenanalyse wurde die reduktiv carboxymethylierte ASA-C69A einem Abbau mit Trypsin unterzogen. Dazu wurden $96 \mu \mathrm{g}$ reduktiv carboxymethylierte ASA im Elutionspuffer der Fast-DesaltingSäule mit $2 \mu \mathrm{g}$ Trypsin versetzt und für $16 \mathrm{~h}$ bei $37^{\circ} \mathrm{C}$ inkubiert. Die tryptischen Peptide wurden auf eine mit $0,1 \% \mathrm{TFA} / \mathrm{H}_{2} \mathrm{O}$ äquilibrierte C8-Reversed-Phase HPLC-Säule (Aquapore-Octyl, 2,1 x 200 mm; BAl, Lautertal) an einem SMART-System (Pharmacia, Uppsala, Schweden) aufgetragen, und durch Zunahme von Acetonitril im Elutionspuffer um $2 \%$ pro Minute bei einer Flußrate von $300 \mu \mathrm{l} / \mathrm{min}$ aufgetrennt. Die Peptide wurden manuell oder über Peakerkennungssoftware automatisch fraktioniert.

\subsubsection{Protein-Bestimmung nach Lowry}

Zur Konzentrationsbestimmung der für die Kristallisation eingesetzten ASA-Chargen wurde eine Proteingehalts-Bestimmung nach Lowry durchgeführt [Lowry et al., 1951].

\begin{tabular}{|c|c|c|}
\hline Reagenz A: & $\begin{array}{l}100 \text { Teile } \\
1 \text { Teil } \\
1 \text { Teil }\end{array}$ & $\begin{array}{l}3 \% \mathrm{Na}_{2} \mathrm{CO}_{3} \text { in } 0,1 \mathrm{~N} \mathrm{NaOH} \\
4 \% \mathrm{Na} \mathrm{K}-\mathrm{T} \text { artrat in } \mathrm{H}_{2} \mathrm{O} \text { bi } \\
2 \% \mathrm{CuSO}_{4} \text { in } \mathrm{H}_{2} \mathrm{O} \text { bidest. }\end{array}$ \\
\hline Reagenz B: & $\begin{array}{l}1 \text { Teil } \\
2 \text { Teile }\end{array}$ & $\begin{array}{l}\text { Folin-Ciocalteus-Reagenz } \\
\mathrm{H}_{2} \mathrm{O}\end{array}$ \\
\hline
\end{tabular}

Beide Lösungen wurden erst kurz vor Gebrauch aus den Stammlösungen angesetzt.

5-20 $\mu \mathrm{g}$ der $\mathrm{zu}$ bestimmenden Proteinlösung wurden mit $\mathrm{H}_{2} \mathrm{O}$ bidest. auf $100 \mu \mathrm{l}$ aufgefüllt. Als Standard wurde eine BSA-Proteinlösung $(1 \mathrm{mg} / \mathrm{ml})$ verwendet (Rinderserumalbumin, Biomol, Hamburg). Dazu wurden 5, 10, 15 und $20 \mu \mathrm{g}$ Protein-Standard eingesetzt und ebenfalls auf $100 \mu \mathrm{l}$ aufgefüllt. Die Reaktion wurde durch Zugabe von 1 $\mathrm{ml}$ Reagenz A gestartet, nach $10 \mathrm{~min}$ bei RT wurden $100 \mu \mathrm{l}$ Reagenz B zu den einzelnen Proben pipettiert und gemischt. Nach weiteren 10 min Inkubation bei RT wurde die Extinktion bei $\lambda=660 \mathrm{~nm}$ gemessen. Aus den Standardwerten konnte eine Eichgerade erstellt werden, mit der die Proteinkonzentration der Proben ermittelt wurde.

\subsubsection{Konzentrationsbestimmung von ASA über $\mathrm{OD}_{280}$-Messung}

Zur Konzentrationsbestimmung der ASA in TBS-Puffer wurde die optische Dichte bei $280 \mathrm{~nm}$ in geeigneter Verdünnung (so daß die Extinktion zwischen 0,1 und 0,6 lag) gegen den TBS-Puffer bestimmt und die Konzentration aus dem molaren Extinktionskoeffizienten der ASA von $39350 \mathrm{~cm}^{2} / \mathrm{mmol}$ berechnet. 


\subsubsection{Bestimmung der Aktivität der Arylsulfatase A (ASA)}

Zur Bestimmung der Arylsulfatase A-Aktivität der unterschiedlichen Proben wurden diese unverdünnt oder mit Puffer verdünnt im Aktivitätsassay eingesetzt, so daß die Werte der optischen Dichtemessung zwischen 0,1 und 0,6 lagen. (Dies entspricht Sulfataseaktivitäten zwischen 20 und $100 \mathrm{mU}$ ASA.)

Substratlösung: $\quad 10 \mathrm{mM} p$-Nitrocatecholsulfat

$$
\begin{aligned}
10 \%(\mathrm{w} / \mathrm{v}) \mathrm{NaCl} \\
0,5 \mathrm{mM} \text { Na-Pyrophosphat } \\
0,5 \mathrm{M} \text { Na-Acetat pH 5,0 }
\end{aligned}
$$

Stopp-Lösung:

$1 \mathrm{M} \mathrm{NaOH}$

Verdünnungspuffer: $\quad 1 \mathrm{mg} / \mathrm{ml}$ BSA

in TBS pH 7,4

Assay-Ansatz

$40 \mu \mathrm{l}$ Probe, evt. m. Verdünnungspuffer versetzt $200 \mu \mathrm{l}$ Substratlösung

wurden auf Eis zusammenpipettiert und für 5 bis $60 \mathrm{~min}$ bei $37^{\circ} \mathrm{C}$ im Schüttelwasserbad oder Heizblock inkubiert

Stopp

durch Zugabe von $\quad 200 \mu$ Stopp-Lösung

Messung der

Extinktion bei $\lambda=$

$515 \mathrm{~nm}\left(\varepsilon=12400 \mathrm{~cm}^{2} / \mathrm{mmol}\right)$

Enzymaktivitätsberechnung:

Aus den Meßwerten wurden mit Hilfe der Leerwerte die $\Delta \mathrm{E}$-Werte berechnet. Die ASAAktivität ergab sich aus:

Assay-Vol. [ml] $\times 1000 \times \Delta \mathrm{E} \times$ Verd.

Probenvol. [ml] x 12,4 x t [min] $=$ Aktivität $[\mathrm{mU} \mathrm{ASA} / \mathrm{ml}]$

1 unit Enzymaktivität $[\mathrm{U}]$ entspricht der Enzymmenge, die $1 \mu \mathrm{mol}$ des Substrats pro Minute hydrolysiert. 


\subsubsection{SDS-Polyacrylamid-Gelelektrophorese von Proteinen}

Die elektrophoretische Trennung von Proteingemischen erfolgte mittels diskontinuierlicher SDS-Polyacrylamid-Gelelektrophorese (SDS-PAGE) nach Laemmli [Laemmli et al., 1970].

Anodenpuffer:

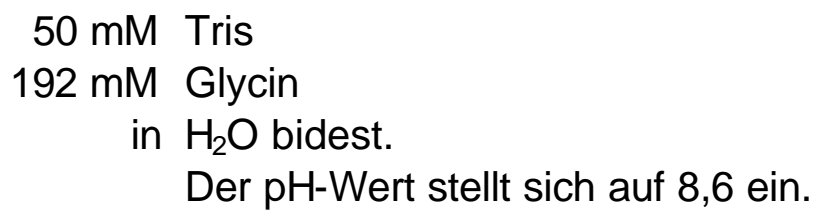

Kathodenpuffer: $\quad 0,1 \%(w / v)$ SDS $0,001 \%(w / v)$ Bromphenolblau

in Anodenpuffer

$2 \times$ Probenpuffer: (reduzierend)

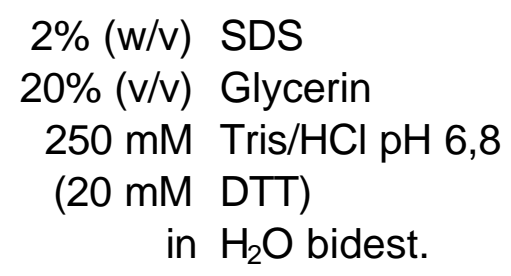

Trenngelpuffer: $\quad 0,4 \%(w / v)$ SDS

1,5 M Tris/HCl pH 8,8

Sammelgelpuffer: $\quad 0,4 \%(w / v)$ SDS

$0,5 \mathrm{M}$ Tris/HCl pH 6,8

Acrylamidlösung: $\quad 30 \%(\mathrm{w} / \mathrm{v})$ Acrylamid

$0,8 \%(w / v)$ Bisacrylamid

in $\mathrm{H}_{2} \mathrm{O}$ bidest.

Ammoniumperoxo-

$10 \%(\mathrm{w} / \mathrm{v})$ rekristallisiertes Ammoniumperoxodisulfat di-sulfat (APS): in $\mathrm{H}_{2} \mathrm{O}$ bidest. 
Die Zusammensetzung von Trenngelen verschiedener Polyacrylamid-(PAA)Konzentrationen und des Sammelgels ist in der folgenden Tabelle angegeben:

\begin{tabular}{|c|c|c|c|c|c|}
\hline & \multicolumn{3}{|c|}{ Trenngel } & Sammelgel \\
\hline PAA-Konzentration & $8 \%$ & $10 \%$ & $12,5 \%$ & $15 \%$ & $4 \%$ \\
\hline Acrylamidlösung $(\mathrm{ml})$ & 8,4 & 10,5 & 13,1 & 17,75 & 1,3 \\
\hline Trenngelpuffer $(\mathrm{ml})$ & \multicolumn{3}{|c|}{7,5} & - \\
\hline Sammelgelpuffer $(\mathrm{ml})$ & \multicolumn{3}{|c|}{-} & 2,5 \\
\hline $10 \%$ APS $(\mu \mathrm{l})$ & \multicolumn{3}{|c|}{250} & 100 \\
\hline TEMED $(\mu \mathrm{l})$ & \multicolumn{3}{|c|}{25} & $\mathrm{ad} 10 \mathrm{ml}$ \\
\hline $\mathrm{H}_{2} \mathrm{O}$ & \multicolumn{3}{|c|}{ ad $30 \mathrm{ml}$} \\
\hline
\end{tabular}

Die Elektrophorese wurde in einem System mit vertikal ausgerichteten Platten durchgeführt (Größe der Glasplatten: $16 \mathrm{~cm}$ \#\# $18 \mathrm{~cm}, 1 \mathrm{~mm}$ Spacer; Eigenbau, Biochemie II, Universität Göttingen). Das frisch gemischte Trenngel wurde zwischen Glasplatten gegossen und sofort mit wassergesättigtem Butanol überschichtet. Nach 30 min Polymerisation bei RT wurde das Butanol abgegossen, die Trenngeloberfläche mit $\mathrm{H}_{2} \mathrm{O}$ gespült, das Sammelgel eingegossen und der Probenkamm eingefügt. Nach 30 min Polymerisation wurde der Probenkamm entfernt, die Probentaschen mit $\mathrm{H}_{2} \mathrm{O}$ gespült und Gelreste aus den Taschen entfernt. Die Proben wurden 1:1 mit Probenpuffer (enthält 2\%SDS) gemischt, $5 \mathrm{~min}$ bei $95^{\circ} \mathrm{C}$ denaturiert und 2 min bei 14000 rpm zentrifugiert. Der Überstand wurde in die Taschen aufgetragen und mit Kathodenpuffer überschichtet. Als Molekulargewichtsmarker diente Rainbow ${ }^{\mathrm{TM}}{ }_{\text {-coloured }}$ protein MG-Standard (Amersham Pharmacia Biotech, Braunschweig). Die Elektrophorese erfolgte über 2 bis $3 \mathrm{~h}$ mit $50 \mathrm{~mA}$ bei $4^{\circ} \mathrm{C}$. 


\subsubsection{SDS-Polyacrylamid-Gelelektrophorese von Proteinen (,Minigelelektrophorese“)}

Zur Trennung und Detektion geringer Proteinmengen wurde eine „Minigelelektrophorese" durchgeführt (modifiziert nach Wiltfang [Wiltfang et al., 1991]). Die SDS-PAGE wurde in Mighty SMALL Vertical Slab Gel Units (Modell SE 200) der Firma Hoefer Scientific mit 0,5 mm starken Spacern durchgeführt. Die Trenngele für jeweils 2 bis 5 Gele wurden parallel in einem Block gegossen und konnten, vor Austrocknung geschützt, bis zu 5 Tagen bei $4^{\circ} \mathrm{C}$ gelagert werden. Sammel- und Kammgel wurde direkt vor der Verwendung auf das Trenngel gegossen.

Anodenpuffer: $0,2 \mathrm{M}$ Tris $0,05 \mathrm{M} \mathrm{H}_{2} \mathrm{SO}_{4}, \mathrm{pH} 8,1$

Kathodenpuffer:

0,2 M Bicine

$0,1 \mathrm{M} \mathrm{NaOH}, \mathrm{pH} 8,2$

$2 \times$ Probenpuffer:

$2 \%(w / v)$ SDS

(reduzierend) $20 \%(\mathrm{v} / \mathrm{v})$ Glycerin $250 \mathrm{mM}$ Tris/HCl pH 6,8

(20 mM Dithiothreitol)

Trenngelpuffer:

1,6 $\mathrm{M}$ Tris $0,4 \mathrm{H}_{2} \mathrm{SO}_{4}, \mathrm{pH} 8,1$

Sammelgelpuffer:

0,8 M Bis-Tris

$0,4 \mathrm{M} \mathrm{H}_{2} \mathrm{SO}_{4}, \mathrm{pH} \mathrm{6,7}$

Acrylamidlösung

$38 \%(\mathrm{w} / \mathrm{v})$ Polyacrylamid

(als fertige Lösung

$2 \%(\mathrm{w} / \mathrm{v}) \quad \mathrm{N}, \mathrm{N}^{\mathrm{k}}$-Methylbisacrylamid

bezogen):

Ammoniumperoxodi-sulfat (APS):

$5 \%(\mathrm{w} / \mathrm{v})$ rekristallisiertes Ammoniumperoxodisulfat in $\mathrm{H}_{2} \mathrm{O}$ bidest.

Glycerin

$87 \%(\mathrm{v} / \mathrm{v})$ Glycerin in $\mathrm{H}_{2} \mathrm{O}$ bidest.

$10 \%$ SDS

$10 \%(\mathrm{w} / \mathrm{v})$ SDS in $\mathrm{H}_{2} \mathrm{O}$ bidest.

$0,002 \%$ BPB $0,002 \%(\mathrm{w} / \mathrm{v})$ Bromphenolblau in $\mathrm{H}_{2} \mathrm{O}$ bidest. 
Das Pipettierschema zum Gießen eines Trenngels:

\begin{tabular}{|c|c|c|c|c|}
\hline & \multicolumn{4}{|c|}{ Trenngel (5 ml) } \\
\hline PAA-Konzentration & $8 \%$ & $10 \%$ & $12 \%$ & $15 \%$ \\
\hline Acrylamidlösung $(\mathrm{ml})$ & 1,053 & 1,316 & 1,579 & 1,974 \\
\hline $\mathrm{H}_{2} \mathrm{O}$ bidest. $(\mathrm{ml})$ & 1,605 & 1,342 & 1,079 & 0,684 \\
\hline Trenngelpuffer $(\mathrm{ml})$ & \multicolumn{4}{|c|}{1,250} \\
\hline $87 \%$ Glycerin & \multicolumn{5}{|c|}{5000} \\
\hline $10 \%$ SDS $(\mu \mathrm{l})$ & 40 \\
\hline $5 \%$ APS $(\mu \mathrm{l})$ & \multicolumn{4}{|c|}{3} \\
\hline TEMED $(\mu \mathrm{l})$ & \multicolumn{5}{|c|}{} \\
\hline
\end{tabular}

Die Polyacrylamid/N,N'-Methylbisacrylamid-Stammlösung wurde als fertige, stabilisierte Lösung bezogen (Rotiphorese Gel40; Roth, Karlsruhe). Das zur Stabilisierung der Lösung enthaltene Ethylen wurde vor dem Gießen der Gele durch 1-minütige Entgasung im Wasserstrahlvakuum entfernt. Die fertige Lösung wurde in die Apparatur bis zu einem Abstand von $1,5 \mathrm{~cm}$ zum oberen Rand der Ohrenplatte eingefüllt, mit wassergesättigtem n-Butanol überschichtet und für mindestens $15 \mathrm{~min}$ zum Polymerisieren erschütterungsfrei stehengelassen. Danach wurde das Butanol entfernt und die Geloberfläche mit Wasser gewaschen.

\begin{tabular}{|c|c|c|}
\hline & Sammelgel $(1 \mathrm{ml})$ & Kammgel $(1 \mathrm{ml})$ \\
\hline PAA-Konzentration & $6 \%$ & $9 \%$ \\
\hline Acrylamidlösung $(\mu \mathrm{l})$ & 158 & 237 \\
\hline $\mathrm{H}_{2} \mathrm{O}$ bidest. $(\mu \mathrm{l})$ & 228 & 49 \\
\hline Sammelgelpuffer $(\mu \mathrm{l})$ & 500 & - \\
\hline Kammgelpuffer $(\mu \mathrm{l})$ & - & 500 \\
\hline $1 \%$ SDS $(\mu \mathrm{l})$ & 100 & 100 \\
\hline $0,002 \%$ BPB $(\mu \mathrm{l})$ & - & 100 \\
\hline $5 \%$ APS $(\mu \mathrm{l})$ & 12 & 12 \\
\hline TEMED $(\mu \mathrm{l})$ & 2 & 2 \\
\hline
\end{tabular}


Auf das Trenngel wurde ein $0,5 \mathrm{~cm}$ starkes Sammelgel aufgetragen und erneut bis zur Polymerisation unter n-Butanol stehen gelassen. Nach Absaugen des Butanols und Waschen der Geloberfläche mit Wasser wurde die Apparatur bis zum Rand der Ohrenplatte mit Kammgellösung aufgefült. In die Kammgellösung wurde eine Geltaschenform (Kamm) eingesetzt und das Gel für $15 \mathrm{~min}$ polymerisiert. Danach wurde der Kamm entfernt, die Taschen mit Wasser gespült und das Gel mit den Proben beladen. Proben ( 0,1 bis $1 \mu \mathrm{g}$ je Protein bzw. max.10 $\mu \mathrm{g}$ Gesamtprotein) wurden mit 1 Volumen zweifach konzentriertem Probenpuffer versetzt und für 5 min bei $95^{\circ} \mathrm{C}$ inkubiert und vollständig aufgetragen. Als Molekulargewichtsmarker diente der Protein Molecular Weight Marker, Broad Range (New England Biolabs, Bad Schwalbach). Die Geltaschen wurden mit einfach konzentriertem Probenpuffer aufgefüllt und die Kathoden- und Anodenpuffer in die dafür vorgesehenen Reservoire gegeben.

Zunächst wurden die Proteine für $2 \mathrm{~min}$ bei $50 \mathrm{~mA}$ im Sammelgel fokussiert und anschließend für 60 bis 90 min bei $15 \mathrm{~mA}$ aufgetrennt.

\subsubsection{Färbung von Polyacrylamid-Gelen mit kolloidaler Coomassie-Lösung \\ Fixier-Lösung:

$$
\begin{aligned}
50 \%(\mathrm{v} / \mathrm{v}) & \text { Methanol } \\
25 \%(\mathrm{w} / \mathrm{v}) & \text { Trichloressigsäure } \\
2 \%(\mathrm{w} / \mathrm{v}) & \text { Kupfer-(II)-Chlorid }
\end{aligned}
$$$$
25 \%(w / v) \text { Trichloressigsäure }
$$$$
0,1 \%(\mathrm{v} / \mathrm{v}) \text { Formaldehyd }
$$

Coomassie-Stammlösung:

$20 \mathrm{~g} \mathrm{H}_{3} \mathrm{PO}_{4}$

$100 \mathrm{~g}$ Ammoniumsulfat

$20 \mathrm{ml} \mathrm{5 \%} \mathrm{(w/v)} \mathrm{Coomassie} \mathrm{G-250}$

ad $1000 \mathrm{ml} \mathrm{H}_{2} \mathrm{O}$ bidest.

Das Gel wurde etwa $30 \mathrm{~min}$ in frisch angesetzter Fixier-Lösung inkubiert und anschließend zweimal für 15 min mit Wasser gespült. $80 \mathrm{ml}$ der gut aufgeschüttelten Coomassie-Stammlösung wurden mit $20 \mathrm{ml}$ Methanol (techn.) versetzt und ÜN bei RT mit dem Gel auf einem Schütteltisch inkubiert. Die Entfärbung des Hintergrunds erfolgte durch zweimaliges Waschen mit 25\% ( $\mathrm{v} / \mathrm{v})$ Methanol für 5 min und dreimaliges Spülen mit $\mathrm{H}_{2} \mathrm{O}$ für jeweils $10 \mathrm{~min}$. Die Gele wurden anschließend in Cellophan-Folie eingeschlagen und bei $90^{\circ} \mathrm{C}$ im Umlufttrockner getrocknet. 


\subsubsection{Silberfärbung von Polyacrylamid-Gelen}

Zur Detektion geringer Proteinmengen wurde eine Silberfärbung nach Ansorge, [Ansorge, 1985] durchgeführt.

Fixierer:

Lösung A:

Kaliumpermanganat-

Lösung:

Ethanol:

Silbernitrat-Lösung:

Kaliumcarbonat-Lösung:

Entwickler-Lösung:
$50 \%(\mathrm{v} / \mathrm{v})$ Methanol, technisch

$12 \%(\mathrm{w} / \mathrm{v})$ TCA

$2 \%(\mathrm{w} / \mathrm{v}) \quad \mathrm{CuCl}_{2} * 2 \mathrm{H}_{2} \mathrm{O}$

10\% (v/v) Ethanol, p.a.

$5 \%(\mathrm{v} / \mathrm{v})$ Essigsäure, technisch

$0,01 \%(\mathrm{w} / \mathrm{v}) \mathrm{KMnO}_{4}$

$10 \%(\mathrm{v} / \mathrm{v})$ in $\mathrm{H}_{2} \mathrm{O}$ bidest.

$0,1 \%(w / v) \mathrm{AgNO}_{3}$

$10 \%(\mathrm{w} / \mathrm{v}) \quad \mathrm{K}_{2} \mathrm{CO}_{3}$

$2 \%(\mathrm{w} / \mathrm{v}) \mathrm{K}_{2} \mathrm{CO}_{3}$

0,02\% (v/v) Formaldehyd (37\%)

Alle Lösungen für die Silberfärbung wurden in $\mathrm{H}_{2} \mathrm{O}$ bidest. angesetzt. Die Färbung erfolgte bei Raumtemperatur auf einem Horizontalschüttler in Glasschalen. Die SDSGele wurden nach der elektrophoretischen Auftrennung für mindestens $1 \mathrm{~h}$ oder über Nacht in der Fixierlösung fixiert. Danach wurden die Gele für 15 min in Lösung $A$ equilibriert und anschließend für $15 \mathrm{~min}$ in der Kaliumpermanganatlösung inkubiert. Nach erneuter Equilibrierung in Lösung $A(15 \mathrm{~min}$ ) wurde für jeweils 15 min zunächst mit $10 \%$ Ethanol und anschließend mit $\mathrm{H}_{2} \mathrm{O}$ bidest. gewaschen. Dann wurden die Gele für $15 \mathrm{~min}$ in Silbernitratlösung geschwenkt, je 1 min mit $\mathrm{H}_{2} \mathrm{O}$ bidest. und der Kaliumkarbonatlösung gespült und für 5-15 min entwickelt bis eine ausreichend klare Färbung der Proteine erreicht war. Darauf wurde die Farbentwicklung durch Inkubation mit Lösung A gestoppt (10 min). Abschließend wurden die Gele für 2 × 30 min gewässert, 20 min in 1\% (w/v) Glycerin inkubiert und dann für die Dokumentation in feuchte Cellophanfolie eingeschlagen und im Trockner getrocknet. 


\subsubsection{Westernblot-Nachweis von Arylsulfatase A}

Zum Nachweis von ASA aus Zellkulturüberständen und aus Material nach der Reinigung wurden 50 bzw. $100 \mu \mathrm{g}$ Gesamtprotein unter reduzierenden Bedingungen über SDS-PAGE (10\% Polyacrylamid) aufgetrennt. Dazu wurden die Proben 5 min auf $95^{\circ} \mathrm{C}$ erhitzt, $2 \mathrm{~min}$ bei $14000 \mathrm{rpm}$ in der Eppendorf-Tischzentrifuge zentrifugiert und der Überstand aufgetragen.

ASA-Western-Analyse über Semi-Dry-Blot:

Kathodenpuffer:

$40 \mathrm{mM} \varepsilon$-Aminocapronsäure

$25 \mathrm{mM}$ Tris

$20 \%(\mathrm{v} / \mathrm{v})$ Methanol

mit $\mathrm{HCl}$ auf $\mathrm{pH} 9,0$ einstellen

Anodenpuffer:

$75 \mathrm{mM}$ Tris/ $\mathrm{HCl} \mathrm{pH} \mathrm{7,4}$

$20 \%$ Methanol

PBS-Tween:

$$
0,1 \%(w / v) \text { Tween-20 }
$$

in $1 \times$ PBS

Blotto:

$5 \%(w / v)$ Milchpulver in PBS-Tween

1. Antikörper:

1: 100 verd. Kaninchen $\alpha$ humane ASA (aus Placenta), (polyklonales Antiserum)

in Blotto

2. Antikörper:

1:40000 verd. Ziege $\alpha$ Kaninchen IgG, HRP-konjugiert (Dianova, Hamburg) in Blotto

Der Elektrotransfer der Proteine erfolgte im Semi-Dry-Blot-Verfahren auf eine Nitrocellulose-Membran und die Immunodetektion der ASA mittels Chemilumineszenz. Nach Beendigung der Elektrophorese wurde das Sammelgel vom Trenngel entfernt und letzteres 10-15 min in Kathodenpuffer äquilibriert. Drei Lagen Whatman-Papier (extra dick, GB 003) und die $1 \mathrm{~min}$ in Methanol benetzte Nitrocellulose-Membran von der Größe des Gels wurden ebenfalls in Kathodenpuffer eingelegt. Drei weitere WhatmanPapiere wurden in Anoden-Puffer äquilibriert.

Für den Elektrotransfer der Proteine wurden Trenngel und Nitrocellulose-Membran luftblasenfrei zwischen die drei jeweils in Anoden- bzw. Kathodenpuffer getränkten Whatman-Papiere gelegt. Da der Transfer der Proteine von der Kathode in Richtung Anode erfolgte, mußte die Nitrocellulose-Membran beim Aufbau des Semi-Dry-Blots der 
Anode zugewandt sein. Der Transfer erfolgte für 45 min bei Laufbedingungen von $1,2 \mathrm{~mA} / \mathrm{cm}^{2}$.

Zur Überprüfung des Transfers wurde das Gel anschließend mit kolloidaler CoomassieLösung gefärbt. Die Nitrocellulose-Membran wurde zur Immunodetektion von ASA wie folgt unter kontinuierlicher Bewegung auf einer Wippe mit folgenden Lösungen inkubiert:

1 h Blotto bei $37^{\circ} \mathrm{C}$

ÜN 1. Antikörper bei $4^{\circ} \mathrm{C}$

$3 \times 15$ min mit PBS-Tween waschen, RT

30 min 2. Antikörper bei RT

$3 \times 20$ min mit PBS-Tween waschen, RT

Zur Quantifizierung der von den Zellen produzierten Menge an inaktiver ASA-C69A und ASA-C69S wurden je $5 \mu \mathrm{l}$ des Mediums auf eine Nitrocellulose-Membran pipettiert, die nach Trocknung der Probe wie die Blotmembran des Westernblots nach Entnahme aus der Blotkammer behandelt wurde (Dot-Blot).

Zum Nachweis über Chemilumineszenz konnten im Falle der ASA durch Verwendung selbst angesetzter Chemilumineszenz-Reagenzien stärkere Signale als mit den im Allgemeinen benutzten käuflichen Detektions-Kits erzielt werden:

Lösung A (10 ml):

$100 \mu \mathrm{l} \quad 250 \mathrm{mM} \quad$ Luminol (=3-Aminophthalhydrazid, Fluka) in DMSO

$44 \mu \mathrm{l} \quad 90 \mathrm{mM} \quad \mathrm{p}$-Coumarinsäure (Sigma) in DMSO

$1 \mathrm{ml} \quad 1 \mathrm{M} \quad$ Tris $/ \mathrm{HCl} \mathrm{pH} 8,5$

$8,85 \mathrm{ml} \quad \mathrm{H}_{2} \mathrm{O}$ bidest.

Lösung B (10 ml):

$\begin{array}{lll}6 \mu \mathrm{l} & 30 \% & \mathrm{H}_{2} \mathrm{O}_{2} \\ 1 \mathrm{ml} & 1 \mathrm{M} & \text { Tris/ } / \mathrm{HCl} \mathrm{pH} 8,5 \\ 9 \mathrm{ml} & & \mathrm{H}_{2} \mathrm{O} \text { bidest. }\end{array}$

Die Lösungen wurden jeweils frisch aus Stammlösungen angesetzt und direkt vor Gebrauch gemischt. Die Membran wurde 1 min mit dem Substratgemisch inkubiert und 
danach durch Pressen zwischen zwei Filterpapieren sehr sorgfältig von der Membranoberfläche entfernt. Anschließend wurde die Membran luftblasenfrei in Plastikfolie eingehüllt und für 4-8 min mit einer CSC-Kamera gescannt. Die erhaltenen Abbildungen wurden mit Hilfe des Programms WinScan ausgewertet (Raytest, Straubenhardt).

\subsubsection{Immunaffinitätschromatographische Aufreinigung von ASA aus konditionierten Zellkulturmedien}

Die immunaffinitätschromatographische Aufreinigung von ASA aus konditionierten Zellkulturmedien wurde nach Sommerlade [Sommerlade et al., 1994b; modifiziert] durchgeführt.

Die Proteine wt-ASA, ASA-C69A, ASA-C69S und ASA-P426L mußten für die Kristallisation und für die biochemischen Untersuchungen zur Stabilität der ASA in unterschiedlichen Mengen gereinigt werden. Für die Reinigung im präparativen Maßstab (zwei bis zehn Liter) wurden die Proteine im Medium zunächst durch Zugabe von $50 \%(\mathrm{w} / \mathrm{v})$ Ammoniumsulfat aus dem Medium gefällt und gesammelt. Dann wurde das Ammoniumsulfatpräzipitat in einem JA-10-Rotor bei $9000 \mathrm{rpm}$ und $4^{\circ} \mathrm{C}$ für $30 \mathrm{~min}$ abzentrifugiert. Das Präzipitat wurde in $10-50 \mathrm{ml} \mathrm{H}_{2} \mathrm{O}$ bidest. suspendiert und in Dialyseschläuchen (Ausschlußgrenze: $25 \mathrm{kDa}$ ) mehrfach gegen je 2 । TBS dialysiert bis kein Sulfat mit Bariumacetat mehr nachweisbar war (der Sulfat-Nachweis erfolgte durch Zusatz von $200 \mu \mathrm{l}$ 0,1 M Bariumacetatlösung zu $200 \mu \mathrm{l}$ Dialysepuffer). Das Dialysat wurde durch 45 minütige Zentrifugation bei $4^{\circ} \mathrm{C}$ und $55000 \mathrm{rpm}$ in einem Ti-45-Rotor geklärt und anschließend steril filtriert (Porengröße 0,45 $\mu \mathrm{m}$ ).

Die affinitätschromatographische Reinigung der ASA erfolgte an einer Affigel 15-Säule mit kovalent gekoppelten monoklonalen anti-ASA-Antikörpern (mAK 19-16-3), die von Dr. V. Gieselmann, Universität Kiel, zur Verfügung gestellt wurde. Alle verwendeten Puffer wurden vor dem Auftrag steril filtriert (Porengröße 0,45 $\mu \mathrm{m}$ ).

Puffer:

Elutionspuffer:

Waschpuffer:

Neutralisationslösung:
TBS

$\mathrm{NaH}_{2} \mathrm{PO}_{4} / \mathrm{Na}_{2} \mathrm{HPO}_{4} \mathrm{pH} 4,5$

2,8 $\mathrm{M} \mathrm{MgCl}_{2}$

$10 \mathrm{mM}$ Tris/HCl pH 7,4

$2 \mathrm{M} \mathrm{NaCl}$

$1 \mathrm{M}$ Tris $/ \mathrm{HCl} \mathrm{pH} 7,4$ 
Zunächst wurde das Säulenmaterial (Bettvolumen ca. 2,50 ml) drei mal mit Elutionspuffer gewaschen und dann mit TBS äquilibriert, um schließlich das Dialysat auf die Säule aufzutragen. Die Bindung erfolgte bei einem Fluß von $1 \mathrm{ml} / \mathrm{min}$, der Durchbruch wurde aufgefangen. Die Säule wurde nachfolgend mit 5-10 ml TBS, $5 \mathrm{ml}$ Waschpuffer und wieder $15 \mathrm{ml}$ TBS gewaschen. Die Elution erfolgte fünf mal mit $3 \mathrm{ml}$ Elutionspuffer und die Fraktionen wurden in je $3 \mathrm{ml}$ Neutralisationspuffer aufgefangen. Die Regenerierung der Säule erfolgte mit $30 \mathrm{ml}$ TBS.

Aliquots aller Fraktionen wurden im Falle der aktiven ASA mittels Aktivitätsassays auf ihren Gehalt an ASA untersucht. Die Peak-Fraktionen wurden vereint und mittels Ultrafiltrationshülse (Ausschlußgrenze: $25 \mathrm{kDa}$ ) konzentriert. Die Bestimmung der Proteinmenge wurde mit Hilfe der optischen Dichtebestimmung bei $280 \mathrm{~nm}$ und nach Lowy durchgeführt und ergab in einem Reinigungslauf etwa 0,8 - 1,8 mg Protein.

Anschließend wurde die ASA-Präparationen zur Lagerung bei $-20^{\circ} \mathrm{C}$ eingefroren. Die spezifische Aktivität der gereinigten wt-ASA schwankte zwischen 70 und $110 \mathrm{mU} / \mathrm{mg}$, die der ASA-P426L zwischen 30 und $60 \mathrm{mU} / \mathrm{mg}$.

Gegebenfalls mußte ein zusätzlicher Reinigungsschritt an einer FPLC- oder HPLCAnlage durchgeführt werden (Abschnitte 3.4.14; 3.4.15). Die hierbei eluierte ASA wurde über SDS-Gelelektrophorese identifiziert.

\subsubsection{ASA-Reinigung über Gelfiltration an einer FPLC-Anlage}

Wenn sich nach der Affinitätschromatographie immer noch BSA aus dem FKS des Mediums in der ASA-Probe befand, wurde als zweiter Reinigungsschritt eine Gelfiltration über eine Superdex 200-Säule (HiLoad 16/60; Pharmacia, Uppsala, Schweden; Bettvolumen 120-124 ml) an der FPLC-Anlage durchgeführt. Die Säule wurde zunächst in $150 \mathrm{mM} \mathrm{NaCl}$-haltigem $10 \mathrm{mM} \mathrm{NaAc-Puffer} \mathrm{bei} \mathrm{pH} \mathrm{4,5} \mathrm{äquilibriert.}$ Auf die Säule wurden $2 \mathrm{ml}$ Probenvolumen aufgetragen und die Probe wurde mit einer Flußrate von 0,5 ml/min in $2 \mathrm{ml}$-Fraktionen aufgetrennt. Nach UV-Detektion des Eluates wurden die Fraktionen über SDS-PAGE analysiert und die ASA-haltigen Fraktionen gepoolt, eingeengt und aliquotiert bei $-20^{\circ} \mathrm{C}$ gelagert.

\subsubsection{ASA-Reinigung über Gelfiltration an einer HPLC-Anlage}

Die Experimente zur Untersuchung des Oktamerisierungsverhaltens von ASA sowie die mikropräparative Reinigung der ASA wurden über einer Superdex 200-Säule (PC3.2/30, Amersham Pharmacia Biotech; Bettvolumen 2,4 ml) an einer HPLC-Anlage (SMART-System, Pharmacia, Uppsala, Schweden) aufgetrennt. Die Proben wurden auf eine mit Puffer äquilibrierten Säule aufgetragen und mit einer Flußgeschwindigkeit von 
40 - $50 \mu \mathrm{l} / \mathrm{min}$ eluiert. Die Fraktionierung erfolgte automatisch mit festgelegten Fraktionsgrößen und unter Verwendung der automatischen Signalerkennung. Die Änderung der optischen Dichte wurde bei 210 und $280 \mathrm{~nm}$ verfolgt.

Bei den Oktamerisierungsexperimenten wurde ein TBS-Puffer bei $\mathrm{pH} 7,0$ und ein $\mathrm{NaAc} / \mathrm{HAc}$-Puffer mit $150 \mathrm{mM} \mathrm{NaCl}$ bei pH 4,8 - 6,0 eingesetzt. Die Fraktionen wurden über Aktivitätsbestimmung quantifiziert. Bei der mikropräparative Reinigung der ASA handelte es sich um einen TBS-Puffer bei pH 7,4. Die Peakfraktionen wurden über SDS-PAGE identifiziert und anschließend vereinigt.

\subsubsection{Abbau von ASA mit Cathepsinen}

Analytisch mit Cathepsin L, B, H und S:

Bei den Untersuchungen zur Proteasesensitivität von ASA-P426L wurden folgende Ausgangsmaterialien verwendet:

\begin{tabular}{|l|l|l|}
\hline Enzym & Konzentration & Referenz \\
\hline $\begin{array}{l}\text { rekombinante } \\
\text { humane wt-ASA }\end{array}$ & $\begin{array}{l}41,28 \mu \mathrm{M} \\
(2,58 \mathrm{mg} / \mathrm{ml})\end{array}$ & Dittmer, 1995 \\
\hline $\begin{array}{l}\text { rekombinante } \\
\text { humane ASA-P426L }\end{array}$ & $\begin{array}{l}31,4 \mu \mathrm{M} \\
(1,96 \mathrm{mg} / \mathrm{ml})\end{array}$ & s. Abschnitt 3.3.5 \\
\hline $\begin{array}{l}\text { humanes Cathepsin L } \\
\text { (aus Brochialcarcinomzellinie } \\
\text { EPLC 32 M1) }\end{array}$ & $1,7 \mu \mathrm{M}$ & Weber et al., 1997 \& 1998 \\
\hline $\begin{array}{l}\text { Cathepsin B, Ratte } \\
\text { (aus Leber) }\end{array}$ & $1,6 \mu \mathrm{M}$ & Towatari et al., 1979 \\
\hline $\begin{array}{l}\text { humanes Cathepsin H } \\
\text { (aus MSAB-Zellen, Eppstein Barr } \\
\text { virus transformed human B-lympho- } \\
\text { cytes (Prof. Engleman, Standford } \\
\text { Blood Bank)) }\end{array}$ & $4,6 \mu \mathrm{M}$ & Maubach et al., 1997 \\
\hline $\begin{array}{l}\text { rekombinantes } \\
\text { humanes Cathepsin S }\end{array}$ & $0,15 \mu \mathrm{M}$ & Maubach et al., 1997 \\
\hline
\end{tabular}


Die Konzentrationen der ASA-Chargen wurden über $\mathrm{OD}_{280}$ und Lowry bestimmt. Die Konzentrationen der Cathepsine entsprechen den Konzentrationen an aktivem Enzym, bestimmt über eine Titration mit E64 [Barrett \& Kirschke, 1981], durchgeführt von Dr. K. Schilling, Universität Jena.

Aktivierungspuffer:

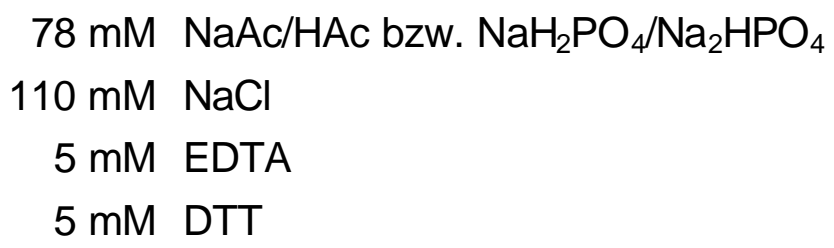

In den Standardversuchsansätzen lagen folgende Inkubationsbedingungen vor:

Inkubationstemperatur: $37^{\circ} \mathrm{C}$

Inkubationsdauer: $8 \mathrm{~h}$

pH-Wert: 4,8 in NaCl-haltigen NaAc/HAc-Puffer mit EDTA und DTT versetzt.

In Vorexperimenten, in denen einzelne Versuchsbedingungen untersucht wurden, wurden jeweils Temperatur ( 25 und $\left.37^{\circ} \mathrm{C}\right)$, Inkubationsdauer $(0,5,1,2,4$ und $8 \mathrm{~h}$ ) und $\mathrm{pH}$-Wert $(4,8,5,0,5,5$ und 6,0$)$ verändert. 
Puffer, ASA und Cathepsin wurden so zusammengegeben, daß in einem Reaktionsansatz folgende Konzentrationen im Volumenbereich von 7 bis $20 \mu \mathrm{l}$ vorlagen:

$$
\begin{aligned}
& 50-60 \mathrm{mM} \text { NaAc/HAc bzw. } \mathrm{NaH}_{2} \mathrm{PO}_{4} / \mathrm{Na}_{2} \mathrm{HPO}_{4} \\
& 70-90 \mathrm{mM} \text { NaCl } \\
& 2,5-3,0 \mathrm{mM} \text { EDTA } \\
& 2,5-3,0 \mathrm{mM} \text { DTT } \\
& 0,2-0,7 \mu \mathrm{M} \text { Cathepsin L oder } \\
& 0,6-1,1 \mu \mathrm{M} \text { Cathepsin B oder } \\
& 1,1 \mu \mathrm{M} \text { Cathepsin } \mathrm{H} \text { oder } \\
& 0,1 \mu \mathrm{M} \text { Cathepsin S } \\
& 2,7 \mu \mathrm{M} \text { ASA beim Verdau mit Cathepsin } \mathrm{L} \\
& 2,2 \mu \mathrm{M} \text { ASA beim Verdau mit Cathepsin } \mathrm{B} \\
& 2,3 \mu \mathrm{M} \text { ASA beim Verdau mit Cathepsin } \mathrm{H} \\
& 0,7 \mu \mathrm{M} \text { ASA beim Verdau mit Cathepsin } \mathrm{S} \\
& 1,9 \mu \mathrm{M} \text { BSA beim Verdau mit Cathepsin } \mathrm{H} \\
& 0,7 \mu \mathrm{M} \text { BSA beim Verdau mit Cathepsin } \mathrm{S}
\end{aligned}
$$

Nach der Inkubation der Proben wurden diese in Probenpuffer für die Gelelektrophorese aufgenommen, 5 min bei $95^{\circ} \mathrm{C}$ erhitzt und auf das jeweilige SDSPolyacrylamidgel aufgetragen. Zur Analyse der Inkubationsansätze von ASA mit Cathepsinen wurden sensitive SDS-Polyacrylamid-Minigele verwendet, in denen mit kolloidaler Coomassiefärbelösung bis zu 0,5 $\mu$ g Protein nachgewiesen werden kann. In einigen Fällen wurden auch normale SDS-Polyacrylamid-Gele mit Silberfärbung verwendet.

\section{Präparativ mit Cathepsin L:}

Für den präparativen Abbau von ASA-P426L mit Cathepsin $L$ wurde ein 20-facher Ansatz des analytischen Verdaus durchgeführt.

$0,63 \mathrm{nmol}$ ASA-P426L $(40 \mu \mathrm{g})$ wurden mit $0,17 \mathrm{nmol}$ Cathepsin $\mathrm{L}$ versetzt und bei $37^{\circ} \mathrm{C}$ und $\mathrm{pH} 4,8$ für $8 \mathrm{~h}$ in $100 \mu \mathrm{l}$ eines $\mathrm{NaCl}$-haltigem NaAc/HAc-Puffer mit EDTA und DTT inkubiert. Die Endkonzentrationen bei diesem Versuchsansatz betrugen: 


$53 \mathrm{mM} \mathrm{NaAc} / \mathrm{HAc} \mathrm{pH} 4,8$
$96 \mathrm{mM} \mathrm{NaCl}$
$2,3 \mathrm{mM}$ EDTA
2,3 mM DTT
6,3 $\mu \mathrm{M}$ ASA-P426L
1,7 $\mu \mathrm{M}$ Cathepsin L

Der präparative Ansatz der mit Cathepsin $\mathrm{L}$ verdauten ASA-P426L wurde über RP-HPLC aufgetrennt (s. 3.4.17), massenspektroskopisch (s. 3.4.18) und durch $\mathrm{N}$-terminale Peptidsequenzierung identifiziert (s. 3.4.19).

\subsubsection{Reversed-Phase Hochauflösende Flüssigchromatographie (RP-HPLC)}

Der präparative Ansatz der mit Cathepsin L verdauten ASA-P426L wurde über eine C4-Reversed-Phase-Säule (Aquapore-Butyl-Säule: 2,1 x $200 \mathrm{~mm}$; BAl, Lautertal) an einer HPLC-Anlage (SMART-System, Pharmacia, Uppsala, Schweden) durch steigende Acetonitrilkonzentration um $2 \%$ pro Minute in $0,1 \% \mathrm{TFA} / \mathrm{H}_{2} \mathrm{O}$ bei einer Flußrate von $300 \mu \mathrm{l} / \mathrm{min}$ aufgetrennt. Die durch Trypsinspaltung entstandenen Peptide wurden über eine C8-Reversed-Phase-Säule (Aquapore-Octyl-Säule; 2,1 x 200 mm; BAl, Lautertal) bei gleichen Bedingungen aufgetrennt.

Die Fraktionierung erfolgte automatisch mit festgelegten Fraktionsgrößen, unter Verwendung der automatischen Signalerkennung oder per Hand. Die Änderung der optischen Dichte wurde bei 210 und $280 \mathrm{~nm}$ verfolgt.

\subsubsection{Matrixunterstützte Laser-Ionisations/Desorptions-Flugzeit- Massenspektrometrie (MALDI-ToF-MS)}

Die durch Cathepsin L bzw. Trypsin entstandenen Peptide der Arylsulfatase A wurden zur Entfernung des Acetonitrils für etwa $10 \mathrm{~min}$ in einem Vakuumkonzentrator eingeengt. $0,5 \mu \mathrm{l}$ in Aceton gelöste Indol-2-carbonsäure oder Sinapinsäure (10 mg/ml) wurden als Matrix auf einen Probenschlitten aufgetragen und getrocknet. Auf diesen dünnen Film aus Matrixkristallen wurden 0,5 $\mu \mathrm{l}$ (5-100 fmol) der eingeengten Elutionsfraktion aufgetragen. Zur Kalibrierung des Massenspektrometers (MALDI3, Shimadzu) diente ein im Institut für Biochemie II (Universität Göttingen) hergestelltes synthetisches Peptid (1979,1 Da). Die Messung erfolgte bei ca. 40\% der maximalen Laserstärke im positiven Reflektor-Modus. 


\subsubsection{N-terminale Sequenzierung von Peptiden durch automatischen Edman- Abbau}

Zur Identifizierung der durch Abbau mit Cathepsin L bzw. Trypsin entstandenen Peptide von Arylsulfatase A wurden von den gepoolten und über SDS-Gelelektrophorese identifizierten RP-HPLC-Fraktionen Aliquots entnommen, die zwischen 50 und 500 pmol Peptid enthielten. Die N-terminale Sequenzierung der Peptide erfolgte in einem automatischen Proteinsequenzer Modell 477A mit PTH-Aminosäureanalysator Modell 120 A (Applied Biosystems, Weiterstadt) nach Protokollen des Herstellers.

\subsubsection{Untersuchung des Dimer-Oktamer-Gleichgewichts der ASA}

In Experimenten zur Untersuchung des Oktamerisierungsverhaltens der gereinigten rekombinanten Proteine ASA-P426L und wt-ASA wurden die Oligomere der ASA über eine Gelfiltration an einer HPLC-Anlage (SMART, Pharmacia, Uppsala, Schweden) aufgetrennt (s. 3.4.15). Hierfür wurde die Superdex 200-Säule (PC3.2/30, Amersham Pharmacia Biotech; Bettvolumen 2,4 ml) bei einer Flußgeschwindigkeit von $50 \mu / / m i n$ verwendet.

Bestimmung von $\mathrm{V}_{0}$ und $\mathrm{V}_{t}$

Puffer: TBS pH7,0;

$25 \mu$ l der Proteinlösungen mit je $300 \mu \mathrm{g}$ Protein in $\mathrm{H}_{2} \mathrm{O}$.

\begin{tabular}{|c|c|c|c|c|}
\hline Standardproteine & & $\begin{array}{c}\text { Molekulargewicht } \\
{[\mathrm{Da}]}\end{array}$ & $\begin{array}{c}\text { Elutionsvolumen } \\
{[\mathrm{ml}]}\end{array}$ & $\begin{array}{c}\text { Retentionszeit } \\
{[\mathrm{min}]}\end{array}$ \\
\hline Dextranblau & $\mathrm{V}_{0}$ & 2000000 & 0,94 & 18,9 \\
\hline Tyrosin & $\mathrm{V}_{\mathrm{t}}$ & 163 & 2,20 & 44,1 \\
\hline
\end{tabular}

Daraus ergibt sich: $V_{t}-V_{0}=1,26 \mathrm{ml}$ 
Erstellung einer Eichkurve

Puffer: TBS pH 7,0

$25 \mu \mathrm{l}$ der Proteinlösungen mit je $300 \mu \mathrm{g}$ Protein in $\mathrm{H}_{2} \mathrm{O}$

Bestimmung der Retentionszeiten von folgenden Standardproteinen:

\begin{tabular}{|c|c|c|c|c|}
\hline Standardproteine & $\begin{array}{c}\text { Molekulargewicht } \\
{[\mathrm{Da}]}\end{array}$ & $\begin{array}{c}\text { Elutionsvolumen } \\
{[\mathrm{ml}]}\end{array}$ & $\begin{array}{c}\text { Retentionszeit } \\
{[\mathrm{min}]}\end{array}$ & Kav $^{*}$ \\
\hline Aldolase & 158000 & 1,50 & 30,0 & 0,444 \\
\hline Catalase & 233000 & 1,46 & 29,2 & 0,413 \\
\hline Ferretin & 440000 & 1,33 & 26,6 & 0,309 \\
\hline Tyroglobulin & 669000 & 1,18 & 23,6 & 0,190 \\
\hline
\end{tabular}

$\mathrm{Kav}^{*}=\left(\mathrm{V}_{\mathrm{E}}-\mathrm{V}_{0}\right) /\left(\mathrm{V}_{\mathrm{t}}-\mathrm{V}_{0}\right)$

Bestimmung des Molekulargewichtes von wt-ASA bei pH 7,0 und 4,8

Puffer: TBS pH7,0 und $100 \mathrm{mM} \mathrm{NaAc/HAc} \mathrm{mit} 150 \mathrm{mM} \mathrm{NaCl} \mathrm{pH} \mathrm{4,8}$

$50 \mu \mathrm{l}$ der Proteinlösungen mit je $30 \mu \mathrm{g}$ Protein in Puffer

Vorinkubation: 3h auf Eis

\begin{tabular}{|c|c|c|c|c|}
\hline $\begin{array}{c}\text { wt-ASA } \\
\text { bei } \mathrm{pH}\end{array}$ & $\begin{array}{c}\text { Elutionsvolumen } \\
{[\mathrm{ml}]}\end{array}$ & $\begin{array}{c}\text { Retentionszeit } \\
{[\mathrm{min}]}\end{array}$ & Kav & $\begin{array}{c}\text { Molekulargewicht nach } \\
\text { Eichkurve [Da] }\end{array}$ \\
\hline 7,0 & 1,50 & 30,1 & 0,448 & 120000 \\
\hline 4,8 & 1,25 & 25,0 & 0,248 & 480000 \\
\hline
\end{tabular}

Bestimmung des Oligomerisierungszustands von wt-ASA und ASA-P426L bei unterschiedlichen $\mathrm{pH}$-Werten

Puffer: $100 \mathrm{mM} \mathrm{NaAc/HAc,} 150 \mathrm{mM} \mathrm{NaCl}$,

eingestellt auf die pH-Werte 4,8, 5,0, 5,2, 5,4, 5,6, 5,8 und 6,0.

$50 \mu \mathrm{l}$ der Proteinlösungen mit je $2 \mu \mathrm{g}$ Protein in Puffer

Vorinkubation: 3h auf Eis in dem entsprechenden Puffer

Fraktionen: 1 Fraktion pro min, entspricht $50 \mu \mathrm{l}$ 
Die Quantifizierung der eluierten ASA wurde durch ASA-Aktivitätsbestimmung durchgeführt und in einem Diagramm dargestellt. Folgende Parameter wurden für die ASA-Aktivitätsbestimmung (s. 3.4.7) verwendet:

\begin{tabular}{|c|c|c|}
\hline & Proben-Volumen & Inkubationszeit \\
\hline wt-ASA & $20-40 \mu \mathrm{l}$ & $5-15 \mathrm{~min}$ \\
\hline ASA-P426L & $20-40 \mu \mathrm{l}$ & $20-30 \mathrm{~min}$ \\
\hline
\end{tabular}




\subsection{Kristallographische Methoden}

\subsubsection{Kristallisation und Strukturanalyse von Dikalium- $p$-Nitrocatecholsulfat (pNCS)}

Dikalium- $p$-Nitrocatecholsulfat (SIGMA) wurde aus einer 1:1 Mischung aus Wasser und Ethanol durch langsames Abdampfen des Lösungsmittels bei Raumtemperatur rekristallisiert. Nach einigen Tagen lagen gelbe, quaderförmige Kristalle mit Kantenlängen von etwa $0,3 \mathrm{~mm}$ vor, die für die Röntgenstrukturanalyse geeignet waren.

Ein Kristall dieser Verbindung wurde auf einem Stoe-Siemens-Huber Vierkreisdiffraktometer mit einem CCD-Flächendetektor und einer konventionellen MolybdänRöntgenröhre gemessen (Mo-K $\alpha$-Strahlung: $\lambda=0,71073 \AA$ ). Die Meßtemperatur betrug 133(2) K. Die Bestimmung der Orientierungsmatrix, der Zelldimensionen und des Bravaisgitters erfolgte durch das Diffraktometersteuerungsprogramm SMART [SMART, 1996]. Es wurden $\phi$ und $\omega$ scans durchgeführt und Daten im $\theta$-Bereich von $2,8-29,5^{\circ}$ aufgenommen. Anschließend wurden die so erhaltenen Daten mit dem Integrationsprogramm SAINT prozessiert [SAINT, 1997]. Die Rohdaten wurden dann mit Hilfe einer semiempirischen Absorptionskorrektur mit dem Programm SADABS [Sheldrick, 1997] korrigiert. Die Raumgruppenbestimmung sowie die Mittlung der Daten wurde mit dem Programm XPREP [XPREP, 1997] durchgeführt. Die Strukturlösung erfolgte mit Direkten Methoden mit dem Programm SHELXS [Sheldrick, 1990], die Verfeinerung mit dem Programm SHELXL [Sheldrick \& Schneider, 1997]. Alle Nichtwasserstoffatome wurden anisotrop verfeinert. Die Phenylwasserstoffe wurden mittels constraints gesetzt. Die Wasserstoffatome an den Wassermolekülen wurden aus der Differenzelektronendichte lokalisiert und mit Abstands-restraints frei verfeinert.

Ein constraint ist eine exakte mathematische Bedingung, die Parameter spart, indem der jeweilige Parameter auf einen bestimmten Wert oder als Funktion anderer Parameter festgesetzt wird (z.B. werden C-H-Bindungsabstände als konstante Werte eingegeben). Ein restraint ist zusätzliche chemische oder kristallographische Information über die Struktur einer Verbindung, die mit einer Standardabweichung versehen ist (z.B. Festsetzung der 1,2- oder 1,3-Abstände von chemisch, aber nicht kristallographisch äquivalenten Atomen auf einen nicht vorgegebenen, aber gleichen Wert innerhalb einer bestimmten Fehlergrenze). Die restraints gehen als zusätzliche Daten in die Verfeinerung mit ein. Während der Verfeinerung mit dem Programm SHELXL wird eine Funktion minimiert, die aus einem kristallographischen und einem geometrischen Teil besteht und bei der die Quadrate der Differenzen zwischen observierten und berechneten Meßdaten sowie zwischen definierten und berechneten restaints-Werte minimiert werden. 


$$
M=\Sigma w_{x}\left(F_{o}^{2}-F_{c}^{2}\right)^{2}+\Sigma w_{r}\left(T_{\text {def }}-T_{c}\right)^{2}
$$

mit $\quad w_{x}$ : Gewichtungsfaktor zur Normalisierung des kristallographischen Teils

$\mathrm{w}_{\mathrm{r}}=1 / \sigma^{2} \quad$ mit $\sigma:$ Gewichtungsfaktor der restraints

$\mathrm{T}_{\text {def }}$ : definierter restraint-Wert und $\quad \mathrm{T}_{\mathrm{C}}$ : berechneter restraint-Wert

$F_{0}$ : observierter Strukturfaktor und $\quad F_{c}$ : berechneter Strukturfaktor

Die Modellierung und Bearbeitung sowie die graphische Darstellung des Kleinmoleküls erfolgte mit Hilfe des Programms XP [XP, 1997].

\subsubsection{Kristallisation der ASA-Mutanten}

Die Kristallisation der drei gereinigten ASA-Mutanten wurde nach der Kristallisationsvorschrift für den Wildtyp der ASA durchgeführt [Lukatela et al., 1998]. Dies war die Gasdiffusionsmethode im hängenden Tropfen, bei der es sich um die in der Proteinkristallographie am häufigsten angewendeten Kristallisationsweise handelt [Ducruix \& Griegé, 1992; McPherson, 1998]. Sie hat den Vorteil, daß auch mit einer geringen Probenmenge Kristalle erhalten werden können und diese für die Messung leicht zu handhaben sind. Bei dieser Methode macht man sich einer Konzentrationserhöhung verschiedener Stoffe im Kristallisationsansatz zum Nutzen, so daß eine thermodynamisch instabile Proteinübersättigung entsteht und somit im optimalen Falle die Bildung wohlgeordneter Kristalle erfolgt. Sie wurde in Gewebekulturplatten mit runden Deckgläschen durchgeführt, die das Gefäß mit Hilfe von Silikonhochvakuumfett luftdicht abschließen. Diese Deckgläschen mußten bei hängenden Tropfen silikonisiert sein, um eine möglichst geringe Oberfläche und eine gleichmäßige Form der Kristalltropfen zu erhalten.

In dem abgeschlossenen Gefäß von etwa $1,6 \mathrm{~cm}^{3}$ befand sich ein Reservoir aus Fällungsmittel und getrennt davon ein Tropfen aus einer Mischung aus Protein und Fällungsmittel. Als Fällungsmittel wurden 0,5 ml einer 12-13\%igen PEG 6000 Lösung benutzt, die mit $100 \mathrm{mM} \mathrm{NaAc/HAc}$ auf $\mathrm{pH}$ 5,3 oder 5,4 gepuffert wurde. Eine $30 \%$ ige Stammlösung des PEG 6000 sowie eine 1 M Stammlösung des NaAc-Puffers konnten bei $4^{\circ} \mathrm{C}$ mehrere Wochen gelagert werden. Alle Substanzen, die zur Kristallisation verwendet wurden hatten p.a. Qualität und wurden vor der Benutzung sterilfiltriert (Porengröße 0,45 $\mu \mathrm{m}$ ).

Die Kristallisationstropfen hatten ein Volumen von 4-8 $\mu$ l und wurden durch 1:1 Mischung der Proteinlösung mit dem Fällungsmittel hergestellt. Für die Kristallisationsansätze lagen folgende ASA-Konzentrationen vor: 


\begin{tabular}{|c|c|}
\hline Proteinlösung in TBS $\mathrm{pH} 7,4$ & Konzentration \\
\hline ASA-C69S & $8-12 \mathrm{mg} / \mathrm{ml}$ \\
\hline ASA-C69A & $7 \mathrm{mg} / \mathrm{ml}$ \\
\hline ASA-P426L & $5-12 \mathrm{mg} / \mathrm{ml}$ \\
\hline
\end{tabular}

Der Tropfen befand sich am silikonisierten Deckelgläschen hängend (hanging drop), oder seltener auf einer kleinen Kunststoffbrücke oberhalb des Reservoirs sitzend (sitting drop). Dadurch, daß sich zwischen den Konzentrationen des Tropfens und des Reservoirs ein Gleichgewicht eingestellt hat, verringerte sich das Volumen des Tropfens und ermöglichte somit eine langsame Konzentrationserhöhung der Substanzen. Da der limitierende Faktor bei der Kristallisation das Bilden von einer kleinen Anzahl an Kristallkeimen war, konnte man durch microseeding wenige kleinste Mikrokristalle in eine Lösung überführen. Dies geschah, indem z.B. mit einer Wimper ein vorhandener Kristall berührt wurde und die nun an der Wimper haftenden Mikrokristalle in den preäquilibrierten Kristallisationstropfen gegeben wurden. Die Methode des microseedings wurde bei allen Mutanten angewendet. Nach zwei bis fünf Tagen bei $18^{\circ} \mathrm{C}$ zeigten sich erste kleine Kristalle, die ihr Wachstum nach zwei bis vier Wochen abgeschlossen hatten. Ein anschließendes macroseeding, bei dem makroskopisch sichtbare Kristalle in einen Tropfen überführt wurden, in dem neben den vorhandenem Fällungsmittel auch wieder eine hohe Proteinkonzentration vorlag, wurde in einigen Fällen durchgeführt, um eine weitere Verbesserung der Kristallgröße zu erhalten.

\subsubsection{Montage von ASA-Kristallen}

Kristalle wurden nur montiert, wenn sie keine optisch erkennbaren Schäden aufwiesen und im polarisierten Licht ein anisotropes Verhalten besaßen. Für die Durchführung einer Datensammlung am Synchrotron mußten sie zusätzlich noch eine Mindestauflösung von etwa 2,0 ^ zu Anfang der Messung sowie ein qualitativ gutes Beugungsbild zeigen. Die Mindestauflösung sowie die Qualität der Reflexprofile nahm jedoch im Laufe der Messung rapide ab.

Für erste Beugungsexperimente wurde ein Kristall in eine dünnwandige $(0,01 \mathrm{~mm}$ Wandstärke) Quarzkapillare mit einem Durchmesser von 0,5-1,0 mm montiert, die daraufhin mit Hartwachs oder Kleber verschlossen wurde (Abbildung 3.1). Dort befand sich zusätzlich ein Tropfen Mutterlauge, um ein Austrocknen des Kristalls zu verhindern. Die Kristalle erlitten während dieser Montiermethode wenig Schaden, obwohl zu bedenken ist, daß die Montage einige Minuten erfordern kann und in dieser Zeit einzelne Komponenten des Puffers verdunsten, was zu einer Verschlechterung der 
Kristallqualität führen kann. Zur Erzeugung der Enzym-Substrat-Komplexe wurde ein Kristall für $2-3 \mathrm{~h}$ in Kristallisationspuffer getränkt, dem zuvor $20 \mathrm{mM} p$-Nitrocatecholsulfat zugefügt wurden.

Es wurden mehrere Versuche unternommen, die Kristalle bei tiefen Temperaturen $(100-120 \mathrm{~K})$ einzufrieren und dann eine Datensammlung durchzuführen. Hierfür wurden sie in Schlaufen (Loops) aus dünner Faser in einem geeigneten Einfriermittel (Kryoprotektand) schwimmend montiert und anschließend in einem Stickstoffkaltgasstrom schockgefroren (Abbildung 3.1). Der ganz entscheidende Vorteil einer Messung bei $100 \mathrm{~K}$ liegt im stark verringerten Strahlungsschaden, den der Kristall bei Raumtemperaturmessungen erleidet.

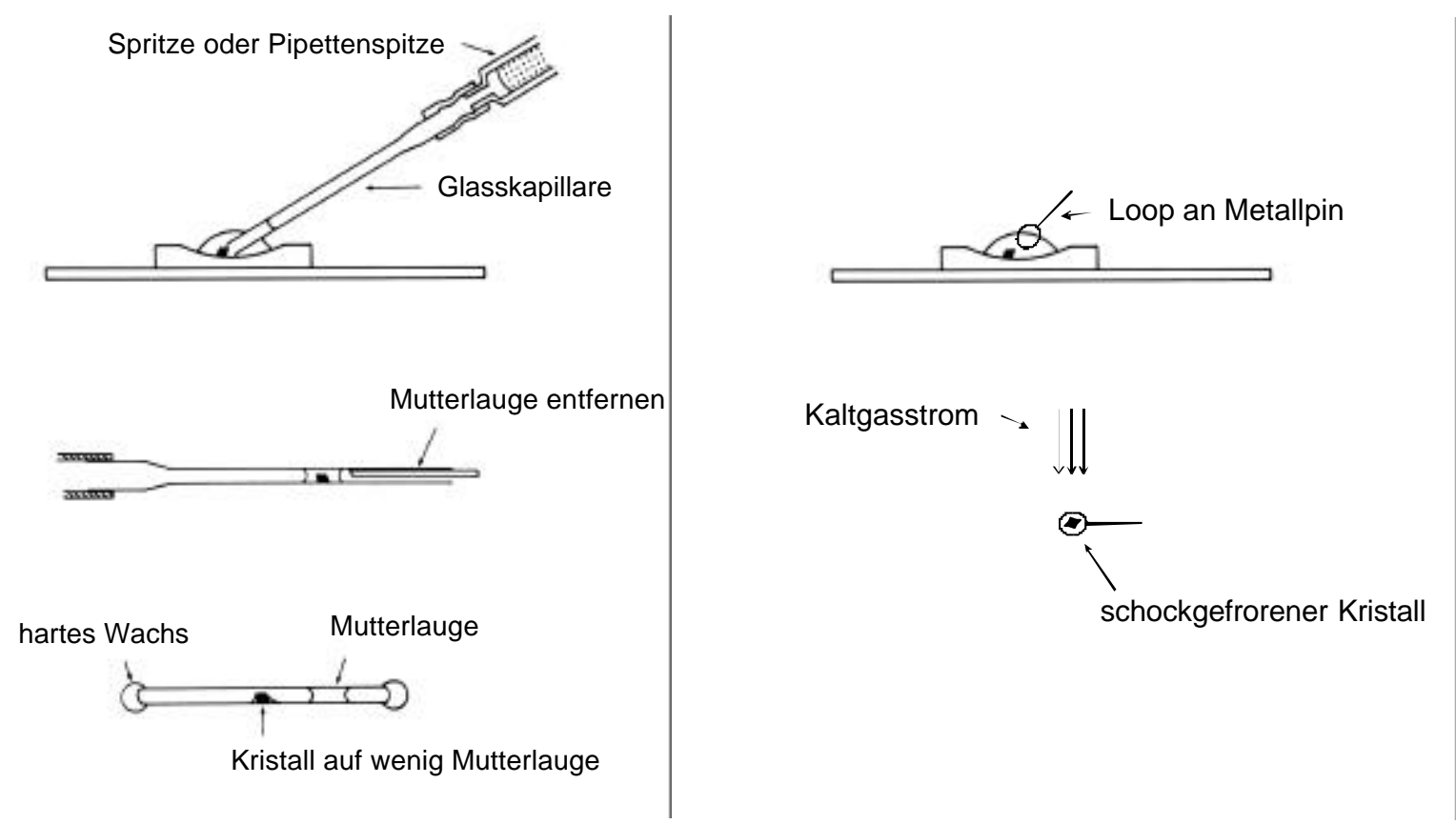

Abbildung 3.1: Kristallmontage in der Kapillare für eine Raumtemperaturmessung (links) und im Loop für eine Tieftemperaturmessung (rechts).

Strahlungsschäden von Kristallen während einer Messung nehmen sowohl mit der Zeit, aber auch mit der Strahlungsintensität und -energie zu [Garman \& Schneider, 1997]. Röntgenstrahlen, die auf ein Molekül im Kristall treffen, können Radikale erzeugen, die in chemischen Reaktionen die Moleküle zerstören können. Diese Schäden nehmen mit höherer Intensität der Röntgenstrahlen zu und sind besonders stark bei der Messung mit Synchrotronstrahlung (dose-dependent). Wenn nun Wassermoleküle zu Radikalen werden, ist durch den meist hohen Wasseranteil in Proteinkristallen eine Ausbreitung und Vermehrung der Radikale im Kristall speziell in nicht gefrorenem Zustand möglich (time-dependent). Ist diese Kettenreaktion einmal gestartet, sollte der Kristall möglichst schnell gemessen werden. Diese zeitabhängige Kristallzerstörung kann verursachen, daß keine kompletten Datensätze an Drehanoden aufgenommen werden können und 
somit eine Datensammlung am Synchrotron erforderlich wird. Unter dem Aspekt der Strahlungsschäden ist eine Datensammlung am Synchrotron wegen der geringen Wellenlänge der Strahlung sowie der viel kürzeren Meßdauer vorzuziehen.

Die Schwierigkeit dieser Methode bestand darin, einen geeigneten Kryoprotektand zu finden, der die Kristalle nicht zerstört und ohne Einschlüsse von Eis in glasartigem Zustand gefriert. Puffer, die verwendet wurden, enthielten neben den gleichen oder erhöhten Mengen an Fällungsmittel und Acetatpuffer auch noch unterschiedliche Chemikalien wie niedermolekulare (Poly-)Alkohole (wie Glycerin, Glukose, MPD, Isopropanol, PEG 100, 200 und 400), Salze (wie Ammoniumacetat und Kaliumphosphat) und verschiedene Öle (wie Paraffinöl und perfluorierten Polyether). Diese Ansätze blieben jedoch alle ohne Erfolg, da die Kristalle Risse bekamen, sobald sie in einem anderen Puffer überführt wurden. Folglich waren auch die Diffraktionsbilder von schlechter Qualität.

Zusätzlich wurden einige Kristallisationsansätze in Puffern durchgeführt, die sich als Kryoprotektanden eignen, um den Transfer des Kristalls von einem Puffer in einen anderen zu vermeiden. In diesen Ansätzen konnten Kristalle gezüchtet werden, die jedoch selbst bei einer Raumtemperaturmessung in einer Quarzkapillare schlechte Reflexprofile zeigten. Außerdem streuten die Kristalle nur bis zu einer um etwa $1 \AA$ geringeren Auflösung als die zuvor gemessenen Kristalle.

Da kein Kryoprotektand gefunden werden konnte, wurden die ASA-Kristalle alle bei $4^{\circ} \mathrm{C}$ oder bei Raumtemperatur gemessen. Sie erlitten dabei innerhalb von 1 bis 2 Stunden so starke Strahlungsschäden, daß nach etwa 3 bis 4 Stunden die Messung des Kristalls beendet werden mußte. Um einen kompletten Datensatz zu erhalten, wurde - wenn möglich - der Kristall etwas im Synchrotronstrahl verschoben, so daß der Kristall zwar in der gleichen Orientierung blieb, aber an einem anderen Teil bestrahlt werden konnte. Dies konnte bei der Messung von ASA-C69A genutzt werden. Bei den Datensätzen von ASA-C69S und ASA-P426L konnten komplette Datensätze nur durch Vereinigung der Daten verschiedener Kristalle erhalten werden.

Die resultierende höchste Auflösung der gesamten Daten war jedoch im Vergleich zur höchsten Auflösung im ersten aufgenommenen Diffraktionsbild stark reduziert. 


\subsubsection{Datensammlung und -reduktion}

Erste Kristalle wurden an der Kupfer-Drehanode (Cu-Ko $=1,5418 \AA)$ mit einem Dreikreisdiffraktometer mit Plattformgeometrie und einem MWPC-Flächenzähler (Bruker, Karlsruhe) bei 263 - $293 \mathrm{~K}$ gemessen. Die Datensammlung, die Bestimmung der Zelldimensionen und Orientierungsmatrix erfolgte mit dem Diffraktometersteuerungsprogramm FRAMBO [FRAMBO, 1994], die gemessenen Reflexe wurden anschließend mit SAINT [SAINT, 1997] integriert und mit SADABS [Sheldrick, 1997] absorptionskorrigiert. Mit Hilfe des Programms XPREP [XPREP, 1997] wurde zum einen entschieden, bis zu welcher Auflösung die Daten zur Auswertung benutzt werden können und zum anderen wird die Raumgruppe bestimmt.

Um eine so hohe Auflösung wie möglich und einen möglichst kompletten Datensatz jeder Mutante zu erlangen, wurden die Röntgenbeugungsexperimente am Deutsche Elektronensynchrotron in Hamburg (DESY) durchgeführt. Die Synchrotronstrahlung hat für Beugungsexperimente an Proteinkristallen gegenüber der Röntgenstrahlung, z.B. der Drehanode, die Hauptvorteile der höheren Intensität und Brillianz [Helliwell, 1992]. Zudem kann die Wellenlänge variiert werden, so daß eine normale Datensammlung meist bei einer Wellenlänge von 0,8 bis $1,0 \AA$ aufgenommen wird. Bei dieser Wellenlänge sind die Absorptionseffekte von Luft oder Protein geringer als bei $1,5418 \AA$ (Cu-Drehanode) und zudem sind die während der Datensammlung auftretenden Strahlungsschäden an Kristallen aufgrund der geringeren Energie bei gleicher Leistung und der generell am Synchrotron schnelleren Meßdauer schwächer (s. 3.5.3).

Die Datensammlungen erfolgten an der Beamline X11 der EMBL Heidelberg-Outstation am Speicherring DORIS. Die Wellenlängen bei den verschiedenen Messungen betrugen $0,91 \AA$. In allen Fällen wurden die Beugungsbilder mit Mar Imaging-Plates aufgenommen. Die Daten wurden in zwei Sätzen gesammelt, einem bis zur jeweils höchsten Auflösung und einem bis zu einer Auflösung von 4,6 bis 4,1 $\AA$. Das Problem von Reflexen bei niedriger Auflösung ist, daß diese Reflexe sehr starke Intensitäten haben, da die Meßbedingungen an die höher aufgelösten, schwachen Daten angepaßt sind. Sie treten dann als overloads auf, d.h. der Zähler an der Stelle ist gesättigt. Da der Wert der Reflexintensität so die Grenze der Auswertungsmöglichkeit überschreitet, ist eine genaue Bestimmung des Wertes nicht möglich und die Messung sollte bei geringerer Strahlungsintensität, größerem Abstand und kürzerer Belichtungsdauer wiederholt werden.

Die Bestimmung der Zelldimensionen und die Integration der aufgenommenen Daten erfolgte mit DENZO [Otwinowski \& Minor, 1997]. Die indizierten und integrierten Reflexe wurden anschließend mit SCALEPACK [Otwinowski \& Minor, 1997] skaliert, und symmetrieäquivalente Reflexe wurden gemittelt. Die Daten wurden in ihrer höchsten 
Auflösung so weit geschnitten, daß in der äußeren Schale das Verhältnis von Reflexintensität zu Rauschen (I/ $\sigma$-Wert) über 2 lag. Auch von den aufgenommenen Diffraktionsbildern wurden nicht alle in die Skalierung miteinbezogen. Ab dem Bild, bei dem der Kristall einen zu starken Qualitätsverlust in Form hoher Mosaizität, schlechter Reflexprofile und eines hohen $R_{\text {sym }}$-Wertes in den Daten zeigte, wurden die darauffolgenden Diffraktionsbilder nicht in der Skalierung verwendet. Der $R_{\text {sym }}$-Wert gibt an, wie gut die gemittelten symmetrieäquivalenten Reflexe übereinstimmen.

$$
\left.\mathrm{R}_{\mathrm{sym}}=\left(\Sigma\left|\mathrm{I}_{\mathrm{hkl}}-<\mathrm{I}_{\mathrm{hkl}}>\right|\right) / \Sigma\left(\mathrm{I}_{\mathrm{hkl}}\right)\right)
$$

\begin{tabular}{|l|l|l|l|l|}
\hline Verbindung & ASA-C69S & $\begin{array}{l}\text { ASA-C69S } \\
+p N C S\end{array}$ & $\begin{array}{l}\text { ASA-C69A } \\
+p N C S\end{array}$ & ASA-P426L \\
\hline Wellenlänge $[\mathrm{nm}]$ & 0,9097 & 0,9097 & 0,9057 & 0,9097 \\
\hline Zählerabstand $[\mathrm{mm}]$ & $185 / 450$ & $200 / 410$ & $200 / 450$ & $210 / 400$ \\
\hline Auflösungsbereich [̊̊] & $2,0 / 4,6$ & $2,2 / 4,2$ & $2,2 / 4,6$ & $2,4 / 4,1$ \\
\hline Belichtungsdosis [counts] ${ }^{*}$ & $2000 / 800$ & $2000 / 300$ & $2000 / 300$ & $2500 / 1000$ \\
\hline Scanwinkel $\Delta \phi\left[^{\circ}\right]^{*}$ & $0,8 / 2,5$ & $0,5 / 1,5$ & $0,8 / 2,0$ & $0,5 / 1,5$ \\
\hline Anzahl der Kristalle & 2 & 1 & 1 & 3 \\
\hline Anzahl der Bilder * & $47+49 / 40$ & $122 / 26$ & $143 / 27$ & $100+72 / 55$ \\
\hline Gesamtrotation um $\phi\left[^{\circ}\right]^{*}$ & $37,6+39,2 / 100$ & $61 / 39$ & $114,4 / 54$ & $50+36 / 82,5$ \\
\hline
\end{tabular}

Tabelle 3.1: Parameter bei der Datensammlung der Kristalle am EMBL/DESY.

* Messung bei hoher / niedriger Auflösung

Die bei den einzelnen Datensätzen benutzten Abstände und Belichtungszeiten sind in Tabelle 3.1 angegeben. Ebenso findet sich dort der eingesetzte Scanwinkel $\Delta \phi$ und die Gesamtrotation um $\phi$ der verschiedenen Messungen. Um einen vollständigen Datensatz zu erhalten, gibt es einen minimalen Winkelbereich des reziproken Gitters, der gemessen werden muß. Für die Raumgruppe 1422 ist dieser minimale Winkelbereich eine Rotation um $45^{\circ}$ um die 4-zählige kristallographische Achse des Kristalls oder aber um $90^{\circ}$ bei Rotation um eine 2-zählige Achse. Die mindeste Gesamtrotation um $\phi$ lag bei den hier gezeigten Messungen jeweils zwischen $45^{\circ}$ und $90^{\circ}$, jedoch wurde meist etwas weiter rotiert, um eine höhere Redundanz ( > 4) zu erhalten. Denn eine hohe Redundanz verbessert die Datenqualität. 
Eine hohe Redundanz ist außerdem zur Skalierung zweier oder mehrerer Kristalle notwendig, da die Bereiche der gemessenen Reflexe der verschiedenen Kristalle sich überlappen müssen, um die Skalierung durchführen zu können. Generell ist die Skalierung von Kristallen ein Problem und meist fehlerbehaftet. Die bei der Messung und durch Strahlungsschäden auftretenden Fehler sind von den Fehlern der Skalierung nicht trennbar.

Die Raumgruppenbestimmung wurde mit dem Programm XPREP [XPREP, 1997] durchgeführt. Strukturfaktoramplituden wurden mit TRUNCATE [CCP4, 1994] berechnet.

\subsubsection{Strukturlösung und -verfeinerung}

Alle Strukturen der hier gezeigten ASA-Mutanten wurden mit der gleichen Strategie gelöst und verfeinert.

Vor Beginn der eigentlichen Strukturlösung und -verfeinerung wurden die gemessenen Reflexe eines Datensatzes auf Zufallsbasis mit dem Programm RFREEFLAG [CCP4, 1994] in einen Arbeits- und einen Testsatz aufgeteilt. 5\% der Reflexe befanden sich im Testsatz und wurden nicht zur Strukturlösung und -verfeinerung, sondern zur Berechnung des freien R-Werts benutzt. Die Verfeinerung wurde gegen die restlichen Daten durchgeführt. Unrealistisch niedrige R-Werte sowie ein schlechtes Strukturmodell sollten somit verhindert werden. Um bei den Verfeinerungen der vier Datensätze möglichst die gleichen Reflexe zur Berechnung des freien R-Werts zu verwenden, wurden diese für die drei übrigen Datensätze mit dem Programm CAD [CCP4, 1994] festgelegt. Dies verhindert die künstliche Erniedrigung des freien R-Wertes.

Die Strukturen wurden gelöst, indem als Startmodell ein leicht modifiziertes Strukturmodell der wt-ASA verwendet wurde [Lukatela et al., 1998]. Die Modifikation umfaßte die Entfernung aller Wassermoleküle sowie die Seitenketten der Aminosäure 69 für die Lösung der Struktur von ASA-C69-Mutanten sowie der Aminosäuren der $\beta$-Stränge 17 und 18 für die Lösung der Struktur von ASA-P426L. Dies wurde unternommen, um ein Modelbias zu verhindern. Modelbias entsteht dadurch, daß die Phasen aus dem Modell der schon bekannten, zum Start der Verfeinerung eingesetzten Struktur, resultieren, wohingegen die Amplituden aus dem Meßexperiment stammen. Für die Berechnung der Elektronendichte sind die Phasen entscheidender als die Amplituden. Verfeinerungsmethoden tendieren außerdem dazu, das Modell so anzupassen, daß der Unterschied von berechneten und observierten Amplituden minimiert wird, die Phasenfehler aber unterschätzt werden. 
Die Verfeinerung der Struktur wurde mit dem Programm REFMAC [Murshudov et al., 1997] durchgeführt. Als Verfeinerungsalgorithmus der Koordinatenparameter wurde die „Maximum Likelihood Funktion“ verwendet. Weiterhin beinhaltet REFMAC eine wirkungsvolle Beschreibung des „Bulk Solvents“. Ungeordnete Wassermoleküle im Kristall besitzen einen nicht zu vernachlässigenden Streubetrag, der sich vorwiegend auf Reflexe bei niedriger Auflösung auswirkt. Das Programm definiert eine Region in der Elementarzelle, in der sich das Solvent befindet. Diese „Bulk Solvent Maske“ wird einer mittlere Elektronendichte zugeordnet und ermöglicht so, daß dem kalkulierten Strukturfaktor des Proteins ein Strukturfaktor des Solvents addiert werden kann und somit die für die Verfeinerung verwendeten Strukturfaktoren verbessert werden.

Einzelne B-Faktoren wurden mit restraints verfeinert. Wassermoleküle aus dem Modell des Wildtyps wurden in das Modell miteinbezogen, sobald die Verfeinerung des Proteins abgeschlossen war. Diese Wassermoleküle mußten in der gewichteten SigmaA-Elektronendichte sowie der Differenzelektronendichte $\left(2 \mathrm{mF}_{\mathrm{o}}-\mathrm{DF}_{\mathrm{c}}\right.$ und $\left.\mathrm{mF}_{\mathrm{o}}-\mathrm{F}_{\mathrm{c}}\right)$ bei $3 \sigma$ sichtbar sein und zu einem weiteren Wassermolekül oder zu einem Protonendonor oder -akzeptor mit einem Abstand von 2,3 - 3,5 $\AA$ eine Wasserstoffbrücke ausbilden. Sie mußten im Laufe der Verfeinerung einen Auslenkungsparameter von unter $80 \AA^{3}$ besitzen. An Stellen hoher positiver Elektronendichte wurden neue Wassermoleküle per Hand eingesetzt, sofern sie sinnvolle Wasserstoffbrückenbindungen ausbildeten.

Bei der Verfeinerung der Struktur der Komplexe wurde an Stelle der Wassermoleküle, die sich beim Wildtyp im aktiven Zentrum befinden, die Struktur des $p$-Nitrocatecholsulfats ( $p N C S$ ) in das Modell aufgenommen. Restraints für 1,2- und 1,3Abstände wurden mit dem Programm PROTDIC [CCP4, 1994] aufgrund der experimentell bestimmten Geometrie (Abschnitt 3.5.1) erzeugt.

Zur Darstellung der Elektronendichte wurde das Programm XtalView [McRee, 1999] verwendet. Die Elektronendichte wurde als gewichtete SigmaA-Karte $\left(2 \mathrm{mF}_{0}-\mathrm{DF}_{\mathrm{c}}\right)$ bei $3 \sigma$ konturiert [Read, 1986], die Differenzelektronendichte wurde als gewichtete SigmaAKarte $\left(\mathrm{mF}_{\mathrm{o}}-\mathrm{F}_{\mathrm{c}}\right)$ bei $+/-3 \sigma$ konturiert.

Zur Berechnung der Abweichungen der Lagen der C $\alpha$-Atome der jeweiligen Mutante zur wt-ASA wurde das Programm Shelxpro [Shelxpro, 1996-1997] verwendet.

Die Abbildungen der Kristallstrukturen wurden mit den Programmen XP [XP; 1997], Molscript [Kraulis, 1991] und BobScript [BobScript, 1994-1999] erzeugt und teilweise „gerendert“ mit Raster3D [Merritt \& Bacon, 1997]. 


\subsubsection{Gütekriterien}

Das wichtigste Gütekriterium für eine Proteinstruktur ist die Auflösung, denn je höher sie ist, desto genauer können die Atomkoordinaten bestimmt werden. Das Verhältnis der beobachteten Daten zur Anzahl der Parameter, die die Struktur beschreiben ( $x, y, z, B)$, ist größer. In einer guten Röntgenstruktur sind die Konformationen und Torsionswinkel meist gut bestimmt, und die atomaren Auslenkungsparameter (B-Werte), die die Aufenthaltswahrscheinlichkeit eines Atoms beschreiben, sind gering (10-40 $\left.\AA^{2}\right)$. Einige Bereiche können dabei jedoch auch beweglicher oder fehlgeordnet sein. Auslenkungsparameter sollten keine zu großen Werte annehmen, denn diese würden bedeuten, daß die Position der Atome nicht eindeutig bestimmt werden kann.

Neben diesen unmittelbar sichtbaren Kriterien, beschreibt ein weiteres Kriterium, der R-Wert, die Konvergenz der Verfeinerung einer Kristallstruktur. Im R-Wert findet sich die Differenz aus gemessenen Beugungsdaten und denen aus dem Modell errechneten Beugungsdaten wieder. Der R-Wert ist kein unabhängiger Faktor, da die Anzahl der Parameter mit in seine Berechnung eingeht. Wenn viel mehr Parameter das Modell beschreiben, als aus den Daten bestimmt werden können, ist die Struktur unterbestimmt. Um zu kontrollieren, ob der RWert künstlich allein durch Erhöhung der Parameterzahl erniedrigt wird, bedient man sich des freien RWertes $\left(R_{\text {free }}\right)$ [Bünger, 1993]. Dieser ermöglicht es, mit Hilfe von zufällig ausgewählten Reflexen - etwa $5-10 \%$ der zur Verfeinerung noch nicht benutzten Meßdaten - ein unabhängiges Kriterium für die Güte der Verfeinerung zu erhalten.

Der R-Wert ist ein Maß für die Abweichung der mit dem Modell berechneten Strukturfaktoramplituden $F_{c}$ von den gemessenen Strukturfaktoramplituden $F_{0}$, und er ist definiert als:

$$
\mathrm{R}=\left(\Sigma\left|\mathrm{F}_{\mathrm{o}}-\mathrm{kF}_{\mathrm{c}}\right|\right) / \Sigma\left|\mathrm{F}_{\mathrm{o}}\right| \text { mit k=Skalierungsfaktor }
$$

Der R-Wert sollte idealerweise unter 20\% liegen. Ein erhöhter R-Wert (größer als etwa

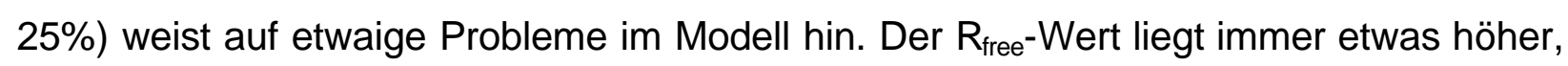
jedoch sollte er nicht mehr als $5 \%$ über dem R-Wert liegen.

Die verfeinerten Datensätze wurden mit dem Programm PROCHECK [Laskowski et al., 1993] untersucht. Die wenigen hierbei gefundenen Abweichungen der Aminosäuren von Standardgeometrien wurden abschließend gesondert kontrolliert. Der von PROCHECK generierte Ramachandranplot [Ramachandran \& Sassiekharan, 1968] gibt die Qualität der Hauptkettenfaltung der Polypeptidkette an. Er beruht auf folgenden Überlegungen: Die Hauptkette eines Proteins ist auf beiden Seiten jeder starren Peptideinheit frei drehbar. Die beiden Torsionswinkel $\varphi=\mathrm{C}-\mathrm{N}-\mathrm{C} \alpha-\mathrm{C}$ und $\psi=\mathrm{N}-\mathrm{C} \alpha-\mathrm{C}-\mathrm{N}$ beschreiben diese frei drehbaren Bindungen. Die Geometrie einer Peptidbindung ist so eingeschränkt, daß bestimmte Kombinationen dieser Winkel nicht möglich sind und 
andere bevorzugt. Die erlaubten Bereiche der Diederwinkel $\varphi$ und $\psi$ werden in dem zweidimensionale Diagramm darstellbar. So können Unstimmigkeiten am Ende der Verfeinerung leicht erkannt werden. Eine Strukturverfeinerung bei hoher Auflösung ist dann zufriedenstellend, wenn sämtliche Aminosäuren in bevorzugten Bereichen des Konformationsraums liegen. Abweichungen sind zwar möglich, sollten aber kontrolliert werden. Glycine besitzen wegen des sterisch anspruchslosen Wasserstoffatoms zusätzlich erlaubte Winkelbereiche. Dagegen verursacht bei Prolinen die festgelegte Konformation des Ringsystems eine stärkere Einschränkung der Torsionswinkel.

Um die Standardabweichung von Parametern wie Bindungslängen und Auslenkungsparametern im Strukturmodell zu bestimmen, muß eine full-matrix least squares-Berechnung durchgeführt werden. Bei großen Strukturen ist diese Berechnung extrem rechenaufwendig und wird deswegen in der Regel nicht durchgeführt. Die Standardabweichungen können aber nach einem Ansatz von Cruickshank [Cruickshank, 1999] abgeschätzt werden. Einige der dafür benötigten Parameter sind allerdings strukturabhängig und müssen empirisch bestimmt werden. Bislang ist die Anzahl der genau untersuchten Strukturen aber zu gering, um Werte für diese Parameter vorherzusagen. In REFMAC wird die Genauigkeit der Parameterbestimmung empirisch nach Cruickshank oder nach einem Maximum Likelihood-Ansatz abgeschätzt.

\begin{tabular}{|l|l|l|l|l|}
\hline & $\begin{array}{l}\text { ASA-C69A } \\
+p N C S\end{array}$ & ASA-C69S & $\begin{array}{l}\text { ASA-C69S } \\
+p N C S\end{array}$ & ASA-P426L \\
\hline $\begin{array}{l}\sigma(r) \text { nach Cruickshank basierend } \\
\text { auf R-Wert / } R_{\text {free }}-\text { Wert }\end{array}$ & $0,192 / 0,179$ & $0,226 / 0,210$ & $0,350 / 0,261$ & $0,257 / 0,235$ \\
\hline$\sigma(r)$ basierend auf ML & 0,119 & 0,127 & 0,160 & 0,154 \\
\hline$\sigma(B)$ basierend auf ML & 4,61 & 5,42 & 7,52 & 7,08 \\
\hline
\end{tabular}

Tabelle 3.2: Mittlerer Koordinatenfehler $(\sigma(r))$ und Standardabweichung der B-Werte $(\sigma(B))$ nach Cruickshank basierend auf R-Wert / $\mathbf{R}_{\text {free }}$-Wert bzW. nach einem Maximum Likelihood-Ansatz (ML).

Eine weitere Analyse der Strukturgüte beruht auf der Überprüfung der korrekten Wechselwirkungen der verschiedenen Atome. Dazu gehört das Vorliegen von Wasserstoffbrückenbindungen bei starken Protonendonoren und -akzeptoren oder beispielsweise die hydrophobe Umgebung einer hydrophoben Gruppe.

Die bei der Strukturlösung und -verfeinerung erhaltenen Daten sind in Abschnitt 4 aufgeführt und in einer Übersicht im Anhang gezeigt. 


\section{Ergebnisse}

\subsection{Enzym-Substrat-Komplex}

Im ersten Teil der vorliegenden Arbeit sollte die Frage geklärt werden, welche Aminosäurereste an der Bindung und an der katalytischen Spaltung des Substrates beteiligt sind. Dafür sollte ein Enzym-Substrat-Komplex der ASA hergestellt und röntgenstrukturanalytisch untersucht werden. Für diese Fragestellung wurde als Substrat $p$-Nitrocatecholsulfat ( $p N C S$ ) gewählt, dessen Kristallstruktur zunächst aufgeklärt werden sollte. Um die Spaltung von pNCS durch die ASA zu verhindern, wurde für den Enzym-Substrat-Komplex die inaktive Mutante ASA-C69A gewählt, in der das katalytisch aktive Formylglycin in Position 69 durch ein Alanin ersetzt ist [Knaust et al., 1998]. Ein zweiter Versuchsansatz wurde mit der Mutante ASA-C69S durchgeführt. Diese Mutante enthält in Position 69 ein Serin, das im Unterschied zum hydratisierten Formylglycin der wt-ASA nur eine Hydroxylgruppe besitzt. Dadurch ist die Mutante zwar in der Lage unter Ausbildung eines Enzym-Sulfat-Esters pNCS zu spalten, nicht aber das gebundene Sulfat abzuspalten [Recksieck et al., 1998]. Die Kristallisation eines ASA-C69S+pNCS-Komplexes sollte daher die Strukturaufklärung des Enzym-SulfatEsters als Intermediat der Katalyse ermöglichen.

Die Diffraktionsdaten der hergestellten Enzym-Substrat-Komplexe mußten am Synchrotron aufgenommen werden, da für diese Fragestellung eine Auflösung im Bereich von mindestens etwa 2,5 $\AA$ erforderlich ist und diese mit Hilfe eines Drehanodengenerators nicht erreicht werden kann.

\subsubsection{Expression und Reinigung der Mutante ASA-C69A}

cDNA, die für die Mutante ASA-C69A kodiert und in den pMPSV-Vektor einkloniert ist, wurde von Dr. A. Knaust (Abteilung Biochemie II, Universität Göttingen) zur Verfügung gestellt [Knaust et al., 1998]. Nach Vermehrung der DNA wurden immortalisierte MPRRezeptoren-defiziente MEF-Zellen in Anwesenheit eines Resistenz-Gens mit der cDNA transfiziert. In einem Westernblot mit einem polyklonalen Antikörper gegen wt-ASA konnte ein Klon identifiziert werden, der ASA in das Medium sezerniert (Abbildung 4.1C). Dieser Zellklon wurde daraufhin für die Großproduktion von ASA-C69A eingesetzt. Die Expressionsrate betrug etwa 2,0 $\mu \mathrm{g} / \mathrm{ml}$ Zellkulturmedium.

Die Mutante wurde aus den Zellkulturüberständen mit Ammoniumsulfat gefällt, gegen TBS-Puffer dialysiert und über Immunoaffinitätschromatographie gereinigt. Eine Reinheitskontrolle wurde mit Hilfe der SDS-Gelelektrophorese und anschließender Coomassiefärbung durchgeführt (Abbildung 4.1A+B). Insgesamt konnten so aus 3,1 I 
Zellkulturüberständen 6,2 mg ASA-C69A gereinigt werden. Die gereinigte Mutante ASAC69A zeigte eine Sulfataseaktivität von weniger als $0,1 \mathrm{U} / \mathrm{mg}$.

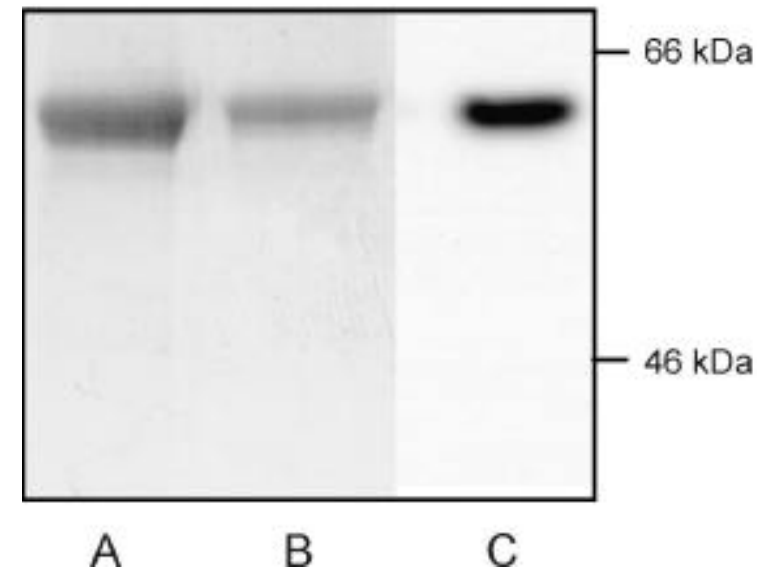

Abbildung 4.1: Westernblot und SDS-Polyacrylamidgel der gereinigten ASA-C69A. In (A) und (B) sind die Banden des coomassie-gefärbten 10\%igen SDS-Mini-Geles gezeigt: $2 \mu \mathrm{g}(\mathrm{A})$ und $1 \mu \mathrm{g}$ (B) gereinigte ASA-C69A wurden aufgetragen. Im Westernblot $(C)$ wird die ASA über einen polyklonalen Antikörper gegen ASA identifiziert.

Zur Kontrolle der Mutation wurde die Anwesenheit von Alanin in Position 69 durch Edman-Sequenzierung bestätigt. Hierfür wurde die gereinigte ASA-Mutante reduktiv carboxymethyliert, an einer HPLC-Anlage über Gelfiltration umgepuffert und anschließend mit Trypsin verdaut. Die tryptischen Peptide wurden über RP-HPLC getrennt mit Hilfe von MALDI-ToF-Massenspektrometrie identifiziert. Das nach Spaltung mit Trypsin erwartete Peptid mit der Masse von 1701 Da (Aminosäuren 59 - 71 mit Alanin in Position 69) wurde gefunden und seine Aminosäuresequenz durch Sequenzierung bestätigt.

\subsubsection{Kristallisation und Strukturanalyse von Dikalium- $p$-Nitrocatecholsulfat (pNCS)}

Da zur makromolekularen Strukturverfeinerung der Komplexe aus ASA-Mutante und pNCS keine Abstands- und Winkel-restraints für das Kleinmolekül-Anion pNCS bekannt waren, wurden zuvor die Kristallstruktur des chromogenen Sulfatasesubstrats aufgeklärt [von Bülow \& Usón, in press].

Der gelbe Feststoff Dikalium- $p$-Nitrocatecholsulfat wurde von der Firma SIGMA bezogen und aus einer 1:1 Mischung aus Wasser und Ethanol durch langsames Abdampfen des Lösungsmittels bei Raumtemperatur rekristallisiert. Nach einigen Tagen 
lagen gelbe, quaderförmige Kristalle vor, die für die Röntgenstrukturanalyse geeignet waren.

Die Struktur wurde mit Direkten Methoden mit dem Programm SHELXS [Sheldrick, 1990] gelöst. Alle Nichtwasserstoffatome wurden anisotrop verfeinert. In der asymmetrischen Einheit dieser Kristallstruktur befindet sich ein einzelnes Molekül. Die Phenylwasserstoffe wurden mittels constraints gesetzt. Die Wasserstoffatome an den Wassermolekülen konnten in der Differenz-Fourier-Synthese lokalisiert werden. Ihre Positionen wurden mit Abstands-restraints verfeinert. Die Auslenkungsparameter wurden frei verfeinert.

\begin{tabular}{|l|l||l|l|}
\hline Summenformel & $\mathrm{C}_{6} \mathrm{H}_{7} \mathrm{~K}_{2} \mathrm{NO}_{9} \mathrm{~S}$ & gesammelte Reflexe & 9928 \\
\hline Kristallgröße $[\mathrm{mm}]$ & $0,3 \times 0,2 \times 0,2$ & unabhängige Reflexe & 2993 \\
\hline Raumgruppe & $\mathrm{P} \overline{-}$ & $\mathrm{R}_{\text {int }}[\%]^{*}$ & 3,8 \\
\hline $\mathrm{a}[\mathrm{pm}]$ & $7,000(1)$ & Anz. d. restraints & 7 \\
\hline $\mathrm{b}[\mathrm{pm}]$ & $7,413(1)$ & Daten / Parameter & $3098 / 192=16,1$ \\
\hline $\mathrm{c}[\mathrm{pm}]$ & $12,348(2)$ & $\mathrm{R} 1(\mathrm{I}>2 \sigma(\mathrm{I}))[\%]$ & 3,5 \\
\hline$\alpha\left[^{\circ}\right]$ & $105,63(1)$ & wR2 (alle Daten) $[\%]$ & 9,7 \\
\hline$\beta\left[^{\circ}\right]$ & $90,46(1)$ & GooF & 1,075 \\
\hline$\gamma\left[^{\circ}\right]$ & $95,91(1)$ & $\begin{array}{l}\text { Differenzelektronen- } \\
\text { dichte max /min }\left[\mathrm{e} \AA^{-3}\right]\end{array}$ & $0,468 /-0,447$ \\
\hline $2 \theta-$ Bereich $\left[^{\circ}\right]$ & $2,8-29,5$ & & \\
\hline
\end{tabular}

Tabelle 4.1: Kristallographische Daten von Dikalium- $p$-Nitrocatecholsulfat ( $p$ NCS).

${ }^{*}: \mathrm{R}_{\mathrm{int}}=\Sigma\left|\mathrm{F}_{\mathrm{o}}^{2}-\left\langle\mathrm{F}_{\mathrm{o}}^{2}\right\rangle\right| / \Sigma\left[\mathrm{F}_{\mathrm{o}}^{2}\right]$

Die Packung der Struktur zeigt Ebenen, welche über die Kaliumionen und die Sulfatgruppen verbunden sind. Wechselwirkungen der aromatischen Ringe bilden einen weiteren Kontakt zwischen den Ebenen. Der Phenylring, die Nitrogruppe und die beiden am Phenylring gebundenen Sauerstoffatome liegen in einer Ebene mit einer r.m.s. Abweichung von 0,071 $\mathrm{A}$. Der Winkel zwischen der aromatischen Ebene und der gebundenen Sulfatgruppe (C1-O4-S1) beträgt 118,9(1) ${ }^{\circ}$. Die Bindungslängen innerhalb der Sulfatgruppe liegen im Bereich von 1,441(2) bis 1,451(2) $\AA$, ein Bereich, der auch in Strukturen anderer $\mathrm{SO}_{4}$-Tetraeder gefunden wurde [Kálmán, 1971]. Der Abstand zum verbrückenden Sauerstoffatom beträgt 1,621(2) A. Zwei Wassermoleküle befinden sich außerdem in Koordination zu der Kaliumkationen. 


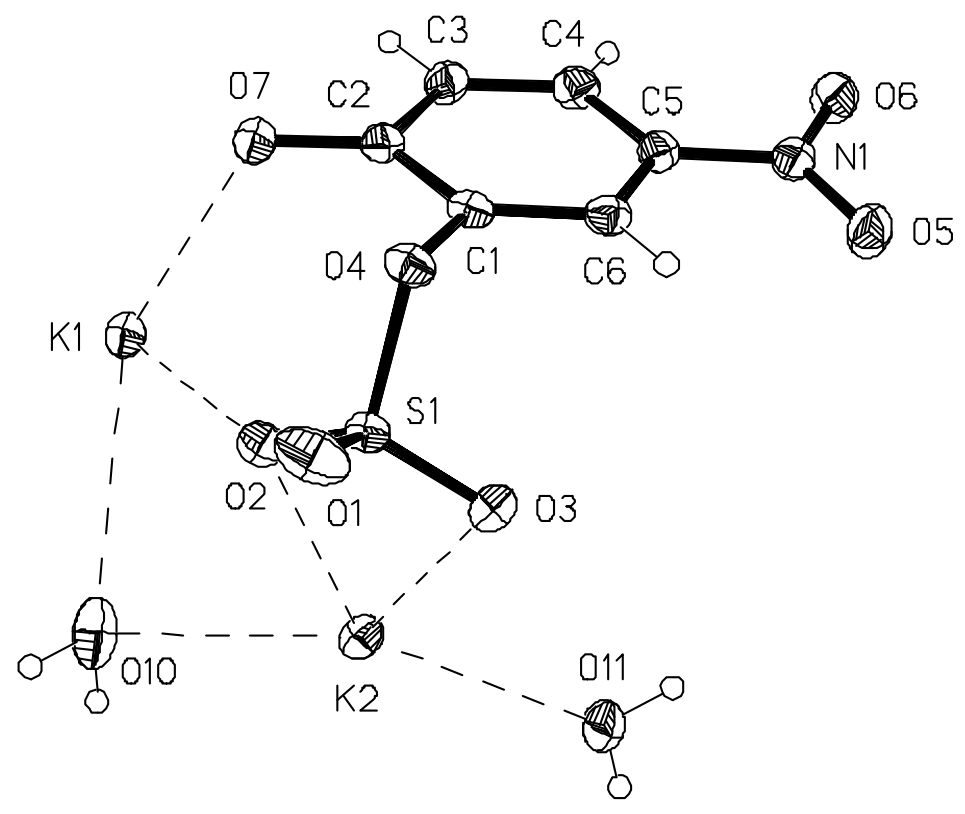

Abbildung 4.2: Kristallstruktur von Dikalium- $p$-Nitrocatecholsulfat. Im diesem Bild stellen die Auslenkungsellipsoide $50 \%$ der Aufenthaltswahrscheinlichkeit der Elektronen dar. Die Ionenbindungen sind gestrichelt eingezeichnet.

Anschließend wurden mit diesen Strukturdaten mit Hilfe des Programms PROTIN [CCP4,1994] restraints generiert, die dann für die Verfeinerung in REFMAC eingesetzt wurden.

\subsubsection{Kristallisation von ASA-C69A und Komplexierung mit $p N C S$}

Die Kristallisation der gereinigten ASA-C69A wurde nach der Gasdiffusionsmethode im hängenden Tropfen bei $18^{\circ} \mathrm{C}$ durchgeführt [McPherson, 1998]. Protein und Kristallisationspuffer wurden im Verhältnis 1:1 auf einem Deckgläschen gemischt und über das Pufferreservoir gebracht. Der Kristallisationspuffer entsprach dem, der für die Kristallisation des Wildtyps eingesetzt worden war (PEG6000, Natriumacetat, pH-Wert $5,3-5,4$ ) [Lukatela et al., 1998]. Nach einigen Tagen bildeten sich erste kleine Kristalle, die nach zwei bis vier Wochen als farblose Kristalle in Form von tetragonalen Pyramiden oder Bipyramiden mit Kantenlängen von bis zu 0,6 mm vorlagen (Abbildung 4.3). Um einen Enzym-Substrat-Komplex zu erhalten, wurde ein Kristall etwa zwei Stunden vor der Messung in Mutterlauge getränkt, die zusätzlich $20 \mathrm{mM}$ pNCS enthielt, so daß er die gelbe Farbe des Substrats annahm. Kristalle, die nicht mit pNCS komplexiert wurden, wurden nicht gemessen. 

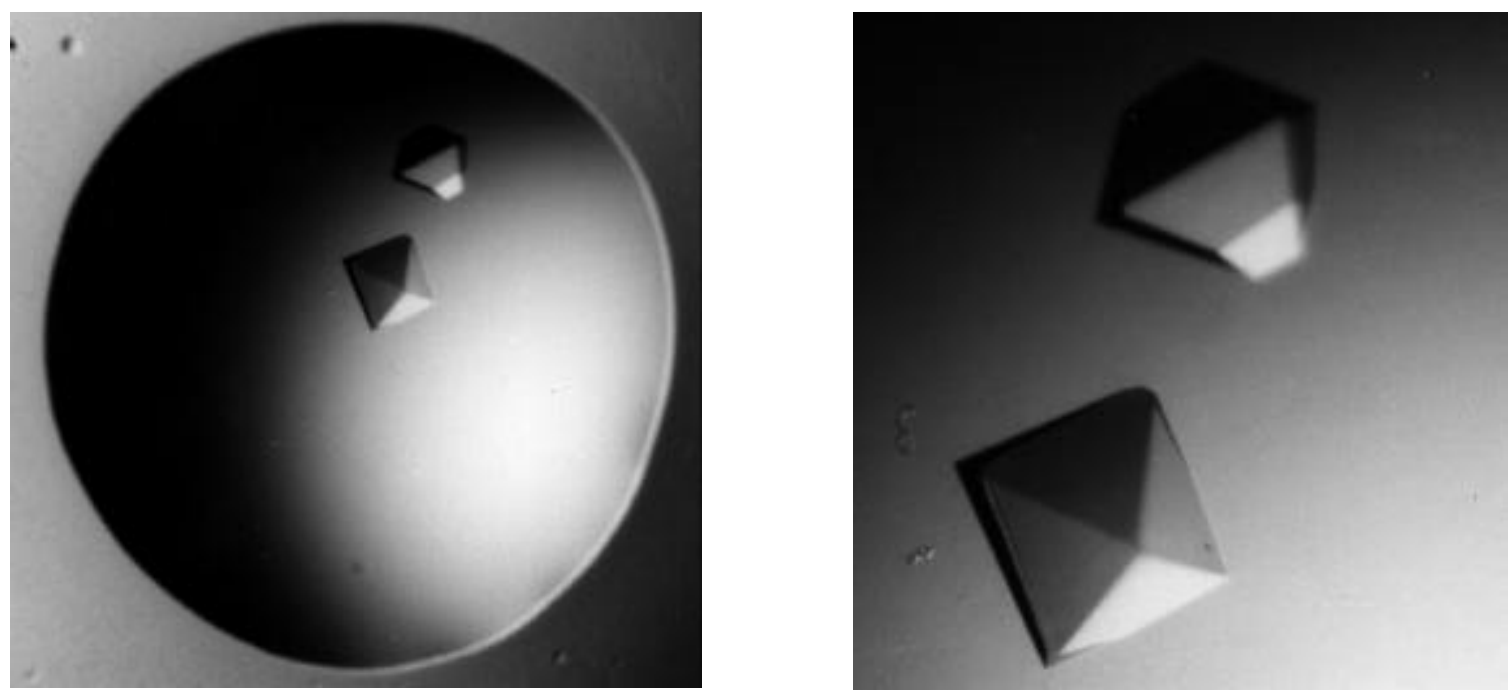

Abbildung 4.3: Kristalle von ASA-C69A. Links sind die Kristalle mit dem hängenden Tropfen dargestellt, rechts eine Großaufnahme. Die Kristalle besitzen ein Kantenlänge von 0,6 mm.

\subsubsection{Datensammlung, Strukturlösung und -verfeinerung ASA-C69A+pNCS}

Die Kristalle der ASA-C69A+pNCS-Komplexe hatten die gelbe Farbe des Substrats angenommen. Sie wurden in Quarzkapillaren montiert und zunächst an der KupferDrehanode bis zu einer Auflösung von etwa $4 \AA$, später am Synchrotron (EMBL/DESY in Hamburg) bis zu einer Auflösung von 2,35 Å gemessen. Die ermittelte Raumgruppe war 1422. Die Gitterkonstanten waren ähnlich zu denen des Wildtyps, der ebenfalls in der Raumgruppe 1422 kristallisiert (Übersicht in Tabelle 4.2).

Die Datenprozessierung und -reduktion wurde mit den Programmen XDISP, DENZO und SCALEPACK [Otwinowski \& Minor, 1997] durchgeführt. Die asymmetrische Einheit der ASA besteht aus einem Monomer. Aufgrund der geringen Sequenzänderung der gemessenen Struktur zum Wildtyp (FGly69 $\rightarrow$ Ala) und der daraus resultierenden nahezu 100\%ig übereinstimmenden Kristallstruktur, konnte die Struktur durch Einsetzen der Koordinaten eines leicht modifizierten Strukturmodells der wt-ASA gelöst werden. Eine Verfeinerung der Koordinaten wurde mit dem Programm REFMAC [Murshudov et al., 1997] durchgeführt. Als Verfeinerungsalgorithmus wurde die „Maximum Likelihood Funktion“ der Methode der „Kleinsten Fehlerquadrate“ vorgezogen. Einzelne B-Faktoren wurden mit restraints verfeinert. Die ersten Verfeinerungsschritte wurden ohne Wassermoleküle und ohne die Seitenkette an der Mutationsstelle durchgeführt. Seitenketten, deren Position in der Elektronendichte nicht erkennbar waren, wurden aus dem Modell entfernt. Der Aufbau der Aminosäuren des beim Wildtypmodell fehlenden Schleifenbereiches (Gly444 - Ala447), des C-Terminus (Asp504 - Ala507) sowie einiger einzelner Seitenketten konnte aus diesem Grund ebenso wie bei der Struktur des Wildtyps nicht durchgeführt werden. 
Nach Abschluß der Verfeinerung des Proteins, wurden die Wassermoleküle aus der Struktur des Wildtyps in die Verfeinerung mit einbezogen und auf ihre Auslenkungsparameter sowie Wechselwirkungen kontrolliert. Wassermoleküle, die einen Auslenkungsparameter von über $80 \AA^{3}$ besaßen, wurden hierbei aus dem Modell entfernt. An Stellen hoher positiver Elektronendichte wurden neue Wassermoleküle per Hand eingesetzt, sofern sie sinnvolle Wasserstoffbrückenbindungen ausbildeten. Zur Darstellung der Elektronendichten sowie der Differenzelektronendichten wurden gewichtete SigmaA-Karten $\left(2 \mathrm{mF}_{0}-\mathrm{DF}_{\mathrm{c}}\right.$ bei $3 \sigma$ und $\mathrm{mF}_{\mathrm{o}}-\mathrm{F}_{\mathrm{c}}$ bei $+/-3 \sigma$ konturiert $)$ [Read, 1986] mit dem Programm XtalView [McRee, 1999] verwendet.

Ein Gütekriterium, das Auskunft über die Qualität der Struktur gibt, ist der R-Wert. Er wird schon während der Verfeinerung der Struktur beachtet. Der R-Wert ist ein Maß für die Abweichung der mit dem Modell berechneten Strukturfaktoramplituden von den gemessenen Strukturfaktoramplituden. Bei der alleinigen Benutzung des konventionellen R-Wertes besteht die Gefahr, daß ein Modell bei der Verfeinerung mittels unbestimmter Parameter zu weit an die kristallographischen Daten angepaßt wird. Dies hat unrealistisch niedrige R-Werte und ein schlechteres Strukturmodell zur Folge. Es werden $5-10 \%$ der Meßdaten zufällig ausgewählt und von der Verfeinerung ausgeschlossen [Brünger, 1993]. Die Verfeinerung wird gegen die restlichen $90-95 \%$

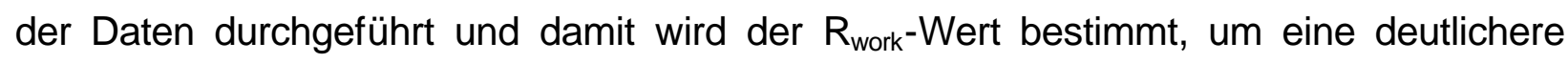
Korrelation von Modell zu Meßdaten zeigen zu können. Der freie $R-W e r t ~\left(R_{\text {free }}\right)$ wird nur für die ausgeschlossenen Reflexe bestimmt. Die Anpassung der Modellparameter an die restlichen Meßdaten beeinflußt diesen freien R-Wert nicht.

Während der Verfeinerung der Strukturen wurde stets darauf geachtet, daß sowohl der $R_{\text {work }}$-Wert als auch der freie R-Wert ( $R_{\text {free }}$-Wert) in gleichem Maße abnahmen. Bei den beiden Datensätzen wurden jeweils $5 \%$ und möglichst die gleichen Reflexe aus den Verfeinerungsdaten herausgenommen und für die Berechnung des $R_{\text {free }}$-Wertes verwendet, um eine künstliche Verbesserung des $R_{\text {free }}$-Wertes zu vermeiden. Die R-Werte betrugen am Ende der Verfeinerung 19,1\% ( $R_{\text {work }}$-Wert $)$ und 23,6\% ( $R_{\text {free }}$ Wert). Diese relativ geringe Differenz der beiden Gütekriterien gilt als Zeichen für eine korrekt bestimmte Struktur und ist vergleichbar mit denen der zuvor verfeinerten Struktur. Im letzten Verfeinerungszyklus wurden alle Reflexe mit einbezogen und es lag ein R-Wert von 19,4\% vor. Die R-Werte der Verfeinerung des Wildtyps sind aufgrund der größeren Auflösung und der damit verbundenen größeren Anzahl an Reflexen etwas höher. 


\begin{tabular}{|c|c|c|c|}
\hline Verbindung & $\begin{array}{l}\text { ASA-C69A } \\
+p N C S\end{array}$ & Verbindung & $\begin{array}{l}\text { ASA-C69A } \\
+p N C S\end{array}$ \\
\hline Kristallparameter & & Verfeinerungsstatistik & \\
\hline $\begin{array}{l}\text { Gitterkonstanten } \mathrm{a}=\mathrm{b}[\AA] \\
\mathrm{c}[\AA \AA\end{array}$ & $\begin{array}{l}131,8 \\
192,1\end{array}$ & Aminosäuren im Modell & 480 \\
\hline Raumgruppe & 1422 & Anz. d. Proteinatome & 3554 \\
\hline Datenstatistik & & Anz. d. Wasser & 167 \\
\hline Auflösungsbereich [Å] & $40-2,35$ & Anz. d. sonstigen Atome & 44 \\
\hline $\begin{array}{l}\text { Anz. der gemessenen } \\
\text { Reflexe }\end{array}$ & 159586 & \begin{tabular}{|l} 
Daten-Parameter- \\
Verhältnis
\end{tabular} & 2,3 \\
\hline $\begin{array}{l}\text { Anz. der unabhängigen } \\
\text { Reflexe }\end{array}$ & 35243 & $\mathrm{R}_{\text {work }}$-Wert $\left(\mathrm{R}_{\text {free }}-\right.$ Wert $)[\%]$ & $19,1(23,6)$ \\
\hline Redundanz & 4,5 & R-Wert ${ }^{* *}[\%]$ & 19,4 \\
\hline Vollständigkeit [\%] & $99,3(100,0)^{\ddagger}$ & $\begin{array}{l}\text { Mittlerer Temperaturfaktor } \\
<B>\text { HK / SK / LM }\left[\AA^{2}\right]\end{array}$ & $\begin{array}{l}41,9 / 43,8 / \\
47,1\end{array}$ \\
\hline $\mathrm{R}_{\text {sym }}{ }^{*}[\%]$ & $8,5(33,7)^{\ddagger}$ & $\begin{array}{l}\text { Mittlere rms-Abweichung } \\
\text { der Bindungslängen }[\AA]\end{array}$ & 0,014 \\
\hline$<\mathrm{l} / \sigma(\mathrm{I})\rangle$ & $16,9(2,8)^{\ddagger}$ & $\begin{array}{l}\text { Mittlere rms-Abweichung } \\
\text { der Bindungswinkel }\left[{ }^{\circ}\right]\end{array}$ & 3,0 \\
\hline$I>3 \sigma(I)[\%]$ & $69,3(31,9)^{\ddagger}$ & & \\
\hline
\end{tabular}

Tabelle 4.2: Übersicht über wichtige kristallographische Daten und Verfeinerungsdaten des Komplexes der ASA-C69A+pNCS. Datenstatistik: Aufgelistet sind die Parameter der für die Verfeinerung des Modells benutzten Synchrotrondatensätze. Die Vollständigkeit, der Anteil der Reflexe mit I > $3 \sigma(\mathrm{I})$ und der R-Wert für symmetrieäquivalente Reflexe $R_{\text {sym }}$ sind für jeweils den vollständigen Datensatz sowie in Klammern und mit ${ }^{\ddagger}$ gekennzeichnet für die äußere Auflösungsschale angegeben, d.h. die äußeren $0,1 \AA$ Verfeinerungsstatistik: Der mittlere Temperaturfaktor der Atome ist für sowohl Hauptkettenatome (HK), Seitenkettenatome (SK) und Lösungsmittelatome (LM) angegeben. Abkürzung: rms $=$ root mean square.

Definitionen: *: $R_{\text {sym }}=\left(\Sigma\left|I_{h k l}-<I_{h k}>\right|\right) / \Sigma\left(I_{h k l}\right) ;{ }^{* *}: R=\left(\Sigma\left|F_{o}-F_{c}\right|\right) / \Sigma\left|F_{o}\right|$ 
Der verfeinerte Datensatz wurde mit dem Programm PROCHECK [Laskowski et al., 1993] untersucht. Die dabei gefundenen Geometrien waren vergleichbar zu denen aus Strukturen mit etwa 2,0 £ Der von PROCHECK generierte Ramachandranplot (Abbildung 4.4) zeigt, daß sich $87,3 \%$ der Hauptkettentorsionswinkel in bevorzugten, $11,9 \%$ in zusätzlich erlaubten Regionen befinden. Die Hauptkettengeometrie von zwei Aminosäuren (Met289 und Cys300) liegen in großzügiger erlaubten Regionen. Allein die mit einer Oligosaccharid-Seitenkette verknüpfte Aminosäure Asparagin 184 liegt bei beiden Strukturen ebenso wie bei der Struktur des Wildtyps außerhalb der erlaubten Bereiche, was wahrscheinlich auf den sterischen Einfluß des gebundenen Oligosaccharidrestes zurückzuführen ist.

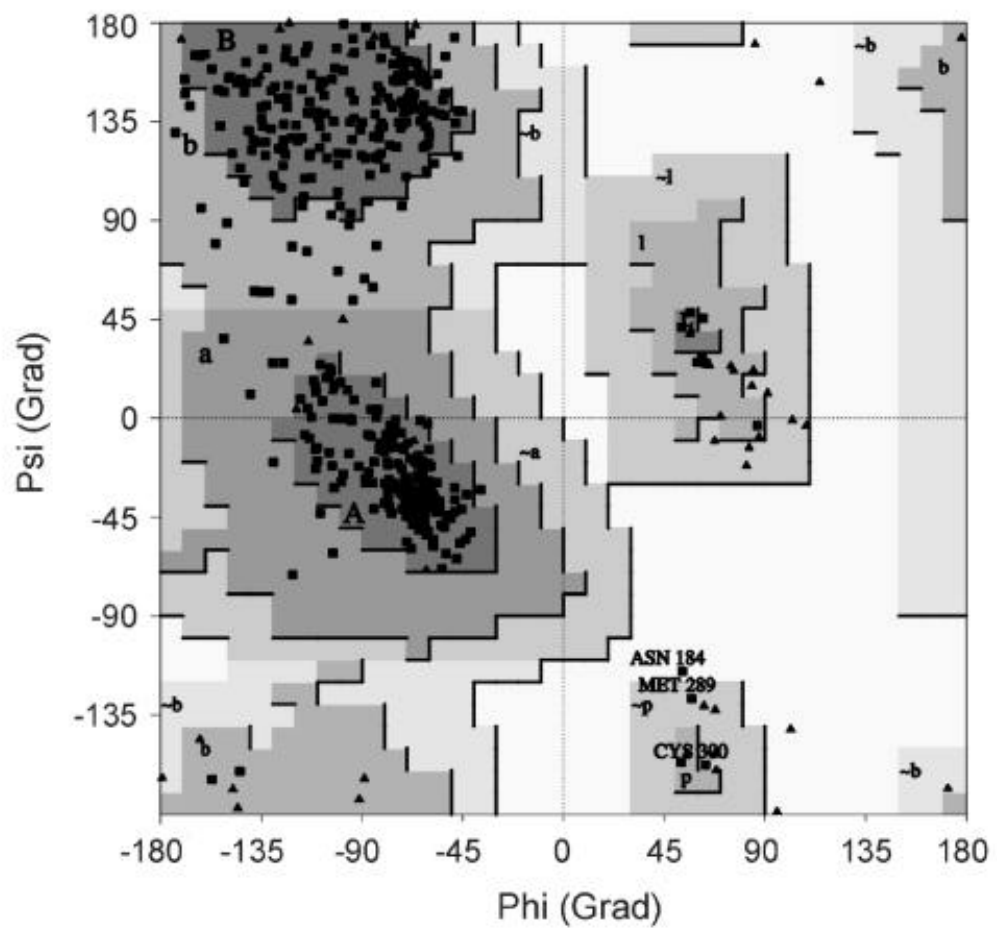

Abbildung 4.4: Ramachandranplot der Kristallstruktur von ASA-C69A+pNCS [Ramachandran \& Sassiekharan, 1968]. Aufgetragen sind die Hauptkettentorsionswinkel $\Phi$ und $\Psi$ eines Monomers der verfeinerten Komplexstruktur der ASA-C69A mit pNCS. 87,3\% der Hauptkettentorsionswinkel befinden sich in bevorzugten (dunkelgrau unterlegt: A, B, L), $11,9 \%$ in zusätzlich erlaubten (mittelgrau unterlegt: a, b, I, p) Regionen. 0,5\% der Hauptkettentorsionswinkel (Met289 und Cys300) liegen in großzügiger erlaubten (hellgrau unterlegt: $\sim a, \sim b, \sim 1, \sim p$ ) und 0,3\% (Asn184) in nicht erlaubten Regionen. Glycinreste sind als Dreiecke dargestellt, Nicht-Glycinreste als Quadrate. 


\subsubsection{Strukturbeschreibung der ASA-C69A+pNCS}

Die Tertiärstruktur der Mutante ASA-C69A im Komplex mit dem in vitro-Substrat der ASA, dem pNCS, entspricht der Struktur der wt-ASA.

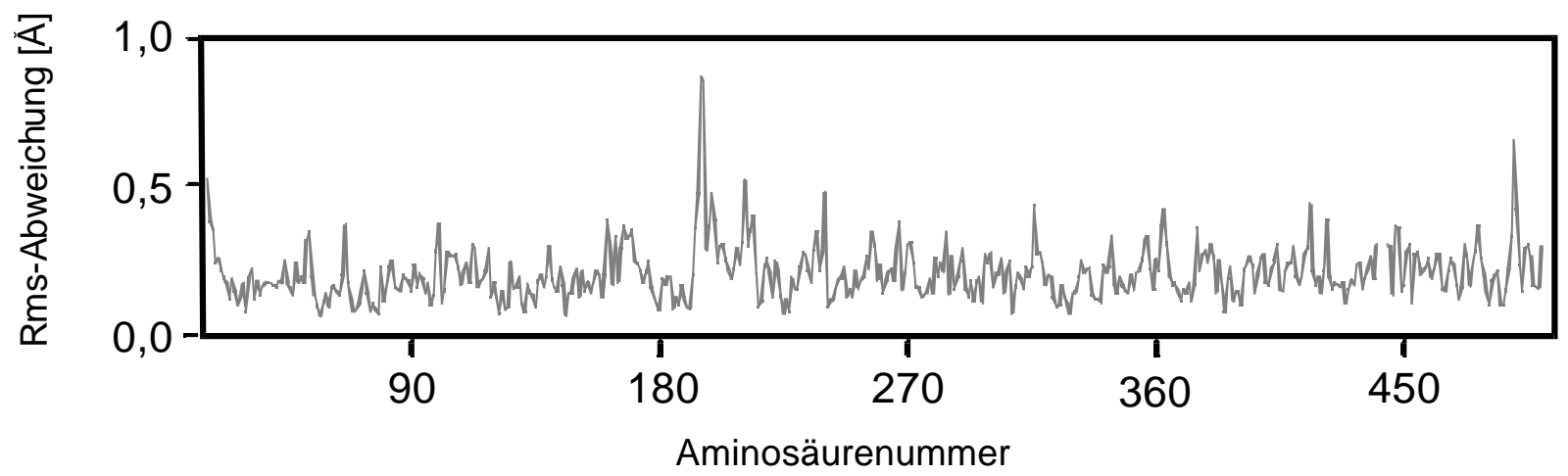

Abbildung 4.5: Rms-Abweichung der Lage der $\mathrm{C} \alpha$-Atome in dem Komplex ASA-C69A+pNCS im Vergleich zur wt-ASA.

Ein Vergleich der Koordinaten der C $\alpha$-Atome von ASA-C69A+pNCS mit denen des Wildtyps zeigt in allen Bereichen eine Abweichung von unter 0,5 $\AA$ mit der Ausnahme der Aminosäuren Glu198, Ala199 und Cys493, die in der Struktur aber unauffällig waren (Abbildung 4.5). Die Elektronendichte zeigt deutlich, daß die Hydroxylgruppen des Formylglycins der wt-ASA in der Alaninmutante nicht vorhanden sind, statt dessen ist das Vorliegen einer Methylgruppe an dieser Stelle in der Elektronendichte sichtbar (Abbildung 4.6).

Die Seitenketten der Aminosäuren im aktiven Zentrum entsprechen innerhalb der Fehlergrenzen den Positionen, welche für die wt-ASA bestimmt wurden [Cruickshank, 1999]. Im gleichen Bereich sind jedoch die koordinierten Wassermoleküle zum größten Teil verdrängt. Dort konnte die Sulfatgruppe und, in zwei Positionen fehlgeordnet, der Arylrest des pNCS modelliert werden. Die Fehlordnung zeigt, daß es zwei energetisch gleichwertige Orientierungen für den Arylrest in der Umgebung des Enzyms gibt. Das pNCS fült so den unteren Teil der Enzymtasche aus und wird von allen Seiten von Aminosäuren umgeben, von denen erwartet wurde, daß sie zum aktiven Zentrum der ASA gehören [Lukatela et al., 1998]. Die Elektronendichte, die um die Sulfatgruppe gefunden wurde, ist gut definiert, der aromatische Rest liegt in einigen Bereichen außerhalb der Elektronendichte (Abbildung 4.6). 

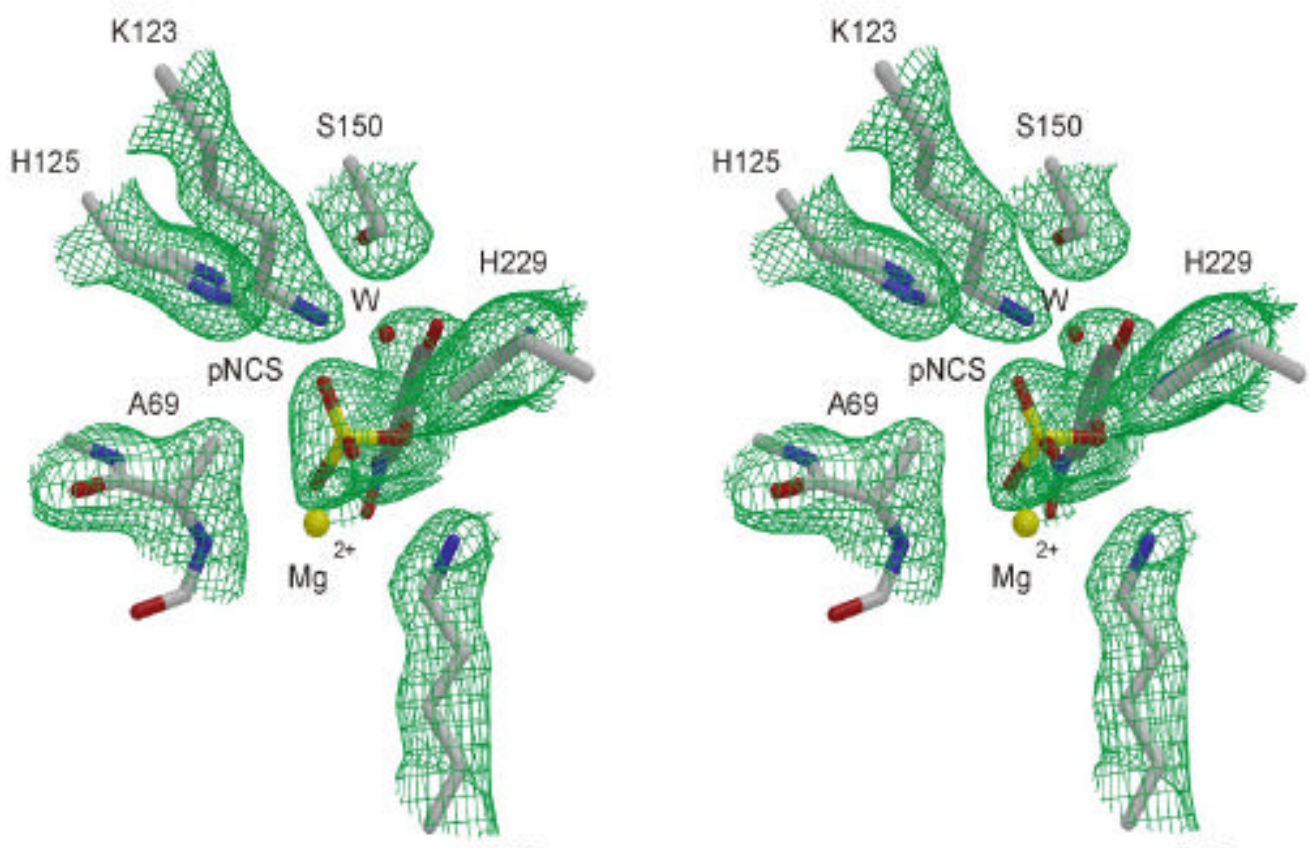

K302

$\mathrm{K} 302$

Abbildung 4.6: Lage des pNCS und der Aminosäuren des aktiven Zentrums innerhalb der Elektronendichte von ASA-C69A+pNCS (Stereobild). Die Haupt- sowie die Seitenkette der Aminosäure A69, sowie die Seitenketten der Aminosäuren K123, H125, S150, H229 und K302 sind mit den gefundenen Elektronendichten bei $3 \sigma$ (grün) dargestellt. In der Mitte der aktiven Tasche befindet sich das Substrat in der Elektronendichte. Die Elektronendichte um das Magnesiumion (gelb) ist aus Gründen der Übersichtlichkeit nicht dargestellt. (Bei dieser Abbildung handelt es sich um ein 3D-Bild durch Überkreuz-Schielen.) 

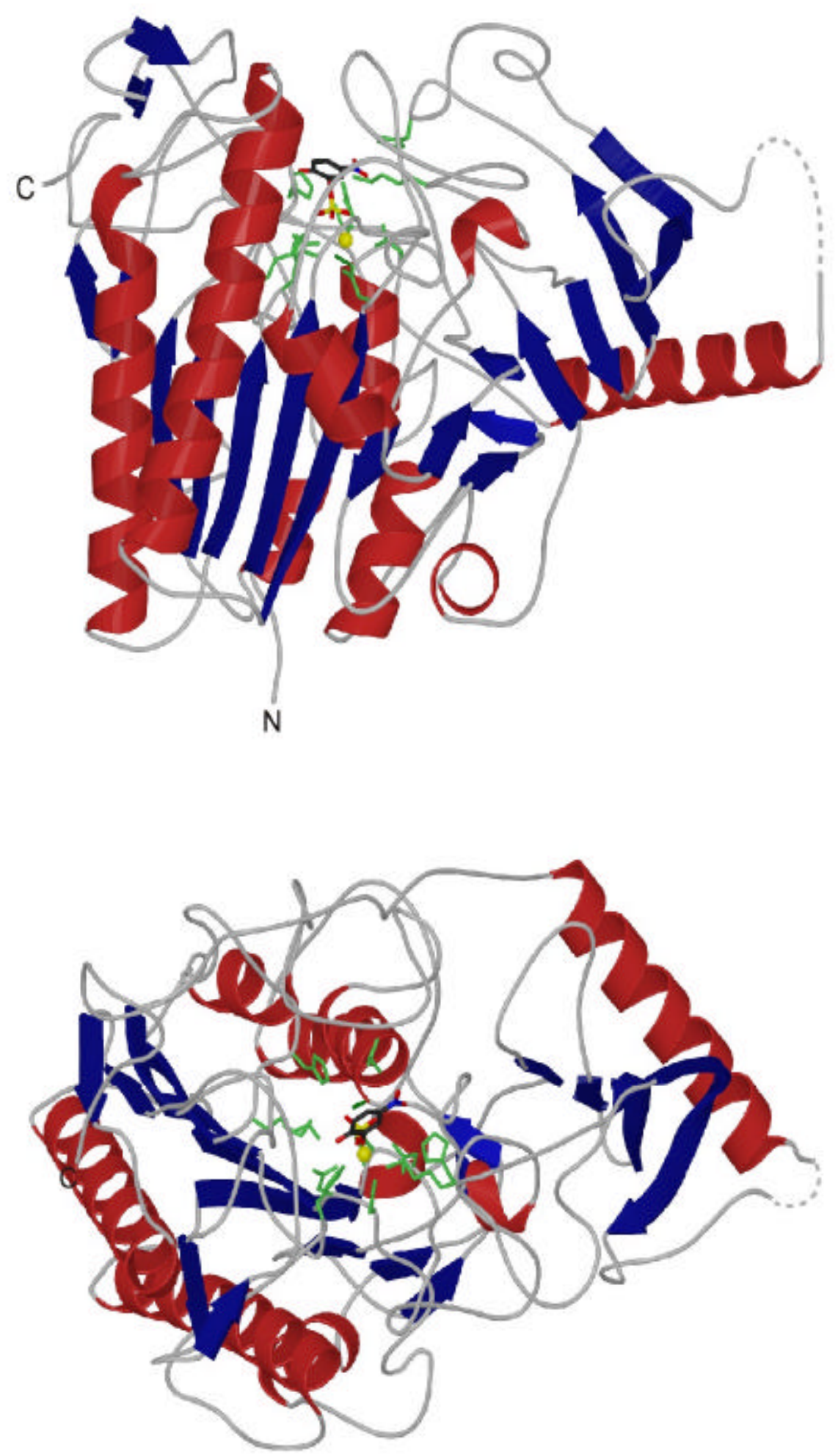

Abbildung 4.7: Kristallstruktur der hutförmigen ASA-C69A im Komplex mit dem in vitro-Substrat pNCS. $\alpha$-Helices sind als rote Spiralen, $\beta$-Stränge als blaue Pfeile und Schleifenbereiche grau dargestellt. Das Magnesiumion ist als gelbe Kugel zu sehen. Die Seitenketten, die sich in der Nähe der Aminosäure 69 befinden, sind hellgrün dargestellt. Die in der Elektronendichte nicht gefundenen Aminosäuren Gly444 - Ala 447 sind gestrichelt eingezeichnet. Der Arylrest des pNCS ist zur Vereinfachung nur in einer der beiden fehlgeordneten Positionen gezeigt. Die Atome des pNCS sind schwarz $(\mathrm{C})$, blau $(\mathrm{N})$, rot $(\mathrm{O})$ und gelb (S) gezeigt. (Seitenansicht oben und Draufsicht unten.) 
Eine genauere Betrachtung der Wechselwirkungen von Enzym und Substrat sollte nun Aufschluß über die Funktionen einzelner Aminosäuren geben (Abbildung 4.8). Das Substrat wird durch mehrere Wasserstoffbrücken sowie elektrostatische Anziehungskräfte in der aktiven Tasche dieser Mutante gehalten.

Die stärkste Wechselwirkung zum Substrat geht von Histidin 229 aus: eine Wasserstoffbücke zum Estersauerstoff $\mathrm{O} 4$, der den Schwefel und den Arylrest des Substrates verbindet. Der Abstand zwischen dem Ring-Stickstoffatom und dem

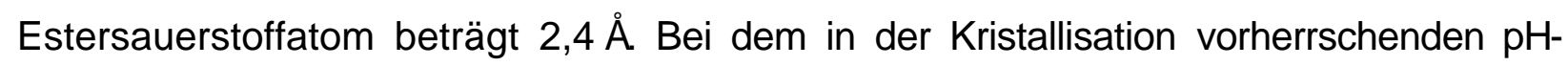
Wert von 5,3 - 5,4 kann man davon ausgehen, daß die Histidinseitenkette an diesem Stickstoffatom protoniert ist (normaler $\mathrm{pK}_{\mathrm{s}}$ der Histidinseitenkette: 6,0). Da das Histidin 229 ein Proton sowie eine positive Ladung trägt und bereits eine Wasserstoffbrücke ausbildet, wird die Wechselwirkung zum freien, eine negative Partialladung tragenden Sulfat-Sauerstoff $\mathrm{O} 1$ als elektrostatische Anziehung gewertet (2,9 Å). Dies könnte auch durch eine fehlgeordnete Position des Protons und somit elektrostatische Anziehung zu beiden Sauerstoffatomen erklärt werden. Diese beiden durch Histidin 229 fixierten Sauerstoffatome werden zusätzlich durch Wechselwirkungen zu weiteren Mitgliedern der aktiven Tasche des Enzyms an dieser Stelle positioniert. Dies ist zum einen eine elektrostatische Wechselwirkung zwischen dem vermutlich negativ geladenen $\mathrm{O} 1$ und dem zweifach positiv geladenen Magnesiumkation $(2,7 \AA)$ und zum anderen eine Wasserstoffbrücke ausgehend von der protonierten terminalen Aminogruppe der Seitenkette von Lysin 302 zum

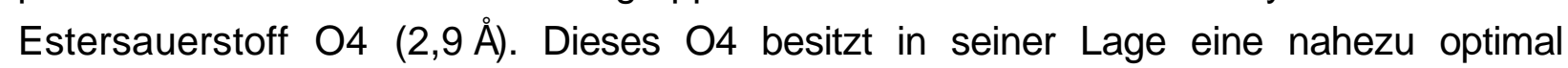
ausgenutzte tetraedrische Koordinationsumgebung.

Neben diesen vier starken Wechselwirkungen, bei denen zwei Substratsauerstoffatome durch zwei Aminosäuren und das Magnesiumion fixiert sind, liegen noch weitere schwächere Wechselwirkungen vor, die es ermöglichen, daß die Sulfatgruppe sich in einer Umgebung befindet, welche die negative Ladungsdichte absättigen kann. Die ع-Aminogruppe von Lysin 123 ist so zwischen $\mathrm{O} 1$ und $\mathrm{O} 2$ positioniert, daß zwei Wasserstoffbrücken ausgebildet werden können (3,2 und $3,4 \AA$ A ). Die vier Koordinationsmöglichkeiten an $\mathrm{O} 1$ sind damit genutzt und bilden eine leicht verzerrt tetraedrische Geometrie. $\mathrm{O} 2$ besitzt zusätzlich noch eine schwache Wechselwirkung zur Hydroxylgruppe von Serin 150 (Abstand 3,3 $\AA$ ). In dieser Orientierung des Sulfats wird außerdem eine Wasserstoffbrücke von der Hauptkettenaminogruppe des Alanin 69 zum dritten freien Sauerstoff $\mathrm{O} 3$ ausgebildet (Abstand 3,3 $\AA$ ). 


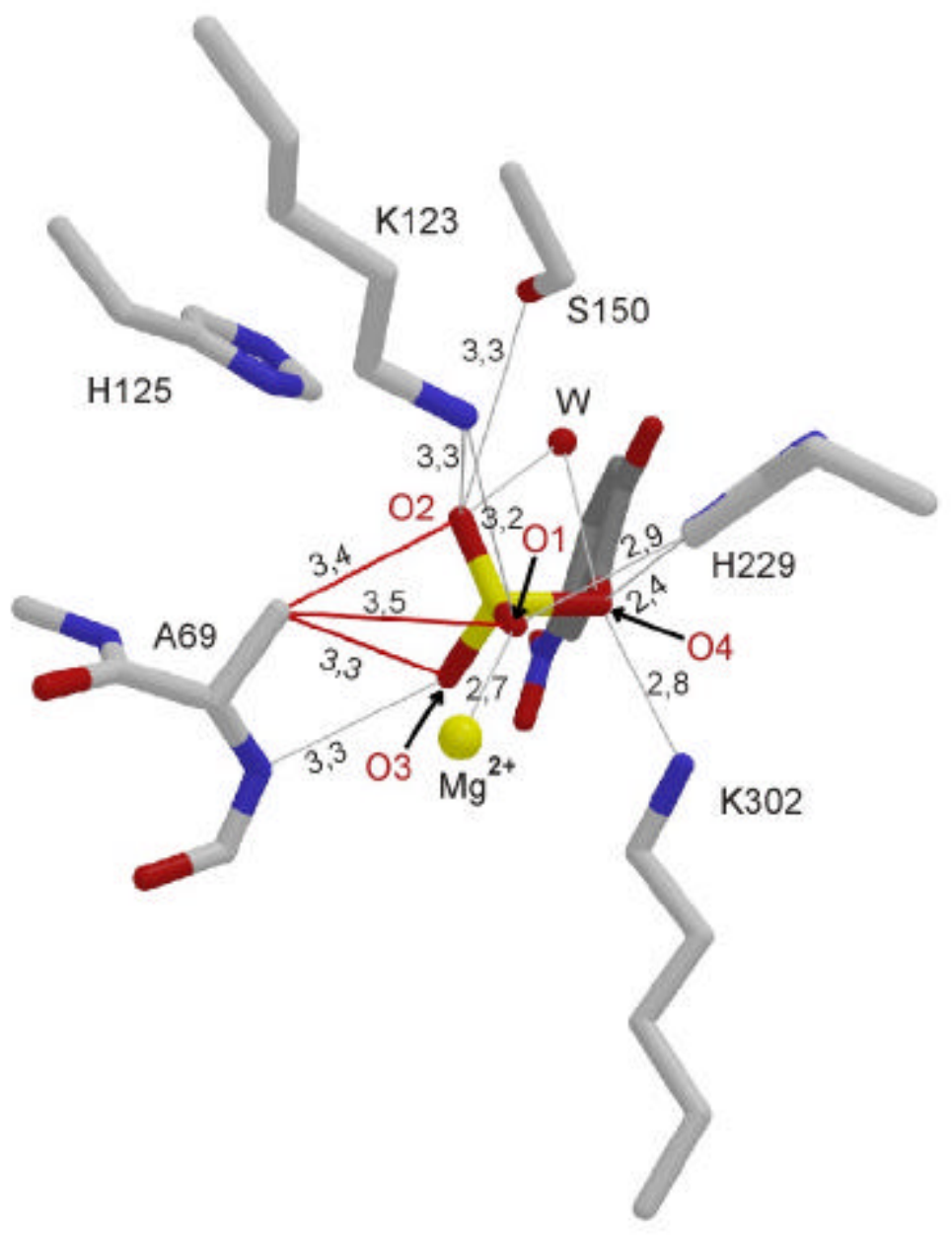

Abbildung 4.8: Aktives Zentrum der Mutante ASA-C69A komplexiert mit $p$ NCS. Dargestellt ist die dreidimensionale Struktur des in vitro-Substrats mit einigen Aminosäuren des aktiven Zentrums der ASA. Von Alanin 69 ist sowohl die Hauptkette (endend mit proximalen Kohlenstoffatomen der benachbarten Aminosäuren) als auch die Seitenkette dargestellt, dagegen sind bei allen übrigen Aminosäuren nur die Seitenkettenatome gezeigt (Schwefel: gelb, Sauerstoff: rot, Stickstoff: blau, Kohlenstoff: hellgrau für Aminosäuren und dunkelgrau für das Substrat). Das Magnesiumion ist als gelbe Kugel, ein Wassermolekül als rote Kugel dargestellt. Wasserstoffbrücken bzw. Salzbrücken zwischen Atomen sind als hellgraue Linien, die Abstände von Ala69C $\beta$ zu den Sulfat-Sauerstoffatomen als rote Linien dargestellt. Die Abstände sind in Å angegeben.

Die Bindung der Sulfatgruppe hat neben der Absättigung der Ladungen zur Folge, daß der Sulfatschwefel in der Nähe der Aminosäure 69 positioniert wird. Der Abstand des Kohlenstoffatoms der Methylgruppe von Alanin zu den Sulfat-Sauerstoffatomen beträgt 3,3 - 3,5 $\AA$, der zum Sulfat-Schwefelatom 3,5. . In der Struktur der wt-ASA liegen an dieser Position zwei Hydroxylgruppen des hydratisierten Aldehyds vor. Nach dem vorgeschlagenen Katalysemechanismus greift einer der Hydroxyl-Sauerstoffatome den Schwefel des Substrats an. Um zu erfahren, welcher der beiden HydroxylSauerstoffatome diesen Angriff durchführen könnte und um für diesen Sauerstoff die Orientierung und den Abstand zum Schwefel zu zeigen, wurde der hydratisierte Formylglycinrest in das Modell von ASA-C69A+pNCS einmodelliert (Abbildung 4.9). 
Die Bindung zwischen $\mathrm{C} \alpha$ und $\mathrm{C} \beta$ des Formylglycins ist theoretisch frei drehbar. In der Struktur des Wildtyps ist sie jedoch durch eine Wasserstoffbrücke $(2,7 \AA)$ zwischen O 2 und Histidin 125 und ebenso durch eine elektrostatische Wechselwirkung $(2,6 \AA$ zwischen dem Sauerstoff der zweiten Hydroxylgruppe und dem Magnesiumion fixiert. In dieser Orientierung betragen die Abstände zwischen den beiden modellierten Hydroxylgruppen und dem Schwefelatom der Sulfatgruppe 2,5 $\AA$ (O $\gamma 1$-S) bzw. 4,0


Elektronenpaars des Sauerstoffs auf den Schwefel ermöglicht. Das Sauerstoffatom besitzt eine leicht verzerrt tetraedrische Umgebung, was mit dem in der modellierten Struktur gefundenen Winkel konsistent ist. Eine Interaktion zwischen $O \gamma 1$ und $S$ ist demnach viel wahrscheinlicher, als eine zwischen O 2 und $\mathrm{S}$.

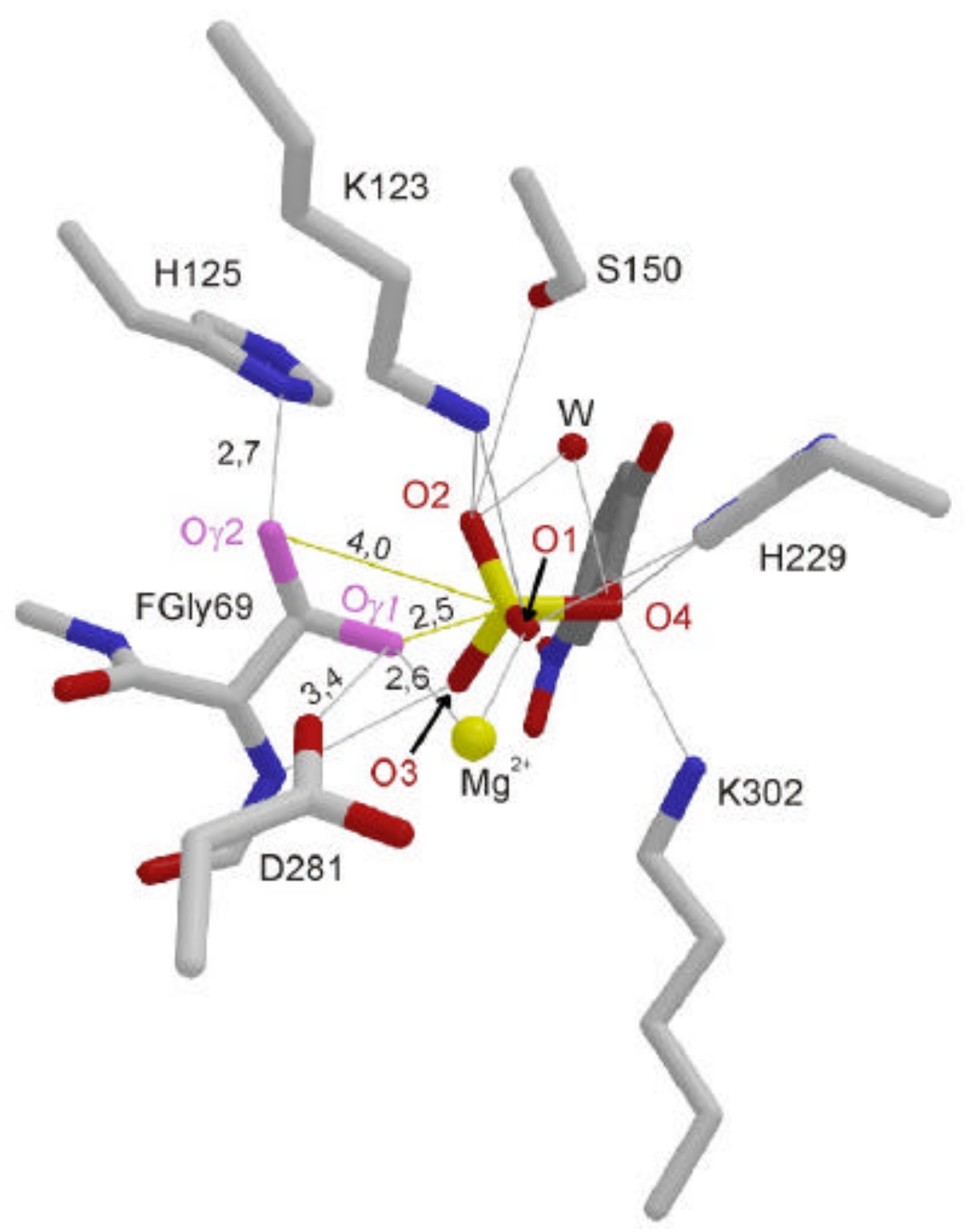

Abbildung 4.9: Aktives Zentrum des ASA-C69A+pNCS mit einmodelliertem Formylglycinhydrat. Wie in Abbildung 4.8 ist das in vitro-Substrat in der aktiven Tasche der Mutante ASA-C69A dargestellt. Zusätzlich sind in die Strukturkoordinaten von ASA-C69A+pNCS die beiden Hydroxylgruppen des hydratisierten Formylglycin 69 aus dem Modell der wt-ASA modelliert (OY: pink). 
Das Magnesiumion wird im Wildtyp-Modell verzerrt oktaedrisch von 6 Sauerstoffatomen koordiniert. Die äquatorialen Sauerstoffatome (von D30, FGly69 und D281) des Oktaeders liegen nahezu in einer Ebene. Der Winkel zwischen D281O 11 und D281082 ist sehr klein $\left(51,9^{\circ}\right)$. Die beiden Winkel zwischen den Sauerstoffatomen von D281 und den benachbarten Sauerstoffatomen von FGly69 und D30 liegen im Bereich, welcher für einen Oktaeder erwartet wird $\left(90^{\circ}\right)$. Im Gegensatz dazu liegt der Wert des Winkels zwischen FGly69O $\gamma 1$ und D300 $\delta$ mit 120,3 deutlich über dem erwarteten Wert. Die axialen Sauerstoffatome (von D29 und N282) besitzen einen Winkel von 161,0 zu einander, sie sind in Richtung zum D281 verschoben. Die Ladung des $\mathrm{Mg}^{2+}$-lons ist nicht von allen Seiten gleichmäßig abgesättigt, im Bereich zwischen FGly690 $\gamma 1$ und D30O $\delta$ liegt eine Lücke in der Koordinationssphäre vor. Dort liegt im Modell von ASAC69A $+p N C S$ das koordinierte Substrat-Sauerstoffatom. Für das Kation ergibt sich so eine gleichmäßige Koordinierungsumgebung, die als pentagonale Bipyramide beschrieben werden kann.

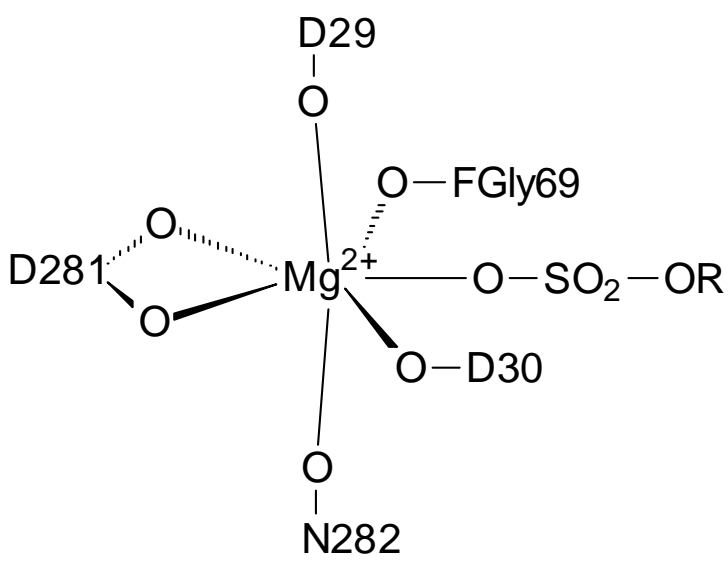

\begin{tabular}{|l|l|}
\hline $\begin{array}{l}\text { O-Atome der Amino- } \\
\text { säuren und des } p \mathrm{NCS}\end{array}$ & $\begin{array}{l}\text { Winkel } \\
\mathrm{O}^{-\mathrm{Mg}^{2+}-\mathrm{O}}\left[^{\circ}\right]\end{array}$ \\
\hline FGly69 - D30 & 120,3 \\
\hline FGly69 - pNCS & 40,6 \\
\hline$p N C S-D 30$ & 82,5 \\
\hline D30 - D281 1 & 99,5 \\
\hline D281 1 - D281 & 51,9 \\
\hline D281 2 - FGly69 & 87,9 \\
\hline D29 - N282 & 161,0 \\
\hline
\end{tabular}

Abbildung 4.10: Koordinationssphäre des Magnesiumions und Winkel zu den koordinierten Sauerstoffatomen.

Weitere Kräfte, die das Substrat in einer Position fixieren, in der eine Reaktion zwischen Enzym und Sulfat stattfinden kann, sind sicherlich auch Wechselwirkungen des Enzyms zum restlichen Teil des Substrates. Der Arylrest des hier untersuchten in vitroSubstrates liegt in zwei Positionen fehlgeordnet vor: Orientierung A $(60 \%)$ bzw. Orientierung $B(40 \%)$. In der Orientierung A wird der Arylrest nur durch eine einzige Wasserstoffbrücke in seiner Position gehalten. Es handelt sich dabei um eine Wechselwirkung der protonierten $\varepsilon$-Aminogruppe des Arginins 288 zum negativ geladenen Nitro-Sauerstoffatom im Abstand von 2,3 $\AA$ Die Orientierung von Teil B 
(40\%) wird durch die Anziehungskräfte beider Sauerstoffatome des Aspartats 152 (2,6 und $2,8 \AA$ ) zur Hydroxylgruppe des Arylrestes gefestigt. Hydrophobe Wechselwirkungen, die vom aromatischen Ring ausgehen, können nicht gefunden werden.

Wie der Rest des natürlichen Substrats, zum Beispiel Cerebrosid-3-Sulfat (vgl. Abbildung 1.2) in die Enzymtasche paßt und welche Wechselwirkungen er eingeht, kann nur grob spekuliert werden. Ein Unterschied des natürlichen Substrats zum in vitro-Substrat ( $p N C S$ ) ist, daß sich der Sulfatester an einem sesselförmigen Zuckerring befindet im Gegensatz zum planaren Phenylring in pNCS. Diese Unterschiede in der Geometrie der Substrate sind offensichtlich und die Anordnung der Atome somit nicht übertragbar. Es ist aber anzunehmen, daß die Wechselwirkungen, die die Hydroxylgruppen beider Substratreste eingehen, qualitativ ähnlich sind.

Die Hydroxylgruppen des Zuckers könnten zusätzlich zu den Seitenketten von Arginin 288 und Aspartat 152 auch noch mit Seitenketten von Histidin 405, Glutamin 153 oder Aspartat 173 interagieren. Die etwas weiter entfernten Alkylketten könnten mit hydrophoben Aminosäuren wie Leucin 68, Valin 91 oder Valin 93 wechselwirken. 


\subsubsection{Gewinnung der gereinigten ASA-C69S}

Immortalisierte MEF-Zellen, die ASA-C69S überexprimieren, wurden von M. Recksieck (Abteilung Biochemie II, Universität Göttingen) zur Verfügung gestellt [Recksieck et al., 1998]. Diese Zellen sezernieren aufgrund ihrer Defizienz von MPR-Rezeptoren den größten Teil der überexprimierten, neusynthetisierten ASA-Mutante in das Zellkulturmedium [Pohlmann et al., 1995]. Die Zellen wurden auf $14 \mathrm{~cm}$-Zellkulturplatten in Kultur gehalten und das Medium für die Reinigung der ASA-C69S gesammelt. In einem Dotblot, der die ASA über einen polyklonalen Antikörper gegen wt-ASA detektiert, wurde die Produktion der ASA-C69S überprüft. Die Expressionsrate betrug etwa $1,8 \mu \mathrm{g} / \mathrm{ml}$ Medium in 48 Stunden. Aus den Zellkulturüberständen wurde das Protein mit Ammoniumsulfat gefällt, gegen TBS-Puffer dialysiert und über Immunoaffinitätschromatographie gereinigt.

Die Reinheitskontrolle wurde mit Hilfe der SDS-Gelelektrophorese und anschließender Coomassiefärbung durchgeführt (Abbildung 4.11A). Da noch Spuren von Verunreinigungen $z u$ sehen waren, wurde als weiterer Reinigungsschritt eine Gelfiltration an einer FPLC-Anlage durchgeführt (Abbildung 4.11B). Die eluierte ASA enthielt keine Verunreinigung und konnte mit Hilfe eines polyklonalen Antikörpers gegen wt-ASA in einem Westernblot eindeutig identifiziert werden (Abbildung 4.11C).

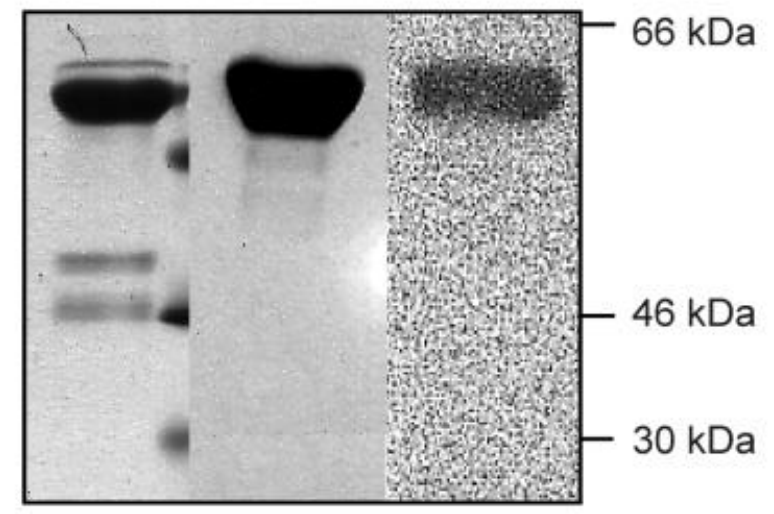

A $\quad$ B $\quad$ C

Abbildung 4.11: Analyse der gereinigten ASA-C69S. ASA-C69S wurde nach der Reinigung in einem $10 \%$ igen SDS-Polyacrylamidgel aufgetrennt und mit kolloidalem Coomassie gefärbt $(A+B)$. Die linke Spur des Coomassiegels zeigt die Probe vor der FPLC-Reinigung (A), die rechte die endgültig gereinigte ASA-C69S (B). Die Identifizierung erfolgte mit einem polyklonalen Antikörper im Westernblot (C).

Die gereinigte Mutante ASA-C69S zeigte eine Sulfataseaktivität von weniger als $0,1 \mathrm{U} / \mathrm{mg}$, wie sie auch für die von M. Recksieck eingesetzte Mutante gemessen wurde [Recksieck et al., 1998]. Insgesamt konnten so aus 6,8 I Zellkulturüberständen 10,4 mg ASA-C69S gereinigt werden. 


\subsubsection{Kristallisation von ASA-C69S und Komplexierung mit pNCS}

Nach einigen Tagen bildeten sich erste kleine Kristalle, die nach zwei bis vier Wochen als farblose Kristalle in Form einer tetragonalen Pyramide oder Bipyramide mit Kantenlängen von bis zu $0,4 \mathrm{~mm}$ vorlagen (Abbildung 4.12). Für die Röntgenstrukturanalyse des Enzym-Substrat-Komplexes wurden Kristalle in Kristallisationspuffer überführt, der zusätzlich $20 \mathrm{mM}$ pNCS enthielt, und darin bei $4^{\circ} \mathrm{C}$ für etwa zwei Stunden getränkt. Diese Kristalle waren danach durch das Substrat gelb gefärbt.

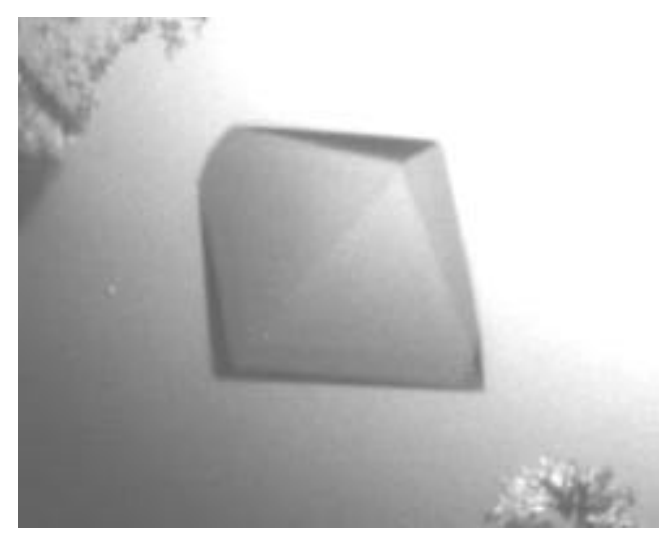

Abbildung 4.12: Kristall der ASA-C69S. Der hier gezeigte Kristall besitzt eine Kantenlänge von 0,4 mm.

Die Kristallisation der gereinigten Mutante ASA-C69S wurde nach dem Protokoll der Kristallisation von ASA-C69A durchgeführt (Gasdiffusionsmethode, hängender Tropfen, $18^{\circ} \mathrm{C}$, PEG6000, pH-Wert 5,3-5,4, s. Abschnitt 4.1.3).

\subsubsection{Datensammlung, Strukturlösung und -verfeinerung von ASA-C69S und von ASA-C69S+pNCS}

Die Kristalle der ASA-C69S wurden jeweils in einer Quarzkapillare an der Beamline X11 am EMBL/DESY in Hamburg bis zu einer Auflösung von 2,40 $\AA$ für ASA-C69S ohne Substrat und 2,65 $\AA$ für den ASA-C69S+pNCS-Komplex (ASA-C69S getränkt mit $p N C S)$ gemessen. Die Mutante kristallisierte in der Raumgruppe 1422 mit ähnlichen Gitterkonstanten zum Wildtyp und zur ASA-C69A, die sich auch durch Tränken der Kristalle nicht ändern. Die Kristallparameter sind in Tabelle 4.3 angegeben. Aufgrund des rapiden Qualitätsverlustes der Meßdaten mit zunehmender Meßdauer, konnte ein kompletter Datensatz für die Struktur von ASA-C69S nur durch Vereinigung der Daten zweier Kristalle erhalten werden. Bei der Messung des getränkten Kristalls war ein geringerer Qualitätsverlust während der Messung zu beobachten, jedoch streuten die Kristalle aufgrund ihrer geringeren Größe schwächer. 
Die Strukturlösung und -verfeinerung, wie auch die Darstellung der Elektronendichten erfolgte nach der gleichen Methode, wie sie in Abschnitt 4.1.4 bereits erläutert wurde (Lösung durch Einsatz der wt-ASA-Koordinaten, Verfeinerung nach „Maximum Likelihood Funktion“, Verfeinerung der B-Faktoren mit restraints, SigmaA-gewichtete $2 \mathrm{mF}_{\mathrm{o}}-\mathrm{DF}_{\mathrm{c}}{ }^{-}$und $\mathrm{mF}_{\mathrm{o}}-\mathrm{F}_{\mathrm{c}}$-Elektronendichtekarten). Die ersten Verfeinerungsschritte wurden ohne Wassermoleküle und ohne die Seitenkette an der Mutationsstelle durchgeführt. Seitenketten, deren Positionen in der Elektronendichte nicht erkennbar waren, wurden aus dem Modell entfernt, die fehlende Schleifenregion (Gly444 Ala447) und der GTerminus (Asp504 - Ala507) konnte wie auch bei ASA-C69A nicht modelliert werden.

Bei der Verfeinerung der Struktur des Komplexes wurde an Stelle der Wassermoleküle, die sich beim Wildtyp im aktiven Zentrum befinden, die Struktur des $p$-Nitrocatecholsulfats (Abschnitt 4.1.2) in das Modell aufgenommen. Da das Substrat aber nicht in der aktiven Tasche verfeinert werden konnte, beziehen sich die hier angegebenen Werte auf eine Verfeinerung, in der sich weder Wasser noch Substrat in der aktiven Tasche befinden.

Bei der Verfeinerung des Strukturmodells wurde stets auf die beiden R-Werte geachtet (s. Abschnitt 4.1.4). Bei diesem Datensatz wurden ebenfalls die gleichen $R_{\text {ree-Reflexe }}$ verwendet wie bei den oben beschriebenen Datensätzen. Der $R_{\text {work }}$-Wert der Datensätze lag am Ende der Verfeinerung jeweils unter 20 bzw. 18\% wobei der $R_{\text {free-Wert mit }}$ 24\% höher lag (Tabelle 4.3). Die geringe Differenz der beiden Gütekriterien in den Strukturen von ASA-C69S und ASA-C69S+pNCS gilt als Indikator für eine jeweils korrekt bestimmte Struktur. Der letzte Verfeinerungszyklus wurde mit 100\% der Reflexe berechnet. Es resultierte ein R-Wert von 19,6\% (für ASA-C69S) bzw. 17,4\% (für ASAC69S $+p N C S)$. 


\begin{tabular}{|c|c|c|}
\hline Verbindung & ASA-C69S & ASA-C69S+pNCS \\
\hline \multicolumn{3}{|l|}{ Kristallparameter } \\
\hline $\begin{array}{l}\text { Gitterkonstanten } \mathrm{a}=\mathrm{b}[\AA] \\
\mathrm{c}[\AA \AA \mathrm{A}] \\
\text { Raumgruppe }\end{array}$ & $\begin{array}{l}131,5 \\
192,0 \\
1422\end{array}$ & $\begin{array}{l}131,8 \\
192,1 \\
1422\end{array}$ \\
\hline \multicolumn{3}{|l|}{ Datenstatistik } \\
\hline Auflösungsbereich $[\AA ̊]$ & $30-2,40$ & $40-2,65$ \\
\hline \begin{tabular}{|l|} 
Anz. der gemessenen Reflexe \\
\end{tabular} & 163833 & 114670 \\
\hline Anz. der unabhängigen Reflexe & 33144 & 24966 \\
\hline Redundanz & 4,9 & 4,6 \\
\hline \begin{tabular}{|l|} 
Vollständigkeit [\%] \\
\end{tabular} & $99,2(98,3)^{\ddagger}$ & $99,8(100,0)^{\ddagger}$ \\
\hline $\mathrm{R}_{\text {sym }}{ }^{*}[\%]$ & $7,5(43,9)^{\ddagger}$ & $7,7(36,4)^{\ddagger}$ \\
\hline$<\mathrm{l} / \sigma(\mathrm{I})>$ & $12,3(3,6)^{\ddagger}$ & $16,6(2,6)^{\ddagger}$ \\
\hline$I>3 \sigma(I)[\%]$ & $73,9(43,1)^{\ddagger}$ & $75,4(43,2)^{\ddagger}$ \\
\hline \multicolumn{3}{|l|}{ Verfeinerungsstatistik } \\
\hline Aminosäuren im Modell & 480 & 480 \\
\hline Anz. d. Proteinatome & 3540 & 3572 \\
\hline Anz. d. Wasser & 171 & 173 \\
\hline Anz. d. sonstigen Atome & 29 & 29 \\
\hline Daten-Parameter-Verhältnis & 2,2 & 1,7 \\
\hline $\mathrm{R}_{\text {work }}-$ Wert $\left(\mathrm{R}_{\text {free }}-\right.$ Wert $)[\%]$ & $19,3(24,3)$ & $17,3(24,3)$ \\
\hline R-Wert ** [\%] & 19,6 & 17,4 \\
\hline $\begin{array}{l}\text { Mittlerer Temperaturfaktor <B> } \\
\text { HK / SK / LM }\left[\AA^{2}\right]\end{array}$ & $38,1 / 39,2 / 42,8$ & $37,5 / 38,5 / 44,0$ \\
\hline \begin{tabular}{|l} 
Mittlere rms-Abweichung der \\
Bindungslängen [Å]
\end{tabular} & 0,017 & 0,019 \\
\hline $\begin{array}{l}\text { Mittlere rms-Abweichung der } \\
\text { Bindungswinkel }\left[^{\circ}\right]\end{array}$ & 4,0 & 3,2 \\
\hline
\end{tabular}

Tabelle 4.3: Übersicht über wichtige kristallographische Daten und Verfeinerungsdaten der ASA-C69S und des Komplexes ASA-C69S+pNCS. Datenstatistik: Aufgelistet sind die Parameter der für die Verfeinerung des Modells benutzten Synchrotrondatensätze. Die Vollständigkeit, der Anteil der Reflexe mit $\mathrm{I}>3 \sigma(\mathrm{I})$ und der R-Wert für symmetrieäquivalente Reflexe $\mathrm{R}_{\text {sym }}$ sind für jeweils den vollständigen Datensatz sowie in Klammern für die äußere Auflösungsschale $\left({ }^{\ddagger}\right)$ angegeben, d.h. die äußeren $0,1 \AA$ Verfeinerungsstatistik: Der mittlere Temperaturfaktor der Atome ist für sowohl Hauptkettenatome (HK), Seitenkettenatome (SK) und Lösungsmittelatome (LM) angegeben. Abkürzung: rms $=$ root mean square. Definitionen: ${ }^{*}: R_{\text {sym }}=\left(\Sigma\left|I_{h k l}-<I_{h k l}>\right|\right) / \Sigma\left(I_{h k}\right) ;{ }^{*}: R=\left(\Sigma\left|F_{0}-F_{c}\right|\right) / \Sigma\left|F_{0}\right|$ 
Die verfeinerten Datensätze wurden mit dem Programm PROCHECK untersucht [Laskowski et al., 1993]. Die wenigen hierbei gefundenen Abweichungen der Aminosäuren von Standardgeometrien wurden abschließend gesondert kontrolliert. Der Ramachandranplot ist ähnlich zu dem der Struktur von C69A und zeigt bei den Datensätzen, daß 99,2\% aller Hauptkettentorsionswinkel in den bevorzugten und zusätzlich erlaubten Regionen liegen (Abbildung 4.13). Der Ramachandranplot ist für die verfeinerte Struktur von ASA-C69S abgebildet. Für ASA-C69S+pNCS liegen 98,7\% aller Hauptkettentorsionswinkel in den bevorzugten und zusätzlich erlaubten Regionen (nicht gezeigt). Bei den beiden Strukturen liegen 2 bzw. 4 Hauptketten in den großzügiger erlaubten Bereichen. Dies sind Methionin 289 und Cystein 300 sowie bei ASA-C69S+pNCS zusätzlich noch Cys172 und Cys493, welche in der Kristallstruktur jedoch keine auffällige Geometrie zeigen. Wiederum liegt die Geometrie der mit einer Oligosaccharid-Seitenkette verknüpften Aminosäure Asparagin 184 außerhalb der erlaubten Bereiche. Allgemein kann man davon ausgehen, daß bei gut interpretierten Strukturen, die eine Auflösung von mindestens 2,0 A und einem R-Wert von unter 20\% besitzten, über $90 \%$ der Aminosäuren in den bevorzugten Regionen liegen sollten.



Abbildung 4.13: Ramachandranplot der Kristallstruktur von ASA-C69S [Ramachandran \& Sassiekharan, 1968]. Aufgetragen sind die Hauptkettentorsionswinkel $\Phi$ und $\Psi$ eines Monomers der verfeinerten Struktur der ASA-C69S. 85,2\% der Hauptkettentorsionswinkel befinden sich in bevorzugten (dunkelgrau unterlegt: A, B, L), 14,0\% in zusätzlich erlaubten (mittelgrau unterlegt: a, b, I, p) Regionen. 0,5\% der Hauptkettentorsionswinkel (Met289 und Cys300) liegen in großzügiger erlaubten (hellgrau unterlegt: $\sim a, \sim b, \sim 1, \sim p$ ) und 0,3\% (Asn184) in nicht erlaubten Regionen. Glycinreste sind als Dreiecke dargestellt, Nicht-Glycinreste als Quadrate. 


\subsubsection{Strukturbeschreibungen der ASA-C69S und ASA-C69S+pNCS}

Die Kristallstruktur der ASA-C69S sowie der ASA-C69S+pNCS zeigen im gesamten Bereich - ausgenommen in dem Bereich der Mutation - eine innerhalb der Fehlergrenzen [Cruickshank, 1999] identische Struktur zur Struktur der wt-ASA. Wie der Vergleich der Koordinaten der C $\alpha$-Atome in Abbildung 4.14 zeigt, liegen die Abweichungen der C $\alpha$-Atome von ASA-C69S im Vergleich zur wt-ASA im Bereich von 0 bis $0,5 \AA$, was weniger als einem Drittel der Länge einer C-C-Bindung entspricht. Bei der Struktur des mit Substrat getränkten Kristalls sind diese Abweichungen in ähnlichen Größen (nicht gezeigt).

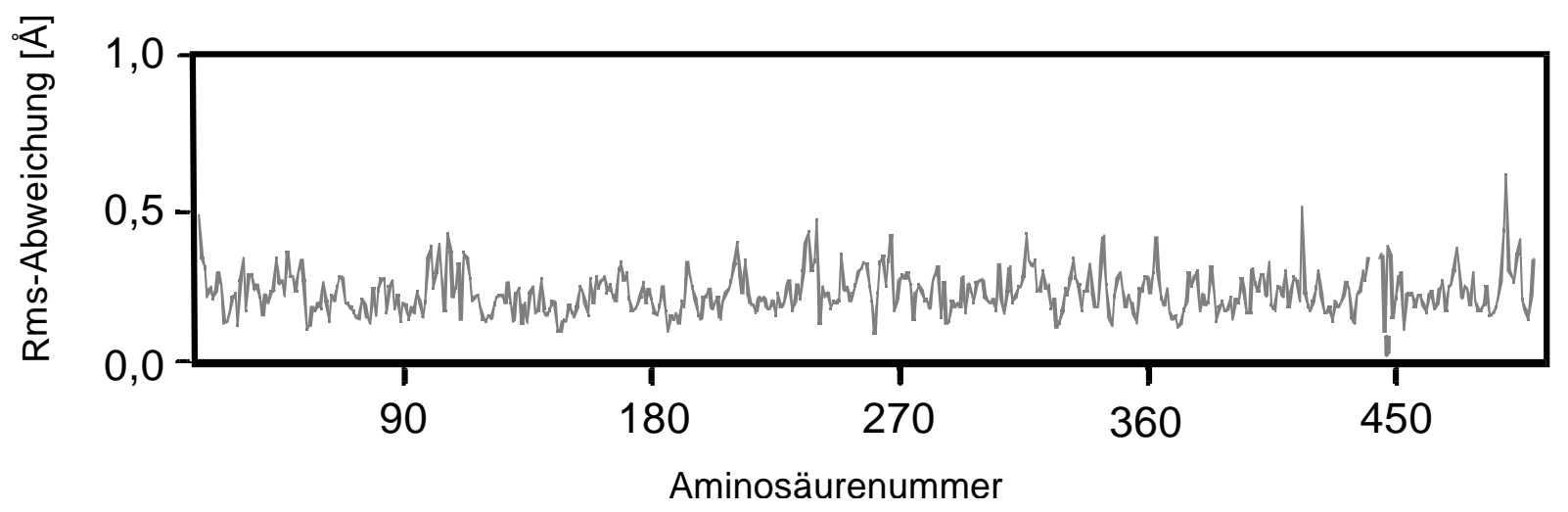

Abbildung 4.14: Rms-Abweichung der Lage der $\mathrm{C} \alpha$-Atome in der ASA-C69S im Vergleich zur wt-ASA.

Die Elektronendichte an Position 69 zeigte in beiden Strukturen sehr deutlich das Vorliegen einer Hydroxylgruppe, welche mit einem Stickstoffatom im benachbarten Histidin-Ring ( $\mathrm{H} 125)$ eine Wasserstoffbrücke bildet (Abstand in beiden Strukturen: 2,7 $\AA ̊$, Abbildung 4.15). Dieser Histidin-Ring ist zusätzlich durch eine Wasserstoffbrücke des zweiten, protonierten Stickstoffatoms zur Carbonylgruppe von Leucin 92 in dieser Position fixiert (Abstand in beiden Strukturen: 2,8 Å). An der Position, an der bei der wtASA eine zweite Hydroxylgruppe vorliegt, welche das Magnesiumion koordiniert, wurde keine Elektronendichte gefunden. Die Seitenkette des Serins liegt also nicht fehlgeordnet in zwei möglichen Positionen vor, sondern bevorzugt die offensichtlich energetisch günstigere Wechselwirkung zum Histidin 125. Dieses Histidin kommt für die Übernahme des Protons bei der Eliminierung des Sulfats des sulfatierten Enzyms in Frage (s. Abschnitt 5) [Waldow et al., 1999]. Die aufgenommene positive Ladung kann im Histidin-Ring delokalisiert werden.

Im aktiven Zentrum der Struktur der nicht-komplexierten Mutante konnten sechs Wassermoleküle gefunden werden. 


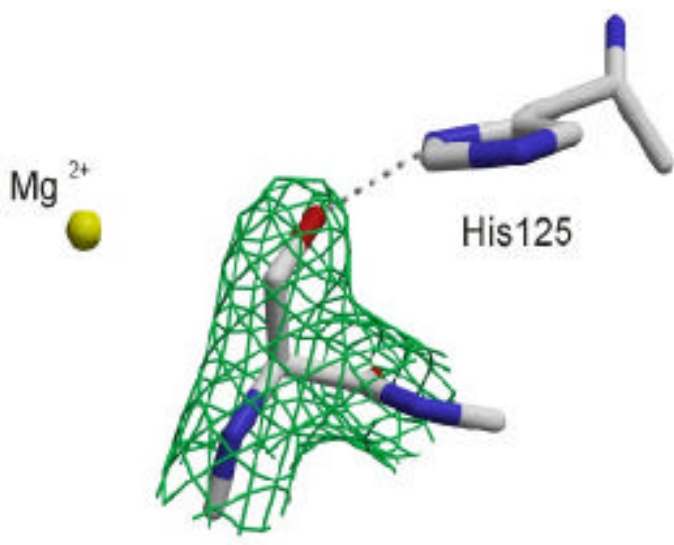

Ser69 in ASA-C69S



FGly69 in wt-ASA

\begin{abstract}
Abbildung 4.15: Struktur der Aminosäure 69 von ASA-C69S im Vergleich zu wt-ASA. Die Hauptsowie die Seitenkette der Aminosäure 69 von ASA-C69S (links) sowie von wt-ASA (rechts) sind dargestellt. In der linken Darstellung ist zusätzlich die gefundene Elektronendichte abgebildet. Die Hydroxylgruppe des Serinrestes liegt deutlich in dieser Elektronendichte und bildet eine Wasserstoffbrückenbindung zum His125 aus. Für die in der Struktur des Wildtyps vorliegende, das Magnesiumion koordinierende Hydroxylgruppe ist in der ASA-C69S keine Elektronendichte zu sehen.
\end{abstract}

In der Enzymtasche des mit pNCS getränkten Kristalls von ASA-C69S befindet sich Restelektronendichte. Diese Elektronendichte hat eine unregelmäßige aber generell kugelförmige Struktur und befindet sich in der Nähe zum Histidin 229, ist aber klar vom Serin 69 entfernt. Da in die Elektronendichte das pNCS nicht gefittet werden konnte, wurde versucht, nur das Sulfat hinein zu modellieren. Eine zufriedenstellende und eindeutige Verfeinerung konnte jedoch nicht durchgeführt werden, so daß das Sulfat wieder aus dem Modell der Struktur entfernt wurde. Die Elektronendichte, die in den mit pNCS getränkten ASA-C69S-Kristallen im aktiven Zentrum gefunden wurde und zunächst nicht interpretiert werden konnte, scheint nach einem Vergleich mit der Elektronendichte des ASA-C69A+pNCS-Komplexes erklärbar zu sein. Es könnte sich hierbei um eine teilweise Besetzung der aktiven Tasche mit $p N C S$ handeln, das in der gleichen Koordination vorliegt wie in ASA-C69A+pNCS. Bei der Auflösung von 2,7 $\AA$ ist das Substrat jedoch nicht gut zu lokalisieren. Das Eindiffundieren des Substrates in den Kristall der Mutante ASA-C69S hat demnach nicht zu dem gewünschten homogenen Vorliegen des Sulfats geführt. 
K123

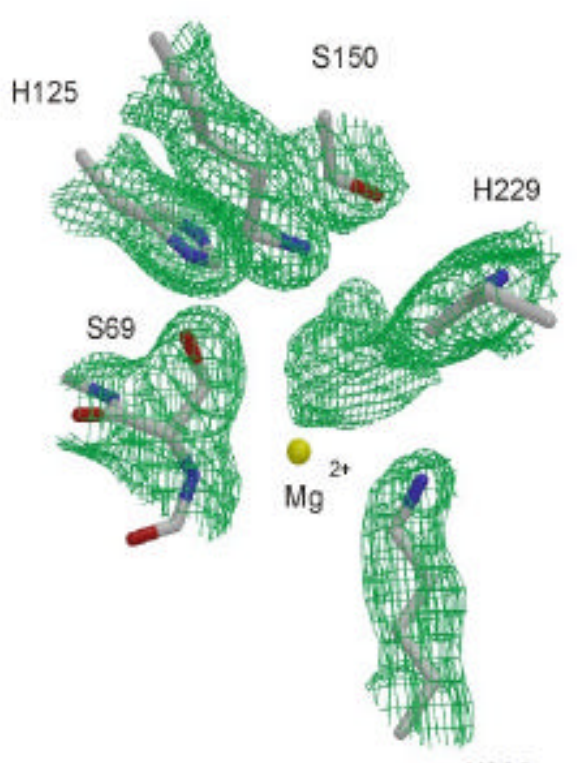

K123

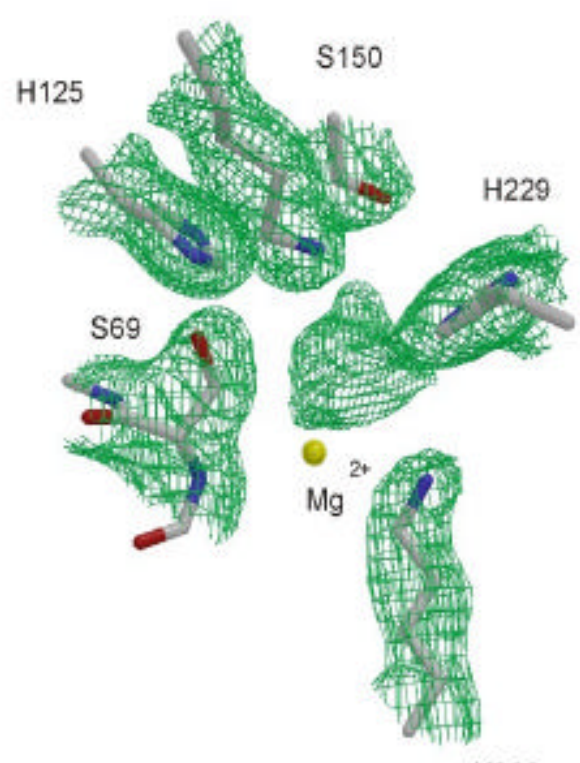

$\mathrm{K} 302$

Abbildung 4.16: Stereoabbildung der Elektronendichte im aktiven Zentrum des mit pNCS getränkten Kristalls der ASA-C69S. Die Haupt- sowie die Seitenkette der Aminosäure S69 sowie die Seitenketten der Aminosäuren K123, H125, S150, H229 und K302 sind mit den gefundenen Elektronendichten bei $3 \sigma$ (grün) dargestellt. In der Mitte der aktiven Tasche befindet sich die Elektronendichte, die jedoch nicht interpretiert werden konnte. Die Elektronendichte um das Magnesiumion (gelb) ist aus Gründen der Übersichtlichkeit nicht dargestellt. (Bei dieser Abbildung handelt es sich um ein 3D-Bild durch Überkreuz-Schielen.) 


\subsection{Die Arylsulfatase A-Mutante ASA-P426L}

Der zweite Teil der vorliegenden Arbeit befaßt sich mit der Mutante ASA-P426L, die $25 \%$ der Fälle von metachromatischer Leukodystrophie verursacht. Durch bisherige Untersuchungen war bekannt, daß das mutierte Enzym in der Zelle synthetisiert und korrekt zu den Lysosomen transportiert wird, wo es jedoch durch Cysteinproteinasen rasch abgebaut wird.

Zunächst sollten die beteiligten Proteinasen und die entsprechenden Spaltstellen in der ASA-P426L bestimmt werden, um anschließend die in vitro-Ergebnisse in einem Zellkultursystem zu bestätigen. Um den strukturellen Zusammenhang zwischen der Mutation und der Instabilität der Sulfatase zu untersuchen, wird im nächsten Abschnitt die Kristallisation und Röntgenstrukturanalyse der Mutante beschrieben. Im letzten Abschnitt werden Experimente zur Oligomerisierung der Mutante gezeigt, die auf den Ergebnissen der Strukturanalyse basieren.

\subsubsection{In vitro-Untersuchung zum Abbau der ASA-P426L durch Cathepsine}

Um die Stabilität von wt-ASA und der Mutante ASA-P426L gegenüber lysosomalen Cysteinproteinasen zu untersuchen, wurden beide Sulfatasen in vitro dem Abbau durch die Cysteinproteinasen Cathepsine L, B, H und $\mathrm{S}$ ausgesetzt. Die gereinigten Cathepsine wurden von Dr. K. Schilling, Universität Jena, und Dr. E. Weber, Universität Halle, bereitgestellt. ASA-P426L bzw. wt-ASA wurden exprimiert und gereinigt wie unter Abschnitt 4.2.4 beschrieben. Nach Inkubation mit den Cathepsinen wurden die ASAFragmente durch SDS-PAGE nachgewiesen.

\subsubsection{Abbau von ASA-P426L und wt-ASA mit Cathepsin L}

Cathepsin $L$ wurde als erste Proteinase auf seinen Einfluß auf die Stabilität der ASAMutante untersucht, da es eine gut charakterisierte Proteinase mit hoher Aktivität ist [Barrett \& Kirschke, 1981; Kirschke et al., 1995].

Erste Vorversuche mit unterschiedlichen Abbaubedingungen deuteten darauf hin, daß ASA-P426L durch Cathepsin L gespalten wird, nicht aber der Wildtyp. Daraufhin wurden gezielt die Parameter Zeit, Temperatur, pH-Wert und Konzentrationsverhältnis von Cathepsin zu Sulfatase untersucht, um die optimalen Abbaubedingungen herauszufinden, wobei Bereiche gewählt wurden, die denen in den Lysosomen nahekommen oder denen, die in in vitro-Untersuchungen mit synthetischen Substraten bestimmt wurden. 
Zunächst wurde ASA-P426L bei $25^{\circ} \mathrm{C}, \mathrm{pH} 4,8$ und verschiedenen Inkubationszeiten mit humanem Cathepsin $L$ in einem molaren Konzentrationsverhältnis von 10:1 (ASA:Cathepsin L) abgebaut (Abbildung 4.17). Nach einer Inkubation von 8 Stunden wurde die Sulfatase auf etwa $43 \%$ abgebaut, wobei ein Fragment von ca. $53 \mathrm{kDa}$ nachgewiesen werden konnte.

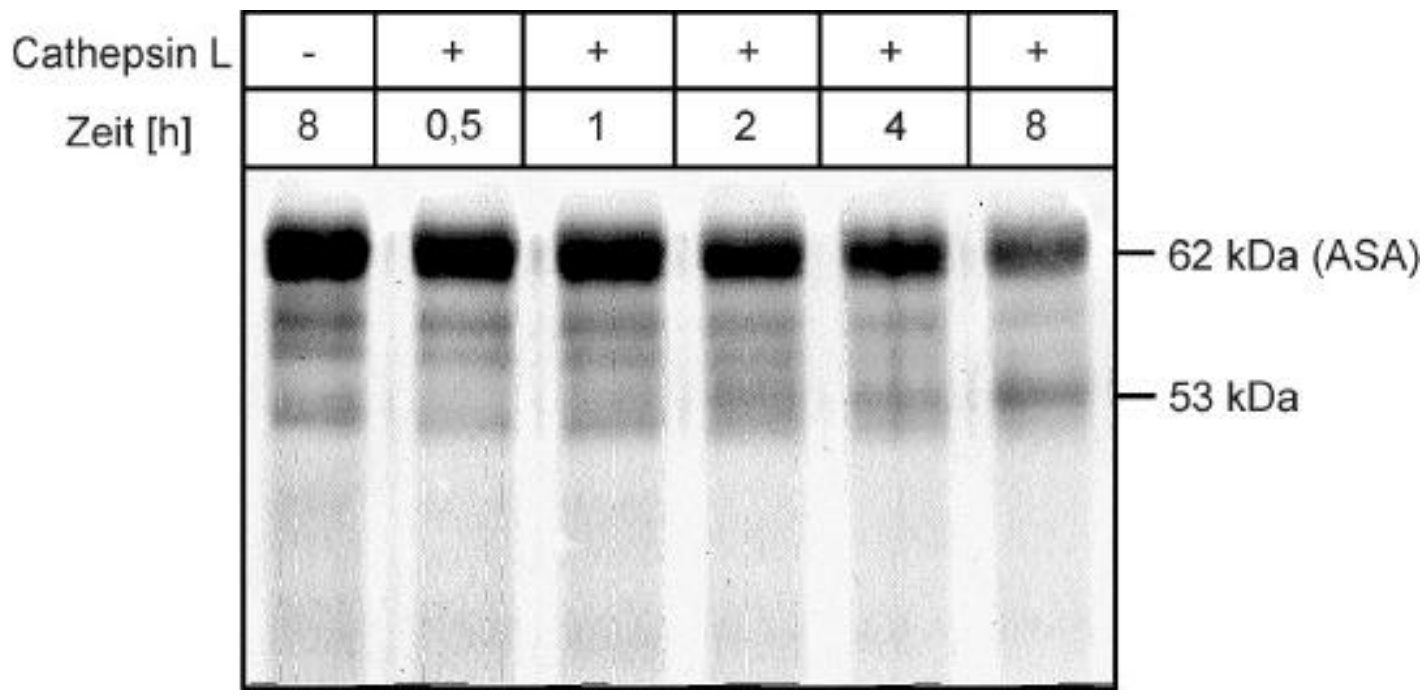

Abbildung 4.17: Zeitabhängigkeit des Verdaus von ASA-P426L mit humanem Cathepsin L. Jeweils $2 \mu \mathrm{g}$ ASA-P426L wurde mit Cathepsin L in einem molaren Verhältnis von 10:1 (ASA:Cath. L) bei pH 4,8 und $25^{\circ} \mathrm{C}$ inkubiert. Nach den angegebenen Zeiten wurde der Verdau durch Zugabe von $2 \%$ SDS im Probenpuffer und Erhitzen für $5 \mathrm{~min}$ auf $95^{\circ} \mathrm{C}$ abgestoppt. Anschließend wurden die Proben über ein $10 \%$ iges SDS-Polyacrylamidgel aufgetrennt und mit Silberfärbung sichtbar gemacht.

Von Cathepsin L war aus Experimenten mit synthetischen Substraten bekannt, daß es bei einer Temperatur von $25^{\circ} \mathrm{C}$ länger aktiv und stabil ist, als bei $37^{\circ} \mathrm{C}$ [Dr. Schilling, Universität Jena, persönliche Mitteilung]. Eine höhere Temperatur erhöht jedoch in der Regel die katalytische Aktivität eines Enzyms. Daher wurde im nächsten Experiment untersucht, bei welcher Temperatur letztlich stärker abgebaut wird. Nach einer 8 stündigen Inkubation von ASA-P426L mit Cathepsin L bei pH 4,8 zeigte sich, daß bei $37^{\circ} \mathrm{C}$ die Sulfatase stärker abgebaut wird (Rest: $12 \%$ ) als bei $25^{\circ} \mathrm{C}$ (Rest: $43 \%$ ), sichtbar am Verschwinden der $62 \mathrm{kDa}$-Bande und dem Auftauchen des $53 \mathrm{kDa}$ Fragments (Abbildung 4.18). Die folgenden Experimente wurden daher bei $37^{\circ} \mathrm{C}$ durchgeführt. 


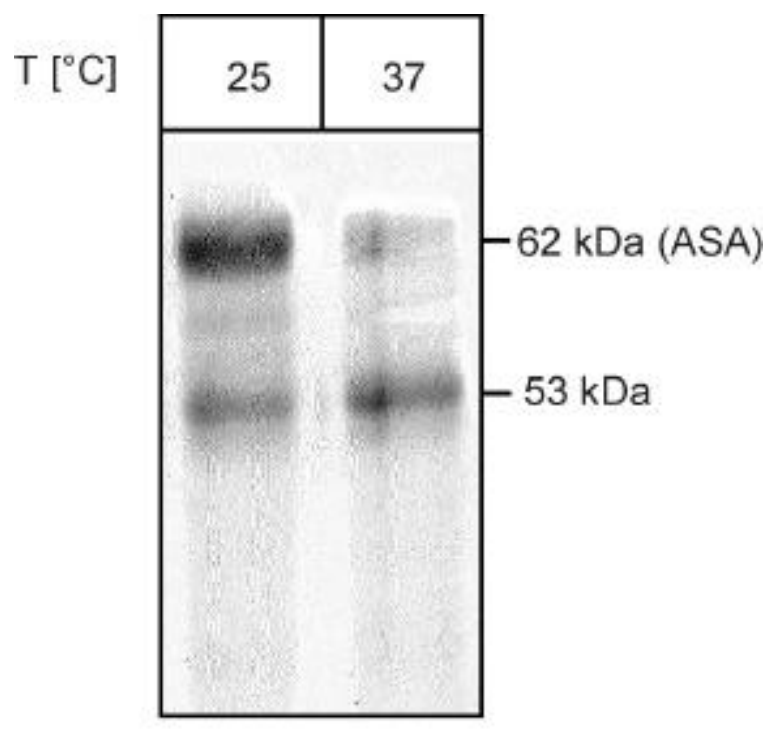

Abbildung 4.18: Temperaturabhängigkeit des Verdaus von ASA-P426L mit humanem Cathepsin L. Je $2 \mu \mathrm{g}$ ASA-P426L wurde für $8 \mathrm{~h}$ bei $\mathrm{pH} 4,8$ mit humanem Cathepsin $\mathrm{L}$ in einem molaren Verhältnis von 10:1 (ASA:Cath. L) verdaut. Die Reaktionen wurden bei $25^{\circ} \mathrm{C}$ (links) bzw. bei $37^{\circ} \mathrm{C}$ (rechts) durchgeführt und durch Aufkochen mit 2\% SDS im Probenpuffer abgestoppt. Nach Auftrennung in einem 10\%igen SDS-Polyacrylamidgel wurden die Proteine durch Silberfärbung angefärbt.

Im nächsten Experiment wurde der pH-Wert variiert. Wie Abbildung 4.19 zeigt, fand nach 8 stündiger Inkubation bei $37^{\circ} \mathrm{C}$ und einem pH-Wert von 6,5 und 6,0 kein signifikanter Abbau statt, wohl aber bei einem pH von 5,5 und, stärker noch, bei pH 4,8. Dieser Befund steht wiederum im Gegensatz zu dem der Untersuchungen von Cathepsin $L$ mit synthetischen Substraten, die zeigten, daß dort der optimale Abbau bei pH 6,5 stattfindet [Dr. K. Schilling, Universität Jena, persönliche Mitteilung]. Der pHWert von 4,8, der auch dem lysosomalen $\mathrm{pH}$-Wert entspricht, erweist sich für den Abbau der ASA-Mutante als besonders günstig. Um auch kleinere Fragmente mit hoher Sensitivität zu detektieren, wurde bei diesem Ansatz zur Auftrennung ein 15\%iges MiniPolyacrylamidgel $(0,5 \mathrm{~mm}$ Geldicke) gewählt. Dadurch konnten nach dem Abbau neben dem 53 kDa-Fragment zwei weitere Fragmente mit der Masse von 30 und 9 kDa nachgewiesen werden. 


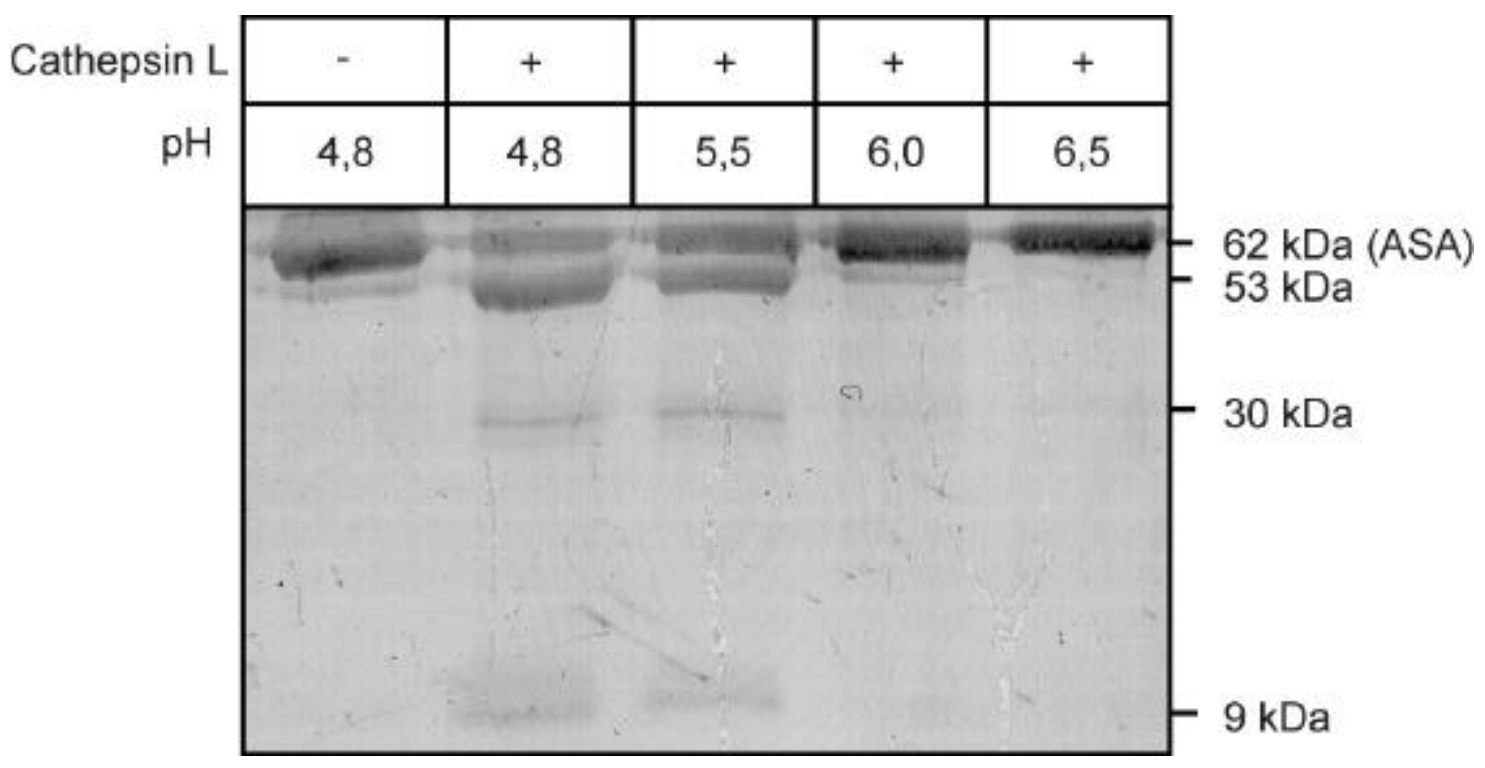

Abbildung 4.19: pH-Wert-Abhängigkeit des Verdaus von ASA-P426L mit humanem Cathepsin L. Der Verdau von ASA-P426L mit humanem Cathepsin $\mathrm{L}$ wurde bei $37^{\circ} \mathrm{C}$ und unterschiedlichen $\mathrm{pH}$-Werten durchgeführt. Das molare Konzentrationsverhältnis betrug 10:1 (ASA:Cath. L). Jeweils $2 \mu \mathrm{g}$ ASA-P426L wurden nach $8 \mathrm{~h}$ Verdau in Probenpuffer (2\% SDS) aufgenommen und aufgekocht. Das 15\%ige SDSPolyacrylamid-Minigel wurde mit kolloidalem Coomassie angefärbt.

Für die bisherigen Abbauten war ein molares Konzentrationsverhältnis von ASA zu Cathepsin $L$ von 10:1 gewählt worden. Im folgenden Experiment wurden verschiedene Konzentrationsverhältnisse getestet (Abbildung 4.20). Nur die höchste eingesetzte Konzentration von Cathepsin L (ASA:Cath. $L=4: 1$ ) führte zu einem Abbau von ASA nach 8 Stunden.

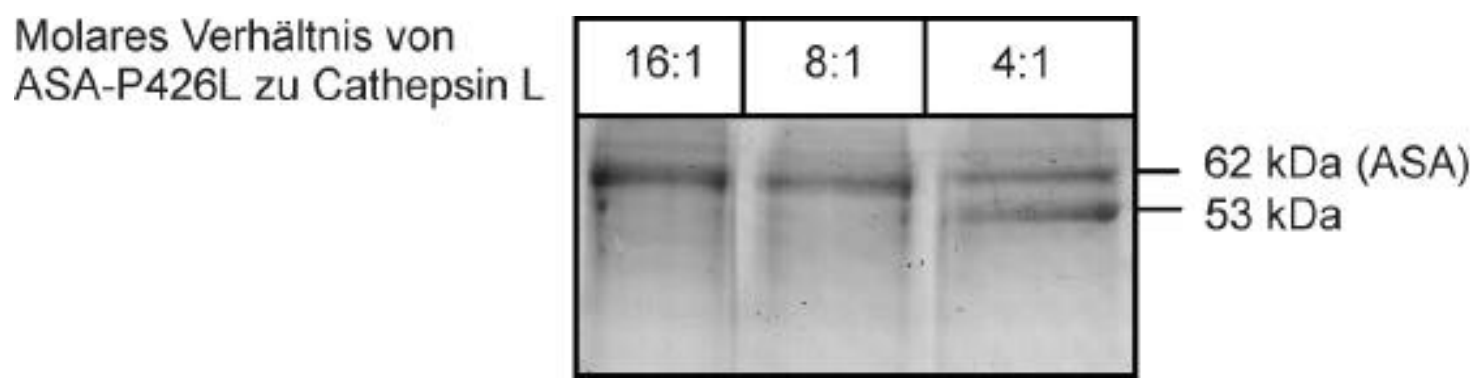

Abbildung 4.20: Abhängigkeit des Verdaus vom molaren Verhältnis von ASA-P426L zu humanem Cathepsin L. Die Inkubation von $2 \mu \mathrm{g}$ ASA-P426L mit humanem Cathepsin L fand für $8 \mathrm{~h}$ bei pH 4,8 und $37^{\circ} \mathrm{C}$ statt. Die molaren Konzentrationsverhältnisse von Cathepsin $\mathrm{L}$ zu ASA wurden variiert. Anschließend wurden die Proben in $2 \%$ SDS-haltigem Probenpuffer aufgenommen, für 5 min bei $95^{\circ} \mathrm{C}$ inkubiert und über ein 15\%iges SDS-Polyacrylamid-Minigel aufgetrennt. Die Proteinfärbung erfolgte mit kolloidalem Coomassie. 
Die Beobachtung, daß bei einem Konzentrationsverhältnis von 4:1 ein Abbau stattfand, der dem der vorherigen Experimente bei einem Verhältnis von 10:1 entspricht, kann dadurch erklärt werden, daß für diesen Abbau eine andere Charge Cathepsin L verwendet werden mußte, die gegenüber ASA-P462L weniger aktiv war.

Bei den optimierten Bedingungen $\left(37^{\circ} \mathrm{C}, \mathrm{pH} 4,8\right.$, ASA:Cathepsin $\left.\mathrm{L}=4: 1\right)$ wurde nun geprüft, ob die Spaltung der ASA-Mutante durch Cathepsin L selektiv ist oder ob die wtASA unter diesen Bedingungen auch gespalten wird. Es zeigte sich deutlich, daß der Wildtyp unter diesen Bedingungen nicht angegriffen wurde, wohl aber die Mutante Abbildung 4.21). Der selektive Verdau der ASA-Mutante durch Cathepsin L im Gegensatz zum Wildtyp konnte auch unter anderen Temperatur- und pH-Bedingungen bestätigt werden (Daten nicht gezeigt). Cathepsin L kommt daher als Proteinase (oder eine der Proteinasen) in Frage, die für die Instabilität der ASA-P426L in den Lysosomen verantwortlich ist.

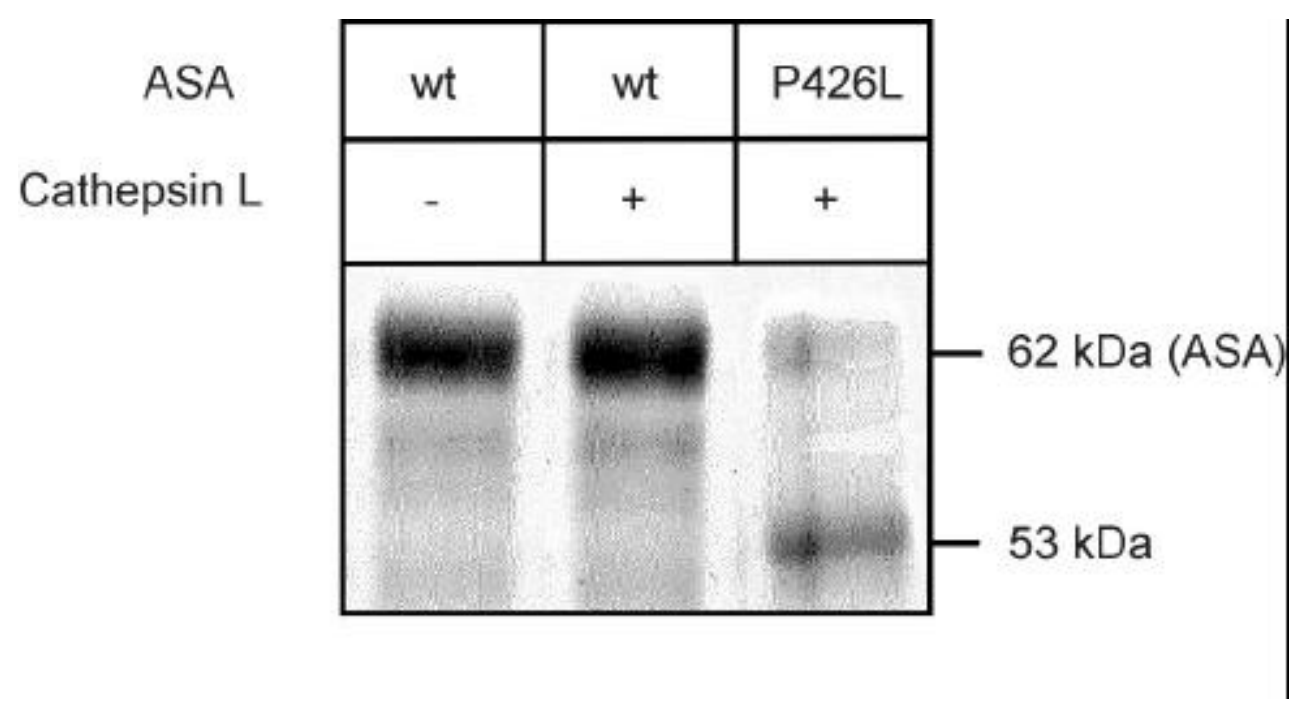

Abbildung 4.21: Verdau von wt-ASA und ASA-P426L mit humanem Cathepsin L. Der Abbau von jeweils $3 \mu \mathrm{g}$ ASA mit humanem Cathepsin $\mathrm{L}$ in einem molaren Verhältnis von ASA:Cath. $\mathrm{L} .=4: 1$ wurde bei $\mathrm{pH} 4,8$ und $37^{\circ} \mathrm{C}$ für $8 \mathrm{~h}$ durchgeführt. Die Proben wurden anschließend über ein $10 \%$ iges SDSPolyacrylamidgel aufgetrennt und mit Silber gefärbt.

\subsubsection{Verdau von ASA-P426L und wt-ASA mit Cathepsin B}

Die Cysteinproteinase Cathepsin B gehört neben Cathepsin L zu den aktivsten Proteinasen des Lysosoms. Daher sollte ihr Einfluß auf die Stabilität von ASA untersucht werden. Da kein humanes Cathepsin B zur Verfügung stand, wurde Cathepsin B aus Ratte verwendet, welches ähnliche Spalteigenschaften zeigt wie das menschliche Enzym [Barrett \& Kirschke, 1981]. Als Reaktionsbedingungen wurden die gleichen verwendet, die sich beim Verdau mit Cathepsin $\mathrm{L}$ als optimal herausgestellt hatten, nämlich eine Inkubationstemperatur von $37^{\circ} \mathrm{C}$, ein $\mathrm{pH}$-Wert von 4,8 und eine Inkubationsdauer von 8 Stunden. 
Das Ergebnis der elektrophoretischen Auftrennung nach dem Verdau mit Cathepsin B zeigt eine Verringerung der Intensität der ASA-Bande bei $62 \mathrm{kDa}$ sowohl bei ASAP426L als auch, etwa in gleichem Maße, bei wt-ASA (Abbildung 4.22). Die ASA wurde also in beiden Fällen etwa gleich stark abgebaut. Es werden jeweils zwei Fragmente gebildet mit einer Größe von $37 \mathrm{kDa}$ und 28 kDa (Cathepsin B selbst zeigt im Gel zwei Banden, eine bei $20 \mathrm{kDa}$ und eine schwächere bei $29 \mathrm{kDa}$ ). Da die im Gel gefundenen Abbaumuster von wt-ASA und ASA-P426L keinen Unterschied aufweisen, spricht dieses Ergebnis dagegen, daß Cathepsin B für die selektive Instabilität von ASA-P426L in den Lysosomen verantwortlich ist.



Abbildung 4.22: Verdau von ASA-P426L und wt-ASA mit Cathepsin B (aus Ratte). Von ASA-P426L und wt-ASA wurden jeweils $3 \mu \mathrm{g}$ mit Cathepsin B (Ratte) in einem molaren Verhältnis on 2:1 versetzt und diese für $8 \mathrm{~h}$ bei $\mathrm{pH} 4,8$ und $37^{\circ} \mathrm{C}$ inkubiert. Die Ansätze wurden in $2 \%$ SDS (Probenpuffer) aufgenommen und für $5 \mathrm{~min}$ bei $95^{\circ} \mathrm{C}$ aufgekocht. Über ein $10 \%$ iges Polyacrylamidgel mit anschließender kolloidaler Coomassiefärbung wurden die Proben aufgetrennt und sichtbar gemacht.

\subsubsection{Verdau der ASA-P426L und der wt-ASA mit den Cathepsinen H und S}

Humanes Cathepsin $\mathrm{H}$ und humanes Cathepsin $\mathrm{S}$ wurden unter den bei den Versuchen mit Cathepsin $\mathrm{L}$ und $\mathrm{B}$ verwendeten Bedingungen für den Abbau von ASA eingesetzt. Es zeigte sich, daß durch Cathepsin $\mathrm{H}$ kein Abbau stattfand, weder beim Wildtyp noch bei der Mutante, denn die Intensitäten der 62 kDa-Banden auf dem SDS-Gel blieben im Vergleich zur unverdauten Probe gleich stark, und es wurden keine Fragmente gebildet. Die schwachen Banden bei etwa 28 kDa werden durch das Cathepsin $\mathrm{H}$ verursacht. Der Wildtyp und die Mutante verhalten sich in diesem Falle gleich und werden nicht gespalten. 


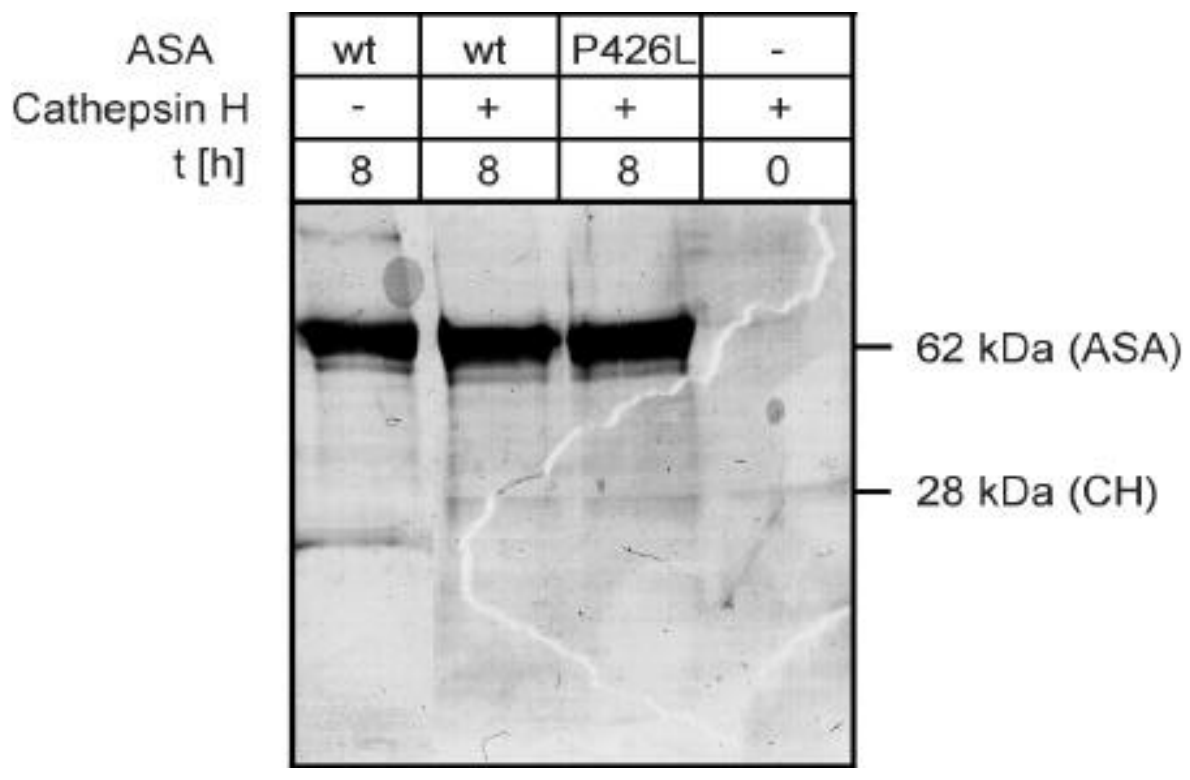

Abbildung 4.23: Verdau von ASA-P426L und wt-ASA mit humanem Cathepsin H. Diese Abbildung zeigt das Ergebnis der 8 stündigen Inkubation von $3 \mu \mathrm{g}$ ASA (Wildtyp und Mutante) mit humanem Cathepsin $\mathrm{H}$ bei $37^{\circ} \mathrm{C}$ und $\mathrm{pH}$ 4,8. Das molare Verhältnis von ASA zu Cath. $\mathrm{H}$ betrug 2:1. Das mit kolloidalem Coomassie gefärbte 10\%ige SDS-Polyacrylamidgel zeigt, daß kein Abbau der ASA durch Cathepsin $\mathrm{H}$ stattgefunden hat.

Auch beim Verdau mit humanem Cathepsin S wurde die ASA-Mutante nicht angegriffen (Abbildung 4.24). Die im Gel zusätzlich gefundenen Banden stammen aus dem Cathepsin S (nicht gezeigt). In diesem Ansatz wurde in einem molaren Überschuß von 8:1 der ASA über Cathepsin $S$ gearbeitet, da nicht mehr Cathepsin $S$ zur Verfügung stand.

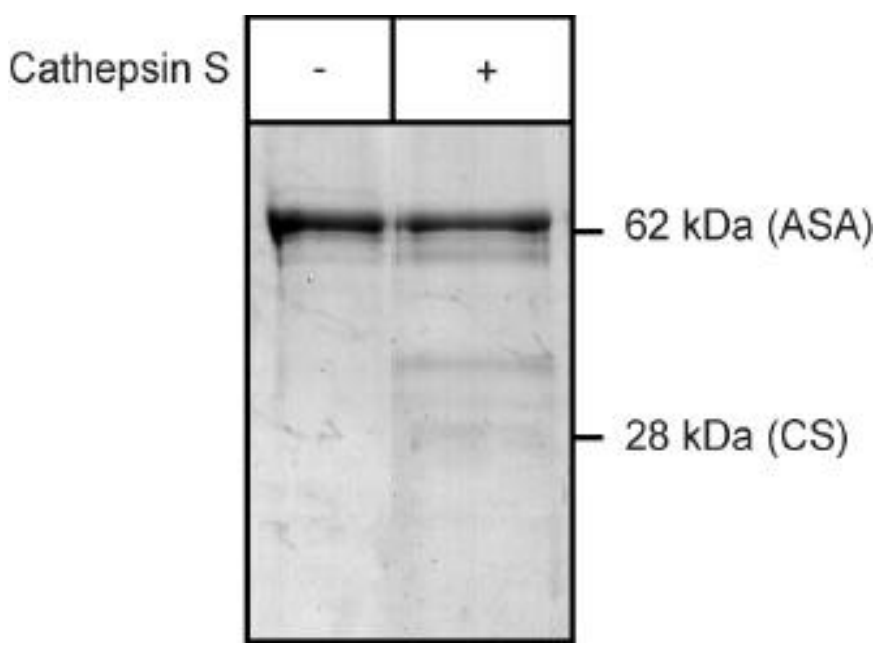

Abbildung 4.24: Verdau von ASA-P426L mit humanem Cathepsin S. Der Verdau von $1 \mu \mathrm{g}$ ASA-P426L mit humanem Cathepsin $S$ in einem molaren Verhältnis von 8:1 wurde unter Inkubationsbedingungen durchgeführt, die den für Cathepsin $\mathrm{H}$ beschriebenen entsprachen.

Die Fähigkeit der verwendeten Chargen von Cathepsin H und S Protein abzubauen, wurde durch den Abbau von denaturiertem BSA gezeigt. Nach einem Verdau von denaturiertem und reduktiv carboxymethyliertem BSA mit beiden Cathepsinen konnte durch SDS-Gelelektrophorese ein völliges Verschwinden der Banden bei 66 kDa (BSA) 
gezeigt werden (Abbildung 4.25). Folglich handelte es sich bei den eingesetzten Proteasen um aktive Enzyme, die denaturiertes BSA, nicht aber die ASA abbauen konnten.

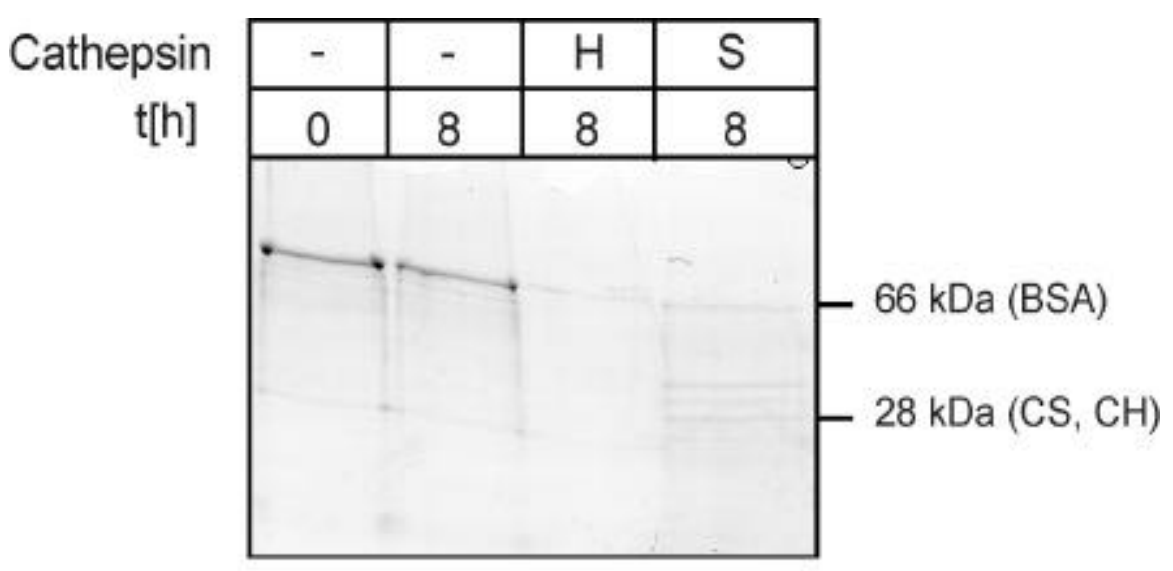

Abbildung 4.25: Verdau von reduktiv carboxymethyliertem BSA mit den Cathepsinen H und S. Bei $37^{\circ} \mathrm{C}$ und einem pH-Wert von 4,8 wurde jeweils $1 \mu \mathrm{g}$ reduktiv carboxymethyliertes BSA mit den Cathepsinen $\mathrm{H}$ und $\mathrm{S}$ inkubiert (molare Verhältnisse wie beim Verdau mit ASA, d.h. BSA:Cath. $\mathrm{H}=2: 1$ und BSA:Cath. $S=8: 1$ ). Die Proben wurden über ein 10\%iges SDS-Polyacrylamidgel aufgetrennt und mit kolloidalem Coomassie gefärbt.

Zusammenfassend zeigen diese Experimente, daß von den vier hier untersuchten Cysteinproteinasen in vitro nur Cathepsin $\mathrm{L}$ zwischen ASA-P426L und wt-ASA differenziert, indem es die Mutante angreift, nicht aber den Wildtyp, während die Cathepsine H, S und B unter den gewählten Bedingungen beide Sulfatasen entweder überhaupt nicht (Cathepsin $\mathrm{H}$ und $\mathrm{S}$ ) oder in gleicher Weise abbauen (Cathepsin B). Dies deutet darauf hin, daß von den hier untersuchten Proteinasen in erster Linie Cathepsin L für die geringere Stabilität der ASA-P426L verantwortlich zu sein scheint.

\subsubsection{Einfluß von Cathepsin L auf die Stabilität der ASA-P426L im Zellkultur- System}

Nachdem gezeigt werden konnte, daß Cathepsin L in vitro ASA-P426L spaltet, während wt-ASA nicht angegriffen wird, wurde versucht, die spezifische Spaltung durch Cathepsin $L$ in Zellen nachzuweisen.

Aus einer in der Literatur beschriebenen Untersuchung zur Stabilität von ASA in humanen Hautfibroblasten von MLD-Patienten war bekannt, daß metabolisch markierte endogene ASA-P426L im Vergleich zu wt-ASA in gesunden Zellen eine geringere Stabilität besitzt, die aber mit Cysteinproteinase-Inhibitoren wiederum erhöht werden konnte [von Figura et al., 1983 \& 1986]. 
Diese Ergebnisse konnten in Experimenten bestätigt werden, in denen die Stabilität metabolisch markierter ASA-P426L nach Endocytose in Fibroblasten gemessen wurde. Hierfür wurden Zellen, die ASA-P426L überexprimieren, mit $\left[{ }^{35} \mathrm{~S}\right]$ Methionin markiert. Die $\left[{ }^{35}\right.$ S]Methionin-markierte Sulfatase wurde aus dem Medium mit Ammoniumsulfat gefällt und gegen Zellkulturmedium dialysiert. Konfluente Platten mit humanen Hautfibroblasten wurden für 16 Stunden mit $\left[{ }^{35}\right.$ S]ASA-P426L in DMEM-Medium mit oder ohne dem für Cysteinproteinasen spezifischen Inhibitor CBZ-Phe-Ala-CHN $\mathrm{N}_{2}$ inkubiert. Die endocytierte $\left[{ }^{35}\right.$ S]ASA wurde anschließend aus den Fibroblastenzellen immunpräzipitiert, gelelektrophoretisch aufgetrennt, mittels Phosphoimaging sichtbar gemacht und quantifiziert.

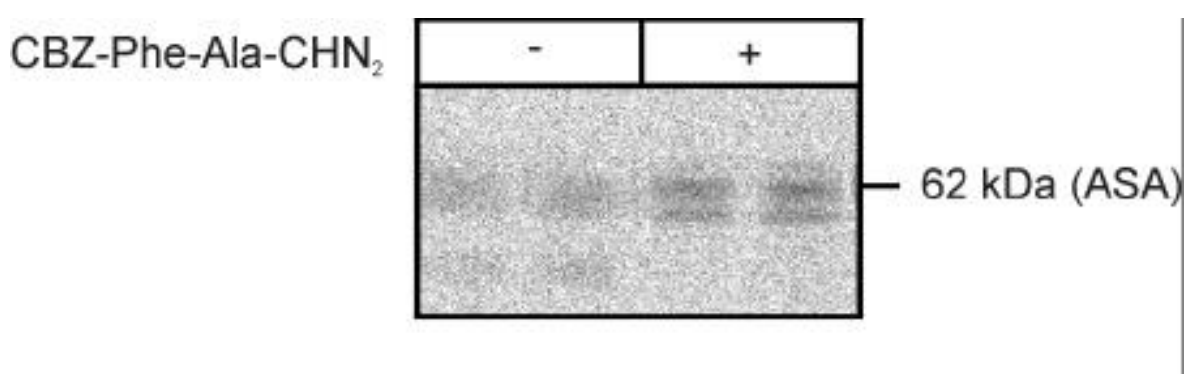

Abbildung 4.26: Stabilität endocytierter $\left.{ }^{35} \mathrm{~S}\right]$ ASA-P426L in humanen Hautfibroblasten. Nach $16 \mathrm{~h}$ Endocytose von $\left[{ }^{35}\right.$ S]ASA-P426L in humane Hautfibroblasten mit und ohne Cysteinproteinase-Inhibitor wurden die Zellen geerntet und die ASA durch Immunpräzipitation und SDS-Gelelektrophorese gereinigt. Gezeigt sind jeweils Doppelwerte nach Phosphoimaging.

\begin{tabular}{l||c|c}
\multicolumn{1}{l||}{ Endocytose } & \multicolumn{2}{c}{ Menge an $\left[{ }^{35} \mathrm{~S}\right] \mathrm{ASA}-\mathrm{P} 426 \mathrm{~L}[\mathrm{\%}]$ (Doppelwerte [Pixel]) } \\
\hline \hline & ohne CBZ-Phe-Ala-CHN & mit CBZ-Phe-Ala-CHN \\
\hline Experiment 1 & $58 \%(283 ; 369)$ & $100 \%(568 ; 560)$ \\
\hline Experiment 2 & $48 \%(388 ; 312)$ & $100 \%(896 ; 582)$ \\
\hline
\end{tabular}

Tabelle 4.4: Quantifizierung endocytierter $\left[{ }^{35} \mathrm{~S}\right] \mathrm{ASA}-\mathrm{P} 426 \mathrm{~L}$ in humanen Hautfibroblasten. Die beiden Tabellenzeilen entsprechen den Quantifizierungsergebnissen jeweils von Doppelwerten (in Klammern) von zwei verschiedenen Experimenten. Das experimentelle Vorgehen und eine Phosphoimaging-Darstellung sind in Abbildung 4.26 gezeigt. Die Werte bei Anwesenheit des Inhibitors wurden auf $100 \%$ gesetzt.

Das Ergebnis zeigt in Übereinstimmung mit den bisherigen Experimenten, daß in Hautfibroblasten die $\left[{ }^{35}\right.$ S]ASA-P426L durch den Cysteinproteinase-Inhibitor stabilisiert wird (Abbildung 4.26, Tabelle 4.4). Nach einer Inkubationszeit von 16 Stunden sind ohne Inhibitor nur $48-58 \%$ der Menge an $\left[{ }^{35}\right.$ SJASA-P426L nachweisbar, die in Anwesenheit des Inhibitors gefunden wurden (100\%). 
Um die Beteiligung von Cathepsin L am Abbau von ASA-P426L in Zellen nachzuweisen, wurden Experimente mit MEF-Zellen durchgeführt, die für Cathepsin $L$ defizient sind. Diese Zellen wurden von Dr. W. Roth, Universität Freiburg, zur Verfügung gestellt. Konfluente Cathepsin L-defiziente MEF-Zellen (MEF -/-) sowie Kontrollzellen (MEF $+/+$ ) wurden mit $\left[{ }^{35}\right.$ S]ASA-P426L inkubiert. Nach 16 Stunden wurde das Medium abgenommen und die ASA aus den Zellen immunpräzipitiert, gelelektrophoretisch aufgetrennt und durch Phosphoimaging quantifiziert (Abbildung 4.27, TAbelle 4.5).



Abbildung 4.27: Stabilität endocytierter $\left[{ }^{35} \mathrm{~S}\right] \mathrm{ASA}-\mathrm{P426L}$ in Cathepsin L-defizienten MEF-Zellen. Nach $16 \mathrm{~h}$ Endocytose von ${ }^{35}$ S]ASA-P426L in Wildtyp-MEF-Zellen (+/+) sowie Cathepsin L-defiziente MEF-Zellen (-/-) wurden die Zellen geerntet und die ASA durch Immunpräzipitation und SDSGelelektrophorese gereinigt. Gezeigt sind jeweils Doppelwerte nach Phosphoimaging.

\begin{tabular}{c|c} 
Menge an $\left[{ }^{35}\right.$ S]ASA-P426L [\%] (Doppelwerte [Pixel]) \\
\hline$+/+$ & $-/-$ \\
\hline $100 \%(5025 ; 5911)$ & $100 \%(5612 ; 5343)$ \\
\hline
\end{tabular}

Tabelle 4.5: Ergebnis der Quantifizierung endocytierter [ ${ }^{35}$ S]ASA-P426L in Cathepsin L-defizienten MEF-Zellen. In Klammern sind jeweils die Doppelwerte angegeben. Das experimentelle Vorgehen und eine Phosphoimaging-Darstellung sind in Abbildung 4.27 gezeigt.

Das Ergebnis zeigt keinen signifikanten Unterschied in der Stabilität der ASA-P426L in den beiden Zelltypen, was bedeutet, daß die Abwesenheit von Cathepsin $L$ die Mutante ASA-P426L in MEF-Zellen nicht stabilisiert. Der Grund dafür kann darin liegen, daß die Mauszellen die humane ASA-P426L grundsätzlich nicht oder mit niedriger Aktivität spalten, oder der Abbau in Mauszellen über andere lysosomale Proteinasen erfolgt. Da in den MEF-Zellen der Einfluß von Cathepsin L beim Abbau von ASA-P426L nicht untersucht werden konnte, wurde dieser Versuchsansatz nicht weiter verfolgt. 


\subsubsection{Identifizierung der Spaltprodukte nach Verdau von ASA-P426L mit Cathepsin L}

Wie die analytischen in vitro-Verdaus von ASA-P426L mit Cathepsin $L$ zeigten, werden beim Verdau ein $53 \mathrm{kDa}$-, ein $9 \mathrm{kDa}$ - und in geringer Menge ein $30 \mathrm{kDa}$-Fragment gebildet (Abschnitt 4.2.1.1). Um die Lage der neuen Spaltstellen in der ASA-Mutante zu identifizieren, mußten die beim Verdau von ASA-P426L mit Cathepsin L entstandenen Fragmente isoliert und identifiziert werden. Dafür wurde ein präparativer Verdau durchgeführt. $40 \mu \mathrm{g}$ ASA und humanes Cathepsin L wurden im molaren Verhältnis 4:1 bei einem $\mathrm{pH}$-Wert von 4,8 und $37^{\circ} \mathrm{C}$ für 8 Stunden inkubiert und die Produkte über eine C4-Reversed-Phase-HPLC-Säule aufgetrennt. Im Eluat konnten vier Peaks identifiziert werden (Abbildung 4.28A). Aliquots der entsprechenden Fraktionen wurden auf ein SDS-Minigel aufgetragen, und nach Anfärbung mit kolloidalem Coomassie konnten die Fraktionen den Spaltprodukten zugeordnet werden (Abbildung 4.28B).

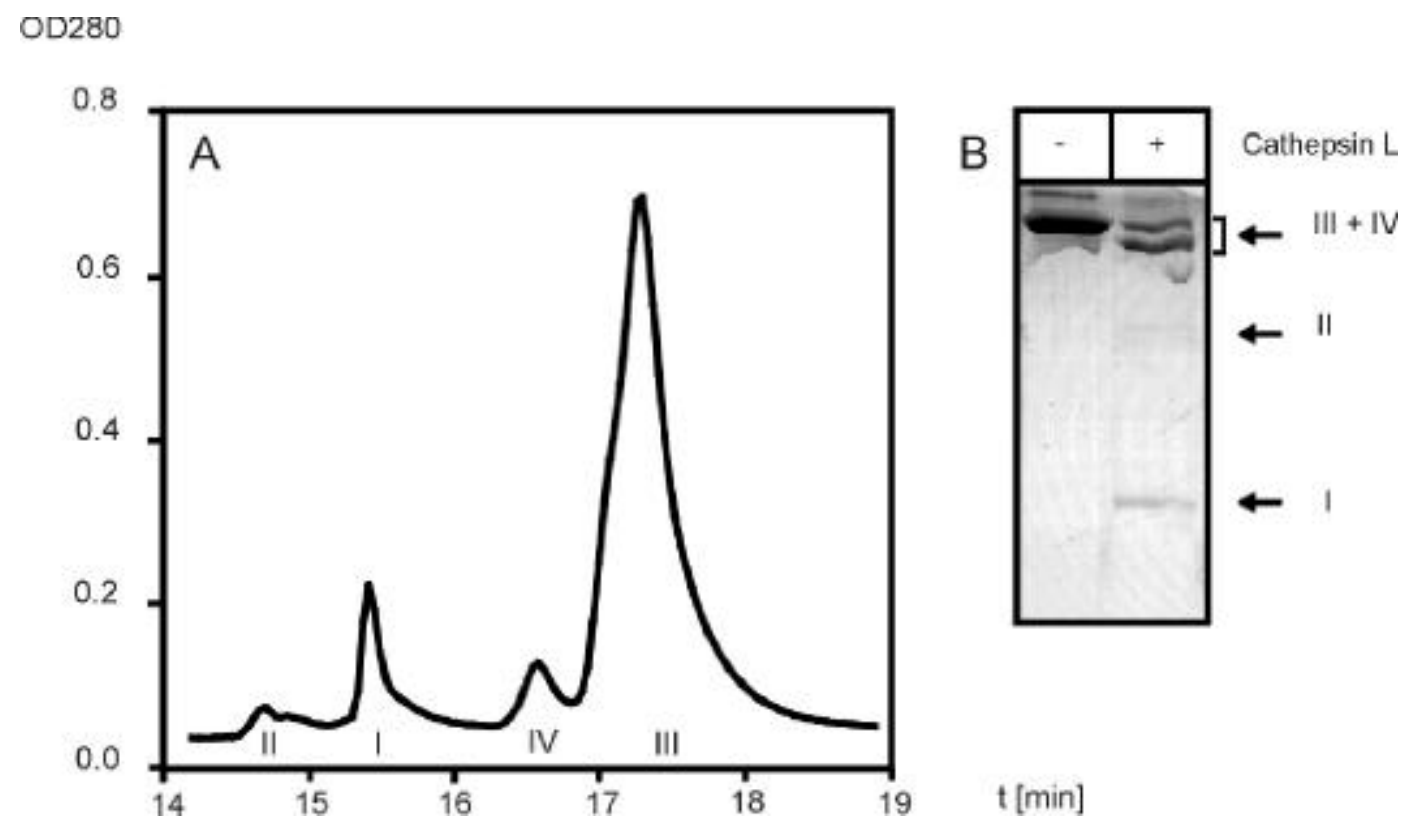

Abbildung 4.28: Chromatographische Trennung der Fragmente nach präparativem Verdau von ASA-P426L mit humanem Cathepsin L. Nach dem präparativen Verdau von ASA-P426L mit Cathepsin L wurden die Fragmente über C4-Reversed-Phase-HPLC getrennt (A). Aliquots der Fraktionen wurden anschließend in einem 15\%igen SDS-Polyacrylamid-Minigel analysiert. B zeigt ein Aliquot des präparativen Abbaus nach Trennung in einem 15\%igen SDS-Polyacrylamidgel und die Zuordnung der gefundenen Fragmente zu den HPLC-Fraktionen.

Die vier HPLC-Fraktionen wurden daraufhin zu 95\% einer Aminosäuresequenzanalyse durch Edman-Abbau unterzogen, die restlichen 5\% einer MALDI-Tof-Massenanalyse. Fraktion II, welche das $30 \mathrm{kDa}$-Fragment enthielt, konnte aufgrund der geringen Menge weder durch die Aminosäuresequenzanalyse noch durch Massenspektrometrie identifiziert werden. Die Aminosäuresequenzanalyse des $9 \mathrm{kDa}$-Fragmentes (Fraktion I) zeigte, daß 72\% der Probe mit der Sequenz AHEPLLYDL beginnen und 28\% mit der 
um eine Aminosäure verkürzten Sequenz HEPLLYDL (Abbildung 4.29). Diese Sequenzfolgen beginnen in der ASA an Position 422 bzw. 423 (Abbildung 4.30).



A HEP L L L Y D L S KD P G gefundene Aminosäuren
Abbildung 4.29: Edman-Sequenzierung des 9 kDa-Fragments. Gezeigt sind die 15 aminoterminalen Aminosäuren, die $72 \%$ der gefundenen Aminosäuresequenz nach Edman-Abbau des $9 \mathrm{kDa}$-Fragmentes (Fraktion I) entsprechen. 28\% beginnen mit der zweiten Aminosäure (HEPLL...). Bei der Interpretation der Daten ist zu berücksichtigen, daß die Aminosäuren $S$, $\mathrm{H}, \mathrm{D}, \mathrm{K}$ und z.T. auch $\mathrm{P}$ methodisch bedingt schwächere Signale bilden.

Parallel dazu wurde von dem 9 kDa-Fragment eine MALDI-ToF-Massenanalyse durchgeführt, wobei die Masse von 9057 und 8983 Da gefunden wurde. Die theoretischen Massen der Peptide 422-507 und 423-507 betragen 9031 bzw. 8960 Da. Berechnet man die Massen der Natriumaddukte, die bei Peptiden mit mehreren Aspartat- und Glutamatresten häufig auftreten, ergeben sich die Werte 9054 bzw. 8983 Da, welche gut mit den experimentell ermittelten Massen übereinstimmen und somit das Ergebnis der Sequenzanalyse bestätigen (Abbildung 4.30).

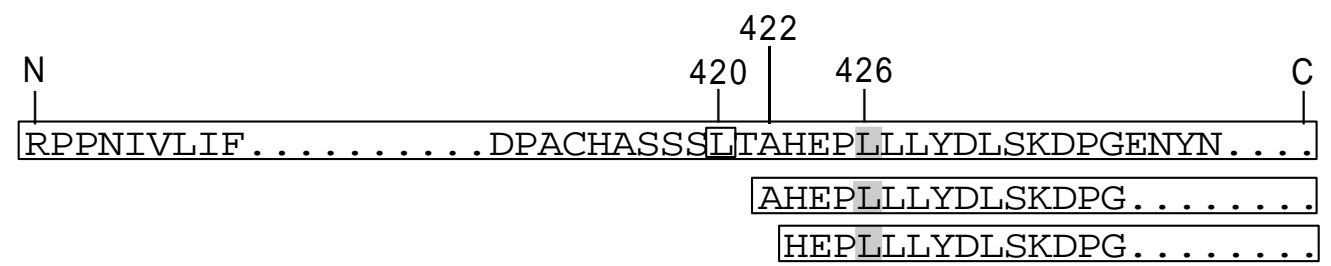

Peptid 422-507 (72\%)

Theoretische Masse: 9031,35 Da

incl. $1 \mathrm{Na}$-Ion: $9054,35 \mathrm{Da}$

Gefundene Masse: 9057,2 kDa

$$
\Delta+2,85 / 0,03 \%
$$

Peptid 423-507 (28\%)

Theoretische Masse: 8960,27 Da

incl. $1 \mathrm{Na}$-lon: 8983,27 Da

Gefundene Masse: 8983,2 Da

$\Delta-0,07 / 0,001 \%$

Abbildung 4.30: Position des 9 kDa-Fragments innerhalb der Aminosäuresequenz der ASA-P426L. Vereinfacht sind die beiden abgespaltenen Peptide 422-507 und 423-507 (72 und 28\%) im Bezug zur Aminosäuresequenz der ASA-P426L dargestellt. Die Mutation P426L ist grau unterlegt, das für die Spaltspezifität von Cathepsin L vorliegende Leu420 ist eingerahmt eingezeichnet. Die theoretischen und experimentell gefundenen Massen sind im unteren Teil der Abbildung angegeben. 
Die Fraktionen III und IV des HPLC-Laufs zeigten beide ein Gemisch aus unverdauter ASA (62 kDa) und dem $53 \mathrm{kDa}$-Fragment. $\mathrm{Da}$ in der Sequenzanalyse nur die Aminosäuresequenz des $\mathrm{N}$-Terminus der reifen ASA gefunden wurde (RPPNIVL...), und die Massendifferenz exakt $9 \mathrm{kDa}$ beträgt, handelt es sich bei dem $53 \mathrm{kDa}-F r a g m e n t$ folglich um das zweite Fragment, das durch die Abspaltung des $9 \mathrm{kDa}$-Fragments von der ASA entsteht.

Bei der neuen Spaltstelle, an der Cathepsin L die ASA-P426L nicht aber die wt-ASA angreift, handelt es sich demnach um die Position vor Alanin 422 und zum geringeren Teil um die Position vor Histidin 423, welche sich vier bzw. drei Aminosäuren vor der Mutation P426L befinden. Betrachtet man die Aminosäuren, die diese Spaltstelle umgeben in Hinblick auf die Spezifizität von Cathepsin L, so scheint dies nicht zu erklären, warum die Proteinase bei ASA-P426L und wt-ASA ein unterschiedliches Verhalten zeigt. Für Cathepsin L wurde bislang nur eine Präferenz für das Vorliegen einer hydrophoben Aminosäure in Position 2 vor der Spaltstelle beschrieben [Kirschke et al., 1995]. In der wt-ASA sowie der Mutante befindet sich hier ein Leucin (Abbildung 4.30).

\subsubsection{Kristallstrukturanalyse der Mutante ASA-P426L}

Wie die bisherigen Untersuchungen zeigten, findet der Angriff von Cathepsin $\mathrm{L}$ auf die Mutante ASA-P426L in direkter Nachbarschaft zur Mutation des Enzyms statt. Es stellte sich daraufhin die Frage, ob diese Mutation eine starke Veränderung der Proteinstruktur im Vergleich zum Wildtyp verursacht. Um diese Frage zu klären, wurde eine Röntgenstrukturanalyse an ASA-P426L-Kristallen durchgeführt.

\subsubsection{Expression und Reinigung der Mutante ASA-P426L}

Für die Kristallisation der ASA-P426L mußte erneut Protein in großer Menge gereinigt werden. Für die Produktion von ASA-P426L standen immortalisierte MEF-Zellen, die ASA-P426L überexprimieren, aus der Abteilung Biochemie II (Universität Göttingen) zur Verfügung. Diese Zellen sezernieren aufgrund ihrer Defizienz von MPR-Rezeptoren den größten Teil der überexprimierten, neusynthetisierten ASA-Mutante in das Zellkulturmedium. Die Zellen wurden auf $14 \mathrm{~cm}$-Zellkulturplatten in Kultur gehalten und das Medium für die Reinigung der ASA-P426L gesammelt. In einem ASA-Aktivitätstest wurde die Produktion der ASA überprüft. Die Expressionsrate betrug etwa $0,9 \mu \mathrm{g} / \mathrm{ml}$ Medium in 48 Stunden. Aus den Zellkulturüberständen wurde das Protein mit Ammoniumsulfat gefällt, gegen TBS-Puffer dialysiert und über Immunoaffinitätschromatographie gereinigt. Das Ergebnis der Immunoaffinitätsreinigung zeigte im SDSGel eine Verunreinigung durch aus dem Zellkulturmedium stammendes BSA, so daß 
als weiterer Reinigungsschritt eine Gelfiltration an einer FPLC-Anlage vorgenommen wurde. Die Reinheitskontrolle durch anschließende SDS-Gelelektrophorese zeigte nur noch die Bande der ASA bei $62 \mathrm{kDa}$ (Abbildung 4.31).

Die gereinigte Mutante ASA-P426L zeigte eine Sulfataseaktivität von etwa $50 \mathrm{U} / \mathrm{mg}$. Insgesamt konnten so aus 12,6 I Zellkulturüberständen 10,4 mg ASA-P426L gereinigt werden.



\begin{abstract}
Abbildung 4.31: Präparative Reinigung der ASAP426L. ASA-P426L wurde über Immunoaffinitätschromatographie an einer $\alpha$-ASA-Säule und anschließender Gelfiltration gereinigt. Aliquots der gereinigten Sulfatase wurden in einem 10\%igen Polyacrylamidgel analysiert. A zeigt die Probe vor, B nach Reinigung über Gelfiltration.
\end{abstract}

\title{
4.2.4.2 Kristallisation von ASA-P426L
}

Die Kristallisation der gereinigten ASA-P426L wurde nach der Gasdiffusionsmethode im hängenden Tropfen bei $18^{\circ} \mathrm{C}$ durchgeführt, wobei Protein und Kristallisationspuffer (PEG6000, Natriumacetat, pH-Wert 5,3 - 5,4) im Verhältnis von 1:1 auf einem Deckgläßchen gemischt und über das Pufferreservoir gebracht wurden. Nach zwei bis vier Wochen war das Kristallwachstum abgeschlossen und farblose Kristalle in Form einer tetragonalen Pyramide oder Bipyramide mit Kantenlängen von bis zu 0,4 mm lagen vor.

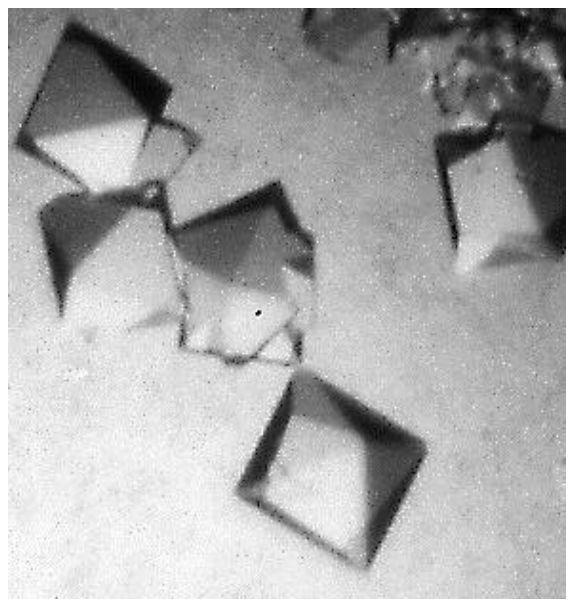

Abbildung 4.32: ASA-P426L-Kristalle. Die größten Kristalle besaßen Dimensionen von 0,3 x 0,3 x 0,4 $\mathrm{mm}^{3}$. Einige Kristalle in dieser Abbildung waren mit kleineren Kristallen verwachsen. 


\subsubsection{Datensammlung, Strukturlösung und -verfeinerung von ASA-P426L}

Für die Röntgenstrukturanalyse wurden die Kristalle in Quarzkapillaren montiert und zunächst an der Kupfer-Drehanode bis zu einer Auflösung von etwa $4 \AA$ gemessen. Daten bis zu einer Auflösung von 2,50 A wurden am EMBL/DESY in Hamburg an der Beamline $\mathrm{X} 11$ bei $4^{\circ} \mathrm{C}$ gesammelt, mit DENZO integriert und mit SCALEPACK gemittelt [Otwinowski \& Minor, 1997]. Die Datenstatistik ist in Tabelle 4.6 zusammengefaßt. Aufgrund des rapiden Qualitätsverlustes der Meßdaten mit zunehmender Meßdauer, konnte ein kompletter Datensatz nur durch Vereinigung der Daten dreier Kristalle erhalten werden. Die Kristalle besitzen Zelldimensionen, die denen der wt-ASA und der oben beschriebenen Mutanten ähneln. Sie kristallisieren in der Raumgruppe 1422 mit einem Monomer in der asymmetrischen Einheit (Übersicht in Tabelle 4.6).

Die Strukturen wurden gelöst, indem als Startmodell ein leicht modifiziertes Strukturmodell der wt-ASA verwendet wurde. Zuvor wurden die $\beta$-Stränge 17 und 18, welche die Umgebung der Mutation ausmachen, aus dem Modell entfernt, um eine Verfälschung der neuen Struktur in dieser Region durch die Vorgabe des Modells der wt-ASA (Modelbias) zu vermeiden. Diese Aminosäuren wurden in die vorhandene Elektronendichte mit Hilfe des Programms XtalView [McRee, 1999] unter Benutzung von Differenzelektronendichtekarten modelliert. Die Elektronendichte wurde als gewichtete SigmaA-Karte $\left(2 \mathrm{mF}_{\mathrm{o}}-\mathrm{DF}_{\mathrm{c}}\right)$ bei $3 \sigma$ [Read, 1986], die Differenzelektronendichtekarte $\left(\mathrm{mF}_{\mathrm{o}}-\mathrm{F}_{\mathrm{c}}\right)$ bei $+/-3 \sigma$ konturiert. Eine Verfeinerung der Koordinaten wurde mit dem Programm REFMAC [Murshudov et al., 1997] durchgeführt. Als Verfeinerungsalgorithmus wurde die "Maximum Likelihood Funktion" verwendet. Die ersten Verfeinerungsschritte wurden ohne die Wassermoleküle durchgeführt, sie wurden später jedoch mit einbezogen und kontrolliert, so daß nur Wassermoleküle mit sinnvollen Auslenkungsparametern sowie sinnvollen Wasserstoffbrückenbindungen im Modell vorlagen. Im letzten Modell fehlte wie bei der wt-ASA die Schleifenregion Gly444 - Ala447 und der C-Terminus (Asp504 - Ala507).

Um die Qualität des Strukturmodells zu untersuchen, wurden bei der Verfeinerung stets auf die beiden R-Werte geachtet. $5 \%$ der Meßdaten wurden für die Bestimmung des

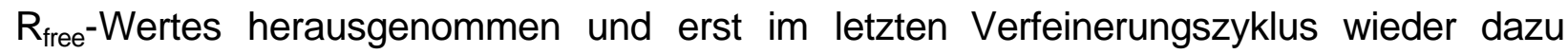

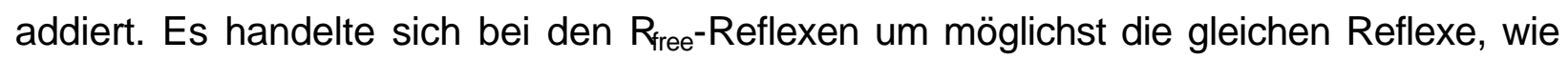
bei den oben beschriebenen Datensätzen. Die R-Werte betrugen am Ende der Verfeinerung $18,5 \%$ (R-Wert) und $25,0 \%$ ( $R_{\text {free }}$-Wert). 


\begin{tabular}{|c|c|c|c|}
\hline Verbindung & ASA-P426L & Verbindung & ASA-P426L \\
\hline Kristallparameter & & Verfeinerungsstatistik & \\
\hline $\begin{array}{l}\text { Gitterkonstanten } \mathrm{a}=\mathrm{b}[\AA] \\
\mathrm{c}[\AA] \\
\text { Raumgruppe }\end{array}$ & \begin{tabular}{|l}
131,4 \\
192,0 \\
1422
\end{tabular} & Aminosäuren im Modell & 480 \\
\hline Datenstatistik & & Anz. d. Proteinatome & 3552 \\
\hline Auflösungsbereich [̊̊] & $30-2,50$ & Anz. d. Wasser & 174 \\
\hline $\begin{array}{l}\text { Anz. der gemessenen } \\
\text { Reflexe }\end{array}$ & 151131 & Anz. d. sonstigen Atome & 29 \\
\hline $\begin{array}{l}\text { Anz. der unabhängigen } \\
\text { Reflexe }\end{array}$ & 29188 & \begin{tabular}{|l} 
Daten-Parameter- \\
Verhältnis
\end{tabular} & 2,2 \\
\hline Redundanz & 5,4 & $\mathrm{R}_{\text {work }}$-Wert $\left(\mathrm{R}_{\text {free }}\right.$-Wert $)[\%]$ & $18,5(25,0)$ \\
\hline Vollständigkeit [\%] & $99,2(99,3)^{\ddagger}$ & R-Wert ** [\%] & 18,7 \\
\hline $\mathrm{R}_{\mathrm{sym}}{ }^{*}[\%]$ & $8,3(36,0)^{\ddagger}$ & $\begin{array}{l}\text { Mittlerer Temperaturfaktor } \\
<\mathrm{B}>\mathrm{HK} / \mathrm{SK} / \mathrm{LM}\left[\AA^{2}\right]\end{array}$ & $\begin{array}{l}40,0 / 39,9 / \\
46,1\end{array}$ \\
\hline$<\mathrm{l} / \sigma(\mathrm{I})\rangle$ & $14,9(2,8)^{\ddagger}$ & $\begin{array}{l}\text { Mittlere rms-Abweichung } \\
\text { der Bindungslängen }[\AA]\end{array}$ & 0,020 \\
\hline $\mathrm{I}>3 \sigma(\mathrm{I})[\%]$ & $73,5(38,4)^{\ddagger}$ & $\begin{array}{l}\text { Mittlere rms-Abweichung } \\
\text { der Bindungswinkel }\left[{ }^{\circ}\right]\end{array}$ & 3,2 \\
\hline
\end{tabular}

Tabelle 4.6: Übersicht über wichtige kristallographische Daten und Verfeinerungsdaten der ASAP426L. Datenstatistik: Aufgelistet sind die Parameter der für die Verfeinerung des Modells benutzten

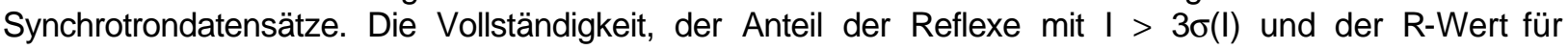
symmetrieäquivalente Reflexe $R_{\text {sym }}$ sind für jeweils den vollständigen Datensatz sowie in Klammern gekennzeichnet mit ${ }^{\ddagger}$ für die äußere Auflösungsschale angegeben, d.h. die äußeren $0,1 \AA$ Verfeinerungsstatistik: Der mittlere Temperaturfaktor der Atome ist sowohl Hauptkettenatome (HK), Seitenkettenatome (SK) und Lösungsmittelatome (LM) angegeben. Abkürzung: rms = root mean square.

Definitionen: *: $R_{\text {sym }}=\left(\Sigma\left|I_{h k l}-<I_{h k}>\right|\right) / \Sigma\left(I_{h k l}\right) ;{ }^{*}: R=\left(\Sigma\left|F_{o}-F_{c}\right|\right) / \Sigma\left|F_{0}\right|$

Betrachtet man die Ergebnisse des Strukturgüte-Kontrollprogramms PROCHECK [Laskowski et al., 1993] sowie den Ramachandranplot, so ist die Güte der Struktur von ASA-P426L mit der des Wildtyps und mit anderen Proteinstrukturen bei ähnlicher Auflösung vergleichbar.

Der Ramachandranplot zeigt, daß die mit einer Oligosaccharid-Seitenkette verknüpfte Aminosäure Asparagin 184 außerhalb der erlaubten Bereiche liegt, wohingegen die restliche Struktur kaum Aminosäuren mit weniger erlaubten Geometrien besitzt (Abbildung 4.33). 99,0\% der Hauptkettentorsionswinkel befinden sich in bevorzugten und zusätzlich erlaubten Regionen. 


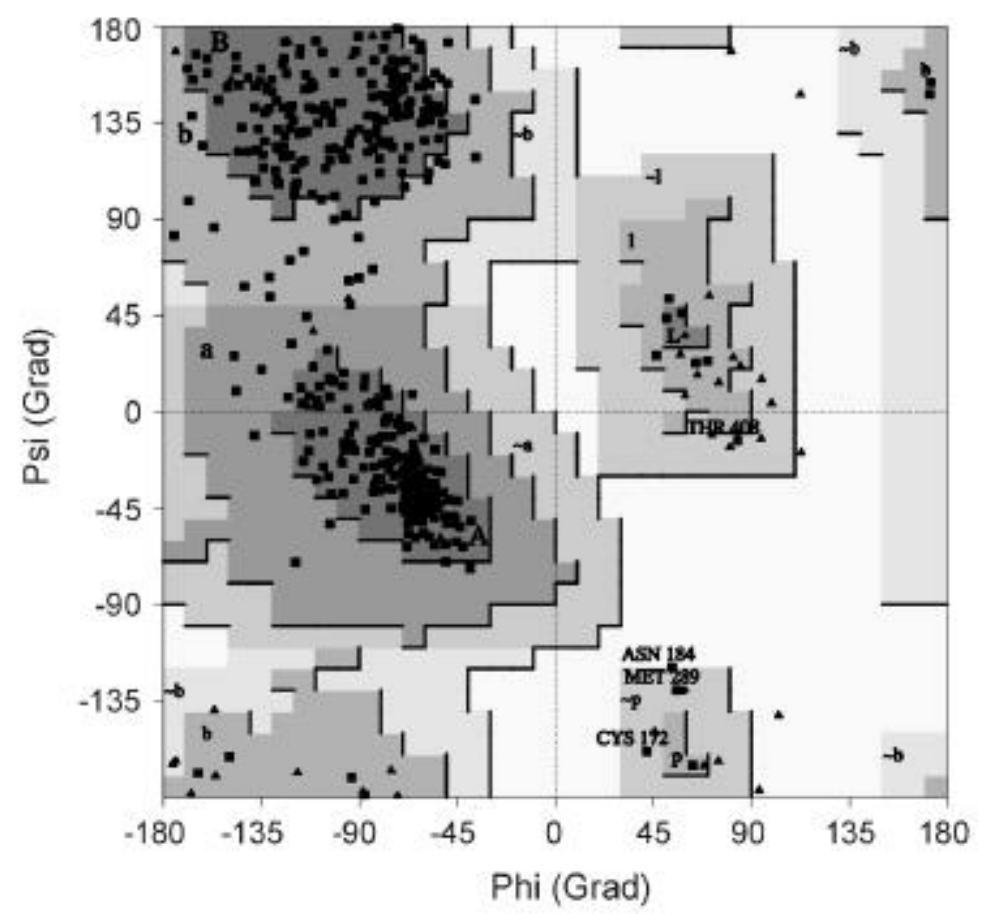

Abbildung 4.33: Ramachandranplot der Kristallstruktur von ASA-P426L. Aufgetragen sind die Hauptkettentorsionswinkel $\Phi$ und $\Psi$ eines Monomers der verfeinerten Struktur der Arylsulfatase AP426L. 85,3\% der Hauptkettentorsionswinkel befinden sich in bevorzugten (dunkelgrau unterlegt: A, B, L), 13,7\% in zusätzlich erlaubten (mittelgrau unterlegt: a, b, I, p) Regionen. 0,8\% der Hauptkettentorsionswinkel (Met289, Cys172 und Thr408) liegen in großzügiger erlaubten (hellgrau unterlegt: $\sim a, \sim b, \sim 1, \sim p$ ) und $0,3 \%$ (Asn184) in nicht erlaubten Regionen. Glycinreste sind als Dreiecke dargestellt, Nicht-Glycinreste als Quadrate.

\subsubsection{Strukturbeschreibungen der ASA-P426L}

Die Mutante ASA-P426L besitzt die gleiche allgemeine Tertiärstruktur wie die wt-ASA. Ein Vergleich der Koordinaten der C $\alpha$-Atome von ASA-P426L mit denen des Wildtyps zeigt in allen Bereichen eine Abweichung von unter 0,7 $\AA$ (Abbildung 4.34). Im aktiven Zentrum konnte an Position 69 ein hydratisiertes Formylglycin in die Elektronendichte modelliert werden, wie es auch für die wt-ASA beschrieben wurde. 


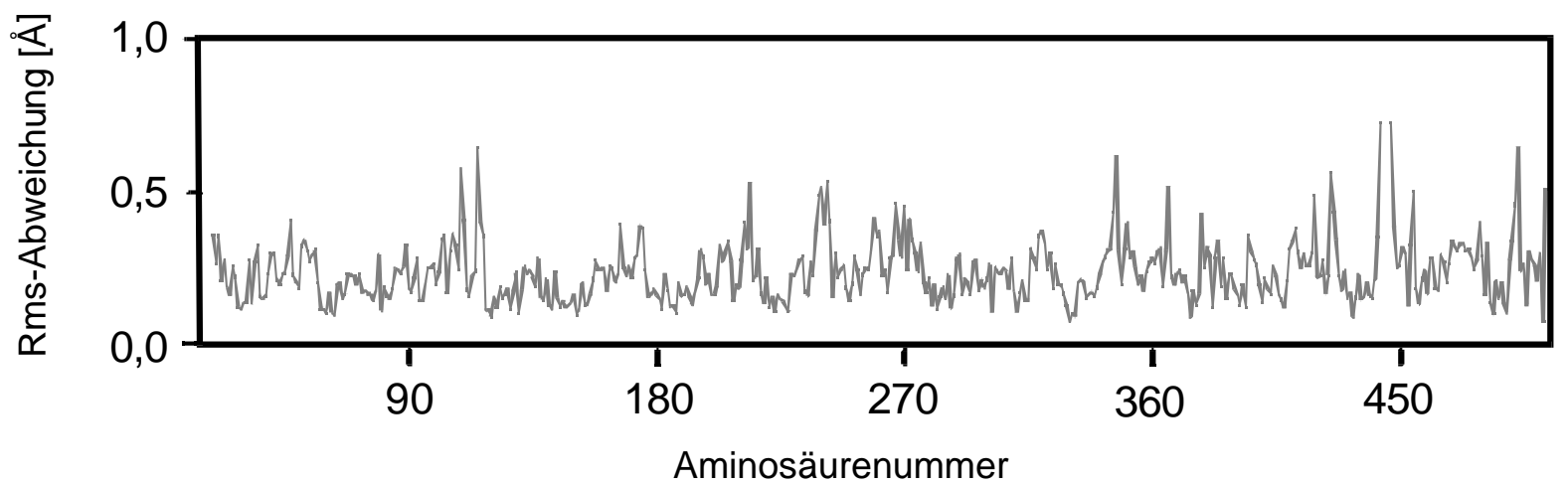

Abbildung 4.34: Rms-Abweichung der Lage der C $\alpha$-Atome in der ASA-P426L im Vergleich zur wtASA. Die Daten zu den Aminosäuren 443 - 448 liegen nicht in den Modellen vor und erzeugen deswegen in dieser Abbildung eine Lücke im Graphen.

In Position 426 ist erwartungsgemäß statt des Prolins ein Leucinrest zu finden. Seine Lage innerhalb der Elektronendichte ist in Abbildung 4.35 gezeigt. Der Leucinrest ist umgeben von hydrophoben Resten des selben Monomers (Phe398, Leu428, Leu442, Leu459 und Leu456). Die kürzesten Abstände zwischen den Seitenkettenatomen des Leucins 426 und den hydrophoben Resten in der Umgebung liegen bei 3,7 $\AA$ In dieser hydrophoben Tasche befindet sich also genügend Platz, um die Seitenkette unterzubringen, so daß keine sterisch ungünstigen Wechselwirkungen vorliegen.

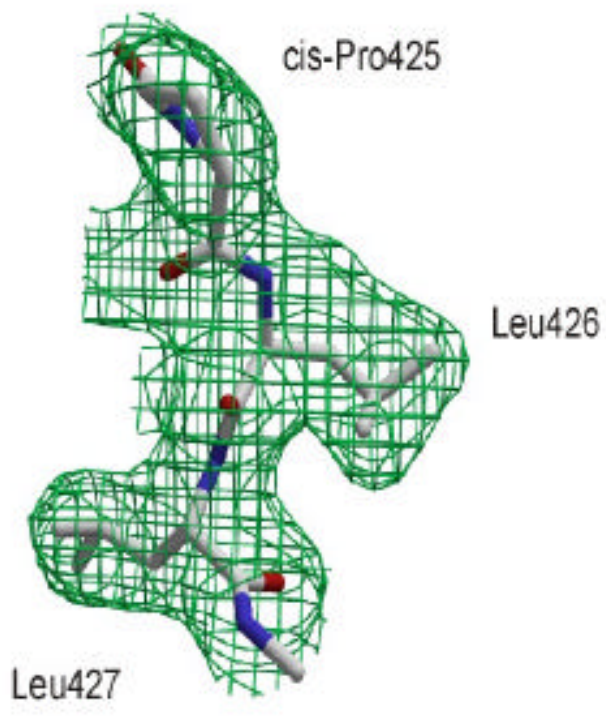

Abbildung 4.35: Struktur der Aminosäuren cis-Pro425 bis Leu427 der ASA-P426L mit Elektronendichte. Dargestellt ist die Polypeptidkette der Aminosäuren cis-Pro425, Leu426 und Leu427. Kohlenstoffatome sind hellgrau, Sauerstoffatome rot und Stickstoffatome blau wiedergegeben. Das Proteinfragment endet in der Abbildung stets mit einem Kohlenstoffatom. Die Elektronendichte $(3 \sigma)$ ist grün dargestellt.

Die Mutation befindet sich innerhalb des aus 10 Aminosäuren gebildeten $\beta$-Stranges 18 (s. Anhang), welcher mit dem aus 7 Aminosäuren bestehenden $\beta$-Strang 17 über 7 Wasserstoffbrücken in Wechselwirkung tritt (Abbildung 4.36). Drei Aminosäuren des $\beta$-Stranges 18 bilden keine Wasserstoffbrücken aus, da sie aufgrund des sterischen Zwanges, den ein cis-Prolin ausübt, nicht parallel zum gegenüberliegenden $\beta$-Strang 17 
stehen. Dies sind die Aminosäuren Glutamin 424, cis-Prolin 425 sowie das Leucin 426. Die Position der Spaltstelle für Cathepsin L (vor Ala422) befindet sich vor der Auswölbung in einem Bereich, in dem Wasserstoffbrücken ausgebildet werden.

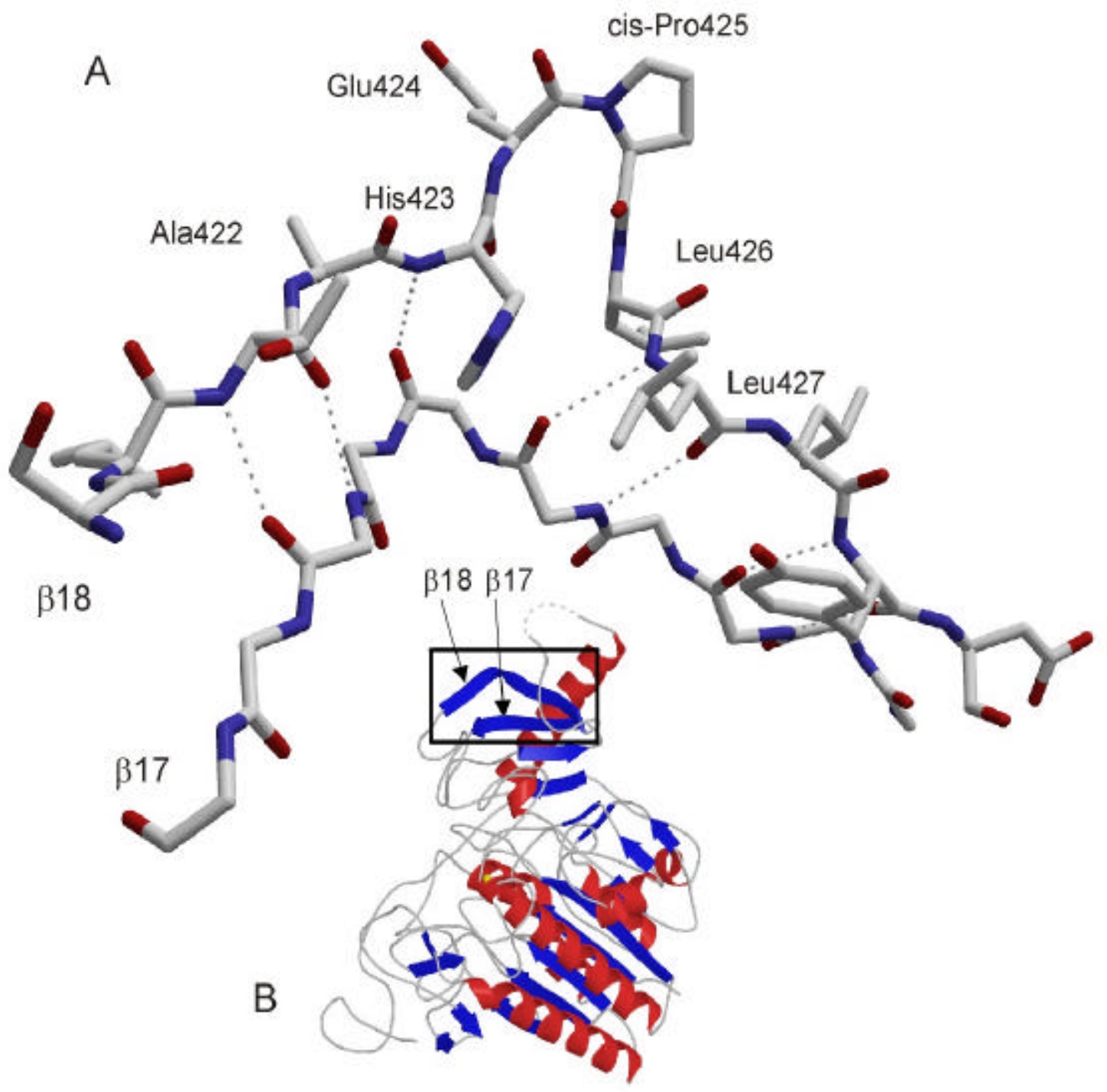

Abbildung 4.36: Struktur der $\beta$-Faltblätter 17 und 18 der ASA-P426L. A: Dargestellt sind die Hauptkettenatome von $\beta$-Faltblatt 17 (Aminosäuren 394 bis 400) sowie die Hauptketten- und Seitenkettenatome von $\beta$-Faltblatt 18 (Aminosäuren 421 bis 430) und daran angrenzende Aminosäuren. Für Glu424 ist nur der stärker besetzte Anteil der Fehlordung gezeigt. Kohlenstoffatome sind hellgrau, Stickstoffatome blau und Sauerstoffatome rot dargestellt. Wasserstoffbrückenbindungen sind als gestrichelte Linien dargestellt. B: Position der $\beta$-Faltblätter 17 und 18 innerhalb des ASA-P426L-Moleküls.

Vergleicht man nun speziell in diesem Bereich der Struktur die Lage der Haupt- und Seitenkettenatome von ASA-P426L mit denen der wt-ASA, zeigt sich, daß die Atome des $\beta$-Stranges $17 \mathrm{zu}$ nahezu $100 \%$ in ihrer Lage übereinstimmen, nicht aber alle Atome des $\beta$-Stranges 18 (Abbildung 4.37A). Zum einen nehmen natürlich die Atome der Seitenkette von Leu426 (Mutante) eine andere Position ein, als die des Pro426 (Wildtyp), da der Leucinrest weiter von der Hauptkette weg ragt und in diesem Bereich 
die Atome der Hauptkette zudem etwas verschoben sind (Abbildung 4.37A+C). Das cisPro425 zeigt im Vergleich eine leichte Verschiebung der Positionen aller Atome (Abweichung ca. 0,8-1,2 A, Abbildung 4.37A-C).
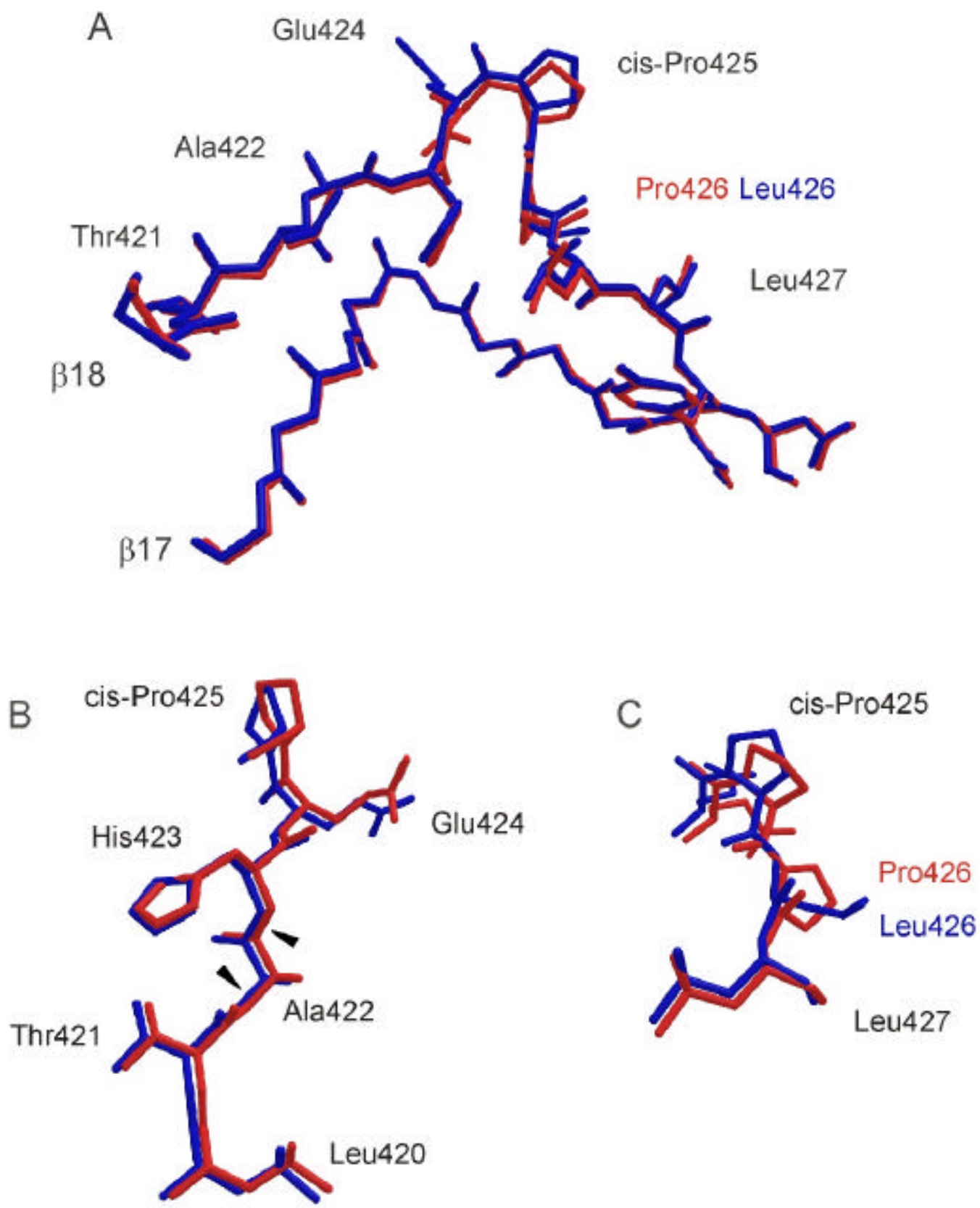

Abbildung 4.37: Lage der Atome in der Region des $\beta$-Faltblatts 18 von ASA-P426L im Vergleich zur wt-ASA. Die Abbildungen zeigen eine vergleichende Darstellung der Polypeptidketten von ASA-P426L und wt-ASA im Bereich der Aminosäure 426. Die Atome der ASA-P426L sind blau dargestellt, die der wtASA rot. Für Glu424 ist nur der stärker besetzte Anteil der Fehlordnung gezeigt. A: Hauptkettenatome von $\beta$-Faltblatt 17 (Aminosäuren 394 bis 400 ) sowie Hauptketten- und Seitenkettenatome von $\beta$-Faltblatt 18 (Aminosäuren 421 bis 430) und daran angrenzende Aminosäuren. B: Aminosäuren $420-425$. Die Pfeile markieren die Spaltstellen für Cathepsin L in ASA-P426L (blau). C: Aminosäuren 425 - 428.

Die Hauptkette der Aminosäure Glu424 liegt in beiden Enzymen nahezu an der

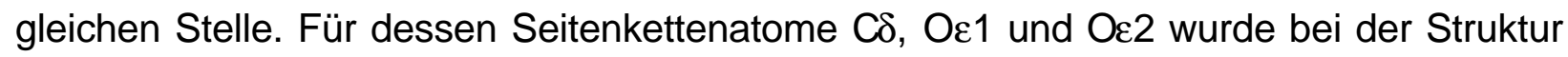


des Wildtyps eine Fehlordnung in 2 Positionen beschrieben. Der kleinere Anteil liegt in Position A (Torsionswinkel $\mathrm{C} \alpha-\mathrm{C} \beta-\mathrm{C} \gamma-\mathrm{C} \delta$ : $-163,6^{\circ}$ ), der größere Anteil in Position B (Torsionswinkel $\mathrm{C} \alpha-\mathrm{C} \beta-\mathrm{C} \gamma-\mathrm{C} \delta$ : $68,8^{\circ}$ ). Für die hier untersuchte ASA-Mutante konnte ebenfalls eine Fehlordnung modelliert werden, jedoch sind de Anteile der Besetzungen anders als beim Wildtyp: der Hauptanteil der Seitenketten befindet sich hier in Position A (in Abbildung 4.37A+B werden jeweils die bevorzugten Positionen gezeigt).

Die Aminosäuren Ala422 und His423, die den beiden gefundenen Spaltstellen für Cathepsin L folgen, zeigen im Vergleich von Wildtyp und Mutante keine Abweichung, und auch im Bereich vor den Spaltstellen ist kaum eine Abweichung in den Koordinaten der Aminosäurenatome zu erkennen (Abbildung 4.37B).

Die Feinstrukturanalyse im Bereich der Mutation P426L und der Spaltstelle für Cathepsin L zeigt somit keine dramatische Strukturänderung, die durch die Mutation hervorgerufen sein könnte und die Bildung einer neuen Spaltstelle für Cathepsin L erklären würde. Die schwache Verschiebung der Hauptkette im Bereich der Aminosäuren 425 und 426 sowie die veränderte Position der einzelnen Seitenketten (Glu424, cis-Pro425 und Pro426/Leu426) kommt für die Neubildung einer Spaltstelle schwerlich in Frage, da für Cathepsin L keine Spaltspezifität bekannt ist, die zu diesen Resten paßt. Die Lage des Leucin 420, für das als hydrophober Rest eine Präferenz bekannt ist (siehe oben), ist in seiner Lage bei der Mutante kaum verändert.

Wahrscheinlicher ist daher, daß die Mutation P426L indirekt Cathepsin L ermöglicht, an der (bereits im Wildtyp vorhandenen) Spaltstelle aktiv zu werden. Auf der Suche nach einem solchen Mechanismus fiel auf, daß die Aminosäure 426 zur Region gehört, welche an der Oktamerisierung beteiligte Aminosäuren enthält (Abbildung 4.38). wt-ASA und ASA-P426L wurden jeweils bei pH 5,3 - 5,4 als Oktamere kristallisiert, die aus vier Homodimeren bestehen. 
Die Kontaktregion zwischen den Dimeren (Oktamerisierungsregion) wird von Seitenketten der langen $\alpha$-Helix I (Leu453, Lys457, Leu461, Ala464, Asp467 und Ala468), einer Schleifenregion (Glu382, Val383) und außerdem von Seitenketten des $\beta$ Stranges 17 (Phe398 und Phe399) und 18 (Ala422, und cis-Pro425) und einigen Wassermolekülen gebildet. In $\beta$-Strang 18 befindet sich auch die mutierte Aminosäure 426. Eine zweizählige kristallographische Achse überführt die beiden aneinander grenzenden Dimere ineinander. Die Oktamerisierungsregion setzt sich hauptsächlich aus hydrophoben Aminosäureresten zusammen, die die beiden Dimere zusammenhalten (Phe398, Phe399, Ala422, cis-Pro425, Leu453, Leu461, Ala464, Ala468 und der aliphatische Teil der Seitenkette von Lys457). Ausgehend von zwei Aminosäureseitenketten werden drei direkte Wasserstoffbrücken zwischen den beiden Monomeren ausgebildet. Zum einen sind dies zwei Wasserstoffbrücken ausgehend von Lys457Nع welches mit den peptidischen Carbonylsauerstoffatomen von Glu382 (Abstand: 3,1 $\AA$ ) sowie Asp467 (Abstand: 3,0 ̊̊) wechselwirken, und zum anderen liegt eine Wasserstoffbrücke zwischen einem Glu4240 $\varepsilon$ und dem peptidischen Carbonylsauerstoffatom von Phe398 vor (Abstand: 2,9 A) .

Von diesen an der Oktamerisierung beteiligten Resten sind die Atome der Aminosäuren der $\alpha$-Helix und des Schleifenbereichs in Wildtyp und Mutante gleich positioniert. Im Bereich des $\beta$-Stanges 18 liegen jedoch leichte Veränderungen in der Struktur vor, insbesondere im Bereich der Aminosäuren 424 - 426 (s. Text oben und Abbildung 4.37). Diese Strukturunterschiede in der Mutante sind offenbar nicht stark genug, um eine im Vergleich zum Wildtyp unterschiedliche Oligomerisierung im Proteinkristall hervorzurufen. Es ist auch generell nicht davon auszugehen, daß eine geringe strukturelle Änderung der Aminosäuren in der Oktamerisierungsregion einen Effekt auf die Anordung der ASA-Dimere im Kristallgitter zeigt, da schwache Strukturänderungen in einer begrenzten Region eines Proteins in der Regel zu keiner Neuordnung im Kristall führen. In wässriger Lösung dagegen ist durchaus denkbar, daß solche Strukturänderungen zu Änderungen im Oligomerisierungsverhalten führen.

Die bei der ASA-P426L genutzte Spaltstelle von Cathepsin L liegt am äußeren Rand der Oktamerisierungsregion (Abbildung 4.38) und ein Angriff an den Positionen Ala422 und His423 sollte im Oktamer aus sterischen Gründen erschwert sein, da dort für ein angreifendes Enzym wie Cathepsin $L$ viel weniger Platz zur Verfügung steht als beim Dimer. Liegt die ASA als Oktamer vor, sollte sie daher in dieser Region vor Angriffen durch Proteinasen geschützt sein. 


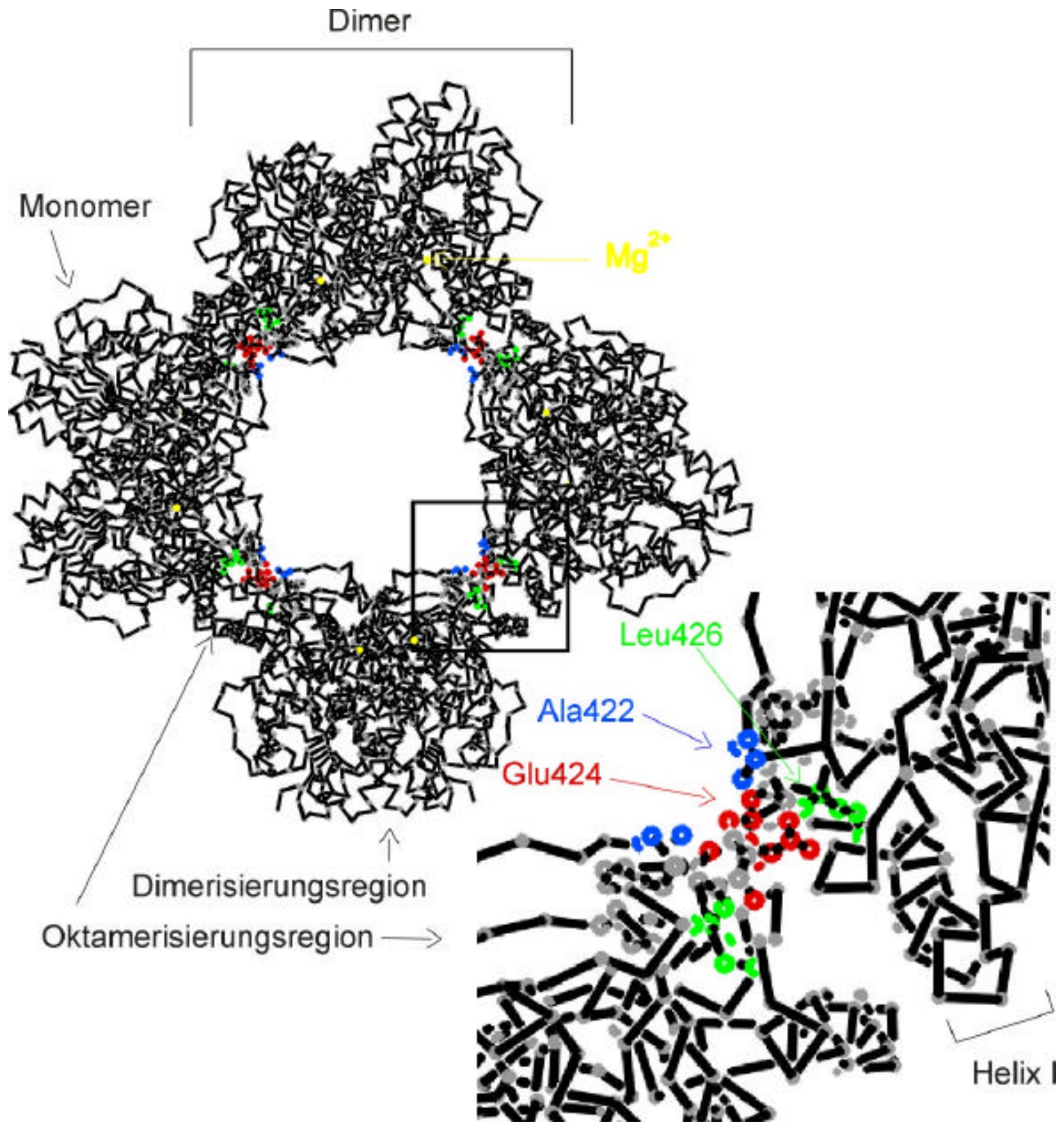

Abbildung 4.38: Oktamer und Oktamerisierungsregion der ASA-P426L. Im oberen Teil der Abbildung ist das aus vier Homodimeren aufgebaute Oktamer der ASA zu sehen, welches in der Kristallstruktur gefunden wurde. Im unteren Teil der Abbildung ist eine vergrößerte Ansicht der Oktamerisierungsregion gezeigt. Die Atome der Aminosäuren 422 bis 426 sind als Kugeln dargestellt, von denen Ala422 blau, Glu424 rot und Leu426 grün gefärbt sind. Das Magnesiumkation (gelbe Kugel) deutet die Lage des aktiven Zentrums im Monomer an. 


\subsubsection{Oligomerisierung der ASA-P426L in Lösung}

Die Strukturuntersuchungen der ASA-P426L im Bereich der Mutation haben gezeigt, daß die Positionen einzelner an der Oktamerisierung beteiligter Aminosäuren (hauptsächlich Glu424 und cis-Pro425) im Vergleich zum Wildtyp verändert sind, was zu der Hypothese führte, daß die ASA-P426L in Lösung anders oligomerisiert als der Wildtyp. Sollte die ASA-P426L bei lysosomalem pH-Wert im Gegensatz zum Wildtyp vermehrt als Dimer vorliegen, in dem die Spaltstelle für Cathepsin L zugänglich ist, könnte das die verminderte Stabilität der Mutante erklären. Um diese Hypothese zu überprüfen, wurde eine Untersuchung zur pH-Abhängigkeit des Dimer-OktamerGleichgewichts der wt-ASA und der Mutante mit Hilfe einer analytischen Gelfiltration durchgeführt. Jeweils $2 \mu \mathrm{g}$ ASA wurden für 3 Stunden auf Eis bei verschiedenen $\mathrm{pH}$ Werten im Bereich von $\mathrm{pH}$ 4,8 - 7,0 vorinkubiert. Anschließend wurden die Sulfatasen auf eine analytische Gelfiltrationssäule aufgetragen, die mit den entsprechenden $\mathrm{pH}$ Werten äquilibriert war. Die Elution der ASA wurde über die Bestimmung der Aktivität in den Elutionsfraktionen verfolgt. Die Retentionszeiten der eluierten ASA wurden mit denen von Standardproteinen verglichen und daraus das Molekulargewicht der eluierten ASA berechnet. Abbildung 4.39 zeigt die Elutionsprofile der wt-ASA und der ASA-P426L bei pH 5,4. Abbildung 4.40 zeigt zusammenfassend die Ergebnisse aller Gelfiltrationsläufe.

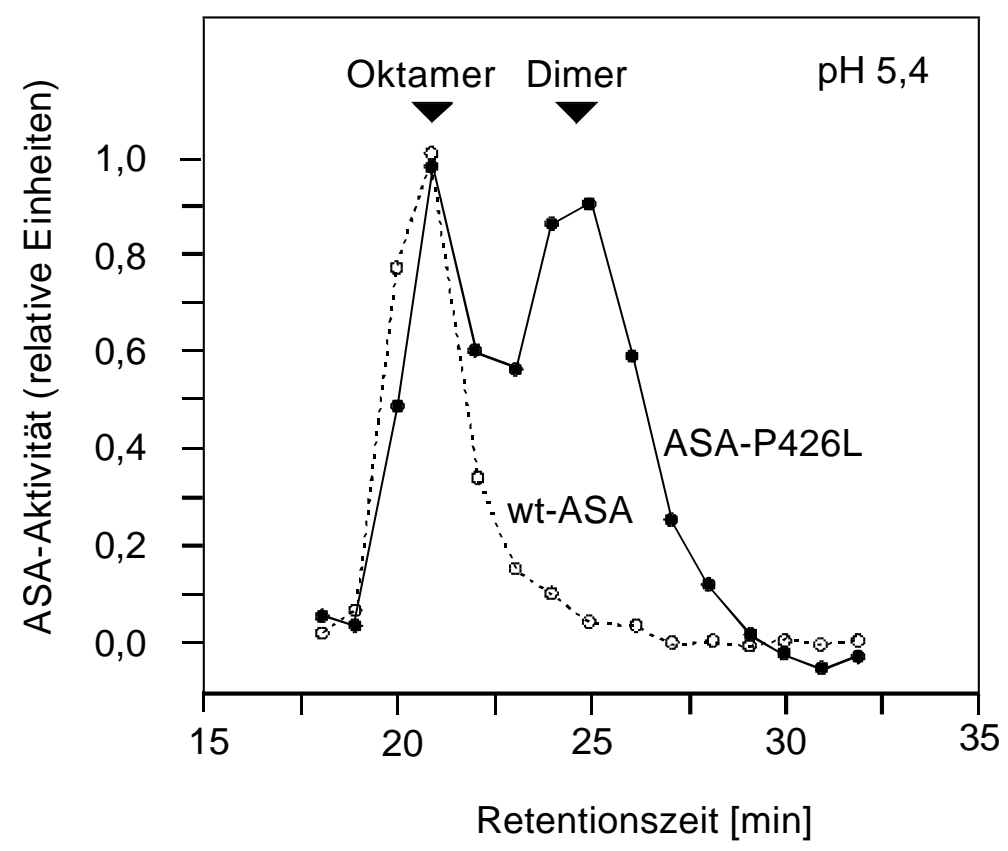

Abbildung 4.39: Elutionsprofile von ASA-P426L und wt-ASA nach Gelfiltration bei pH 5,4. Die relative ASA-Aktivität (der höchste Aktivitätswert entspricht jeweils 1,0 ) ist gegen die Retentionszeit (in min) aufgetragen. Die Meßwerte für die ASA-P426L sind als gefüllte Kreise, die für wt-ASA sind als nicht ausgefüllte Kreise dargestellt. Die Elutionszeiten von Oktamer (ca. 480 kDa) und Dimer (ca. 120 kDa) sind angegeben. 
Bei pH 4,8 lagen sowohl wt-ASA als auch ASA-P426L als Oktamer vor, bei pH 6,0 und 7,0 vollständig als Dimer. Zwischen diesen beiden pH-Werten zeigten die beiden Enzyme jedoch ein unterschiedliches Verhalten. Die wt-ASA liegt im Bereich von pH 4,8 bis 5,6 zu $100 \%$ als Oktamer vor und dissoziiert bei höheren pH-Werten zum Dimer. Die Mutante hingegen ist schon bei $\mathrm{pH} 5,0$ zu ca. 10\% zum Dimer dissoziiert mit rasch zunehmendem Anteil an Dimer bei steigenden pH-Werten (Abbildung 4.40).

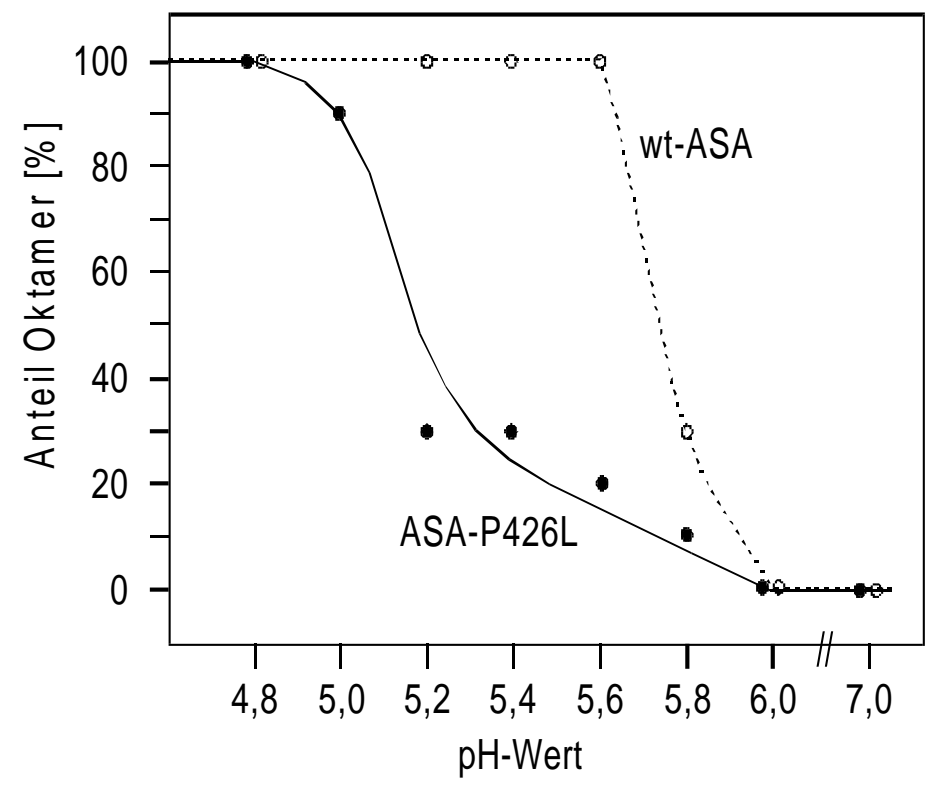

Abbildung 4.40: pH-Wert abhängige Oligomerisierung von ASA-P426L und wt-ASA. Nach Gelfiltration der Sulfatasen bei verschiedenen $\mathrm{pH}$-Werten wurden die Elutionsprofile in den Positionen des Oktamers und des Dimers integriert (s. Abbildung 4.39) und der relative Anteil der Oktamere gegen den $\mathrm{pH}$-Wert aufgetragen.

Neben Seitenketten, die Wasserstoffbrücken ausbilden, um die Oktamerisierung zu stabilisieren, und die in Bezug auf die pH-Abhängigkeit der Oktamerisierung diskutiert werden müssen (s. Diskussion), sind hauptsächlich hydrophobe Wechselwirkungen an der Oktamerisierung beteiligt. Um Unterschiede dieser hydrophoben Wechselwirkungen zwischen ASA-P426L und wt-ASA zu untersuchen, wurden Gelfiltrationsexperimente in Gegenwart von 20\% Acetonitril durchgeführt (Tabelle 4.7). Während die wt-ASA bei pH 4,8 in Gegenwart von $20 \%$ Acetonitril zu $100 \%$ als Oktamer vorliegt, dissoziiert die ASA-P426L unter diesen Bedingungen zu 20\% zum Dimer. Die hydrophoben Wechselwirkungen innerhalb der Oktamerisierungsregion scheinen daher in der ASAP426L schwächer ausgeprägt zu sein als beim Wildtyp. Eine Dissoziation des Oktamers zum Dimer durch Zugabe von Acetonitril kann bei der wt-ASA nur durch eine gleichzeitige Erhöhung des pH-Wertes auf 5,6 erreicht werden. Versuche mit höheren Acetonitrilkozentrationen führten zur vollständigen Inaktivierung der ASA. 


\begin{tabular}{|c||c|c|c|}
\hline \multicolumn{1}{|c||}{ Acetonitrilgehalt [\%] } & \multicolumn{2}{c|}{$\mathrm{pH} 4,8$} & $\mathrm{pH} 5,6$ \\
\hline & wt-ASA & ASA-P426L & wt-ASA \\
\hline \hline 0 & $100 \%$ & $100 \%$ & $100 \%$ \\
\hline 20 & $100 \%$ & $80 \%$ & $60 \%$ \\
\hline
\end{tabular}

Tabelle 4.7: Abhängkeit der Oktamerisierung von wt-ASA und ASA-P426L vom Acetonitrilgehalt im Puffer. Angegeben ist der Anteil an Oktamer (in \%), der bei Gelfiltrationsexperimenten gefunden wurde. Die Gelfiltration wurde bei pH 4,8 (wt-ASA und ASA-P426L) und 5,6 (wt-ASA) durchgeführt. Zur weiteren Beschreibung von Durchführung und Auswertung s. Abbildung 4.40.

Diese Ergebnisse zeigen, daß es Unterschiede im Oligomerisierungsverhalten der beiden Enzyme gibt, die vom pH-Wert und von der Anwesenheit von hydrophobem Lösungsmittel abhängen. Die Strukturdaten zeigen, daß zwei Positionen innerhalb der Oktamerisierungsregion in der ASA-P426L und der wt-ASA auffällig sind, die das unterschiedliche Oligomerisierungsverhalten begründen könnten: Im Bereich der hydrophilen Wechselwirkungen zwischen den Dimeren ist dies die Fehlordnung der Seitenkette von Glu424, und im Bereich der hydrophoben Wechselwirkungen die unterschiedliche Lage von cis-Pro425 (s. Diskussion, Abschnitt 5.2.1). 


\section{Diskussion}

\subsection{Substratbindung und Katalysemechanismus}

\subsubsection{Substratbindung}

Die ASA ist ein Enzym, welches sehr verschiedene sulfatierte Substrate spaltet wie z.B. Cerebrosid-3-sulfat und $p$-Nitrocatecholsulfat. Die allen ASA-Substraten gemeinsame Gruppe ist der Sulfatester, während der Rest von hydrophilen Zuckerresten bis hydrophoben Lipiden variiert. Bei den Untersuchungen zur Bindung von pNCS am ASAMolekül wurde daher das Hauptaugenmerk auf die Bindung des Sulfatesters und die daran beteiligten Aminosäurereste der ASA gerichtet.

Das Substrat wird durch Aminosäureseitenketten über starke (His229 und Lys302) und schwache Kräfte (Lys123 und Ser150) sowie das Magnesiumion im aktiven Zentrum festgehalten. Die spezielle Anordnung der mit dem Substrat wechselwirkenden Aminosäuren spielt zum einen für die Spezifität der Bindung eine Rolle, aber wahrscheinlich auch für die unterschiedlichen Anziehungs- und Abstoßungskräfte, die während der Katalyse durchlaufen werden. So muß das sulfatierte Substrat vor der Katalyse angezogen werden, nach der Spaltung jedoch die Bindung zu den Produkten Alkohol und Sulfat gelockert oder sogar in Abstoßungskräfte gewandelt werden, so daß die Produkte aus der Tasche abdiffundieren können.

Da bei diesen Untersuchungen mit einer katalytisch inaktiven Mutante gearbeitet wurde, spiegelt die Position des Sulfatrestes am Enzym den Status vor der Substratspaltung wider. Die Struktur des Komplexes von ASA-C69A mit pNCS zeigt das Substrat in der Vertiefung des ASA-Moleküls, die aufgrund der Anwesenheit des für die Katalyse essentiellen Formylglycinrestes auch bisher als aktives Zentrum bezeichnet wurde.

Daß die ASA in der Lage ist, auch Phosphat zu binden, zeigt sich darin, daß die Sulfatesterspaltung durch anorganisches Phosphat inhibiert wird [Lee \& van Etten, 1975] und, daß für die ASA eine geringe Phosphataseaktivität beschrieben wurde [Uchida et al., 1981]. Phosphat trägt eine negative Ladung mehr als Sulfat, aber da Phosphat und Sulfat in etwa die gleiche Geometrie und Größe aufweisen, ist das Verhalten der ASA gegenüber Phosphat nicht verwunderlich. Dennoch besitzt die ASA eine hohe Substratspezifität, welche neben der recht engen Enzymtasche wahrscheinlich auch auf spezifische Bindungen der Hydroxylgruppen der Zucker- oder Arylreste mit Aminosäureseitenketten des Proteins im äußeren Bereich der Enzymtasche zurückzuführen sind. Die meisten Phosphatesterverbindungen, welche in vivo vorkommen, können dadurch offenbar die Spaltung der seltener vorkommenden Sulfate nicht behindern. 


\subsubsection{Katalysemechanismus der ASA}

Im ASA-C69A+pNCS-Komplex wird die Sulfatgruppe des Substrats durch Aminosäureseitenketten und das zweiwertige Magnesiumion in direkter Nachbarschaft zum Alanin 69 fixiert, das in dieser Mutante das $\mathrm{C} \alpha$-Formylglycin ersetzt. Um eine Vorstellung von den Wechselwirkungen zwischen dem Sulfatester mit dem für die katalytische Aktivität essentiellen Formylglycinrest der wt-ASA zu erhalten, wurden die Strukturdaten des Komplexes mit denen der wt-ASA kombiniert. In diesem Modell befindet sich das Hydroxylsauerstoffatom Oy1 des hydratisierten Formylglycins in einem Abstand von 2,5 ̊̊ zum Sulfatschwefel. Eine solche unmittelbare Nähe schafft optimale Bedingungen für eine Reaktion zwischen diesem Hydroxylsauerstoffatom und dem Substratschwefel. Diese Reaktion entspricht dem ersten Schritt der Sulfatesterspaltung, wie sie für die ASA vorgeschlagen wurde [Lukatela et al., 1998].

Den Ausgangspunkt dieses Reaktionsmechanismus der ASA bildet das hydratisierte $\mathrm{C} \alpha$-Formylglycin (Abbildung 5.1). Der Sulfatschwefel wird durch die positiv geladenen Reste Histidin 229, Lysin 302 und das Magnesiumion in die Nähe des geminalen Diols positioniert. Weitere, aber schwächere Wechselwirkungen zu Lysin 123, Serin 150 und der Peptidkette von Formylglycin 69 unterstützen diese Positionierung. Die Wechselwirkungen der positiv geladenen Seitenketten zu den Sulfatsauerstoffatomen bewirken einen verstärkten Abzug der Elektronen vom Schwefel, wodurch ein nukleophiler Angriff auf das Schwefelatom des Sulfatesters erleichtert wird. Dieser Angriff wird durch den Hydroxylsauerstoff Oy1 des Aldehydhydrats gestartet, der dem Schwefel am nächsten kommt und zum Magnesium koordiniert ist. Um die Nukleophilie dieses Sauerstoffes zu erhöhen, wird möglicherweise das Proton durch die Carboxylgruppe des Aspartats 281 abgezogen (Abstand 3,4 ̊̊). Die Carboxylgruppe des Asp281 sollte bei einem pH-Wert von 5,3 - 5,4 deprotoniert vorliegen (normaler $\mathrm{pK}_{\mathrm{S}}$ der Aspartat-Seitenkette: 4,0). Die Rolle des Magnesiums könnte hierbei sein, die negative Ladung des deprotonierten Sauerstoffs Oy1 zu stabilisieren. Es folgt nun ein nukleophiler Angriff von $\mathrm{O} \gamma 1$ auf das Schwefelatom. Dort findet daraufhin eine $\mathrm{S}_{\mathrm{N}} 2-$ Substitutionsreaktion mit einem fünfbindigen Schwefel im Übergangszustand statt. Die zuvor tetraedrische Umgebung des Schwefels wird invertiert und die SchwefelEstersauerstoff-Bindung heterolytisch gespalten. 
Das abgespaltene Alkoholation kann ein Proton von Histidin 229 oder einem benachbarten Wassermolekül übernehmen und als neutraler Alkohol abdiffundieren. Das Verlassen des aktiven Zentrums wird dadurch erleichtert, daß die Bindung über die Sulfatgruppe fehlt und die noch vorhandenen Wechselwirkungen des Enzyms zum Restmolekül offenbar nicht stark genug sind, um es am Enzym zu binden. Das Sulfat ist nun kovalent an das Enzym gebunden und zwei Sulfat-Sauerstoffatome koordinieren das Magnesiumion.


Abbildung 5.1: Erster Schritt der Sulfatesterspaltung. Nur die wichtigsten Wechselwirkungen zwischen den beteiligten Komponenten sind gezeigt.

Im zweiten Schritt der Katalyse wird die C-O-Bindung des Enzym-Sulfat-Esters gespalten, wobei die treibende Kraft der Energiegewinn aus der Rückbildung der Carbonylverbindung ist (Abbildung 5.2). Histidin 125 könnte aufgrund seiner sterischen Nähe die Deprotonierung der benachbarten Hydroxylgruppe erleichtern. Die zweifach negative Ladung des abgespaltenen Sulfats wird teilweise durch das Magnesium ausgeglichen, jedoch sind die Wechselwirkungen zwischen Enzym und Sulfat offenbar so gering, daß das Sulfat die Enzymtasche verläßt.

$$
\text { (K302) } \stackrel{\oplus}{\mathrm{N}}-\mathrm{H}
$$

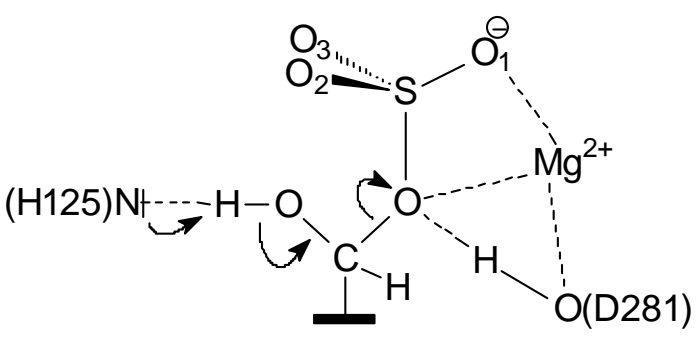

IN(H229)<smiles>CCC=CC(C)C</smiles>

$\mathbb{N}(\mathrm{H} 229)$<smiles>[Y6]OCCO</smiles>

Abbildung 5.2: Zweiter Schritt der Sulfatesterspaltung. 
Wassermoleküle, welche zuvor vom Substrat verdrängt worden waren, treten wieder in die Tasche ein und können dort durch Hydratisierung der Aldehydgruppe zum geminalen Diol für die Regeneration des hydratisierten Formylglycins sorgen (Abbildung 5.3). Außerdem können sie den Protonenausgleich innerhalb der aktiven Tasche ermöglichen. Nach Bindung eines neuen Substratmoleküls beginnt ein neuer Zyklus.

$$
(\mathrm{K} 302) \stackrel{\oplus}{\mathrm{N}}-\mathrm{H}
$$

IN(H229)

$$
(\mathrm{K} 302) \stackrel{\oplus}{\mathrm{N}}-\mathrm{H}
$$

$\mathrm{H}_{\backslash}^{\oplus}(\mathrm{H} 229)$
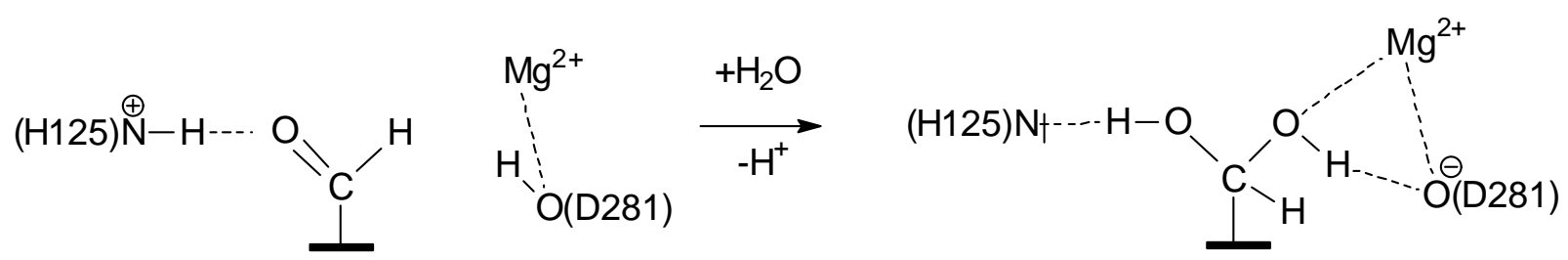

Abbildung 5.3: Regeneration des Grundzustandes des Enzyms.

Um den Enzym-Substrat-Ester als Intermediat der Katalyse nachweisen zu können, wurde die Kristallstruktur der ASA-C69S nach Inkubation mit pNCS untersucht. ASAC69S sollte pNCS unter Bildung eines Enzym-Sulfat-Esters spalten. Da jedoch die zweite Hydroxylgruppe in Position 69 fehlt, sollte dieses Intermediat stabil bleiben. Leider konnte im Kristall kein Sulfatester in Position 69 nachgewiesen werden. Weitere biochemische Experimente mit $\left[{ }^{35}\right.$ S]pNCS zeigten, daß das Sulfat nur zu etwa $20 \%$ kovalent an das Serin 69 gebunden wird [Recksieck et al., 1998]. Ein Sulfateinbau von etwa $20 \%$ würde in der Röntgenstrukturanalyse nur ein schwaches Signal geben und bei einer Auflösung von ca. 2,7 ̊̊ vermutlich überhaupt nicht sichtbar sein.

Der geringe Sulfateinbau könnte durch die Lage der Serinseitenkette erklärt werden, wie sie in der Kristallstruktur der ASA-C69S gefunden wurde. Die Hydroxylgruppe des Serin 69 ist so ausgerichtet, daß sie mit Histidin 125 eine Wasserstoffbrücke ausbildet. Die Hydroxylgruppe befindet sich daher in der Position der Hydroxylgruppe O 2 des Aldehydhydrates der wt-ASA, welche einen relativ großen Abstand zum Sulfatschwefel bildet $(4,0 \AA)$ und daher nicht für den Angriff auf den Schwefel in Frage kommt. Zu einem geringen Anteil jedoch könnte die Hydroxylgruppe auch in der energetisch weniger bevorzugten Lage vorliegen und somit einen geringen Sulfateinbau ermöglichen. 


\subsubsection{Vergleich der ASA mit der Arylsulfatase B und der alkalischen Phosphatase}

Die aktiven Zentren der drei Enzyme ASA, Arylsulfatase B (ASB) und der alkalischen Phosphatase (AP) sind strukturell sehr ähnlich, was ebenfalls für große Teile der Gesamtstruktur gilt. In Tabelle 5.1 sind einige Aminosäuren bzw. die Metallkationen der aktiven Zentren aufgeführt, welche in den drei Strukturen an nahezu äquivalenten Positionen zu finden sind:

\begin{tabular}{|c|c|c|}
\hline ASA & ASB & AP \\
\hline FGly69 & FGly91 & Ser102 \\
\hline $\mathrm{Mg}^{2+}$ & $\mathrm{Ca}^{2+}$ & $\mathrm{Zn2^{2+ }}$ \\
\hline Lys123 & Lys145 & Arg166Nn1 \\
\hline His229 & His242 & Arg166Nn2 \\
\hline Lys302 & Lys318 & $\mathrm{Zn}^{2+}$ \\
\hline
\end{tabular}

Tabelle 5.1: Metallkationen und Aminosäuren, die in der ASA, ASB und der AP an äquivalenten Positionen liegen.

Die streng konservierten Aminosäuren der aktiven Zentren befinden sich in der ASA und ASB an den gleichen Positionen. Der wohl größte Unterschied der beiden Sulfatasemodelle liegt in der Interpretation der Seitenketten der modifizierten Formylglycinreste. In der ASA wird dort ein fehlgeordneter Aldehyd bzw. ein geminales Diol des hydratisierten Formylglycins $-\mathrm{CH}(\mathrm{OH})_{2}$ beschrieben, während in der ASB ein Sulfatester $-\mathrm{CH}(\mathrm{OH}) \mathrm{OSO}_{3}{ }^{-}$in die Differenzelektronendichte modelliert wurde. Dieser Unterschied ist bisher nicht erklärbar.

Die Sulfatbindungsstelle befindet sich in beiden Sulfatasen in der gleichen Region. Die Sulfatgruppe des ASB-Sulfatesters bildet zu einigen protonierten Seitenketten (Lys145, His242, Lys318) Wasserstoffbrücken aus, die äquivalent zu den Wasserstoffbrücken im Komplex der ASA-Mutante (Lys123, His229 und Lys302) sind. Ebenso findet in beiden Enzymen eine direkte Wechselwirkung zum divalenten Metallkation statt.

Für die ASB ist ein Katalysemechanismus beschrieben worden, der auf dem in der Ruheform gefundenen Enzym-Sulfat-Ester basiert [Bond et al., 1997]. Durch Abspaltung des Sulfates wird der freie Aldehyd regeneriert und ein Substratmolekül gebunden. Ein Sauerstoffatom der Sulfatgruppe greift nun den Carbonylkohlenstoff nukleophil an, wodurch ein Enzym-Substrat-Diester entsteht. Anschließend wird die 
Esterbindung des Substrates gespalten und der Restalkohol freigesetzt. Der wichtigste Unterschied zum Katalysemechanismus der ASA liegt in der Art der Bildung des Enzym-Sulfat-Esters (Abbildung 5.4). Während beim Mechanismus der ASA ein nukleophiler Angriff von einem Sauerstoffatom des Formylglycinhydrates erfolgt, impliziert der von Bond et al. für die ASB vorgeschlagene Mechanismus einen nukleophilen Angriff eines Sulfat-Sauerstoffatoms auf den Aldehyd-Kohlenstoff des $\mathrm{C} \alpha$-Formylglycins.

Betrachtet man die Abstände zwischen Formylglycin und Sulfat, so scheint ein Angriff, wie er für die ASB postuliert wurde, für die ASA unwahrscheinlich, da die Abstände der Sulfatsauerstoffatome zum Carbonylkohlenstoffatom der Formylglycin-Seitenkette mit 3,3 - 3,5 Å groß ausfallen. Das Oy-Atom der Formylglycin-Seitenkette dagegen hat zum Sulfatschwefel einen Abstand von 2,5 $\AA$, für einen nukleophilen Angriff eine günstige Distanz. Somit wird der von Lukatela et al. postulierte Mechanismus durch die in dieser Arbeit erhaltenen Strukturdaten untermauert.
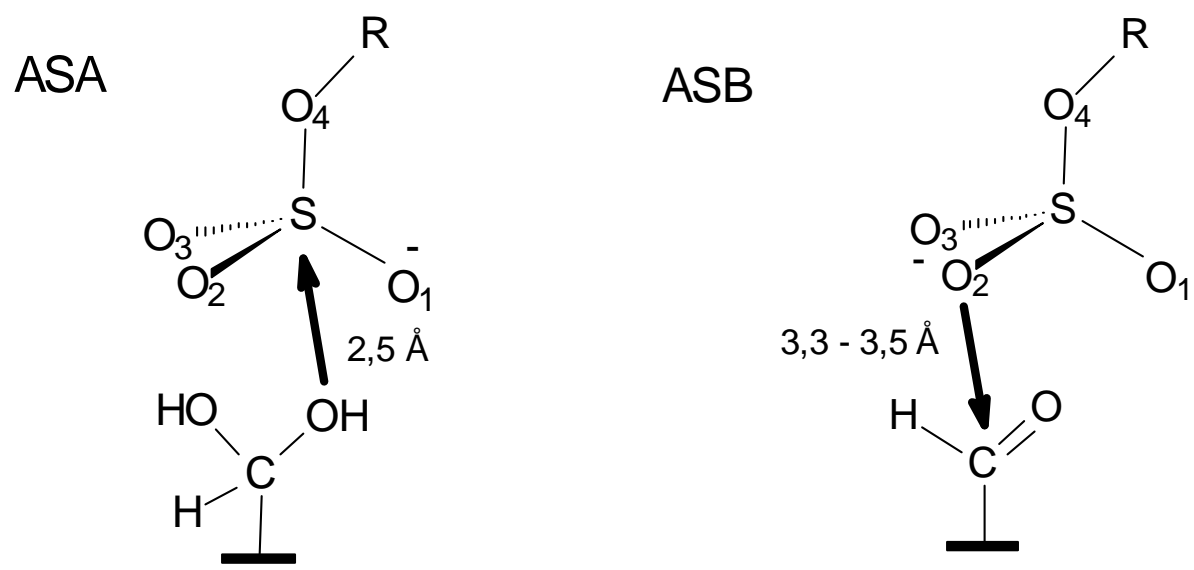

Abbildung 5.4: Nukleophiler Angriff bei der Sulfatesterspaltung, wie er für ASA und ASB beschrieben wird. Die eingezeichneten Atomabstände beziehen sich auf die Struktur der ASA.

Die alkalische Phosphatase zeigt nach Superposition mit der ASA eine hohe Übereinstimmung. Der für die AP kristallisierte und röntgenstrukturanalytisch untersuchte Komplex aus Enzym und substratanalogem Inhibitor (anorganisches Phosphat) zeigte, daß das Phosphat in unmittelbarer Nähe zum Serin 102, das dem Formylglycin der ASA entspricht, durch Wechselwirkungen zu zwei Stickstoffatomen des Arginin 166 und zwei Zinkionen fixiert wird [Kim \& Wyckoff, 1991]. Die Aminosäurereste His229 und Lys302 sowie das Magnesiumion an äquivalenten Positionen der ASA gehen vergleichbare Wechselwirkungen ein. Das Estersauerstoffatom des Sulfats und das äquivalente Sauerstoffatom des Phosphats sind am stärksten fixiert. 
Der für die AP aufgestellte Katalysemechanismus geht davon aus, daß das Serin 102 einen nukleophilen Angriff auf den Phosphatphosphor des Substrates durchführt, vergleichbar mit dem Angriff des Formylglycinsauerstoffes der ASA auf den Sulfatschwefel. Wie bei der ASA wird nach der Bildung eines Übergangszustandes der Rest als Alkohol eliminiert. Der Enzym-Phosphat-Ester wird in der AP nun hydrolytisch gespalten und damit das Serin 102 regeneriert.

Die große Strukturähnlichkeit des ASA-C69A+pNCS-Komplexes mit dem AP-PhosphatKomplex ist ein starkes Argument dafür, daß Substratesterspaltung und Bildung des sulfatierten/phosphatierten Enzyms in ASA und AP analog verlaufen. Die Anwesenheit eines zweiten möglicherweise durch Protonenentzug aktivierten Sauerstoffatoms im Formylglycin der ASA, das der AP fehlt, begründet den abweichenden Mechanismus bei der Spaltung des Enzymesters im zweiten Schritt der Katalyse durch die ASA.

\subsubsection{Ausblick}

Für den Nachweis des intermediären Enzym-Sulfat-Esters bietet sich die Röntgenstrukturanalyse eines Komplexes aus Substrat und der Doppelmutante ASAC69S-H125A an. In dieser Mutante sollte die Hydroxylgruppe des Serin 69 zum Magnesium ausgerichtet sein, da Histidin 125 als konkurrierender Koordinationspartner fehlt (Abbildung 5.5). Somit wäre der Serinrest bevorzugt in der Position, in der er den Sulfatschwefel angreifen kann. Da der Enzym-Sulfat-Ester nicht abgespalten werden kann, wie für die ASA-C69S gezeigt wurde, sollte eine Strukturbestimmung des Intermediats möglich sein.
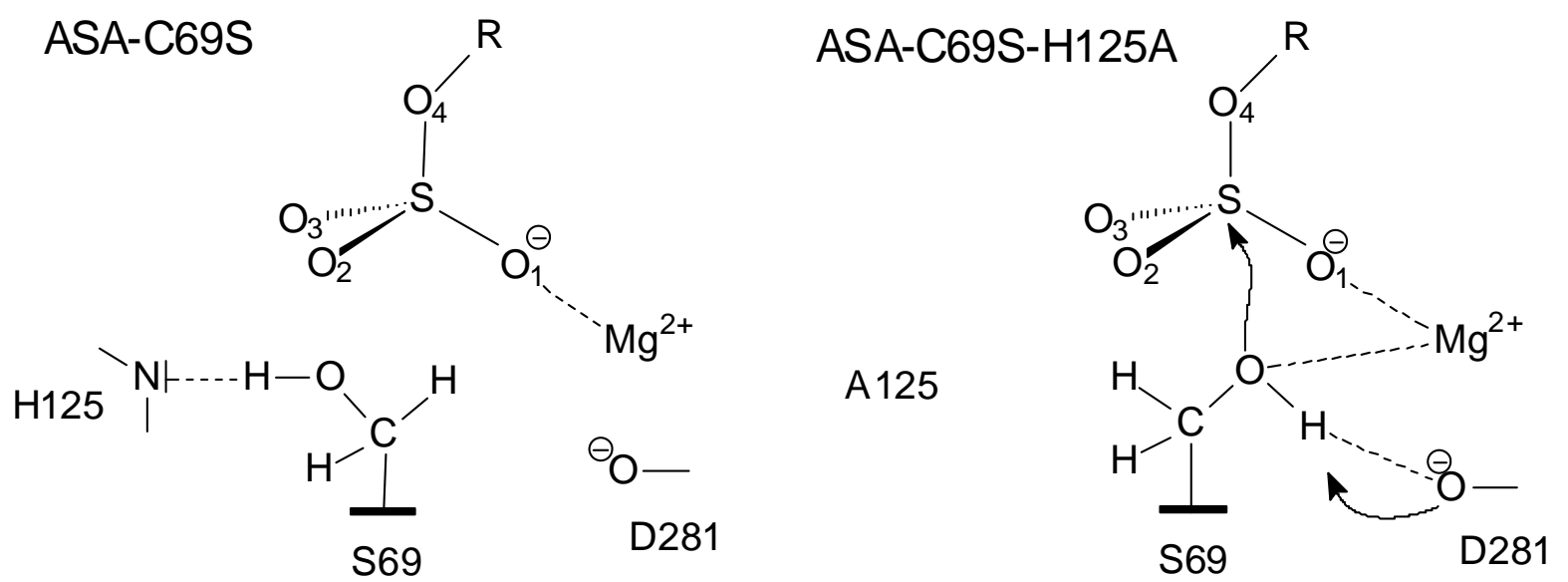

Abbildung 5.5: Mögliche Orientierung der Hydroxylgruppe von Serin 69 in ASA-C69S und ASAC69S-H125A.

Zur Zeit ist nicht klar, wie die Reste der natürlichen ASA-Substrate in der Enzymtasche binden und welche Aminosäurereste dabei beteiligt sind. Da Cerebrosid-3-sulfat durch Sphingolipid-Aktivatorprotein B löslich gemacht wird, wäre die Analyse eines 
Komplexes von ASA mit dem natürlichen Substrat, gebunden an SphingolipidAktivatorprotein $B$, für das Verständnis der Substratbindung in vivo von Interesse.

Die Aufklärung der Struktur zweier bakterieller Sulfatasen, von Pseudomonas aeruginosa und Klebsiella pneumoniae, die bereits in gereinigter Form vorliegen, könnte weitere Informationen über Bindung und Katalyse liefern. Die bakteriellen Sulfatasen besitzen den Vorteil, daß sie nicht glykosyliert sind und deshalb eine höhere Auflösung der Meßdaten erwartet werden kann. Fehlordnungen und Teilbesetzungen könnten mit hochauflösenden Daten besser interpretiert werden. Da die bakteriellen Sulfatasen zur ASA im Bereich der Aminosäuren des aktiven Zentrums eine hohe Sequenzhomologie zeigen und in beiden bakteriellen Enzymen ein für die katalytische Aktivität essentieller Formylglycin-Rest nachgewiesen werden konnte, kann davon ausgegangen werden, daß das aktive Zentrum strukturell sehr ähnlich aufgebaut ist und demnach Rückschlüsse auf die humane ASA möglich sind.

\subsection{ASA-P426L}

\subsubsection{Oktamerisierungsverhalten und Stabilität der wt-ASA und der ASA-P426L}

Die Untersuchungen zur Arylsulfatase A-Mutante ASA-P426L, die im Rahmen dieser Arbeit durchgeführt wurden, führten zu folgendem Modell für die verringerte Stabilität der ASA-P426L im Vergleich zur wt-ASA in den Lysosomen:

An der Oberfläche der ASA befindet sich eine potentielle Spaltstelle für Cathepsin L. Diese Spaltstelle wird jedoch im Lysosom durch eine Oligomerisierung der ASA für Cathepsin L unzugänglich. Hierbei lagern sich ASA-Dimere in der Region der potentiellen Spaltstelle aneinander und bilden so ein ringförmiges Oktamer. Durch die Mutation in der ASA-P426L wird die Oligomerisierung leicht gestört, so daß das DimerOktamer-Gleichgewicht im Lysosom nicht mehr vollständig auf der Seite des Oktamers liegt. Ein geringer Anteil an Molekülen liegt als Dimer vor und trägt nun seine potentielle Spaltstelle für Cathepsin L ungeschützt an der Oberfläche des Enzyms, so daß ein Angriff durch Cathepsin L stattfinden kann. Da das Dimer durch den Abbau aus dem Gleichgewicht entfernt wird, wird nach und nach die ASA-Mutante durch Cathepsin L abgebaut.

Die Grundlage für dieses Modell bilden die folgenden experimentellen Befunde.

Beim Vergleich der Röntgenstrukturen der wt-ASA und der ASA-P426L wurden nur geringe Strukturänderung im Bereich der Mutation und der Spaltstelle für Cathepsin L gefunden. Die Frage, ob diese Strukturänderungen in der ASA-P426L zur Neubildung einer Spaltstelle für Cathepsin L führen, die in der wt-ASA fehlt, oder ob sowohl Mutante als auch Wildtyp die Spaltstelle enthalten, der Wildtyp jedoch auf andere Weise vor 
Proteinasen geschützt ist, läßt sich auf der Basis der vorhandenen Daten nicht eindeutig klären. Für die zweite Möglichkeit spricht jedoch, daß die Strukturunterschiede im Bereich der Spaltstelle schwach ausfallen, und auf der anderen Seite für Cathepsin L keine ausgeprägte Präferenz für Aminosäurereste C-terminal der Spaltstelle beschrieben wurde (die mutierte Aminosäure in Position 426 liegt 4 Aminosäuren C-terminal zur Spaltstelle). Bisher wurde in der Literatur nur eine Spaltspezifität für die Position 2 vor der Spaltstelle beschrieben, wonach dort hydrophobe Reste bevorzugt werden (in der wt-ASA und der ASA-P426L befindet sich hier ein Leucinrest).

Bedingung für die Stabilität der wt-ASA bei Anwesenheit einer Spaltstelle für Cathepsin L wäre ein Schutzmechanismus, beispielsweise durch Maskierung der Spaltregion innerhalb eines ASA-Oligomers. Tatsächlich liegt die wt-ASA unterhalb von $\mathrm{pH} \mathrm{5,6}$ als Oktamer vor, mit Kontaktstellen zwischen den ASA-Dimeren, die sich in unmittelbarer Nähe zur Spaltstelle befinden. Während die Spaltstelle (vor Alanin 422) im Dimer an der Moleküloberfläche gut zugänglich ist, ist die Bindung einer Proteinase wie Cathepsin L an der gleichen Stelle im Oktamer aus sterischen Gründen schwer vorstellbar. Bildet die Oktamerisierung der wt-ASA den effektiven Schutz vor einem Angriff der Proteinase, muß die Ursache für die erhöhte Zugänglichkeit der Spaltstelle in der Mutante in einer verminderten Ausbildung solcher Oktamere begründet sein. Dies konnte experimentell gezeigt werden. Im Bereich von $\mathrm{pH}$ 4,8 - 5,6 liegt die wt-ASA vollständig als Oktamer, die ASA-P426L dagegen mit steigendem pH-Wert zunehmend als Dimer vor. Auch konnte gezeigt werden, daß unter dem Einfluß von organischem Lösungsmittel das Oktamer der Mutante instabiler ist, als das der wt-ASA.

Die Kristallstruktur zeigt, daß sich die Oligomerisierungsregion der ASA aus hauptsächlich hydrophoben Wechselwirkungen, aber auch aus Wechselwirkungen über Wasserstoffbrücken zusammensetzt. Für die Lage des Dimer-Oktamer-Gleichgewichts spielen die beiden aus diesen Wechselwirkungen gewonnenen Energiebeträge eine Rolle. Die Mutation P426L, die diese Änderung im Oligomerisierungsverhalten verursacht, liegt in unmittelbarer Nähe zu den Aminosäuren, die an der Bindung des Oktamers beteiligt sind. Das cis-Prolin 425 ist als einzige hydrophobe an der Oktamerisierung beteiligte Aminosäure in der Mutante deutlich anders positioniert. Daher ist anzunehmen, daß die Schwächung der hydrophoben Wechselwirkungen bei der Mutante in erster Linie durch die Verschiebung der Atome des cis-Prolin 425 zustandekommen.

An der Stabilisierung des Oktamers durch Wasserstoffbrücken sind zwei Aminosäureseitenketten beteiligt (Lysin 457 und Glutamat 424). Lysin 457 bildet zwei Wasserstoffbrücken zum gegenüberliegenden Dimer aus, kommt jedoch für die $\mathrm{pH}$ Wert-Abhängigkeit der Oktamerisierung schwerlich in Frage, da der normale $\mathrm{pK}_{\mathrm{s}}$-Wert der Lysinseitenkette bei 10,8 liegt und die beiden Bindungspartner jeweils 
Carbonylsauerstoffatome innerhalb der Peptidkette sind. Im sauren bis neutralen $\mathrm{pH}$ Bereich sollten diese Wasserstoffbrücken daher stabil sein.

Als Erklärung für die pH-Abhängigkeit der Oligomerisierung der ASA bietet sich allein das Glutamat 424 an, da es einen $\mathrm{pK}_{\mathrm{s}}$-Wert besitzt, der ein ProtonierungsDeprotonierungsgleichgewicht in diesem $\mathrm{pH}$-Bereich zuläßt (normaler $\mathrm{pK}_{\mathrm{s}}$-Wert: 4,3 ). Die Abhängigkeit des Oligomerisierungszustandes vom pH-Wert kann daher durch die Protonierung/Deprotonierung der $\delta$-Carboxylgruppe von Glutamat 424 erklärt werden (Abbildung 5.6). Diese beiden Zustände korrelieren jeweils mit den Positionen A und B, die in der Kristallstruktur als Fehlordnung in der Elektronendichte gefunden wurden. In Position A bildet die protonierte Carboxylgruppe eine intermolekulare Wasserstoffbrücke zu dem Peptid-Sauerstoffatom von Phenylalanin 398 des gegenüberliegenden Dimers (Abstand: 2,9 Å). In Position B wird eine intramolekulare Wasserstoffbrücke zum Glutamin 460 gebildet (Abstand: 3,0 Å). Bei dieser Wechselwirkung wird das Proton von Glutamin 460 gestellt, so daß die Carboxylgruppe wahrscheinlich deprotoniert vorliegt. Bei niedrigem $\mathrm{pH}$-Wert sollte daher die Oktamerisierung durch die intermolekulare Wasserstoffbrücke begünstigt werden.

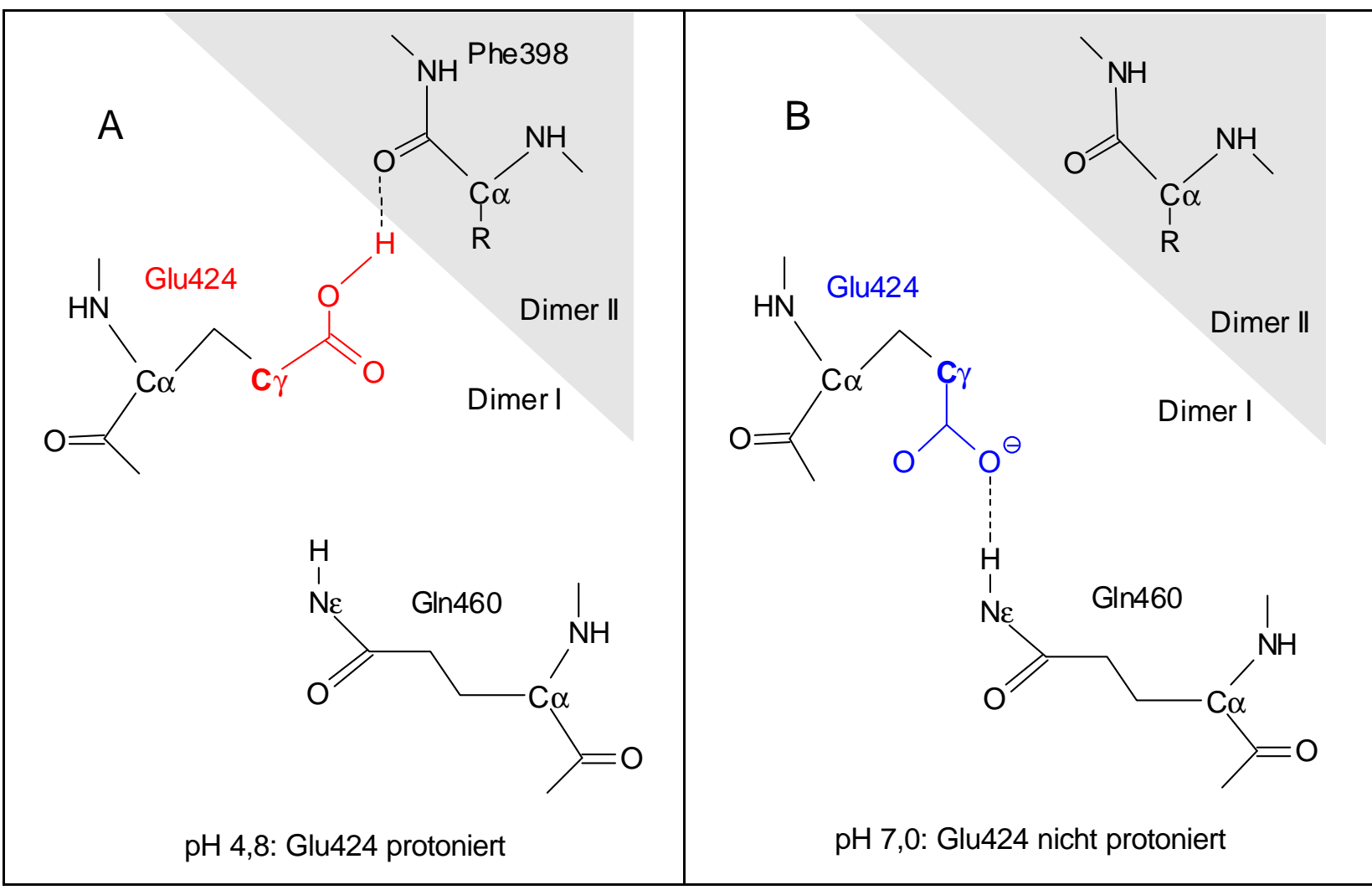

Abbildung 5.6: Beschreibung der pH-abhängigen Positionen der Seitenkette von Glutamat 424. Die Aminosäuren Glutamat 424 und Glutamin 460 in Dimer I, sowie das Phenylalanin 398 in Dimer II (grau unterlegt) sind dargestellt. Die im Kristall fehlgeordneten Atome von Glutamat 424 sind rot (protoniert, A) bzw. blau (nicht protoniert, B) dargestellt. Protonen an Kohlenstoffatomen wurden der Übersichtlichkeit halber weggelassen. 
Während die pH-Abhängigkeit der Oktamerisierung durch die Funktion des Glutamat 424 erklärt werden kann, bleibt die Ursache für die unterschiedliche $\mathrm{pH}$-Abhängigkeit bei Wildtyp und Mutante unklar. Zum einen könnte durch eine veränderte Umgebung in der Mutante der $\mathrm{pK}_{\mathrm{s}}$-Wert des Glutamat 424 erniedrigt sein, was die intramolekularen Wechselwirkungen verstärken und damit die Bildung des Oktamers schwächen würde. Da die Struktur in direkter Umgebung des Glutamatrestes in der Mutante keine großen Abweichungen von der wt-ASA zeigt, ist diese Erklärung unwahrscheinlich. Die zweite Möglichkeit geht davon aus, daß die Wechselwirkung über Glutamat 424 in der Mutante unverändert ist. Dadurch jedoch, daß die hydrophoben Wechselwirkungen in der Mutante destabilisiert sind, erhält die Bindung über Glutamat 424 für die Oktamerisierung ein stärkeres Gewicht.

\subsubsection{Vergleich zu anderen humanen Sulfatasen}

Ein Vergleich der Aminosäuresequenzen der humanen Sulfatasen läßt auf eine große strukturelle Homologie unter den Sulfatasen schließen. Im C-terminalen Bereich der ASA zeigt besonders die Region des $\beta$-Faltblattes 18 und der darauf folgenden Aminosäuren eine hohe Sequenzhomologie zu den Arylsulfatasen $C-F$ und der N-Acetylgalactosamin-6-sulfatase mit Leucin/Valin und Prolin in analogen Positionen zu Leucin 420 (Spaltspezifität für Cathepsin L) und Prolin 426 (Mutation) der ASA. Da jedoch für die Arylsulfatasen $\mathrm{C}-\mathrm{F}$ keine Lokalisation in den Lysosomen bekannt ist, ist für diese Sulfatasen eine Funktion des $\beta$-Stranges 18 für die Oligomerisierung wie sie für die ASA gefunden wurde unwahrscheinlich, für die lysosomale $\mathrm{N}$-Acetylgalactosamin-6-sulfatase aber möglich.

Die ASB zeigt allgemein und speziell in der Region des $\beta$-Stranges 18 eine schwache Sequenzhomologie zur ASA. In diesem Bereich befindet sich in der ASB das Prolin 467 analog zum Prolin 426 der ASA, welches jedoch nur von wenigen zur ASA homologen Aminosäuren umgeben ist. Im Bereich der Spaltstelle für Cathepsin L der ASA ist in der ASB keine Homologie zu finden. Die Struktur der ASB wurde über Röntgenstrukturanalyse bestimmt. Bis auf einige Insertionen bzw. Deletionen in Schleifenbereichen ist die Sekundär- und Tertärstruktur der beiden Sulfatasen identisch. Das Prolin 467 der ASB befindet sich wie das Prolin 426 der ASA an der Oberfläche des Enzyms, jedoch in einem Schleifenbereich vor dem $\beta$-Strang, der dem $\beta$-Strang 18 der ASA entspricht. In diesem Bereich wurden bei ASB-Defizienzen bisher keine Mutation gefunden. Die ASB, die bei vergleichbaren Bedingungen gereinigt und kristallisiert wurde, liegt im Kristall als Monomer vor, und im Gegensatz zur ASA ist die ASB auch in Lösung ein Monomer [McGovern et al., 1982]. Da die ASB als Monomer bei lysosomalem pH-Wert stabil ist und offensichtlich nicht von Cathepsin $L$ angegriffen wird, unterstreicht das die 
Ergebnisse der Strukturdaten, wonach die ASB keine zur ASA homologe Spaltstelle in dieser Region besitzt.

\subsubsection{Ausblick}

Die bisherigen Experimente zur Stabilität der ASA zeigten, daß die Mutation P426L gleichzeitig zur Instabilität und einer Verschiebung des Dimer-Oktamer-Gleichgewichtes führt. Die nächste Aufgabe wird sein, Oktamerisierung und Stabilität der ASA in einen direkten kausalen Zusammenhang zu bringen. Dafür sollen ASA-Mutanten hergestellt werden, in denen Aminosäuren ausgetauscht sind, die direkt an der Oktamerisierung beteiligt sind, um anschließend Oligomerisierung und Stabilität dieser Mutanten zu untersuchen. Da nach den bisherigen Überlegungen der Glutamat 424-Rest für die pH-Abhängigkeit der Oktamerisierung verantwortlich ist, sollen die ASA-Mutanten ASAE424A und ASA-E424Q hergestellt werden. Aufgrund der Strukturdaten ist zu erwarten, daß sich Alanin in dieser Position destabilisierend auf die Oktamerisierung auswirkt, da die Wasserstoffbrücke zum benachbarten Dimer verloren geht. Die Mutante müßte daher leichter von Cathepsin L gespalten werden. Ein Glutaminrest dagegen könnte über die Säureamidgruppe ähnlich dem Glutamatrest eine Wasserstoffbrücke ausbilden, die jedoch pH-unabhängig aufrecht erhalten werden würde.

Um in vivo die Beteiligung von Cathepsin L am Abbau der Mutante ASA-P426L zu zeigen, können Cathepsin L-spezifische Inhibitoren eingesetzt werden, die in humanen Hautfibroblasten den Abbau durch Cathepsin $L$ hemmen. Solche Experimente können die Grundlage dafür bilden, Cathepsin L-spezifische Inhibitoren als therapeutische Mittel bei der Behandlung von MLD-Patienten einzusetzen. Da eine Erhöhung der ASAAktivität auf ca. $10 \%$ der normalen Aktivität bereits für einen ausreichenden Abbau der Sulfatester sorgen würde, könnte eine partielle Inhibition von Cathepsin $L$ ausreichen, um die klinischen Symptome der MLD zu verringern. 


\section{Zusammenfassung}

Die vorliegende Arbeit umfaßt röntgenstrukturanalytische und biochemische Untersuchungen zum Katalysemechanismus und zur Stabilität der humanen Arylsulfatase A (ASA). Dieses Enzym katalysiert den initialen Schritt der Degradation von Cerebrosidsulfaten in den Lysosomen.

Zur Untersuchung der Substratbindung der ASA wurde ein Enzym-Substrat-Komplex aus der katalytisch inaktiven ASA-Mutante ASA-C69A und dem synthetischen Substrat p-Nitrocatecholsulfat erzeugt. Die Röntgenstrukturanalyse dieses Komplexes zeigte die Koordination des Substrats durch Aminosäureseitenketten des aktiven Zentrums. Die Sulfatsauerstoffatome des Substrats werden durch Wasserstoffbrücken zu vier Aminosäureseitenketten (Lysin 123, Serin 150, Histidin 229 und Lysin 302) und durch Koordination zu einem Magnesiumion im aktiven Zentrum fixiert. Einblicke in die katalytische Umsetzung des gebundenen Substrats ergeben sich durch Kombination der Strukturdaten mit denen der wt-ASA, in der sich an Position 69 der für die Katalyse essentielle hydratisierte Formylglycinrest befindet. Es zeigte sich, daß der Abstand zwischen dem Hydroxylsauerstoff $O \gamma 1$ des Formylglycinhydrates und dem Sulfatschwefel 2,5 Å beträgt. Ein nukleophiler Angriff dieses Hydroxylsauerstoffs, aktiviert durch den Abzug des Protons durch das Aspartat 281, auf den Sulfatschwefel, positiv polarisiert durch die Sulfatbindung, wird daher wahrscheinlich. Somit käme es zur Bildung eines Enzym-Sulfat-Intermediats und zur Abspaltung des Substratalkoholats. Für die Protonierung des abgespaltenen Alkoholrests bietet sich Histidin 229 an, das einen Abstand von 2,4 $\AA$ zum Sulfatestersauerstoff des Substrats aufweist. Der Versuch, das sulfatierte Enzym direkt in einer Verbindung der Mutante ASA-C69S mit pNCS durch Röntgenstrukturanalyse nachzuweisen, schlug fehl. In der Struktur zeigt Serin 69 eine freie Hydroxylgruppe in einer Position, die für einen Angriff auf den Schwefel ungünstig ist. Insgesamt stützen die Daten den Mechanismus der Sulfatesterspaltung und der Eliminierung des Alkoholrestes, wie er für die ASA vorgeschlagenen wurde, und widersprechen einer Addition des Substrats an die Formylgruppe, wie er für die verwandte ASB vorgeschlagen wurde.

Im zweiten Teil der Arbeit wurde die Stabilität der wt-ASA im Vergleich zu der Mutante ASA-P426L untersucht. Diese Mutante, die 25\% der Fälle an metachromatischer Leukodystrophie, einer lysosomalen Speicherkrankheit, verursacht, wird in den Lysosomen durch Cysteinproteinasen abgebaut. In vitro-Experimente mit den Cysteinproteinasen Cathepsin L, B, H und S zeigten, daß Cathepsin L die ASA-P426L, nicht aber die wt-ASA abbaut, während die anderen Cathepsine in ihrem Spaltungsverhalten nicht zwischen Mutante und Wildtyp unterscheiden. Durch Edman- 
Sequenzierung der Spaltprodukte konnte die Spaltstelle für Cathepsin L N-terminal von Alanin 422 in Nachbarschaft zur Mutation P426L lokalisiert werden.

Im Vergleich zur wt-ASA zeigte die Röntgenstruktur der ASA-P426L im gesamten Bereich und auch speziell im Bereich der Mutation und Spaltstelle kaum Veränderungen. Allein die Seitenkette der mutierten Aminosäure Leucin 426 und die Position des benachbarten cis-Prolin 425 sind gegenüber der wt-ASA verändert. cisProlin 425 ist über hydrophobe Wechselwirkungen direkt an der Oktamerbildung aus vier ASA-Dimeren beteiligt. In Gelfiltrationsexperimenten konnte gezeigt werden, daß im Bereich des lysosomalen pH-Wertes das Dimer-Oktamer-Gleichgewicht für die Mutante in Richtung zum Dimer verschoben ist. Die pH-Abhängigkeit der Oktamerisierung wird mit dem Protonierungszustand der Seitenkette von Glutamat 424 erklärt, die eine intermolekulare Wasserstoffbrücke zum benachbarten ASA-Dimer ausbilden kann. Diese Wasserstoffbrückenbildung bekommt in der Mutante eine stärkere Bedeutung für die Oktamerisierung, da die hydrophoben Wechselwirkungen in der Oktamerisierungsregion aufgrund der Mutation verringert sind.

Diese Ergebnisse führen zu der Hypothese, daß in den Lysosomen ein Abbau der ASA durch Oktamerisierung verhindert wird. In der Mutante ASA-P426L ist die Oktamerisierung gestört, wodurch die Spaltstelle für die Proteinase Cathepsin L zugänglich gemacht wird und ein Abbau der Mutante erfolgt. Dies wiederum führt zur Akkumulation von Cerebrosidsulfaten und zum Krankheitsbild der metachromatischen Leukodystrophie. 


\section{Literatur}

Ansorge W.: FAst and sensitive detection of protein and DNA bands by treatment with potassium permanganate. J.Biochem.Biophys. Meth 11 (1985) 13-25.

Barrett A.J., Kirschke H.: Cathepsin B, Cathepsin H, and Cathepsin L. Meth.Enzymol. 80 (1981) 535-561.

BobScript: V. 2.5 (1994-1999) (C) Robert Esnouf.

Bond C.S., Clements P.R., Ashby S.J., Collyer C.A., Harrop S.J., Hopwood J.J., Guss J.M.: Structure of a human lysosomal sulfatase. Structure 5 (1997) 277-289.

Brünger A.T.: Assessment of phase accucy by cross validation: The free $R$ value. Methods and applications. Acta Cryst. D49 (1993) 24-36.

CCP4, Collaborative Computational Project, Number 4. The CCP4 Suite: Programs for Protein Crystallography. Acta Cryst. D50 (1994) 760-763.

Chen C., Okayama $\mathrm{H}$.: High-efficiency transformation of mammalian cells by plasmid DNA. Mol.Cell.Biol.7(8) (1987) 2745-2752.

Cruickshank D.W.J.: Remarks about protein structure precision. Acta Cryst. D55 (1999) 583-601.

Dierks T., Schmidt B., von Figura K.: Conversion of cysteine to formylglycine: A protein modification in the endoplasmic reticulum. Proc.Natl.Acad.Sci.USA 94 (1997) 1196311968.

Dierks T., Miech C., Hummerjohann J., Schmidt B., Kertesz M.A., von Figura K.: Formation of formylglycine in prokaryotic sulfatases by oxidation of either cysteine or serine. J.Biol.Chem. 273 (1998) 25560-25564.

Dierks T., Lecca M.R., Schlotterhose P., Schmidt B., von Figura K.: Sequence determinants directing conversion of cysteine to formylglycine in eukaryotic sulfatases. EMBO J. 18 (1999) 2084-2091.

Dittmer F.: Phosphorylierung der Arylsulfatase A. Diplomarbeit, Georg-AugustUniversität Göttingen (1995).

Dittmer F., von Figura K.: Phosphorylation of arylsulphatase A occurs through multiple interactions with the UDP-N-acetylglucosamine-1-phosphotransferase proximal and distal to its retrieval site by the KDEL receptor. Biochem. J. 15 (340) (1999) 729-736.

Ducruix A., Griegé R.: Crystallization of Nucleic Acids and Proteins. 1. Aufl., Oxford University Press, New York (1992) 73-98. 
FRAMBO: Programm zur Diffraktometersteuerung und Datensammlung mit Flächenzählern. (1994), (c) Siemens.

Garman E., Schneider T.R.: Macromolecular Cryocrystallography. J.Appl.Crystallogr. 30 (1997) 211-237.

Gieselmann V., Polten A., Kreysing J., Kappler J., Fluharty A., Bohne W., von Figura K.: Mutations in Arylsulfatase A Alleles Causing Metachromatic Leukodystrophy. Brain Dysfunct. 4 (1991a) 235-243.

Gieselmann V., Polten A., Kreysing J., Kappler J., Fluharty A., von Figura K.: Molecular Genetics of Metachromatic Leukodystrophy. Dev.Neurosci 13 (1991b) 222-227.

Gieselmann V., Zlotogora J., Harris A., Wenger D.A., Morris C.P.: Molecular Genetics of Metachromatic Leukodystrophy. Human Mutations 4 (1994) 233-242.

Gustavson K., Hagberg B.: The incidence and genetics of metachromatic leucodystrophy in northern Sweden. Acta Pediatr.Scand60 (1971) 585-590.

Helliwell J.R.: Macromolecular Crystallography with Synchrotron Radiation. Cambridge University Press (1992).

Kálmán, A.: Mean X-Bond Lengths of the $\mathrm{XO}_{4}{ }^{\mathrm{n}-}$ Tetrahedal Oxyanions. J.Chem.Soc.A (1971) 1857-1859.

Karle I.: Folding Aggregation and Molecular Recognition in Peptides. Acta Cryst. B48 (1992) 341-356.

Kim E.E., Wyckoff H.W.: Reaction Mechanism of Alkaline Phosphatase Based on Crystal Structures. J.Mol.Biol. 218 (1991) 449-464.

Kirschke H., Barrett A.J.: Chemistry of lysosomal proteases in lysosomes: their role in protein breakdown. Academic Press, London (ed. Glaumann H., Ballard F.J.) (1987) 193-238.

Kirschke H., Rawlings N.D., Barett A.J.: Proteinases 1: lysosomal cysteine proteinases. Protein Profile 2 (ed. Sheterline P.) (1995) 1587-1643.

Kasper D., Dittmer F., von Figura K., Pohlmann R.: Neither type of mannose 6phosphate receptor is sufficient for targeting of lysosomal enzymes along intracellular routes. J.Cell Biol. 134 (1996) 615-623.

Knaust A., Schmidt B., Dierks T., von Bülow R., von Figura K.: Residues critical for formylglycine formation and/or catalytic activity of arylsulfatase A. Biochemistry 37, 40 (1998) 13941-13946. 
Kolodny E.H., Fluharty A.L.: Metachromatic leukodystrophy and multiple sulfatase deficiency: sulfatide lipidosis; in: The Metabolic and Molecular Bases of Inherited Disease; hrsg. v. Scriver C.R., Beaudet A.L., Sly W.S., Valle D.; New York, McGraw-Hill (1999) 2693-2739.

Kraulis P.: MOLSCRIPT: a program to produce both detailed and schematic plots of protein structures. J.Appl.Crystallogr. 24 (1991) 946-950.

Laemmli U.K.: Cleavage of structural proteins during assembly of the head of bacteriophage T4. Nature 227 (1970) 680-685.

Laskowski R.A., MacArthur M.W., Moss D.S., Thornton M.T.: PROCHECK: a program to check the stereochemical quality of protein structures. J.Appl.Crystallogr. (1993) 283291.

Lemansky P., Gieselmann V., Hasilik A., von Figura K.: Synthesis and transport of lysosomal acid phosphatase in normal and tcell fibroblasts. J.Biol.Chem. 260 (1985) 9023-9030.

Lee G.D., van Etten R.L.: Purification and properties of homogenous arylsulfatase A from rabbit liver. Arch.Biochem.Biophys. 166 (1975) 280-294.

Lowry O.H., Rosebrough N.J., Fart A.L., Randall R.J.: Protein measurements with folin reagents. J.Biol.Chem. 193 (1951) 265-275.

Lukatela G., Krauß N., Theis K., Selmer T., Gieselmann V., von Figura K., Saenger W.: Crystal structure of human arylsulfatase $A$ : The aldehyde function and the metal ion at the active site suggest a novel mechanism for sulfate ester hydrolysis. Biochemistry 36 (1998) 3654-3664.

Maubach G., Schilling K., Rommerskirch W., Wenz I., Schultz J.E., Weber E., Wiederanders B.: The inhibition of cathepsin $S$ by its propeptide-specificity and mechanism of action. Eur.J.Biochem. 250(3) (1997) 745-750.

McGovern M.M., Vine D.T., Haskins M.E., Desnick R.J.: Purification and properties of feline and human arylsulfatase B isozymes. Evidence for feline homodimeric and human monomeric structures. J.Biol.Chem. 257 (1982) 12605-12610.

McPherson A.: Crystallisation of Biological Macromolecules. J.Crystal Growth 122 (1998) 161-167.

McRee D.: XtalView/Xfit - A Versatile Program for Manipulating Atomic Coordinates and Electron Density. J.Struct.Biol. 125 (1999) 156-165.

Miech C., Dierks T., Selmer T., von Figura K., Schmidt B.: Arylsulfatase from Klebsiella pneumoniae carries a formylglycine generated from a serine. J.Biol.Chem. 273 (1998) 4835-4837. 
Mehl E., Jatzkewitz H.: Eine Cerebrosid-Sulfatase aus Schweineleber. Hoppe Seylers Z. Physiol. Chem. 339(1) (1964) 260-276.

Mehl E., Jatzkewitz $H .:$ Cerebroside 3-sulfate as a physiological substrate of arylsulfatase A. Biochim.Biophys.Acta 151 (1968) 619-627.

Merritt E.A., Bacon D.J.: Raster 3D: Photorealistic Molecula graphics, Meth.Enzymol. 277 (1997) 505-524.

Mortensen R.M., Zubiauer M., Neer E.J., Seidman J.G.: Embryonic steam cells lacking a functional inhibitory G-protein subunit (ai2) produced by gene targeting of both alleles. Proc.Natl.Acad.Sci.USA 88 (1991) 7036-7040.

Murshudov G.N., Vagin A.A., Dodson E.J.: Refinement of Macromolecular Structures by the Maximum-Likelihood Method. Acta Cryst. D53 (1997) 240-255.

Neufeld E.F., Muenzer J.: The mucopolysaccharidoses; in: The Metabolic and Molecular Bases of Inherited Disease; hrsg. v. Scriver C.R., Beaudet A.L., Sly W.S., Valle D.; New York, McGraw-Hill (1995) 2465-2494.

Nichol L.W., Roy A.B.: The sulfatase of ox liver. Some observations on the intermolecular bonding in sulfatase A. Biochemistry 5 (1966) 1379-1388.

Otwinowski Z., Minor W.: Processing of X-ray Diffraction Data Collected in Oscillation Mode. Meth.Enzymol. 276 (1997) 307-326.

Parenti G., Meroni G., Ballabio A.: The sulfatase gene family. Curr.Opin.Genet.Dev. 7 (1997) 386-391.

Pohlmann R.: Mannose-6-phosphate receptors. Biomembranes 4 (1996) 223-253.

Pohlmann R., Wendland M., Boecker C., von Figura K.: The two mannose 6-phosphate receptors transport distinct complements of lysosomal proteins. J.Biol.Chem. 270 (1995) 27311-27318.

Polten A., Fluharty A.L., Fluharty C.B., Kappler J., von Figura K., Gieselmann V.: Molecular Basis of Different Forms of Metachromatic Leukodystrophy. N.Engl.J.Med. 324 (1991) 18-22.

Porter M.T., Fluharty A.L., Kihara H.: Metachromatic Leukodystrophy: Arylsulfatase-A Deficient in Skin Fibroblast Cultures. Biochemistry 62 (1969) 887-891.

Ramachandran G.N., Sassiekharan V.: Conformation of polypeptides and proteins. Adv. Protein Chem. 28 (1968) 283-437.

Read R.J.: Improved Fourier Coefficients for Maps Using Phases from Partial Structures with Errors. Acta Cryst. A42 (1986) 120-129. 
Recksieck M., Selmer T., Dierks T., Schmidt B., von Figura K.: Sulfatases: Trapping of the sulfated enzyme intermediate by substituting the active site formylglycine. J.Biol.Chem. 273 (1998) 6096-6103.

SAINT: Programm zur Integration und Reduktion von kristallographischen Flächenzählerdaten. V 5.00 (1997), Bruker Analytical X-ray systems, ㅇ Bruker AXS.

Sambrook J., Fritsch E.F., Maniatis T.: Moleculare cloning: A laboratory manual (Second edition). Cold Spring Harbour, New York (1989).

Sanger S., Nicklen S., Coulson A.R.: DNA sequenzing with chain terminating inhibitors. Proc.Natl.Acad.Sci.USA 74 (1977) 5463-5467.

Schmidt B., Selmer T., Ingendoh A., von Figura K.: A novel amino acid modification in sulfatases that is defective in multiple sulfatase deficiency. Cell 82 (1995) 271-278.

Selmer T., Hallmann A., Schmidt B., Sumper M., von Figura K.: The evolutionary conservation of a novel protein modification, the conversion of cysteine to serinesemialdehyde in arylsulfatase from Volvox carteri. Eur.J.Biochem. 238 (1996) 341-345.

Shapiro L.J., Aleck K.A., Kaback M.M., Itabashi H., Desnick R.J., Brand N., Stevens R.L., Fluharty A.L., Kihara H.: Metachromatic leukodystrophy without arylsulfatase A deficiency. Pediatr.Res. 13(10) (1979) 1179-1181.

Sheldrick G.M.: SHELXS, Programm zur Strukturlösung. (1990) Universität Göttingen.

Sheldrick G.M.: SADABS, Programm zur Absorptionskorrektur von Bruker (Siemens) Flächenzählerdaten. (1997) Universität Göttingen.

Sheldrick G.M., Schneider T.R.: SHELXL: High-Resolution Refinement. Meth.Enzymol. 277 (1997) 319-343.

Shelxpro: SHELX-interface for protein application. V. 97-2 (1996-1997), C Sheldrick G.M.

SMART: Programm zur Diffraktomeresteuerung und Sammlung von Flächenzählerdaten. V. 4.050 (1996) Siemens Analytical X-ray systems, (C Siemens.

Sommerlade H.J., Hille-Rehfeld A., von Figura K., Gieselmann V.: Four monoclonal antibodies inhibit the recognition of arylsulfatase $A$ by the lysosomal enzyme phosphotransferase. Biochem. J. 297 (1994a) 123-130.

Sommerlade H.J., Selmer T., Ingendoh A., Gieselmann V., von Figura K., Neifer K., Schmidt B.: Glycosylation and phosphorylation of arylsulfatase A. J.Biol.Chem. 269(33) (1994b) 20977-20981. 
Stein C., Gieselmann V., Kreysing J., Schmidt B., Pohlmann R., Waheed A., Meyer H.E., O’Brien J.S., von Figura K.: Cloning and Expression of Human Arylsulfatase A. J.Biol.Chem. 264 (1989) 1252-1259.

Towatari T., Kawabata Y., Katunuma N.: Crystallization and properties of cathepsin B from rat liver. Eur. J. Biochem. 102 (1979) 279-289.

Uchida T., Egami F., Roy A.B.: 3‘,5'-cyclic nucleotide phosphodieesterase activity of the sulfatase of ox liver. Biochim.Biophys.Acta 657 (1981) 356-363.

von Bülow R., Usón I.: p-Nitrocatechol sulfat dipotassium salt. Acta Cryst. $C$, in press.

von Figura K., Steckel F., Hasilik A.: Juvenile and adult metachromatic leukodystrophy: Partial restoration of arylsulfatase $A$ (cerebroside sulfatase) activity by inhibitors of thiol proteinases. Proc.Natl.Acad.Sci.USA 80 (1983) 6066-6070.

von Figura K., Steckel F., Conary J., Hasilik A., Shaw E.: Heterogeneity in Late-Onset Metachromatic Leukodystrophy. Effect of Inhibitors of Cysteine Proteinases. Am.J.Hum.Genet. 39 (1986) 371-382.

von Figura K., Hasilik A.: Lysosomal enzymes and their receptors. Annu.Rev.Biochem. 55 (1986) 167-193.

von Figura K., Schmidt B., Selmer T., Dierks T.: A novel protein modification generating an aldehyde group in sulfatases: its role in catalysis and disease. BioEssays 20.6 (1998) 505-510.

Waheed A., van Etten R.L.: The monomer - dimer association of rabbit liver arylsulfatase $A$ and its relationship to the anomalous kinetics. Arch.Biochem.Biophys. 194(1) (1979) 215-225.

Waheed A., Hasilik A., von Figura K.: Enhanced breakdown of arylsulfatase A in multiple sulfate deficiency. Eur.J.Biochem. 123 (1982) 317-321.

Waheed A., Risley J.M., van Etten R.L.: Structural and immunological relationships among mammalian arylsulfatase A enzymes. Comp.Biochem.Physiol. [B] 82(4) (1985) 855-862.

Waldow A., Schmidt B., Dierks T., von Bülow R., von Figura K.: Amino acid residues forming the active site of arylsulfatase A: role in catalytic activity and substrate binding. J.Biol.Chem. 274 (1999) 12284-12288.

Weber E., Bahn H., Günther D.: Monoclonal antibodies against cathepsin L and procathepsin L of different species. Hybridoma 16 (1997)159-166.

Weber E., Schilling K., Wiederanders B.: Single chain human cathepsin L. J.Biol.Chem 379 (1998) 142. 
Wiltfang J., Arold N., Neuhoff V.: A new multiphasic buffer system for sodium dodecyl sulfate polyacrylamide gel electrophoresis of proteins and peptides with molekular masses 100.000-100, and their detection with picomolar sensitivity. Electrophoresis 12(5) (1991) 352-366.

XP: Programm zur interaktiven, graphischen Darstellung von Molekülen. V. 5.10 (1997), (C) Bruker AXS.

XPREP: Programm zur Bearbeitung von Beugungsdaten \& Untersuchung reziproker Gitter. V. 5.10 (1997), (C) Bruker AXS. 


\section{Anhang}

\section{Aminosäuresequenz der humanen Arylsulfatase A}

1 MGAPRSLLLA LAAGLAVARP PNIVLIFADD LGYGDLGCYG HPSSTTPNLD

51 QLAAGGLRFT DFYVPVSLCT PSRAALLTGR LPVRMGMYPG VLVPSSRGGL

101 PLEEVTVAEV LAARGYLTGM AGKWHLGVGP EGAFLPPHQG FHRFLGIPYS

151 HDQGPCQNLT CFPPATPCDG GCDQGLVPIP LLANLSVEAQ PPWLPGLEAR

201 YMAFAHDLMA DAQRQDRPFF LYYASHHTHY PQFSGQSFAE RSGRGPFGDS

251 LMELDAAVGT LMTAIGDLGL LEETLVIFTA DNGPETMRMS RGGCSGLLRC

301 GKGTTYEGGV REPALAFWPG HIAPGVTHEL ASSLDLLPTL AALAGAPLPN

351 VTLDGFDLSP LLLGTGKSPR QSLFFYPSYP DEVRGVFAVR TGKYKAHFFT

401 QGSAHSDTTA DPACHASSSL TAHEPPLLYD LSKDPGENYN LLGGVAGATP

451 EVLQALKQLQ LLKAQLDAAV TFGPSQVARG EDPALQICCH PGCTPRPACC

501 HCPDPHA

$\mathrm{pK}_{\mathrm{s}}$-Werte der protonierten Form der Aminosäureseitenketten

\begin{tabular}{|l|l||l|l|}
\hline Aminosäure & $\mathbf{p K}_{\mathbf{s}}$-Wert & Aminosäure & $\mathbf{p K}_{\mathbf{s}}$-Wert \\
\hline \hline Arginin & 12,5 & Histidin & 6,0 \\
\hline Aspartat & 4,0 & Lysin & 10,8 \\
\hline Cystein & 8,3 & Tyrosin & 10,1 \\
\hline Glutamat & 4,3 & & \\
\hline
\end{tabular}




\section{Topologie der Sekundärstruktur der Arylsulfatase A}

$\alpha$-Helices sind als Rechtecke und $\beta$-Stränge als Pfeile dargestellt, Cysteine sind als gelbe Ringe gekennzeichnet. Die Aminosäuren, die das aktive Zentrum bilden, sind rot umrandet; die gestrichtelte Umrandung kennzeichnet Aminosäuren, die das Magnesiumion komplexieren. Die drei Asparagine, die mit Oligosaccharidseitenketten verbunden sind, sind durch eine blaue Umrandung und den 3-Buchstabencode für Aminosäuren hervorgehoben.

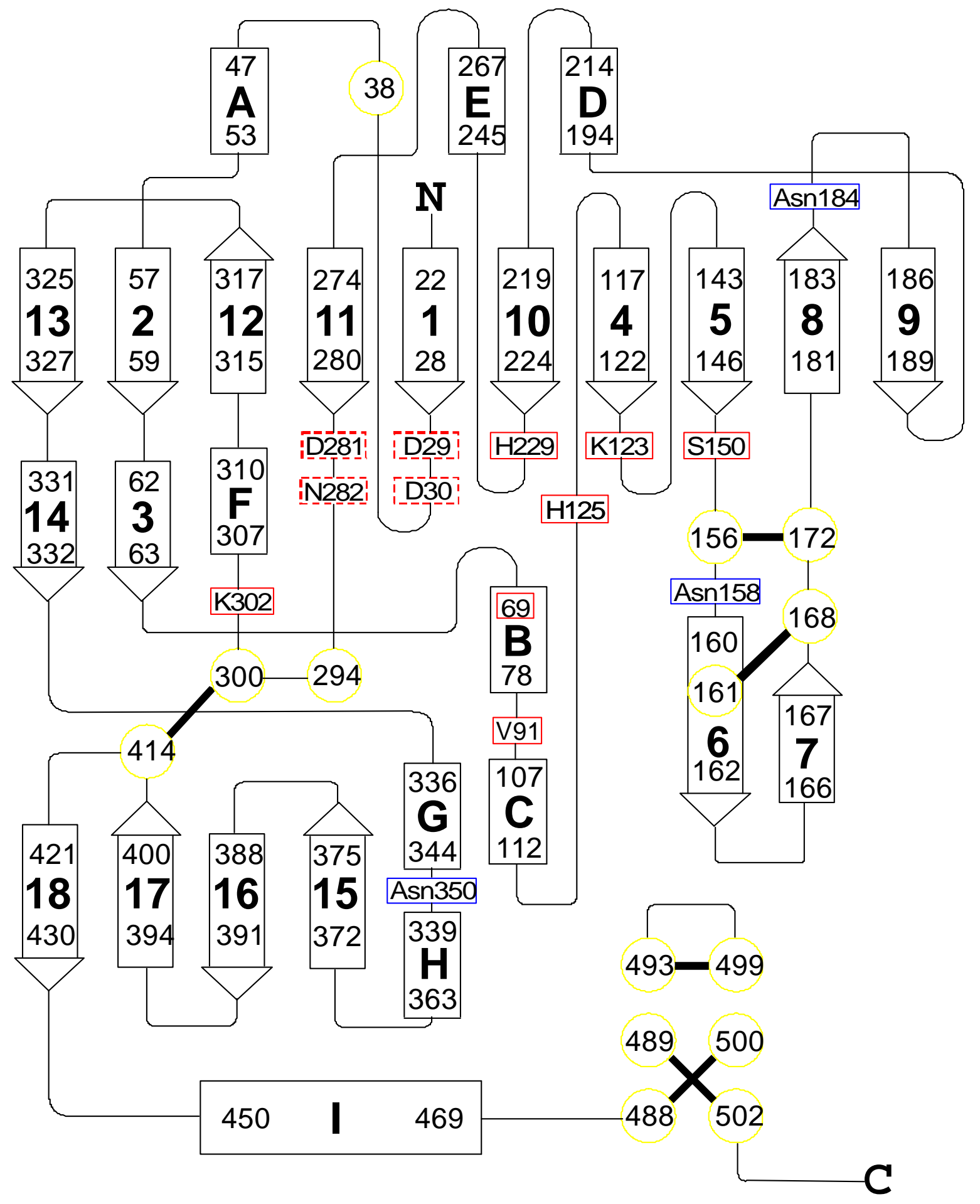




\section{Publikationsliste}

von Bülow R., Gornitzka H., Kottke T., Stalke D., Dimers of THF Solvated Lithium Anilide and Lithium Pentafluoroanilide. Chem. Commun. (1996) 1639-1640.

Knaust A., Schmidt B., Dierks T., von Bülow R., von Figura K., Residues critical for formylglycine formation and/or catalytic activity of arylsulfatase A. Biochemistry 37, 40 (1998) 13941-13946.

Waldow A., Schmidt B., Dierks T., von Bülow R., von Figura K., Amino acid residues forming the active site of arylsulfatase A: role in catalytic activity and substrate binding. J. Biol. Chem. 274 (1999) 12284-12288.

von Bülow R., Usón I., Dipotassium salt of p-Nitrocatechol sulfate. Acta Cryst. C, in press. 


\section{Danksagung}

Herrn Prof. Dr. K. von Figura möchte ich für die Vergabe des interessanten Themas, die sehr konstruktive und motivierende Unterstützung dieser Arbeit sowie die stete Diskussionsbereitschaft danken.

Herrn Prof. G. M. Sheldrick, PhD, danke ich für die Förderung dieser Arbeit sowie meiner proteinkristallographischen Ausbildung.

Die hervorragenden Rahmen- und Arbeitsbedingungen in den beiden Arbeitsgruppen trugen wesentlich zum Gelingen dieser Arbeit bei.

Für die engagierte Betreuung und das Zustandekommen der guten institutsübergreifenden Zusammenarbeit danke ich Frau Dr. Isabel Usón und Herrn Dr. Bernhard Schmidt.

Dr. Thomas Dierks und Dr. Thomas Schneider danke ich für ihre stete Gesprächsbereitschaft und die vielen kleinen und großen Tips und Tricks.

Für die Unterstützung meiner Arbeit im Labor und in der Zellkultur möchte ich Martina Balleininger und besonders Katja Unthan-Hermeling danken.

Jörg Kärcher und Thomas Pape danke ich für das gute Funktionieren des Computersystems und die Tips rund um die Rechner.

Für das Korrekturlesen dieser Arbeit danke ich Dr. Isabel Usón, Dr. Martina Schäfer, Dr. Thomas Dierks und ganz besonders für die konstruktiven Anmerkungen Dr. Bernhard Schmidt.

Den Mitarbeitern beider Arbeitsgruppen sei für die freundliche Atmosphäre, die Hilfsbereitsschaft und die kollegiale Zusammenarbeit gedankt. Ein besonderer Dank an alle, die am Synchrotron Nacht- und Tagwachen übernommen haben und dort für optimierte Arbeitsbedingungen sorgten.

Dr. K. Schilling, Dr. E. Weber und Dr. W. Roth danke ich für die Überlassung der Cathepsine bzw. der Cathepsin L-defizienten MEF-Zellen. 


\section{Lebenslauf}

Am 21. Februar 1971 wurde ich, Rixa von Bülow, als viertes Kind meiner Eltern Dr. Bernd von Bülow und Monika von Bülow, geb. Fischer, in Bochum geboren.

Meine Schulzeit verbrachte ich in Haltern/Westfalen, in deren Verlauf ich die 11. Klasse von Januar 1987 bis Dezember 1987 als Austauschschülerin in Australien besuchte. Sie endete mit der Absolvierung des Abiturs im Sommer 1990 am Städtischen Gymnasium Haltern.

Im Wintersemester 1990 begann ich das Studium der Chemie an der GeorgAugust-Universität in Göttingen. Die Diplomvorprüfung im Fach Chemie erfolgte im Februar 1994. Meine Diplomarbeit fertigte ich unter der Leitung von Prof. G. M. Sheldrick, PhD, am Institut für Anorganische Chemie, Universität Göttingen, mit dem Thema „Strukturanalytische Untersuchungen zur Elektronenverteilung neutraler und anionischer Anilinderivate" an. Die Diplomprüfung im Fach Chemie erfolgte im Mai 1996.

Im Juli 1996 begann ich den experimentellen Teil der hier vorliegenden Dissertation mit dem Titel „Strukturanalyse zum Katalysemechanismus und zur Stabilität der Arylsulfatase A“ in einer Zusammenarbeit der Arbeitsgruppen von Prof. Dr. K. von Figura, Zentrum für Biochemie und Molekulare Zellbiologie, Abteilung Biochemie II, und Prof. G. M. Sheldrick, Lehrstuhl für Strukturchemie, Universität Göttingen. 